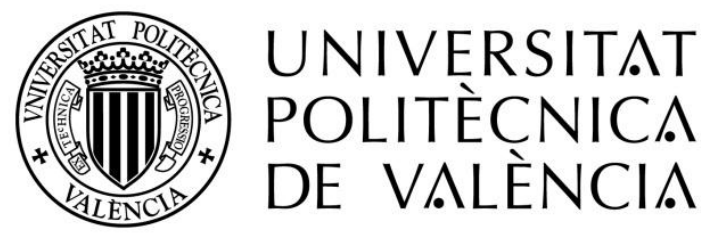

Research Institute of Water and Environmental Engineering

Department of Hydraulic Engineering and Environment

Ph.D. Thesis

\title{
NUTRIENT REMOVAL FROM AN ANAEROBIC MEMBRANE BIOREACTOR EFFLUENT USING MICROALGAE. STUDY AND MODELING OF THE PROCESS
}

Ana Ruiz Martínez

December 2015

Supervisors:

José Ferrer Polo, PhD.

Aurora Seco Torrecillas, PhD. 



\section{AGRADECIMIENTOS}

Es dificil expresar en estas cortas lineas todo el agradecimiento que siento hacia tantas personas que han estado a mi lado durante el desarrollo de este trabajo. Lo voy a intentar:

En primer lugar quisiera agradecer a mis supervisores josé y Aurora por darme la posibilidad de desarrollar mi trabajo, porque sin ellos y sin el grupo que ellos dírigen esta tesis simplemente no existiría. Gracias también a joaquin por su indispensable ayuda en el tratamiento de los datos y el desarrollo de los modelos, por todos sus valiosos comentarios y por darme el ritmo que me ha ayudado a avanzar.

Los comienzos no son fácíles, pero gente como Luis, javier Eduardo o Brenda hicieron el mío mucho más agradable. cracias por motivarme, por Llevarme a por garrafas a la Albufera, por darme la mano en mis primeros pasos en el laboratorio, con el micro o con la programación $y$, en definitiva, por estar ahi y echarme una mano siempre que lo he necesitado.

un hueco ahora para el resto de compañeros de Burja. Gracías por todo lo que he aprendido de vosotros: a juan por su calma, su ejemplo riguroso y metódico y por todas las charlas dentro y fuera del lab; a Rafa por sus trucos, sobretodo el del Foxit, sin él aún no habría terminado de escribir la introducción; a Nacho por la ayuda en el laboratorio con los montajes y a victor por todas las ideas y materiales. Gracias a javi claros por ser un gran ejemplo a seguir y por las risas; a Emérita por escuchar con atención y comprensión y a josep por su paciencía y buen humor en el diseño de la planta. Gracías a Alberto por hacer que todo funcione y a Nuria por ser un encanto. Gracias por supuesto también a Laura $S$, Laura C, Ana, Marta, Cecilía, Patri, Silvia, Mónica y Joana, con quienes he compartido tantos momentos en despachos, laboratorios e incluso una mudanza: el día a día pesa menos con vosotras.

Quiero agradecer también a Ángel y Freddy, los "becarios NASA" que saben (casi) de todo y ayudan siempre. Gracias por aguantar mi chachara y por todo el apoyo y guía que habéis supuesto para mí. Gracias a Dani por el buen rollo constante y por enseñarme a 
mover muy rápido el ratón y a Ruth y Alex por completar de manera inmejorable el despacho. Del montón de cosas que quiero agradecer a Tao me quedo con el "La-Laaa La-Laaa" Limpiando el PBR...porque lo resume todo.

Todo esto sin olvidarme de los demás en el poli: gracías a Antonio y Ramón por su buen humor, a Dani Aguado por su interés, a inma por su calidez y a María y vickey porque siempre me han escuchado, animado y ayudado al instante.

También quiero agradecer a mis amigos porque, aunque a veces sin saber muy bien qué hago, siempre han mostrado su interés por "cómo van mis algas". A Aíxa, Inma, Lore G, Lore S, Ana C, Mayte, Silvia, Amparo, Laura, David, Bea, Paz, Patri, Raquel, Ruth, Aldara, Davide, Bruno... y a los masterfrens Lenin, Anahi, Liz, Benni y Jota por la fantástica "vuelta al poli" que tuve, al principio de esta aventura, gracías a ellos.

La familia se suele dejar para el final en los agradecimientos, pero en realidad es lo primero: gracias a mis padres por ponerme en este mundo y no dejar de cuidarme y dármelo todo desde aquel momento. Gracias a María por estar ahí siempre-siempre, aportando calma y confianza con tus puntos de vista y humor con tus coletillas, tus ironías y bromas y sobretodo con los comentarios hechos al leerte esta tesis. Me he reido un montón. Gracias también a mis abuelos por el valioso recuerdo que me dejan para siempre, a Marta por todo su cariño y atención y a Ana La Mayor por ser inigualable.

Gracias a Nico por inundar la casa de alegría y luz. Me ayudas a encontrar lo mejor que hay en mi y me haces querer ser mejor. Eres nuestra energía! En dankje Erike voor het altijd willen zoeken naar een oplossing en voor het willen veranderen van de wereld:) Dankje voor de liefde, motivatie en steun. And thank you both for the perfect little family that we make. 


\begin{abstract}
Anaerobic membrane bioreactors for urban wastewater treatment present interesting advantages when compared with aerobic treatments, such as less sludge production, lower energy demand and biogas generation. However, the generated effluent cannot generally be discharged without further ammonium and phosphate elimination. This thesis studies the removal of these inorganic nutrients by means of microalgae cultivation.

The main objective of this work is therefore to obtain an autochthonous microalgal culture and to investigate its ability to grow on an already existing anaerobic effluent, as well as to research the extent to which ammonium and phosphate can be removed. Moreover, this thesis aims at providing the kinetic expressions which reproduce the main processes involved, in order to provide the basis for process simulation and design.
\end{abstract}

Microalgae were isolated from a local wastewater treatment plant and their ability to grow on the anaerobic effluent -while successfully removing ammonium and phosphate- was demonstrated. An excellent water quality was obtained with a semicontinuous cultivation mode under constant illumination. The Scenedesmus and Chlorococcum genus proliferated more efficiently and thus became predominant in the culture. Results also showed that phosphorus was the limiting nutrient in the anaerobic effluent to be treated. The influence of phosphorus limitation on ammonium and phosphate removal, as well as the influence of temperature in ammonium removal, were then studied under laboratory conditions. Kinetic expressions which reproduce the observed effects were proposed and validated, taking also into account the effect of light intensity. Additionally, a Scenedesmus-dominated culture was grown under varying light and temperature in an outdoor flat-plate photobioreactor, with constant monitoring of light intensity, temperature and ammonium concentration. Acceptable results were obtained in the reproduction of the experimental data, albeit with less accuracy than under laboratory conditions.

The work here presented demonstrates the feasibility of coupling a microalgal cultivation system to an anaerobic membrane bioreactor for urban wastewater treatment. The basic factors affecting microalgal nutrient removal are researched, and mathematical models are provided which reproduce these effects. 
This $\mathrm{Ph} . \mathrm{D}$. thesis is enclosed in a national research project funded by the Spanish Ministry of Economy and Competitiveness entitled "Estudio experimental de la recuperación como biogás de la energía de la materia orgánica y nutrientes del agua residual, acoplando un AnBRM y un cultivo de microalgas" (MINECO project CTM2011-28595-C02-01/02). This research was also supported by the Spanish Ministry of Education, Culture and Sport via a pre doctoral FPU fellowship to the author (AP2009-4903). 


\section{Resumen}

En el tratamiento de aguas residuales urbanas, los bioreactores anaerobios de membranas presentan ventajas interesantes frente a los tratamientos aerobios. Algunas de estas ventajas son la menor producción de fangos, un menor consumo energético y la producción de biogás. Sin embargo, y generalmente, el efluente obtenido no puede ser vertido al medio sin una etapa previa de eliminación de amonio y fosfato. La presente tesis estudia la eliminación de dichos nutrientes inorgánicos empleando para ello un cultivo de microalgas.

El objetivo principal de este trabajo es, por tanto, la obtención de un cultivo autóctono de microalgas y la evaluación de la capacidad que éstas tienen tanto de crecer en un efluente anaerobio como de eliminar el amonio y el fosfato presentes. Asimismo, se pretenden proporcionar las bases para la simulación y el diseño del sistema de depuración propuesto, mediante la obtención de las expresiones cinéticas que reproduzcan los principales procesos involucrados.

En primer lugar se ha demostrado la capacidad de las microalgas, aisladas en una estación depuradora de aguas residuales, de crecer en el efluente anaerobio y de eliminar con éxito el amonio y fosfato en éste presente. El agua tratada, obtenida mediante un proceso semicontinuo y con iluminación constante, presenta una excelente calidad. Los géneros Scenedesmus y Chlorococcum han proliferado más eficientemente y han llegado a ser los predominantes en el cultivo. Los resultados obtenidos indican que el nutriente limitante en el efluente a tratar es el fósforo y por tanto la influencia de la limitación de fósforo en la eliminación de nutrientes ha sido estudiada en condiciones de laboratorio, junto con la influencia de la temperatura en la velocidad de eliminación de amonio. Han sido propuestas y validadas las correspondientes expresiones cinéticas que reproducen los efectos observados, teniendo en cuenta en todo momento la influencia de la intensidad de la luz.

Por otro lado, un cultivo dominado por la especie Scenedesmus ha sido cultivado en el exterior, bajo condiciones cambiantes de luz y temperatura monitorizadas constantemente junto con la concentración de amonio. Los datos obtenidos han sido reproducidos mediante modelación matemática con resultados aceptables, si bien la precisión obtenida es menor que en condiciones de laboratorio. 
La presente tesis demuestra la viabilidad de combinar un cultivo de microalgas con un bioreactor de membranas para el tratamiento de agua residual urbana. Se exponen asimismo los factores básicos que influyen en la velocidad de eliminación de nutrientes, y se presentan los modelos matemáticos necesarios para reproducir los efectos observados.

Este trabajo se incluye en el marco de un proyecto nacional de investigación financiado por el Ministerio de Economía y Competitividad de título "Estudio experimental de la recuperación como biogás de la energía de la materia orgánica y nutrientes del agua residual, acoplando un AnBRM y un cultivo de microalgas" (CTM2011-28595-C02-01/02). La presente tesis doctoral ha sido también financiada por el Ministerio de Educación, Cultura y Deporte a través de una ayuda para contratos predoctorales de Formación del Profesorado Universitario (AP2009-4903). 


\section{Resum}

En el tractament d'aigües residuals urbanes, els bioreactors anaerobis de membrana tenen avantatges interessants respecte als tractaments aerobis. Alguns d'aquests avantatges són: menys producció de fangs, menys consum energètic i la producció de biogàs. No obstant això, i en general, l'efluent obtingut no es pot tornar al medi sense una etapa prèvia d'eliminació d'amoni i fosfat. Aquesta tesi estudia l'eliminació d'aquests nutrients inorgànics emprant per a fer-ho un cultiu de microalgues.

L'objectiu principal d'aquest treball és, per tant, l'obtenció d'un cultiu autòcton de microalgues i l'avaluació de la capacitat que aquestes tenen tant de créixer en un efluent anaerobi com d'eliminar l'amoni i el fosfat presents. Així mateix, volem proporcionar les bases per a la simulació i el disseny del sistema de depuració proposat, mitjançant l'obtenció de les expressions cinètiques que reprodueixen els principals processos involucrats.

En primer lloc, s'ha demostrat la capacitat de les microalgues, aillades en una estació depuradora d'aigües residuals, de créixer en l'efluent anaerobi i d'eliminar amb èxit l'amoni i el fosfat presents. L'aigua tractada, obtinguda mitjançant un procés semicontinu i amb il-luminació constant, presenta una qualitat excel-lent. Els gèneres Scenedesmus i Chlorococcum han proliferat més eficientment $\mathrm{i}$ han arribat a ser els predominants en el cultiu. Els resultats obtinguts indiquen que el nutrient limitant en l'efluent per tractar és el fòsfor, i per tant la influència de la limitació de fòsfor en l'eliminació tant d'amoni com de fosfat ha sigut estudiada en condicions de laboratori, juntament amb la influència de la temperatura en la velocitat d'eliminació d'amoni. S'han proposat i validat les expressions cinètiques corresponents que reprodueixen els efectes observats, tenint en compte en tot moment la influència de la intensitat de la llum.

D'altra banda, s'ha cultivat a l'exterior un cultiu predominat per Scenedesmus, sota condicions canviants de llum i temperatura, que al seu torn s'han monitorat constantment, juntament amb la concentració d'amoni. Les dades obtingudes s'han reproduït mitjançant simulació matemàtica amb resultats acceptables, encara que la precisió obtinguda és més baixa que en condicions de laboratori. 
La nostra tesi demostra la viabilitat de combinar un cultiu de microalgues amb un bioreactor de membrana per al tractament d'aigua residual urbana. La tesi exposa així mateix els factors bàsics que influeixen en la velocitat d'eliminació de nutrients, i presenta els models matemàtics necessaris per a reproduir els efectes observats.

Aquesta tesi doctoral s'inclou en el marc d'un projecte nacional de recerca finançat pel Ministeri d'Economia i Competitivitat amb el títol "Estudio experimental de la recuperación como biogás de la energía de la materia orgánica y nutrientes del agua residual, acoplando un AnBRM y un cultivo de microalgas" (CTM2011-28595-C02-01/02). La tesi doctoral ha sigut també finançada pel Ministeri d'Educació, Cultura i Esport a través d'una ajuda per a contractes predoctorals de formació del professorat universitari (AP2009-4903). 


\section{Thesis outline}

An introductory chapter I describes the context of the present work and provides some theoretical information on wastewater treatment and microalgal biology and technology. Future trends of microalgal-related fields of study are also sketched.

In chapter II the first approach to microalgae cultivation in the effluent of a Submerged Anaerobic Membrane Bioreactor is presented. The ability of autochthonous microalgae to sustain growth based on this specific waste stream is proved, and a preliminary assessment of the achieved level of nutrient elimination is made. The influence of a light/dark cycle and of the cellular/hydraulic retention time on their productivity is also studied. Chapter III shows the results of a study in which biomass was cultivated in semicontinuous mode for a longer period of time. The high stability of the proposed culture system was demonstrated, together with the ability of the mixed culture to render a high quality wastewater.

Following chapters deal with the mathematical modeling of the processes taking place in the culture. Thus, chapter IV studies the interaction between cellular phosphate content and ammonium removal rate. A kinetic expression for microalgal growth which reproduces this interaction is presented. The study shown in chapter $\mathbf{V}$ demonstrates the influence of cellular phosphate content on phosphate removal and proposes a kinetic expression to reproduce this effect. Chapter VI presents a short study under controlled conditions which confirms the temperature dependence of the microalgal ammonium removal rate and suggests how to mathematically represent this dependence. Chapter VII validates a kinetic expression for reproducing the effect of both temperature and light fluctuations on the microalgal ammonium removal rate when the culture is subject to outdoor varying conditions. Finally, a calibration methodology is proposed in chapter VIII with which to obtain the decay constant of a microalgal culture in the dark.

Chapter IX contains the general discussion whereas the conclusions are enumerated in Chapter X. A flow diagram has been included in an Appendix where the time evolution of the experiments is shown, in order to clarify the history of the cultures used along the chapters. 



\section{Contents}

Chapter I: $\quad$ Introduction and Objectives 1

Chapter II: $\quad$ A first approach to indigenous microalgal cultivation

Chapter III: Microalgae cultivation in wastewater: nutrient removal from an anaerobic membrane bioreactor effluent

Chapter IV: $\quad$ Mixed microalgal culture for ammonium removal in the absence of phosphorus. Effect of phosphorus supplementation and process modeling

Chapter V: $\quad$ Effect of intracellular P content on phosphate removal in Scenedesmus sp. Experimental study and kinetic expression

Chapter VI: Effect of temperature on ammonium removal in Scenedesmus sp.

Chapter VII: $\quad$ Modeling light and temperature influence on ammonium removal by Scenedesmus sp. under outdoor conditions

Chapter VIII: Behavior of mixed Chlorophyceae cultures under prolonged dark exposure. Respiration rate modeling

Chapter IX: $\quad$ Summary and general discussion

Chapter X: General conclusions

Appendix: Diagram of culture chronology 



\section{Nomenclature}

\begin{tabular}{|c|c|}
\hline AnMBR & Anaerobic membrane bioreactor \\
\hline $\mathrm{AOB}$ & Ammonia-oxidizing bacteria \\
\hline AS & Activated sludge \\
\hline ATP & Adenosine triphosphate \\
\hline COD & Chemical oxygen demand \\
\hline CRT & Cellular retention time \\
\hline CTMI & Cardinal temperature model with inflexion \\
\hline DC & Dark kept culture \\
\hline DO & Dissolved oxygen \\
\hline HRAP & High rate algal pond \\
\hline HRT & Hydraulic retention time \\
\hline $\mathrm{LC}$ & Nutrient limited culture \\
\hline LCA & Life cycle assessment \\
\hline MBR & Membrane bioreactor \\
\hline $\mathrm{N}$ & Nitrogen \\
\hline $\mathrm{NADP}^{+} / \mathrm{NADPH}$ & Nicotinamide adenine dinucleotide phosphate and its reduced form \\
\hline $\mathrm{NH}_{4}-\mathrm{N}$ & Nitrogen measured as ammonium \\
\hline $\mathrm{NO}_{2}-\mathrm{N}$ & Nitrogen measured as nitrite \\
\hline $\mathrm{NO}_{3}-\mathrm{N}$ & Nitrogen measured as nitrate \\
\hline NOB & Nitrite-oxidizing bacteria \\
\hline NOR & Nitrogen Only Reactor \\
\hline
\end{tabular}


N\&PR

OUR

PAR

PBR

$\mathrm{P}$

$\mathrm{PO}_{4}-\mathrm{P}$

$\mathrm{RC}$

SAnMBR

SAnMBRe

SRT

TP

TSP

TSS

VSS

WWTP
Nitrogen and Phosphorus Reactor

Oxygen uptake rate

Photosynthetically active radiation

Photobioreactor

Phosphorus

Phosphorous measured as orthophosphate

Replete culture

Submerged anaerobic MBR

Submerged anaerobic MBR effluent

Solids retention time

Total phosphorus

Total suspended phosphorus

Total suspended solids

Volatile suspended solids

Wastewater treatment plant 
Chapter I

Introduction and Objectives 



\section{Introduction}

\section{Situation of the present work}

Water is an essential natural resource for all living forms. It is crucial in all natural ecosystems, and for human health and food supply. We need large amounts of quality water to live and function as a society. As a consequence, liters and liters of wastewater loaded with organic and inorganic pollutants leave our homes, public spaces and industries each day.

Natural water systems have the ability to eliminate water pollutants, the so called selfpurification capacity. However, this capacity has a limit which is very often exceeded by human activities. Therefore, with the increase and concentration of population and industry, water and wastewater treatment systems must be developed to avoid degradation of the resource. Still, water shortage and water pollution are two of the main problems that mankind encounters today, to different degrees, in most areas of the planet.

Water is necessarily at the core of sustainable development, since it is through water that environmental sustainability can be achieved, while encouraging economic growth and helping reduce poverty. It is an enormous challenge for all members of society (users, policy makers, scientists and industry) to strive for a sustainable use of such a vital resource.

At the same time, about $80 \%$ of the global energy demand is provided by fossil fuels (Chen et al., 2011), which are non-renewable and aggravate global climate change. The world is currently faced with energy challenges derived from the increasing demand and shortage of fossil fuel reserves, its variable prices, supply insecurity and related environmental concerns such as the production of greenhouse gases. It is therefore crucial to develop cost-effective means of obtaining renewable energy. Briens (2008) estimated that biomass could provide around $25 \%$ of the world energy demand, while providing a number of valuable products as well.

Microalgae are, in this context, a proposed solution for renewable energy production. Energy from microalgae can be obtained via a series of transformation processes, such as transesterification of the lipid fraction, anaerobic digestion, fermentation, biophotolysis or 
other thermochemical processes (Brenan and Owende, 2010). Microalgal biofuels such as biodiesel, biogas, bioethanol or biohydrogen are already being successfully obtained at small scale, but current methods require significant improvements for attaining feasible industrial scale production (Acién, 2012, Chisti, 2013).

Mass cultivation of microalgae requires a substantial amount of nutrients (mainly $\mathrm{N}$ and $\mathrm{P}$ ). Thus, artificial fertilizer consumption constitutes a significant fraction of the total costs for microalgal growth $(7.5 \%$ of the direct costs of biomass production, according to Molina Grima et al., 2003). The production of these fertilizers also consumes an important amount of energy (Hullat et al., 2012), thus compromising the sustainability of algal biofuels.

Cultivation of microalgae requires important volumes of water as well, due to the low density of the cultures. Calculations of the water footprint of microalgal biodiesel have highlighted the need to use non-potable water for achieving an economic and environmentally sustainable process (Subhadra and Edwards, 2011).

Given the high costs of nutrients and water in microalgae cultivation, the use of wastewater has been proposed as a viable means to enhance the sustainability of algal biofuel production, since it can freely provide both the nutrients ( $\mathrm{N}$ and $\mathrm{P}$ ) and the growth medium (water) (Christenson and Sims, 2011, Craggs et al., 2011). The obvious nexus that microalgae establish between water, energy and nutrients recovery makes this combination possible. It becomes possible for wastewater treatment systems to abandon their traditional role of energy consumers and to aim at being energy producers instead, while inorganic nutrients are not only removed but actually recovered, given the possible use of the microalgal biomass as organic fertilizer (after, for instance, oil extraction (Rodolfi and Zitelli, 2009) or anaerobic digestion (Weiland, 2010)).

For all of the above, current microalgal research is mainly oriented toward biomass and/or lipid production, with a significant number of studies focusing on the use of wastewater as growth medium. The starting point of the work presented here is the need to remove inorganic nutrients from a specific wastewater, and its aim is to do so using a non-conventional treatment method. Instead, a microalgal system is proposed, tested and proven suitable. The behavior and characteristics of the microalgal culture grown on the specific wastewater (a 
submerged anaerobic membrane bioreactor (SAnMBR) effluent) are then further studied and mathematically modeled.

\section{Wastewater treatments. SAnMBR}

Wastewater treatments can be divided into three categories: physical, chemical and biological. In the first category, mechanical forces are applied to remove pollutants, while chemical treatments eliminate contaminants by means of chemical reactions, and are always applied in conjunction with physical or biological processes. As for biological wastewater treatments, they imply the action of microorganisms such as bacteria.

Depending on the degree of pollutant removal required and on the characteristics of the wastewater, different unit operations from the aforementioned categories are combined into a treatment scheme. In a traditional municipal wastewater treatment plant (WWTP), for instance, a primary treatment uses physical processes to eliminate particles from the water, and is followed by a secondary treatment which consists of an aerobic biological treatment, usually an activated sludge system. A tertiary treatment polishes the water with a more specific technique, for instance removing viruses and bacteria with a UV irradiation unit.

Wastewater treatment is an energy-intensive activity. A study of the economic and environmental profile of 24 wastewater treatment plants by Rodriguez-García et al. (2011) found the related energy consumption to lie between 0.13 and $1.37 \mathrm{kWh}$ per $\mathrm{m}^{3}$ of treated wastewater. In the case of aerobic biological treatments, some studies reveal that bioreactor aeration amounts up to $60 \%$ of the total WWTP energy consumption (Metcalf and Eddy, 2003, Hernandez-Sancho et al., 2011). Moreover, the energy demand -and therefore the associated costs- are expected to increase in the future, while restrictions in the quality of the discharged water and the produced sludge also increase.

Anaerobic wastewater treatments are, in this respect, a step forward in reducing energy consumption and promoting organic matter revaluation. The anaerobic treatment of wastewater is based on a series of consecutive biological reactions through which anaerobic bacteria transform, in the absence of oxygen, the complex organic compounds present in the water into simpler products: biogas and digested sludge. Biogas is a gaseous mixture of $\mathrm{CH}_{4}$ 
and $\mathrm{CO}_{2}$ which can also contain small amounts of $\mathrm{H}_{2}, \mathrm{~N}_{2}$, and $\mathrm{H}_{2} \mathrm{~S}$. It is a renewable energy source which can be used, for instance, in a gas engine to generate electricity and heat. The generated sludge can be used as slow-release fertilizer (Mulbry et al., 2005).

Apart from a lower energy demand (since no oxygen supply is needed) and biogas generation, anaerobic treatments present the following advantages versus aerobic treatments: i) reduced amount of sludge generation (up to ten times lower than in aerobic treatment according to Jeison, 2007), ii) high capacity to treat slowly degradable substances and iii) the possibility of nutrient recovery. On the other hand, anaerobic processes for wastewater treatment also present some disadvantages, such as i) the need to operate at high solids retention time or high temperatures (due to the slow growth of the anaerobic microorganisms), ii) the high sensitivity of the biomass to process overloads and iii) its low settleability, which involves operating with big reaction volumes.

Submerged anaerobic membrane bioreactors combine the use of membrane technology with anaerobic processes. In a SAnMBR the treated wastewater is separated from the produced sludge via membrane filtration. This renders a solids-free effluent and allows the decoupling of the solids retention time and the hydraulic retention time. Smaller reactor volumes are thus possible, and low-growth rate microorganisms are not washed out from the system, resulting in a higher microbial biodiversity and enhanced organic matter removal. For the given reasons, SAnMBR technology is a promising alternative for urban wastewater treatment, in which wastewater is treated with a smaller energy demand, biogas is generated, and a small fraction of the inorganic nutrients are recovered in a stabilized sludge which could be used as fertilizer. Pilot-scale SAnMBRs have been evaluated with promising Chemical Oxygen Demand (COD) removal rates (Giménez et al., 2011), but discharge is not always possible without further nitrogen and phosphorus removal (Stuckey, 2012).

\section{Microalgae}

\subsection{Photosynthesis}

Microalgae are unicellular microorganisms which are able to undertake photosynthesis. The term encompasses prokaryotic (cyanobacteria) and eukaryotic microorganisms. Although 
some microalgae have the ability to use organic compounds as energy and/or carbon source, most microalgae are photoautotrophs: they uptake inorganic carbon from the medium in the form of $\mathrm{CO}_{2}$ (gas) or $\mathrm{HCO}_{3}{ }^{-}$, and use light as source of energy. These are the microorganisms this thesis deals with.

Photosynthesis is a process of outmost importance, since it is through photosynthesis that green plants and algae introduce inorganic nutrients in the base of trophic chains in their ecosystems, making use of sunlight to generate organic matter which is consumed by other organisms.

In the overall process of photosynthesis, some reactions are light-dependent while others are light-independent. Light dependent reactions take place in the thylakoid membranes (situated inside chloroplasts and cyanobacteria) and are catalyzed by the protein complexes which conform the photosynthetic reaction centers. First, photons are captured by these reaction centers containing chlorophyll and other pigments. Electrons, protons and $\mathrm{O}_{2}$ are then stripped from water molecules. Electrons reduce $\mathrm{NADP}^{+}$to NADPH, and ATP is also formed. In the dark reactions of photosynthesis (Calvin Cycle), $\mathrm{CO}_{2}$ molecules are converted into carbohydrates such as glucose, using the previously generated NADPH and ATP. The general equation for photosynthesis is therefore:

$$
\mathrm{n} \mathrm{CO}_{2}+\mathrm{n} \mathrm{H}_{2} \mathrm{O}+8 \mathrm{nh} v \rightarrow\left(\mathrm{CH}_{2} \mathrm{O}\right)_{\mathrm{n}}+\mathrm{n} \mathrm{O}_{2}
$$

where $\mathrm{h} v$ represents the energy of one photon, defined by its frequency $(v)$ and the Planck constant $(\mathrm{h})$. The process of transforming $\mathrm{CO}_{2}$ into sugars is called carbon fixation. The $\mathrm{CO}_{2}$ fixation process increases the $\mathrm{pH}$ in the medium, since hydroxyl groups $\left(\mathrm{OH}^{-}\right)$progressively accumulate.

\subsection{Use of microalgae}

Microalgae accumulate organic matter in the form of proteins, lipids, carbohydrates, hydrocarbons, pigments and other small molecules. The commercial interest of microalgae resides in some cases in the latter: special high-value compounds, such as $\beta$-carotene, polyunsaturated fatty acids (PUFA), antioxidants, phycocyanin or astaxanthin, which are used by the pharmaceutical industry (Pulz and Gross, 2004). Microalgae have also been cultivated 
for human and animal nutrition (food-coloring, food supplements, nutraceuticals; aquaculture and animal husbandry, respectively).

In recent decades, however, microalgae have raised an enormous interest as a renewable energy source. Production of biodiesel from microalgae is a rapidly emerging field. Biodiesel is obtained via transesterification of the biomass lipid fraction, which is the reason why a large number of studies on microalgal cultures nowadays focus on lipid productivity maximization. Microalgal biomass can be transformed in other ways too to obtain different fuels: biogas is obtained from anaerobic digestion of the biomass and ethanol is obtained from alcoholic fermentation. Under anaerobic conditions microalgae photoproduce $\mathbf{H}_{2}$ gas, a clean and efficient energy carrier. Different thermochemical conversion processes of microalgal biomass are also possible (gasification, pyrolysis and liquefaction) to obtain products such as syngas, bio-oil, charcoal and other liquid fuels. Finally, direct combustion of microalgal biomass with moisture content below $50 \%$ is also possible for heat, power and steam production.

The residues generated during anaerobic digestion, oil extraction and pyrolysis have potential agricultural applications as animal feed or biofertilizers (soil conditioners), just as some of the biopolymers, proteins and carbohydrates directly produced by the microalgae.

A very interesting and promising feature of microalgal research nowadays is the combined production of renewable energy and biomass resources with distinctive environmental applications for pollution control. The characteristic $\mathrm{CO}_{2}$ fixation and wastewater nutrient removal ability of microalgal cultures, together with the possible recovery of the nutrients in the form of soil fertilizers, support both the sustainability and economy of microalgal production process (Brenan and Owende, 2010).

Microalgae can typically be used to capture atmospheric $\mathrm{CO}_{2}$ and $\mathrm{CO}_{2}$ emissions from power plants and other industrial processes where fossil fuels are burnt, provided they can tolerate the high levels of $\mathrm{SO}_{\mathrm{X}}$ and $\mathrm{NO}_{\mathrm{X}}$ that are present in the flue gases (Lam et al., 2012, Cheah et al., 2015). Some species are also able to assimilate $\mathrm{CO}_{2}$ from soluble carbonate such as $\mathrm{Na}_{2} \mathrm{CO}_{3}$ and $\mathrm{NaHCO}_{3}$ (Guangmin et al., 2014).

Wastewater nutrient removal might be considered as a complementary function from the point of view of microalgal biomass producers, which improves the production process 
economy or sustainability. However, it has long demonstrated a potential per se in the field of wastewater treatment. The combination of both approaches has made microalgal nutrient removal a real alternative in competition to traditional systems. In fact, based on current technologies, algae cultivation for biofuels without the use of wastewater is unlikely to be economically viable or provide a positive energy return, according to Pittman et al (2011). Lundquist et al. (2010) analyzed several different scenarios of algae-based wastewater treatment coupled with biofuel production and came to a similar conclusion: the near-term outcome for large scale algae biofuels production is not favorable without wastewater treatment as the primary goal.

The use of microalgae for wastewater treatment will be discussed in section 4 of this chapter.

\subsection{Factors affecting microalgal growth}

\subsubsection{Light}

Parameters affecting growth are common to all microalgae, although the influence is different among species: the minimum, optimum and maximum values of each parameter are characteristic of each strain. For this reason, the productivities obtained in specific culture systems will also depend on the microalgae considered.

Light is generally the limiting factor in outdoor microalgal productivity (Pulz, 2008). Artificial illumination can contribute to continuous production, but obviously at a higher energy input. Photosynthetic microorganisms make use of the so called photosynthetically active radiation (PAR), the waveband of the solar radiation from $400 \mathrm{~nm}$ to $700 \mathrm{~nm}$, which accounts for approximately $40 \%$ of the total.

Microalgal growth is directly proportional to the intensity of the PAR radiation, provided this intensity is below a certain limit. This phenomenon is called photolimitation. Above a certain light intensity, photosynthesis is inhibited due to damage in the reception centers of the microalgae. This phenomenon is called photoinhibition, and usually happens around intensities of 1700 to $2000 \mu \mathrm{E} \cdot \mathrm{m}^{-2} \cdot \mathrm{s}^{-1}$ (Griffiths, 2013). Microalgae adapt to changes in light intensity by changing their pigment content. 
An important parameter in photobioreactor design and operation is the light penetration distance, which depends on the incident light intensity, the surface scattering and the culture light attenuation. Light attenuation depends on the culture density and the light wavelength. A light gradient is generated inside the reactor in the direction of light penetration, so that cells situated further from the reactor surface receive a lower light intensity than those situated near the reactor surface. Therefore, in a high-density algal culture under high irradiance (such as mid-day sunlight), it is possible that photoinhibition takes place at the culture surface and photolimitation a few centimeters below the surface. An essential interplay is thus established between hydrodynamic characteristics of the reactor, mixing system, light intensity oscillations and cycles, and microalgal metabolism.

\subsubsection{Inorganic nutrients}

The main inorganic nutrients which autotrophic microalgae uptake from their growth medium are carbon, nitrogen, phosphorus and sulfur. Other micronutrients are iron, sodium, potassium, calcium, magnesium, chlorine, manganese, nickel, boron, zinc, copper, molybdenum and cobalt.

According to the Grobbelaar (2004) formula $\left(\mathrm{C}_{106} \mathrm{H}_{181} \mathrm{O}_{45} \mathrm{~N}_{16} \mathrm{P}\right), 1.7 \mathrm{~g} \mathbf{C O}_{2}$ are needed to generate one $\mathrm{g}$ of biomass. For this $\mathrm{CO}_{2}$ to be taken by the microalgae, the pressure of the gas in the culture medium must be at least $0.1-0.2 \mathrm{kPa}$ (Doucha et al., 2005). $\mathrm{CO}_{2}$ supply and $\mathrm{O}_{2}$ removal are, after light supply, the most important challenges in photobioreactor operation.

Nitrogen content of microalgal biomass oscillates between $3-12 \%$ of its dry weight (Reynolds, 2006). Microalgae take nitrogen from the medium in the form of ammonium $\left(\mathrm{NH}_{4}-\mathrm{N}\right)$, nitrate $\left(\mathrm{NO}_{3}-\mathrm{N}\right)$, nitrite $\left(\mathrm{NO}_{2}-\mathrm{N}\right)$ and, in organic form, urea $\left(\mathrm{CO}\left(\mathrm{NH}_{2}\right)_{2}\right)$. Although nitrate is usually the most abundant source of inorganic nitrogen in the environment, ammonium is taken up preferentially, since nitrite and nitrate have to be reduced prior to assimilation, which is a process for which the microalgae need extra energy (Reynolds, 2006). Ammonium is, however, toxic at high concentrations for most microalgal species.

Phosphorus is taken up in the form of orthophosphate $\left(\mathrm{PO}_{4}-\mathrm{P}\right)$, whose bioavailability in the medium depends on the $\mathrm{pH}$ (due to the possibility of precipitation). Phosphorus is an essential requirement for microalgae, since it is a component of nucleic acids which govern protein 
synthesis and of the ATP which powers intracellular processes. Phosphorus content of healthy, replete and active growing cells is $1-1.2 \%$ of their dry weight (Reynolds, 2006).

However, in practice, microalgal $\mathrm{P}$ content varies due to diverse mechanisms of adaptation to the medium. Reynolds (2006) estimated the minimum phosphorus cell quota to be around 0.2 $-0.4 \%$ of ash-free biomass, although some species show a minimum value which is an order of magnitude smaller. Minimal intracellular phosphorus concentrations are achieved when microalgae grow under P-starving conditions.

On the other hand, when luxury phosphorus uptake takes place, microalgal $\mathrm{P}$ content can raise up to values like $3.85 \%$ as measured by Powell et al. (2009). The main phosphorus storage bodies in microalgae are polyphosphates, which are unbranched chains of $\mathrm{PO}_{4}{ }^{-}$groups linked together by oxygen bridges. The amount of polyphosphate present in the cells depends on different factors, such as the available phosphate in the medium, light or temperature (Powell et al., 2008).

\subsubsection{Temperature}

After light, temperature is the most important factor in microalgae cultivation, both for open and closed culture systems (Torzillo et al., 1991). Microalgal growth increases proportionally with temperature below an optimum temperature and is reduced above it. A bell-shaped curve describes the relationship between microalgal activity and temperature, although individual shapes are species dependent, and also influenced by environmental conditions (Ras et al., 2013). Some microalgal species are able to grow in a wide range of temperatures (Chlorella, for example, can grow between 5 and $42{ }^{\circ} \mathrm{C}$ ( $\mathrm{Li}$ et al., 2013)) and most species can tolerate temperatures up to $15^{\circ} \mathrm{C}$ lower than their optimal temperature. However, exceeding the optimum temperatures by only $2-4{ }^{\circ} \mathrm{C}$ may result in the total loss of the culture (Richmond, 1999).

In open pond systems water evaporation compensates for temperature increases, which constitutes a basic temperature control system. In closed cultivation systems cooling or heating might be needed depending on the site climate. The necessity of cooling might be avoided by decreasing the amount of light incident on the reactor with the use of external shading. 


\subsection{4. pH}

Another important parameter affecting algal growth is the $\mathrm{pH}$ of the medium. In most microalgal cultures, pH ranges between 5 and 9 (Razzak et al., 2013). Since photosynthesis raises $\mathrm{pH}$ in the medium due to $\mathrm{CO}_{2}$ depletion (Zhou et al., 2014), $\mathrm{pH}$ control is achieved by $\mathrm{CO}_{2}$ addition and, occasionally, in laboratory scale studies, chemical addition. High $\mathrm{pH}$ in the culture medium also influences microalgal growth indirectly, in the sense that nutrients become unavailable, mainly due to ammonia stripping (loss of ammonium) and precipitation of various compounds (loss of phosphate).

\subsubsection{Dissolved oxygen}

Dissolved oxygen (DO) concentration needs to be controlled in the culture medium since high DO inhibits the process of $\mathrm{CO}_{2}$ fixation. High radiation and high temperatures favor this inhibition. Several microalgal species can only survive for a short period of time, in the range of 2 or 3 hours, in an oxygen supersaturated medium (Tredici and Materassi, 1992). Increasing turbulence and air stripping are strategies used for decreasing DO in the culture medium.

\subsubsection{Agitation}

Agitation facilitates mass and heat transfer, prevents biomass sedimentation and wall biofilm formation and contributes to $\mathrm{pH}$ homogenization. It also contributes to cell distribution among the differently illuminated parts of the culture. In high density cultures, turbulence is of great importance to avoid nutrients gradients and light heterogeneity. On the other hand, the shear stress which each species of microalga can stand also needs to be taken into account.

\subsection{Production of microalgae}

\subsubsection{Microalgal culture systems}

Microalgal culture systems are generally divided into open and closed systems. The most commonly used artificial open systems are raceway ponds, which are shallow recirculation channels $(0.2-0.5 \mathrm{~m}$ deep), usually in an oval shape. A paddle wheel in continuous operation contributes to culture mixing and recirculation. $\mathrm{CO}_{2}$ is normally taken from surface air, 
although sometimes submerged aerators are installed. Open ponds are the cheapest method for large-scale microalgal production because of their lower construction costs, easier maintenance and cleaning and due to a lower energy input. The risks of contamination with other species are, on the other hand, higher than in closed systems and monoculture is only possible for some species which can survive in extreme culture environments (high salinity, high alkalinity). Until today, only a few species of microalgae have been found to grow well at a commercial scale in open ponds (Razzak et al., 2013).

Closed systems are transparent photobioreactors made of plastic or glass and with diverse geometries. Tubular, flat plate and cylindrical columns are the most common. These systems are more expensive to build, maintain and operate, but permit a better control of temperature and other operation parameters. Contamination risk is also reduced, making monocultures easier. Biomass productivity is higher in closed systems, which results in smaller footprint and lower harvesting costs. Nevertheless, global costs are still higher than those of open systems.

Column photobioreactors offer the best controllable growth conditions, the most efficient mixing (they are aerated from the bottom) and the highest volumetric mass transfer rates (Eriksen, 2008). They are low-cost, compact and easy to operate. They can be illuminated internally, and the inner part can be eliminated to create an annular photobioreactor with a smaller fraction of its volume far from the light source.

Tubular photobioreactors consist of arrays of cylinders with smaller diameter (generally smaller than. $0.1 \mathrm{~m}$ ), which can be arranged horizontally, vertically, inclined or as a helix. The culture is recirculated with a pump or an airlift system. $\mathrm{CO}_{2}$ depletion, $\mathrm{O}_{2}$ accumulation and $\mathrm{pH}$ variation limit the possible length of the tubes, making scale up only possible with integration of multiple reactor units (Brenan and Owende, 2010). Tubular reactors are more suitable for outdoors cultures since they expose a larger surface area to sunlight.

Flat plate photobioreactors are some of the earliest forms of closed systems developed. Their entire surface area is well illuminated and therefore they present higher photosynthetic efficiency than tubular reactors (Richmond, 2000). They can also be tilted to assure maximal exposure to direct beam radiation (Hu et al., 1996). The DO path corresponds to the height of the reactor and prevents oxygen buildup, which is a serious problem in other kinds of reactor. Moreover, they are easy to clean, both from the outside and the inside, which means that 
issues like wall fouling by microalgal growth and salt deposition can be handled with ease. Stirring is also very effective, and it is normally achieved by injecting compressed air through perforated tubes on the bottom of the reactor (Cheng-Wu et al., 2001). According to Posten (2009), flat plate reactors are surely the most robust design.

\subsubsection{Microalgal harvest systems}

Microalgae harvesting constitutes around $20-30 \%$ of the total productions costs (Molina Grima et al., 2003) and is therefore a decisive step for energetic and economical balance of the process. Due to their small size $(0.5-30 \mu \mathrm{m})$, it is generally difficult to separate microalgae from their growth medium, although some cyanobacteria settle or float and some species are able to bioflocculate, which results in an easily settleable biomass.

Depending on microalgal size, culture density, subsequent use and economic factors (such as the price of the final product), different harvesting techniques will be applied. Generally, on a first step called bulk harvesting (flocculation, settling or flotation) a microalgal concentration of $2-7 \%$ is achieved (Brenan and Owende, 2010). A second thickening step, requiring more energy (centrifugation or filtration), further concentrates the slurry. In microalgae production for added-value compounds extraction, centrifugation is the most common thickening technique. It is a rapid method and biomass concentrations of up to 95\% are achieved (Heasman et al., 2000). Its disadvantages are the high energy input and the specialized maintenance required and the risk of cell damage due to high gravitational and shear stress forces. Centrifugation is therefore not always economically feasible. Filtration is performed with microfiltration or ultrafiltration membranes, which can be hollow fiber membranes (submerged in the tank) or have tangential flow configuration (external membranes). The higher costs of filtration processes come from pumping and membrane replacement, which makes them cost-effective only for small volumes (less than $2 \mathrm{~m}^{3} \cdot \mathrm{d}^{-1}$ ) (Molina Grima et al., 2003). For processing more than $20 \mathrm{~m}^{3} \cdot \mathrm{d}^{-1}$, centrifugation might be more economic (Molina Grima et al., 2003). 


\section{Microalgae for wastewater treatment}

The use of microalgae for wastewater treatment was first proposed by Oswald and Gotaas (1957). They have since then been used around the world in stabilization ponds or high rate algal ponds (HRAPs). However, these technologies have been used mostly in small communities or farms due to their big spatial footprint and the development and generalization of other systems such as the activated sludge (AS). Dependence of seasonally-changing light and temperature, difficulty in biomass harvesting and risk of protozoa, fungus and virus contamination possibly acted in favor of other treatment methods.

However, in recent decades, the use of microalgal cultures for wastewater treatment has been given more and more consideration, for reasons mentioned in previous sections of this chapter. As possible solutions to biomass harvesting problems, flocculation and biomass immobilization have been researched. Flocculation can be attained by the addition of chemical flocculants, by changing culture conditions $(\mathrm{pH}$, DO, temperature, nutrient depletion) and by use of microalgae which are able to autoflocculate, such as Ankistrodesmus falcatus, Scenedesmus obliquus and Tetraselmis suecica (Salim et al., 2011). Immobilization of microalgae takes place in different kinds of matrices or natural polymers, which are easily separated from the medium. A review of immobilized microalgae for removal of pollutants is presented by de Bashan and Bashan (2010).

On the other hand, high photosynthetic biomass productivities are needed to obtain a significant and effective nutrient removal. It is for this reason that most authors use photobioreactors for microalgal growth and wastewater treatment. Moreover, the right strains have to be selected which are able to stand the specific environmental conditions and wastewater characteristics in each case. Chlorophyceae are a class of microalgae which have demonstrated to be especially resistant to diverse wastewaters and very efficient in removing nutrients from them. Chlorella and Scenedesmus are the most abundant genera found in microalgae-based wastewater treatment systems (Craggs et al, 2003; Pittman et al, 2011). 


\subsection{Microalgal nutrient removal in wastewater}

The use of artificial wastewaters allows for simplified laboratory scale studies, where biotic factors do not need to be addressed. Most artificial media contain high nutrient concentrations, whereas organic matter or potentially toxic compounds are not present. Competition with other bacteria or predation from protozoa are also avoided, as well as inhibitions by segregated substances. These studies cannot be underestimated, since they have made the obtention of a variety of kinetic and stoichiometric parameters possible (see for instance Aslan and Kapdan, 2006). Comparison among species and reactors configurations can also be made. Nonetheless, studies of microalgal growth in wastewater obtained at its source -and not artificially generated- are obviously mandatory when the final objective is the application of microalgae for wastewater treatment.

Abundant literature can be found on microalgal use for wastewater treatment. In the following lines a review of part of this literature is presented. The review mostly focuses on studies treating urban wastewater. A small mention is made to wastewaters from farming activities and other industrial activities, and finally studies dealing with anaerobic effluents are presented.

Most studies with urban wastewaters constitute a sort of tertiary treatment, since the main potential of microalgae in wastewater treatment is the removal of inorganic nutrients such as nitrogen and phosphorus. Chlorella and Scenedesmus are again amongst the most usually found genera. Some specific examples of recent studies follow:

Wang and Min (2009) evaluated the growth of Chlorella in the wastewater from four different points in a WWTP: prior to primary settling, after secondary settling, after AS system and on the sludge centrate. They obtained the corresponding nutrient elimination rates and growth rates (highest for the microalgae grown on centrate). They also demonstrated aluminium, calcium, iron, magnesium and manganese removal.

Ruiz-Marín et al. (2010) obtained 60 - $100 \%$ ammonium elimination in batch cultures of Scenedesmus obliquus and Chlorella vulgaris treating urban wastewater. 
Singh and Baldwin (2012) isolated four microalgal species from the environment and cultivated them in the effluent of an aerobic membrane bioreactor treating domestic wastewater, in order to eliminate the remaining inorganic nitrogen and phosphorus concentrations. They worked with batch and continuous reactors, obtaining in the latter average eliminations of $50 \% \mathrm{NH}_{4}-\mathrm{N}, 75 \% \mathrm{NO}_{2}-\mathrm{N}, 35 \% \mathrm{NO}_{3}-\mathrm{N}$ and $60 \% \mathrm{PO}_{4}-\mathrm{P}$.

De Alva et al. (2013) cultivated Scenedesmus acutus in two different municipal wastewater discharges (pre-treated and post-treated) under laboratory conditions. 94\% organic nitrogen and $66 \%$ phosphate were eliminated in the pretreated wastewater. Better results on biomass productivity and lipid accumulation were obtained in the wastewater than in microalgae grown in an enriched medium.

Dickinson et al. (2013) cultivated Scenedesmus sp. as tertiary treatment of urban wastewater in continuous mode and studied the relationship between carbohydrate, fatty acids and lipid productivities and hydraulic retention times, concluding that the rate of nutrient removal strongly controls the composition of the biomass. They reported maximum removal rates of 22 $\mathrm{mg} \mathrm{N} \cdot \mathrm{l}^{-1} \cdot \mathrm{d}^{-1}$ and $2.5 \mathrm{mg} \mathrm{P} \cdot \mathrm{l}^{-1} \cdot \mathrm{d}^{-1}$.

Samorí et al. (2013) studied biomass growth and productivities of a newly isolated freshwater algal strain (Desmodesmus communis) and a natural consortium of microalgae cultivated in batch under laboratory conditions with primary and secondary effluents from a local WWTP. They obtained higher biomass productivity for $D$. communis than for the natural consortium $\left(0.138-0.227\right.$ vs. $0.078 \mathrm{~g} \cdot \mathrm{l}^{-1} \cdot \mathrm{d}^{-1}$ in the primary effluent enriched with $\left.\mathrm{CO}_{2}\right)$, as well as better nutrient removal efficiency: almost 100\% of ammonium and phosphorus were removed. Due to the resulting biomass composition, anaerobic digestion appeared to be the most appropriate biofuel conversion process.

Gentili (2014) also demonstrated that mixtures of pulp and paper wastewater with municipal and dairy wastewater have great potential as growth medium for algae biomass and lipid production together with effective wastewater treatment. He obtained high (> 90\%) ammonium and phosphate removal from Selenastrum minutum and a locally isolated algal strain (Scenedesmus sp.). 
Ramos Tercero et al. (2014) cultivated Chlorella protothecoides in different urban wastewaters (after primary treatment, in the waste sludge and after disinfection) under laboratory conditions, and obtained high (> 90\%) ammonium and nitrate removals and acceptable $(50-70 \%)$ phosphate removals in most cases. Microalgal growth rate and other kinetic parameters were also obtained.

Gao et al. (2014) cultivated Chlorella vulgaris in a membrane photobioreactor using treated sewage as medium and obtaining a biomass productivity of $0.04 \mathrm{~g} \cdot \mathrm{l}^{-1} \cdot \mathrm{d}^{-1}$, removing $4.13 \mathrm{mg}$ $\mathrm{N} \cdot \mathrm{l}^{-1} \cdot \mathrm{d}^{-1}$ and $0.43 \mathrm{mg} \mathrm{P} \cdot \mathrm{l}^{-1} \cdot \mathrm{d}^{-1}$.

Wastewaters from farming activities usually present a high concentration of nutrients. Several studies have demonstrated the ability of microalgae such as Botryococcus braunii (An et al., 2003), Microspora willeana, Ullothrix sp. or Rhizoclonium hierglyphicum (Pittman et al, 2011) to remove these nutrients.

It has also been proven that some microalgae are able to eliminate organic toxic compounds or heavy metals usually present in some industrial wastewaters. Biomass is, in most of these cases, generated in smaller amounts due to a slower growth caused by low nutrient concentrations. An exception to this is shown in a study by Chinnasamy (2010), where a considerable amount of biomass is generated cultivating three microalgal species (Chlorella saccharophila, Pleurochrysis carterae and Botryococcus braunii) in a wastewater from the textile industry.

Some studies are found in the literature which deal with different kinds of anaerobic effluents treated with microalgae, although in most cases the effluent is diluted due to the high nutrient (especially ammonium) concentrations and/or high turbidity. For example, Park and Jin (2010) reported that the microalga Scenedesmus eliminated $5-6 \mathrm{mg} \mathrm{N} \cdot \mathrm{l}^{-1} \cdot \mathrm{d}^{-1}$ from a filtered anaerobic digestion effluent from a piggery farm. The amount of inorganic carbon supplied by this effluent allowed microalgal growth without additional $\mathrm{CO}_{2}$ injection.

Cai et al. (2013) demonstrated a growth rate of $0.645 \mathrm{~d}^{-1}$ of Nannochloropsis salina in diluted $(6 \%)$ anaerobic digester centrate. The highest biomass productivity, in batch culture, was 92 $\mathrm{mg} \cdot \mathrm{l}^{-1} \cdot \mathrm{d}^{-1}$ and nitrogen and phosphorus elimination in semicontinuous mode were 35.3 and 3.8 $\mathrm{mg} \cdot \mathrm{l}^{-1} \cdot \mathrm{d}^{-1}$, respectively. 
Escudero et al. (2014) demonstrated the ability of Chlamydomonas acidophila to grow in the effluent generated by the anaerobic digestion of a mixture comprising $60 \%$ pig slurry, $30 \%$ cheese whey and $10 \%$ sheep manure. The effluent contained concentrations of up to $1000 \mathrm{mg}$ $\mathrm{NH}_{4}-\mathrm{N} \cdot \mathrm{l}^{-1}$ out of which $8.8 \mathrm{mg} \cdot \mathrm{l}^{-1} \cdot \mathrm{d}^{-1}$ were removed.

Prajapati et al. (2014) diluted the liquid fraction of the digestate after microalgal anaerobic digestion (Chroococcus sp.) and used it as growth medium for further biomass production, demonstrating the stability of this "closed loop" process.

Uggetti et al. (2014) have also reported the growth of a mixed microalgal culture dominated by Scenedesmus sp. on the digester effluent of a WWTP. Their study shows a significant increase in biomass production with higher digestate and microalgal initial concentration, in spite of initial growth rate reduction.

Sepúlveda et al. (2015) recently reported a productivity of $0.4 \mathrm{~g} \cdot \mathrm{l}^{-1} \cdot \mathrm{d}^{-1}$ of Nannochloropsis gaditana grown on anaerobic digestion centrate at $30-50 \%$ dilution. The biomass obtained had the same composition (protein and lipid content) as when grown in artificial medium. An excess of nitrogen in the effluent was indicated by the fact that $80-90 \%$ of the phosphorus was eliminated (at a rate of $5.7 \mathrm{mg} \mathrm{P} \cdot \mathrm{l}^{-1} \cdot \mathrm{d}^{-1}$ ), whereas removed nitrogen (at $35 \mathrm{mg} \mathrm{N} \cdot \mathrm{l}^{-1} \cdot \mathrm{d}^{-1}$ ) resulted only a $20-40 \%$ of the total.

\section{Present and future trends}

As mentioned in section 1 of this chapter, the technical feasibility of microalgal production has, by now, been widely demonstrated. However, economic and environmental sustainability are key obstacles for its commercialization. Dozens of start-up companies are attempting to commercialize algal biofuels, while realizing that current production methods require significant improvement (Chisti, 2011). Most of the recent studies attempting to scaleup microalgal production are in the first stage, i.e., scaling up from laboratory to pilot scale or to modest production plant scale (Wu et al., 2014). Nevertheless, large scale algal biomass production in HRAPs for treatment of municipal wastewaters was reported decades ago (Oswald and Golueke, 1960, Oswald, 1988) and also recently (Park et al., 2011). 
For the establishment of a significant microalgal industry, i.e., for increased sustainability of microalgal production processes, efforts need to be made in two main directions. On the one hand, technical advances are necessary in order to increase the economical and energetic efficiency of the whole process (operation and maintenance of reactor, pumps, utilities, harvesting system and other elements). On the other hand, innovative system integration seems mandatory for the extension of microalgal processes. Microalgae are considered to be futuristic raw material for establishing a biorefinery because of their potential to produce multiple products (Trivedi et al., 2015) -biorefining consists of sustainable biomass processing to obtain energy, biofuels and high value products at the same time, as in Kouia et al. (2015). In this line of action, coupling microalgae cultivation with wastewater treatment is considered as one of the most promising routes to produce bio-energy and bio-based byproducts in an economically viable and environmentally friendly way (Zhou et al., 2014), as previously mentioned in section 3.2 of this chapter.

Indeed, various life cycle assessment (LCA) studies have demonstrated the environmental sustainability of wastewater-based algal biofuel production processes (Clarens et al., 2010). Yang et al. (2011) calculated that $90 \%$ of freshwater, $94 \%$ of nitrogen and $100 \%$ of potassium, magnesium and sulfur could be saved when producing microalgal biofuels using wastewater as growth medium, and $\mathrm{Mu}$ et al. (2013) confirmed the higher sustainability performance of microalgae grown in wastewater than cultures grown in freshwater.

The main problems to overcome when culturing microalgae in wastewater, which are actually common to general microalgae production, are i) the low cell densities, low lipid content and moderate growth rates attained, ii) the risk of culture contamination or culture crash, and iii) the variability of the process when performed under outdoor conditions. A special challenge when treating wastewater with microalgae is the variability of nutrients content in the wastewater, and the possible unsuitable nutrient ratios. Possible solutions and needed research related to these main problems follow:

Higher cell densities and growth rates might be obtained with changes in environmental conditions, such as working in the optimal temperature, light intensity or $\mathrm{pH}$. For this, studies of the microalgal behavior under different conditions must be combined with the design of new cultivation strategies, such as fed-batch operation, deceleration-stat (Van Wagenen et al., 
2015), two phase operation, mixotrophy or semicontinuous cultivation. Semicontinuous operation is one of the simplest and most efficient strategies, although it has rarely been researched in outdoor systems (Zhou et al., 2014).

Lipid accumulation is often enhanced by nitrogen depletion in the medium, which is not a realistic option in the case of wastewater treatment, where the nitrogen content in the medium is necessarily significant. In this case, two stage cultivation systems can be used, as mentioned previously in this section, where in a first step microalgal biomass is allowed to grow, removing nutrients from the wastewater, and in a second step it is maintained in a nitrogen free medium in order to increase its lipid or carbohydrate content (Chen et al., 2015). On the other hand, instead of biodiesel production, other energy recovery options might be better applied in the case of wastewater treatment with microalgae, such as anaerobic digestion or others as presented in section 3.2. Anaerobic digestion of algal biomass (or of its spent fraction after extraction of the substances of interest) has the added advantage of nutrient recovery, since the digested sludge can be applied as fertilizer. According to KleinMarcuschamer et al. (2013), nitrogen recovery through anaerobic digestion is necessary for sustainable production of algal biofuels. Therefore, research in this area should focus on obtaining a microalgal culture which presents the best combination of nutrient removal and biogas yield.

Obtaining robust microalgae strains which tolerate different types of wastewaters and environmental stresses, or which minimize culture collapse risks by being more resistant to contamination by bacteria, virus, fungi, or grazing microorganisms, should be a priority when designing wastewater treatment systems. Locally isolated algal strains tend to adjust better to local environments (Xin et al., 2010, Zhou et al., 2012). The reason for this is that local species are a priori adapted to the regional biotic and abiotic factors dominant in the environment. Regionally-based phycoprospecting (selecting indigenous microalgae with characteristics favourable to pollution control and bioresource production in the area of interest) is, according to Wilkie et al. (2011), the most sustainable path for the development of algae-based solutions and an ongoing line of research. Microalgae consortiums also performed better than monocultures in terms of nutrient removal and biomas productivity (Woertz et al., 2009, Chinnasamy et al., 2010). 
It has been reported that, theoretically, productivity in continuous cultivation systems is two to five times higher than that of batch systems (Fernandes et al., 2015). Operating in continuous mode enables the achievement of higher cell densities, which in turn also reduces harvesting costs. The complexity of operating in continuous mode resides in the dependence of microalgae on light availability and intensity (Cuaresma et al., 2011). This dependence makes it necessary to adjust dilution rates during dark and light periods, or might be counteracted by using artificial illumination, although this incurs higher costs. Moreover, contamination risks are higher due to a prolonged time of operation, and similarly, biomass attachment to the walls of the reactors becomes a bigger problem. This can be fought by increasing turbulence or manual or mechanical wall scraping. It is still necessary to provide demonstrative case studies which prove the advantages of continuous cultivation and allow a rigorous and realistic techno-economic assessment (Fernandes et al., 2015).

For productivity maximization and product quality, permanent control of cultivation parameters is necessary. In the case of continuous cultivation, especially outdoors, it is essential to monitor the parameters by sensors and to know in advance the behavior of the microalgae under the cultivation conditions. As an example of efforts made to overcome the problem of light variability, Mairet et al. (2015) developed a static and an adaptive controller in order to regulate the light attenuation factor by changing the dilution rate, and thus optimize algal productivity. Generally, for a proper control of the process, information about optimal growth conditions and basic performance of the culture should be previously collected. Biomass growth and composition models should be then developed, since models are essential for monitoring and control (Fernandes et al., 2015). Naturally, the same applies regarding water quality in the case of microalgal cultivation for wastewater nutrient removal. Model-based bioprocesses control is not yet a mature technology, but a fundamental research field with high potential (Fernandes et al., 2015).

\section{Mathematical modeling of microalgae}

In the field of wastewater treatment, mathematical models constitute useful tools for WWTP design, simulation and water quality prediction. Simulation and water quality prediction are 
helpful for plant control and operation, and can increase efficiency and reliability of the process.

The effect of single factors influencing algal growth (such as those mentioned in section 3.3 of this introduction) have been modeled separately and different authors have also proposed different combinations of these expressions in order to model multiple factors simultaneously. These include, for instance, multiplicative models, the selection of a single limiting parameter or mathematical equations to express interactions between two parameters (the so called "coupled models"). An additional complication is the fact that microalgae cultures are able to vary their composition in order to adjust to the changing environment and depending on their history (photoadaptation, lipid accumulation under nitrogen stress, or temperature acclimation).

A large part of the first models developed for microalgae were devoted to their behavior in rivers, lakes and oceans (Geider et al., 1998, Reichert, 2001). Some of the selected responses were oxygen production rate, chlorophyll content, $\mathrm{C}: \mathrm{N}$ ratios in the cells, or microalgae measured as suspended solids. It was later, in views of their industrial application, that other kinds of models were developed. Some examples are those models which predict production of lipids, sugars or other storage molecules (Mairet et al., 2011, Packer et al., 2011, Adesanya et al., 2014). Some authors have also developed models which calculate biomass production in bioreactors taking into account -apart from the biological processes- the main physical phenomena (variable light and temperature, mixing, gas transfer or others) (VunjakNovakovic, et al., 2005, García-Camacho et al., 2012, Pegallapati and Nirmalakhandan, 2012,). In this field, computational fluid dynamics has also been applied for designing and modeling photobioreactors, as reviewed by Bitog et al. (2011).

In summary, there exists abundant literature in microalgal modeling, since the number of possible combinations of factors taken into account and parameters chosen as model response is immense. As the number of parameters taken into account increases, the accuracy of the response normally does so, too. Evidently, and unfortunately, the complexity of the model obtained also escalates. Therefore, a compromise always needs to be sought between accuracy and applicability. In practice, authors generally develop models adapted to their needs and the scope of their research. 


\section{References}

Acién, F.G., Fernández, J.M., Magán, J.J., Molina, E. (2012) Production cost of a real microalgae production plant and strategies to reduce it. Biotechnology Advances 30, 1344-1353.

Adesanya, V.O., Davey, M.P., Scott, S.S., Smith, A.G. (2014) Kinetic modelling of growth and storage molecule production in microalgae under mixotrophic and autotrophic conditions. Bioresource Technology 157, $293-304$.

An, J.Y., Sim, S-J., Lee, J-S, Kim, B-W (2003) Hydrocarbon production from secondary treated piggery wastewater by the green alga Botryococcus braunii. Journal of Applied Phycology 15, 185-191

Aslan, S., Kapdan, I.K. (2006) Batch kinetics of nitrogen and phosphorus removal from synthetic wastewater by algae. Ecological Engineering 28, 64-70.

Bitog, J.P., Lee, I-B, Kim, K-S, Hwang, H-S, Hong, S-W, Seo, I-H, Kwon, K-S, Mostafa, E. (2011) Application of computational fluid dynamics for modeling and designing photobioreactors for microalgae production: A review. Computers and Electronics in Agriculture 76, 131-147.

Brenan, M., Owende, P. (2010) Biofuels from microalgae - A review of technologies for production, processing, and extraction of biofuels and co-products. Renewable and Sustainable Energy Reviews 14, 557-577.

Broekhuizen, N., Park, J. B. K., McBride, G. B., Craggs, R. J. (2012) Modification, calibration and verification of the IWA River Water Quality Model to simulate a pilot-scale high rate algal pond. Water Research 46(9) 2911-26.

Cai, T., Park, Y., Racharaks, R., Li, Y. (2013) Cultivation of Nannochloropsis salina using anaerobic digestion effluent as a nutrient source for biofuel production. Applied Energy 108, 486-492.

Cheah, W.Y., Show, P.L., Chang, J.S., Ling, T.C., Juan, J.C. (2015) Biosequestration of atmospheric $\mathrm{CO}_{2}$ and flue gas-containing $\mathrm{CO}_{2}$ by microalgae. Bioresource Technology 184, 190-201.

Chen, C-Y, Yeh, K.L., Aisyah, R., Lee, D.J., Chang, J-S. (2011) Cultivation, photobioreactor design and harvesting of microalgae for biodiesel production: A critical review. Bioresource Technology 102, 71-81.

Chen, G., Zhao, L., Qu, Y. (2015) Enhancing the productivity of microalgae cultivated in wastewater toward biofuel production: A critical review. Applied Energy 137, 282-291.

Cheng-Wu, Z., Zmora, O., Kopel, R., Richmond, A. (2001) An industrial-size flat plate glass reactor for mass production of Nannochloropsis sp. (Eustigmatophyceae). Aquaculture 195, 35-49.

Chinnasamy, S., Bhatnagar, A., Claxton, R., Das, K. (2010) Biomass and bioenergy production potential of microalgae consortium in open and closed bioreactors using untreated carpet industry effluent as growth medium. Bioresource Technology 101 (17), 6751-60.

Chisti, Y., Yan, J. (2011) Energy from algae: current status and future trends algal biofuels - a status report. Applied Energy 88 (10), 3277-3279.

Chisti, Y. (2013) Constraints to commercialization of algal fuels. Journal of Biotechnology 167, 201-214. 
Christenson, L., Sims, R. (2011) Production and harvesting of microalgae for wastewater treatment, biofuels, and bioproducts. Biotechnology advances 29, 686-702.

Clarens, A.F., Resurreccion, E.P., White, M.A., Colosi, L.M. (2010) Environmental life cycle comparison of algae to other bioenergy feedstocks. Environmental Science and Technology 44(5), 1813-1819.

Craggs, R., Lundquist, T., Benemann, J. (2013) Wastewater treatment and algal biofuel production. In: Borowitzka, M.A., Moheimani, N.R., editors. Algae for Biofuels and Energy. Springer, Dordrecht, pp. 153-163.

Craggs, R.J., Heubeck, S., Lundquist, T.J., Benemann, J.R. (2011) Algal biofuels from wastewater treatment high rate algal ponds. Water Science and Technology 63, 660-665.

Cuaresma, M., Janssen, M., van den End, E.J., Vílchez, C., Wijffels, R.H. (2011) Luminostat operation: A tool to maximize microalgae photosynthetic efficiency in photobioreactors during the daily light cycle? Bioresource Technology 102, 7871-7878.

De Bashan, L.E., Bashan, Y. (2010) Immobilized microalgae for removing pollutants: Review of practical aspects. Bioresource Technology 101, 1611-1627.

Dickinson, K.E., Whitney, C.G., McGinn, P.J. (2013) Nutrient remediation rates in municipal wastewater and their effect on biochemical composition of the microalga Scenedesmus sp. AMDD. Algal Research 2 (2) $127-$ 134.

Doucha, J., Straka, F., Livansky, K. (2005) Utilization of flue gas for cultivation of microalgae (Chlorella sp.) in an outdoor open thin layer photobioreactor. Journal of Applied Phycology 17 (5), 403-412.

Eriksen, N. (2008) The technology of microalgal culturing. Biotechnology Letters 30 (9), 1525-1536.

Escudero, A., Lacalle, A., Pinto, M. (2014) Ammonium removal from anaerobically treated effluent by Chlamydomonas acidophila. Bioresource Technology 153, 62-68.

Fernandes, B.D., Mota, A., Teixeira, J.A., Vicente, A.A. (2015) Continuous cultivation of photosynthetic microorganisms: Approaches, applications and future trends. Biotechnology Advances 33, 6(2) 1228-1245.

Gao, F., Yang, Z-H, Li, C., Wang, Y-J, Jin, W-H, Deng, Y-B. (2014) Concentrated microalgae cultivation in treated sewage by membrane photobioreactor operated in batch flow mode. Bioresource Technology 167, 441446.

Garcia-Camacho, F., Sánchez-Mirón, A., Molina-Grima, E., Camacho-Rubio, F., Merchuck, J.C. (2012) A mechanistic model of photosynthesis in microalgae including photoacclimation dynamics. Journal of Theoretical Biology 304, 1-15.

Geider, R.J., MacIntyre, H.L., Kana, T.M., (1998) A dynamic regulatory model of phytoplanktonic acclimation to light, nutrients, and temperature. Limnology and Oceanography 43, 679-694.

Gentili, F.G. (2014) Microalgal biomass and lipid production in mixed municipal, dairy, pulp and paper wastewater together with added flue gases. Bioresource Technology 169, 27-32.

Giménez, J.B., Robles, A., Carretero, L., Duran, F., Ruano, M.V., Gatti, M.N., Ribes, J., Ferrer, J., Seco, A. (2011) Experimental study of the anaerobic urban wastewater treatment in a submerged hollow-fibre membrane bioreactor at pilot scale. Bioresource Technology 102, 8799-8806. 
Griffiths, M.J. (2013) Microalgal cultivation reactor systems. In: Biotechnological applications of microalgae: biodiesel and value-added products. Taylor \& Francis Group, LLC, Boca Raton, Florida, USA.

Guangmin, L., Lina, Q., Hong, Z., Shumei, X., Dan, Z. (2014) The capacity of bicarbonate capture of a continuous microalgae photo-bioreactor system. Energy Procedia 61, 361-364.

Heasman, M., Diemar, J., O’Connor, W., Sushames, T., Foulkes, L. (2000) Development of extended shelf-life microalgae concentrate diets harvested by centrifugation for bivalve molluscs-a summary. Aquaculture Research $31(8-9), 637-59$.

Hernandez-Sancho, F., Molinos-Senante, M., Sala-Garrido, R. (2011) Energy efficiency in Spanish wastewater treatment plants: A non-radial DEA approach. Science of the Total Environment 409, 2693-2699.

Ho, S-H, Ye, X., Hasunuma, T., Chang, J-S, Kondo, A. (2014) Perspectives on engineering strategies for improving biofuel production from microalgae -A critical review. Biotechnology Advances 32 (8) 1448-1459.

Hu, Q., Guterman, H., Richmond, A. (1996) A Flat Inclined Modular Photobioreactor for Outdoor Mass Cultivation of Photoautotrophs. Biotechnology and Bioengineering 51, 51-60.

Hulatt, C.J., Lakaniemi, A.-M., Puhakka, J.A., Thomas, D.N. (2012) Energy demands of nitrogen fertiliser supply in mass cultivation of two commercially important microalgal species, Chlorella vulgaris and Dunaliella tertiolecta. Bioenergy Research 5, 669-684.

Jeison, D. (2007) Anaerobic membrane bioreactors for wastewater treatment: feasibility and potential applications, $\mathrm{PhD}$ thesis, Wageningen University, The Netherlands.

Kim, H.W., Vannela, R. et al. (2010) Photoautotrophic nutrient utilization and limitation during semi-continuous growth of Synechocystis sp. PCC6803. Biotechnology and Bioengineering 106, 553-563.

Kouia, M., Holmberg, H., Ahtila, P. (2015) Microalgae-utilizing biorefinery concept for pulp and paper industry: Converting secondary streams into value-added products. Algal Research 10, 41-47.

Lam, M.K., Lee, K.T., Mohamed, A.R. (2012) Current status and challenges on microalgae-based carbon capture. International Journal of Greenhouse Gas Control 10, 456-469.

Li, T., Zheng, Y., Yu, L., Chen, S. (2013) High productivity cultivation of a heat-resistant microalga Chlorella sorokiniana for biofuel production. Bioresource Technology 131, 60-67.

Mairet, F., Bernard, O., Masci, P., Lacour T., Sciandra, A. (2011) Modelling neutral lipid production by the microalga Isochrysis aff. galbana under nitrogen limitation. Bioresource Technology 102, 142-149.

Mairet, F., Muñoz-Tamayo, R., Bernard, O. (2015) Adaptive control of light attenuation for optimizing microalgae production. Journal of Process Control 30, 117-124.

Metcalf \& Eddy Inc., (2003). Wastewater Engineering: Treatment and Reuse, 4th edition, New York, McGrawHill.

Molina Grima, E., Belarbi, E.H, Acien Fernandez, F.G., Robles Medina, A., and Chisti, Y. (2003) Recovery of microalgal biomass and metabolites: process options and economics. Biotechnology Advances 20, 491-515. 
Mu, D.Y., Min, M., Krohn, B., Mullins, K., Ruan, R., Hill, J. (2013) Life cycle environmental impacts of wastewater-based algal biofuels. Environmental Science and Technology 448 (19), 11696-11704.

Mulbry, W., Westhead, E.K., Pizarro, C., Sikora, L. (2005) Recycling of manure nutrients: use of algal biomass from dairy manure treatment as a slow release fertilizer. Bioresource Technology 96, 451-458.

Oswald, W., Gotaas, H. (1957) Photosynthesis in sewage treatment. American Society of Civil Engineers, Paper No. 2849.

Oswald, W., Golueke, C.G. (1960) Biological transformation of solar energy. Advances in Applied Microbiology 2, 223-62.

Oswald, W. (1988) Microalgae and wastewater treatment. In: Borowitzka, M.A., Borowitzka, L.J., editors. Microalgal biotechnology. Cambridge University Press, pp. 305-328.

Packer, A., Li, Y., Andersen, T., Hu, Q., Kuang, Y., Sommerfeld, M. (2011) Growth and neutral lipid synthesis in green microalgae: A mathematical model. Bioresource Technology 102, 111-117.

Park, J., Craggs, R.J., Shilton, A.N. (2011) Wastewater treatment high rate algal ponds for biofuel production. Bioresource Technology 102, 35-42.

Pegallapati, A.K., Nirmalakhandan, N. (2012) Modeling Algal Growth in Bubble Columns under Sparging with $\mathrm{CO}_{2}$-enriched Air. Bioresource Technology 124, 137-145.

Pittman, J. K., Dean, A. P., Osundeko, O. (2011) The potential of sustainable algal biofuel production using wastewater resources. Bioresource Technology 102, 17-25.

Posten, C. (2009) Design principles of photo-bioreactors for cultivation of microalgae. Engineering in Life Sciences 9, 165-177.

Prajapati, S.K., Kumar, P., Malik, A., Kumar Vijay, V. (2014) Bioconversion of algae to methane and subsequent utilization of digestate for algae cultivation: a closed loop bioenergy generation process. Bioresource Technology $158,174-180$.

Pulz, O., Gross, W. (2004) Valuable products from biotechnology of microalgae. Applied Microbiology and Biotechnology 65, 635-648.

Ramos Tercero, E.A., Sforza, E., Morandini, M., Bertucco, A. (2014) Cultivation of Chlorella protothecoides with urban wastewater in continuous photobioreactor: Biomass productivity and nutrient removal. Applied Biochemistry and Biotechnology 172, 1470-1485

Razzak, S.A., Hossain, M.M., Lucky, R.A., Bassi, A.S., De Lasa, H. (2013) Integrated $\mathrm{CO}_{2}$ capture, wastewater treatment and biofuel production by microalgae culturing - A review. Renewable and sustainable Energy Reviews 27, 622-653.

Reichert, P., Borchardt, D., Henze, M., Rauch, W., Shanahan, P., Somlyódy, L., Vanrolleghem, P. (2001) River Water Quality Model no. 1 (RWQM1):II. Biochemical process equations. Water Science and Technoloy 43 (5) 11-30.

Reynolds, C. S. (2006) The ecology of phytoplankton, Cambridge University Press, New York. 
Richmond, A. (1999) Physiological principles and modes of cultivation in mass production of photoautotrophic microalgae. In: Cohen Z, editor. Chemicals from microalgae. Taylor \& Francis, London, pp. 353-386.

Richmond, A. (2000) Microalgal biotechnology at the turn of the millennium: a personal view. Journal of Applied Phycology 12 (3-5), 441-51.

Robles, A. (2013) Modelling, simulation and control of the filtration process in a submerged anaerobic membrane bioreactor treating urban wastewater, $\mathrm{PhD}$ thesis, Universitat Politècnica de Valéncia, Valencia, Spain.

Rodolfi, L., Zittelli, G. (2009) Microalgae for oil: Strain selection, induction of lipid synthesis and outdoor mass cultivation in a low-cost photobioreactor. Biotechnology and Bioengineering 102, 100-112.

Sepúlveda, C., Acién, F.G., Gómez. C., Jiménez-Ruiz, N., Riquelme, C., Molina-Grima, E. (2015) Utilization of centrate for the production of the marine microalgae Nannochloropsis gaditana. Algal Research 9, 107-116.

Singh, G., Baldwin Thomas, P. (2012) Nutrient removal from membrane bioreactor permeate using microalgae and in a microalgae membrane photoreactor. Bioresource Technology 117, 80-85.

Stuckey, D.C. (2012) Recent developments in anaerobic membrane reactors. Bioresource Technology 122, 137 148.

Torzillo, G., Sacchi, A., Materassi, R., Richmond, A. (1991) Effect of temperature on yield and night biomass loss in Spirulina platensis grown outdoors in tubular photobioreactors. Journal of Applied Phycology 3, 103-9.

Tredici, M., Materassi, R. (1992) From open ponds to vertical alveolar panels: the Italian experience in the development of reactors for the mass cultivation of phototrophic microorganisms. Journal of Applied Phycology 4, 221-231.

Trivedi, J., Aila, M., Bangwal, D.P., Kaul, S., Garg, M.O. (2015) Algae based biorefinery-How to make sense? Renewable and Sustainable Energy Reviews 47, 295-307.

Ugetti, E., Sialve, B., Latrille, E., Steyer, J-P (2014) Anaerobic digestate as substrate for microalgae culture: The role of ammonium concentration on the microalgae productivity. Bioresource Technology 152, 437-443.

Van Wagenen, J., Pape, M.L., Angelidaki, I. (2015) Characterization of nutrient removal and microalgal biomass production on an industrial waste-stream by application of the Deceleration-stat technique. Water Research 75 , 301-311.

Vunjak-Novakovic, G., Kim, Y., Wu, X., Berzin, I., Merchuk, J.C. (2005) Air-Lift Bioreactors for Algal Growth on Flue Gas: Mathematical Modeling and Pilot-Plant Studies. Industrial and Engineering Chemical Research 44, 6154-6163.

Wilkie, A.C, Edmundson, S.J., Duncan, J.G. (2011) Indigenous algae for local bioresource production: Phycoprospecting. Energy for Sustainable Development 15 (4), 365-371.

Wang, L., Min, M., Li, Y., Chen, P., Chen, Y., Liu, Y., Wang, Y., Ruan, R. (2010) Cultivation of green algae Chlorella sp. in different wastewaters from municipal wastewater treatment plant. Applied Biochemical Biotechnology 162, 1174-1186. 
Weiland, P. (2010) Biogas production: current state and perspectives. Applied Microbiology and Biotechnology 85(4), 849-60.

Woertz, I., Feffer, A., Lundquist, T., Nelson, Y. (2009) Algae grown on dairy and municipal wastewater for simultaneous nutrient removal and lipid production for biofuel feedstock. Journal of Environmental Engineering 135 (11), 1115-22.

Xin, L., Hong-Ying, H., Jia, Y. (2010) Lipid accumulation and nutrient removal properties of a newly isolated freshwater microalga, Scenedesmus sp. LX1, growing in secondary effluent. New Biotechnology 27 (1), 59-63.

Yang, J., Xu, M., Zhang, X., Hu, Q., Sommerfeld, M., Chen, Y. (2011) Life-cycle analysis on biodiesel production from microalgae: water footprint and nutrients balance. Bioresource Technology 102, 159-65.

Zhen-Feng, S., Xin, L., Hong-Ying, H., Yin-Hu, W., Tsutomu, N. (2011) Culture of Scenedesmus sp. LX1 in the modified effluent of a wastewater treatment plant of an electric factory by photo-membrane bioreactor. Bioresource Technology 102, 7627-7632.

Zhou. W., Li, Y., Min, M., Hu, B., Zhang, H., Ma, X., Liang, L., Cheng, Y., Chen, P., Ruan, R. (2012) Growing wastewater-born microalga Auxenochlorella protothecoides UMN280 on concentrated municipal wastewater for simultaneous nutrient removal and energy feedstock production. Applied Energy 98, 433-440.

Zhou, W., Chen, P., Min, M., Ma, X., Wang, J., Griffith, R., Hussain, F., Peng, P., Xie, Q., Li, Y., Shi, J., Meng, J., Ruan, R. (2014) Environment-enhancing algal biofuel production using wastewaters. Renewable and sustainable Energy Reviews 36, 256-269. 



\section{Objectives}

The aim of this thesis is to study the nutrient recovery process from an anaerobic membrane bioreactor effluent by using a microalgal culture. Moreover, this thesis aims at obtaining the main kinetic expressions governing the process.

The partial objectives which must be accomplished to achieve the main objective are:

To isolate the autochthonous microalgae culture and to study its growth in the existing anaerobic effluent, as well as its evolution (changes in the population) and its stability.

To assess the nutrient removal levels attained during microalgal cultivation, thus proving the microalgal system to be a valid option for anaerobic effluent treatment.

To study the influence of the operational parameters of the process, such as cellular retention time or light cycles, as well as the influence of temperature.

To study microalgal intracellular nutrient storage and its influence on nutrient uptake (ammonium, phosphate) from the media, developing reliable mathematical expressions to represent these interactions.

To study the influence of outdoor varying conditions (light and temperature) in microalgal nutrient removal, developing a kinetic expression for successful prediction of nutrient removal in an outdoor and pilot scale wastewater treatment facility. 



\title{
Chapter II
}

\section{A first approach to indigenous microalgal cultivation}

\author{
A: Ruiz-Martínez, A., Martí Ortega, N., Ferrer, J., Seco, A. Cultivation of microalgae for \\ nutrient removal from the effluent of a submerged anaerobic membrane bioreactor \\ (SAnMBR). IWA International Conference EcoTechnologies for Wastewater Treatment \\ (ecoSTP). Santiago de Compostela (Spain), June $25^{\text {th }}$ to $27^{\text {th }}, 2012$.
}

\section{and}

B: Ruiz-Martinez, A., Murgui, M., Ferrer, J., Seco, A. Cultivation of indigenous microalgae for nutrient removal using a submerged anaerobic membrane bioreactor (SAnMBR) effluent: Effect of cellular retention time. Young Algaeneers Symposium. Wageningen (The Netherlands), June $14^{\text {th }}$ to $16^{\text {th }}, 2012$.

An already existing SAnMBR system, run at pilot plant scale by the CALAGUA research group, eliminates organic matter from municipal wastewater to desired levels. A posttreatment was proposed, intended to further eliminate inorganic nutrients (ammonium and phosphate) which display variable concentrations between $40-60 \mathrm{mg} \mathrm{NH} 4 \cdot \mathrm{N} \cdot 1^{-1}$ and $6-7 \mathrm{mg}$ $\mathrm{PO}_{4}-\mathrm{P} \cdot 1^{-1}$.

The aim of the studies here presented was to assess the performance of a wastewater treatment consisting of autochthonous microalgae cultivation for nutrient elimination in this anaerobically treated wastewater. The ability of natural occurring microalgae to grow in the SAnMBR effluent (SAnMBRe) was proved, and the extent of biomass growth and nutrient elimination were analyzed under different conditions of cultivation mode, cellular retention time and illumination. 

A: Ruiz-Martínez, A., Martí Ortega, N., Ferrer, J., Seco, A. Cultivation of microalgae for nutrient removal from the effluent of a submerged anaerobic membrane bioreactor (SAnMBR). IWA International Conference EcoTechnologies for Wastewater Treatment (ecoSTP). Santiago de Compostela (Spain), June $25^{\text {th }}$ to $27^{\text {th }}, 2012$.

\section{Introduction}

The term microalgae encompasses a wide spectrum of microorganisms, which can be eukaryotic or prokaryotic (cyanobacteria) but have one ability in common: the use of inorganic carbon (in the form of $\mathrm{CO}_{2}, \mathrm{HCO}^{-}$or $\mathrm{CO}_{3}^{-2}$ ) for biomass growth through photosynthesis. This process in which organic matter is created from inorganic compounds (nutrients and carbon) takes the necessary energy from a light source, thus transforming light energy into chemically stored energy.

Microalgal biomass is therefore a potential source of renewable energy: it renders lipids for biodiesel production, as well as constituting a readily biodegradable substrate which can be subjected to anaerobic digestion to obtain biogas. Other microalgae applications for obtaining energy are sugar fermentation for ethanol production or different means of thermochemical conversion. Hydrogen production under sulphur deficiency has also been studied (Brenan and Owende, 2010).

Production costs reduction and higher sustainability in terms of energy use and environmental footprint are among the main goals which microalgae cultivation technology still has to achieve. To this respect, the use of wastewater as a source of nutrients for microalgal growth is a promising alternative, given the high costs of artificial cultivation media, and the added benefits of eliminating nutrients from wastewater streams while generating energetically profitable biomass (Pittman et al, 2011).

The present study is the first step in designing and developing a microalgal cultivation system that eliminates inorganic nutrients from urban wastewater which has been previously treated in a submerged anaerobic membrane bioreactor. The SAnMBR removes, on average, $89 \%$ of the COD present in the incoming wastewater (approximately $500 \mathrm{mg} \mathrm{COD} \cdot \mathrm{l}^{-1}$ ) and generates biogas, mainly composed of methane and $\mathrm{CO}_{2}$. The organic matter content in its effluent is 
therefore low, but ammonium and phosphate are still present in concentrations over the legal limit for discharge. Thus, the microalgal cultivation is proposed as a post-treatment of this existing SAnMBR. The aim of this study is twofold: on the one side, to assess the growth of autochthonous microalgae using this effluent (SAnMBRe) as culture media, and to evaluate the extent of nutrient removal achieved. On the other side, to evaluate the influence of light and dark cycles in the process.

\section{Material and methods}

The microalgae used were obtained from the walls of the secondary clarifier in the Carraixet Wastewater Treatment Plant in Valencia, Spain, and Scenedesmus sp. identified as the main group present.

The average concentrations of ammonium and phosphate in the SAnMBRe were $44.6 \mathrm{mg}$ $\mathrm{NH}_{4}-\mathrm{N} \cdot 1^{-1}$ and $7.02 \mathrm{mg} \mathrm{PO}_{4}-\mathrm{P} \cdot 1^{-1}$, respectively.

In the first part of the experiment the microalgae were cultivated in 11 glass bottles illuminated by fluorescent lights. The light intensity was $120 \mu \mathrm{E} \cdot \mathrm{m}^{-2} \cdot \mathrm{s}^{-1}$. The initial dry biomass was $17 \mathrm{mg}$, and a total of $860 \mathrm{ml}$ of SAnMBRe, distributed among the 10 days of total culture time, was added to the bottles.

In the second part of the experiment, the microalgae (with an initial concentration of $400 \mathrm{mg}$ TSS $\cdot 1^{-1}$ ), were cultured for 11 days in semi-batch mode in 11 glass bottles. The light intensity was $120 \mu \mathrm{E} \cdot \mathrm{m}^{-2} \cdot \mathrm{s}^{-1}$ and the cellular retention time (CRT) was equal to the hydraulic retention time (HRT): 2 days. The bottles were fed daily.

Finally, the light intensity was increased to $200 \mu \mathrm{E} \cdot \mathrm{m}^{-2} \cdot \mathrm{s}^{-1}$ and the microalgae were cultured during 24 days in 21 glass bottles under light/dark cycles (12:12) and continuous light (24:00) (see figure II.1). The initial biomass concentration was $190 \mathrm{mg} \mathrm{TSS} \cdot \mathrm{l}^{-1}$. Air enriched with $\mathrm{CO}_{2}$ was added to increase agitation and to provide carbon source. The CRT was kept at 2 days. 


\section{Results and discussion}

In the first part of the experiment the initial biomass of $17 \mathrm{mg}$ grew up to $360 \mathrm{mg}$ (dry weight) after 10 days, eliminating $86 \%$ and $100 \%$ of ammonium and phosphate respectively (figure II.1). Nitrite and nitrate concentrations were negligible.

During the second part of the experiment (figure II.2) the microalgal culture was able to maintain its biomass concentration, actually showing a final TSS value of $452 \mathrm{mg} \cdot \mathrm{l}^{-1}$, which means a $13 \%$ increase. On average, $87 \%$ of $\mathrm{NH}_{4}-\mathrm{N}$ and $95 \%$ of $\mathrm{PO}_{4}-\mathrm{P}$ were eliminated. Nutrients were consumed at an N:P ratio of 7. Again, nitrification was not observed.

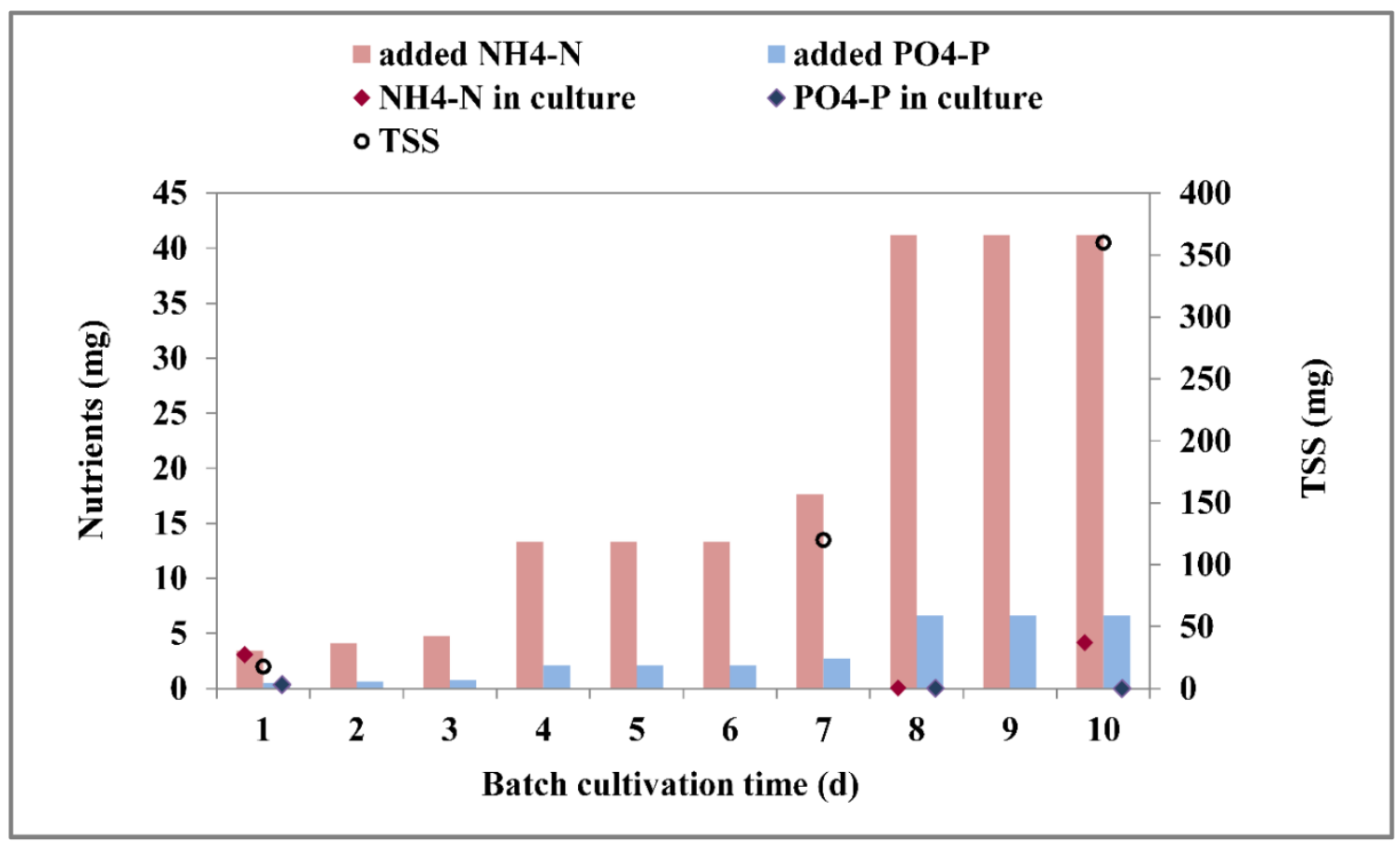

Figure II.1: Batch experiment. The bars show the added amount of nutrients (accumulated). The dots represent nutrients in the media. The biomass concentration, measured as total suspended solids (TSS) (mg), is also shown.

The cultures in the 21 glass bottles subject to light and dark cycles (figure II.3) presented a final biomass concentration after 24 days of $120 \mathrm{mg}$ TSS $\cdot 1^{-1}$, which means a biomass loss of $37 \%$ with respect to the initial value. Therefore, the deprivation of light for 12 hours daily exerted a negative consequence in the growth of the studied microalgae. However, the system still stayed viable during at least the first 24 days of cultivation and eliminated $48 \%$ of $\mathrm{NH}_{4}-\mathrm{N}$ and $68 \%$ of $\mathrm{PO}_{4}-\mathrm{P}$. On the other hand, the continuously illuminated bottles showed an increase 


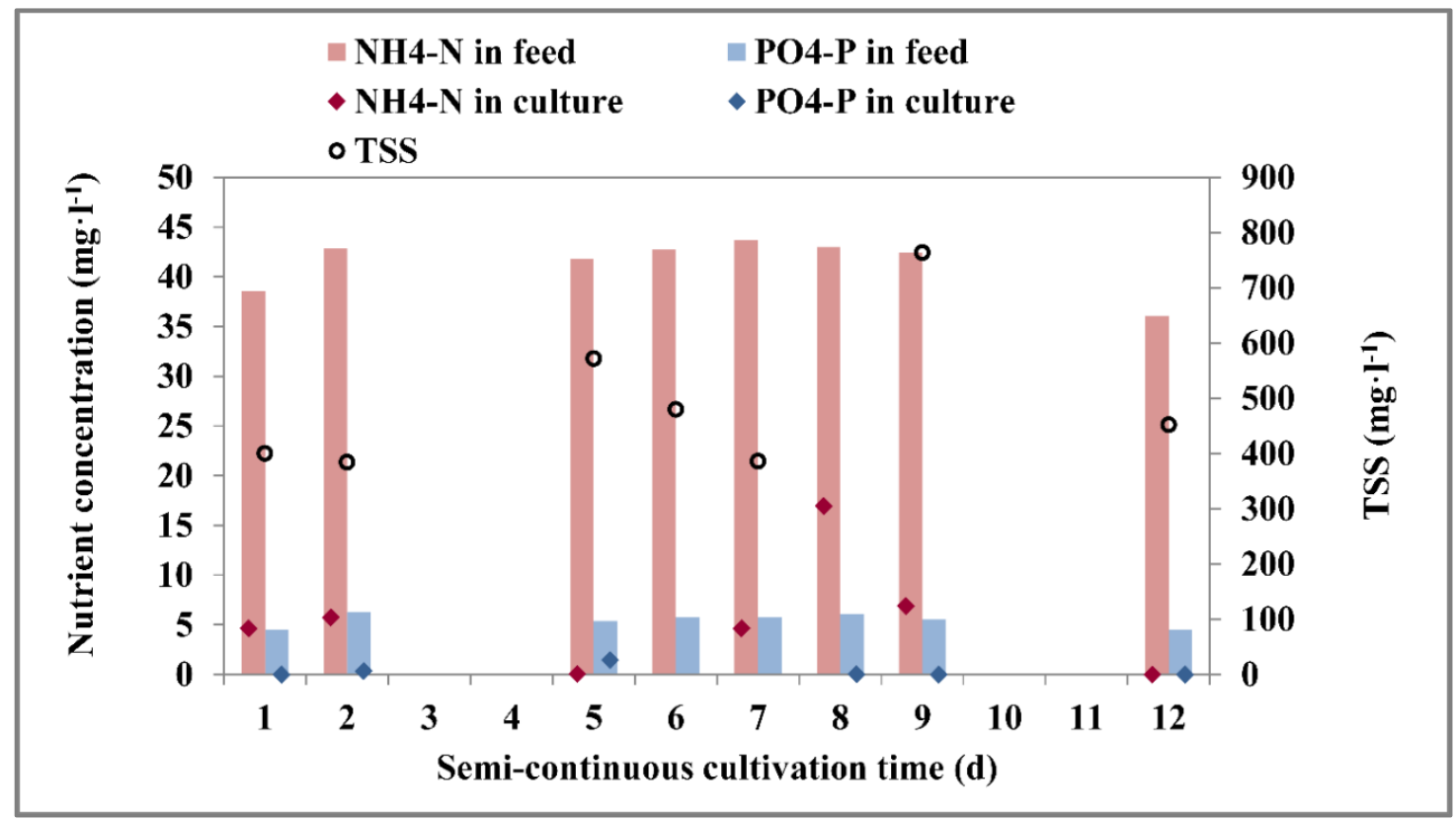

Figure II.2: Semicontinuous mode. The bars show the concentration of incoming nutrients (SAnMBR effluent). The dots represent the concentration of nutrients achieved in the culture. TSS are also shown.

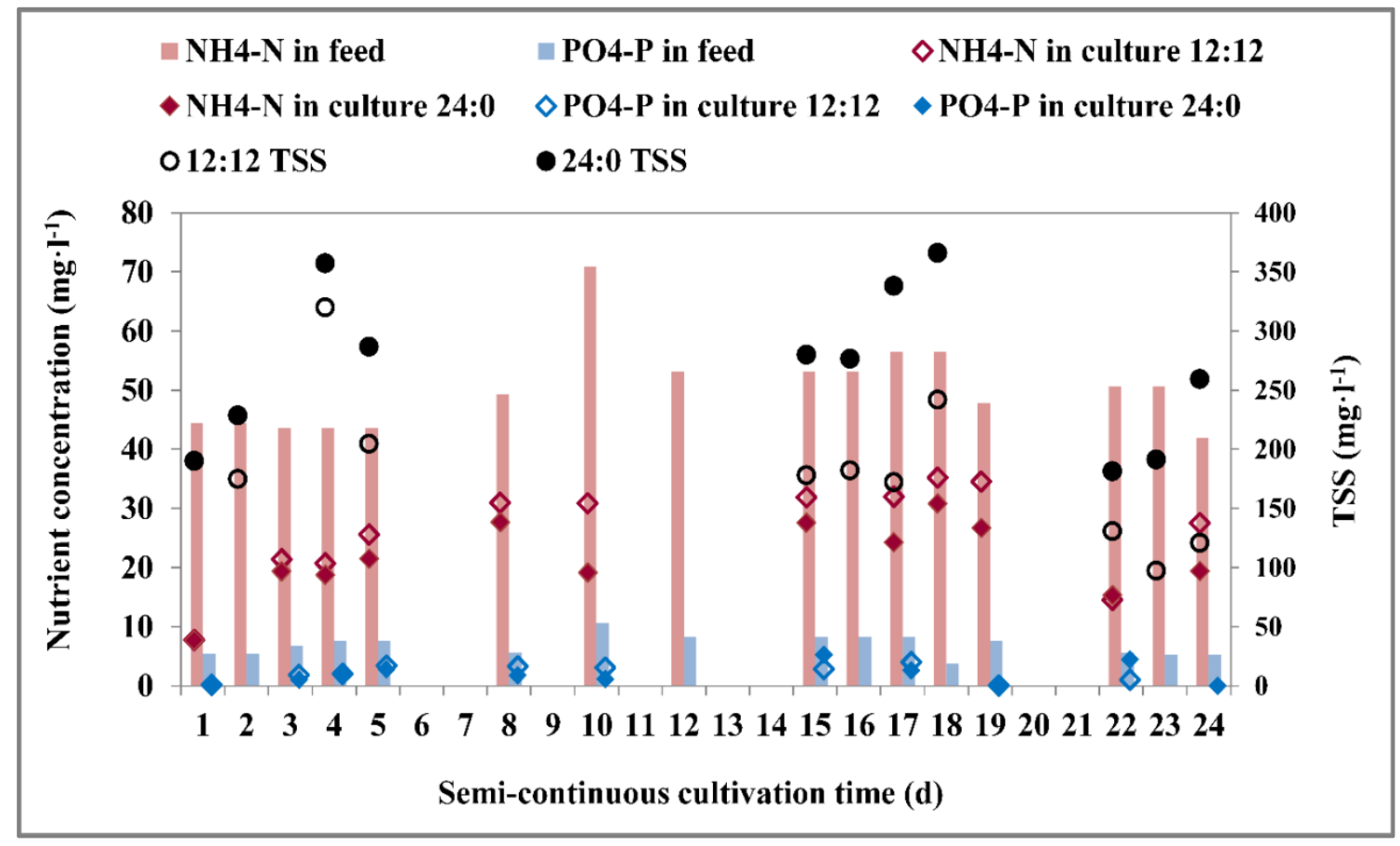

Figure II.3: Semicontinuous mode. Light and dark cycles (12:12) and continuous illumination (24:0). The bars show the concentration of incoming nutrients (SAnMBR effluent). The dots represent the concentration of nutrients achieved in the cultures. TSS are also shown. 
in their microalgae concentration, achieving $259 \mathrm{mg} \mathrm{TSS} \cdot 1^{-1}$. Nitrification was not observed and nitrogen and phosphorus elimination were of $57 \%$ and $69 \%$ respectively. This shows that deprivation of light has a stronger influence on biomass growth than on nutrient removal, in the studied conditions.

\section{Conclusions}

The ability of autochthonous microalgae to sustain growth based on a SAnMBR effluent is demonstrated. A doubling time of approximately one day can be achieved in the conditions studied (CRT of 2 days). Satisfactory nutrient elimination rates were obtained. However, there is place for further research aiming at optimizing the system towards higher biomass concentration and higher nutrient removal rate. Additionally, the light/dark cycle to which the microalgae are subjected influences their productivity and is thus an important factor to analyze, in order to find the optimum illumination time which balances energy consumption, biomass production and nutrient elimination.

\section{Acknowledgements}

This research project has been supported by the Spanish Research Foundation (CICYT, projects CTM2011-28595-C02-01 and CTM2011-28595-C02-02), whose support is gratefully acknowledged. The authors would also like to thank the water management entities of the Generalitat Valenciana (EPSAR). This research was also supported by the Spanish Ministry of Education, Culture and Sport via a pre doctoral FPU fellowship to the first author (AP20094903), which is thankfully acknowledged.

\section{References}

Brenan, M., Owende, P. (2010) Biofuels from microalgae - A review of technologies for production, processing, and extraction of biofuels and co-products. Renewable and Sustainable Energy Reviews 14, 557-577.

Pittman, J. K., Dean, A. P., Osundeko, O. (2011) The potential of sustainable algal biofuel production using wastewater resources. Bioresource Technology 102, 17-25. 
B: Ruiz-Martinez, A., Murgui, M., Ferrer, J., Seco, A. Cultivation of indigenous microalgae for nutrient removal using a submerged anaerobic membrane bioreactor (SAnMBR) effluent:

Effect of cellular retention time. Young Algaeneers Symposium. Wageningen (The

Netherlands), June $14^{\text {th }}$ to $16^{\text {th }}, 2012$.

This study assessed the performance of an indigenous microalgae polyculture for wastewater treatment. The microalgae were isolated from the secondary clarifier of a local wastewater treatment facility and belonged to the chlorococcales order of the Chlorophyceae. The culture was kept in 21 glass bottles under continuous (24:0) and cyclic (12:12) illumination, provided with fluorescent lamps $\left(200 \mu \mathrm{E} \cdot \mathrm{m}^{-2} \cdot \mathrm{s}^{-1} \mathrm{PAR}\right)$, and run in a semicontinuous mode: the microalgae were daily purged and fed with the effluent of a submerged anaerobic membrane bioreactor (SAnMBR) thus keeping a constant volume and identical cellular retention time (CRT) and hydraulic retention time (HRT). The SAnMBR effluent displayed average concentrations of $54 \mathrm{mg} \mathrm{NH} 4-\mathrm{N} \cdot 1^{-1}$ and $7 \mathrm{mg} \mathrm{PO}_{4}-\mathrm{P} \cdot 1^{-1}$.

Algal biomass, evaluated as total suspended solids (TSS) in the culture, showed a definite increase when the CRT was increased from 2 to 3 days (from $256 \mathrm{mg} \cdot \mathrm{l}^{-1}$ to $508 \mathrm{mg} \cdot \mathrm{l}^{-1}$ for the continuous illuminated bottles). Such an increment, however, could not be seen when the CRT increased from 3 to 4 days. Biomass production was possibly hampered by cellular selfshading and low light availability.

It was observed that the wastewater $\mathrm{N}: \mathrm{P}$ ratio was higher than the ratio consumed by microalgae (7.7 vs 6). The highest daily nutrient removal per liter of treated wastewater was, as expected, obtained in the case of $4 \mathrm{~d}$ CRT (figures II.4 and II.5). Maximum eliminations were observed in the continuous illuminated reactors (79\% of incoming $\mathrm{NH}_{4}-\mathrm{N}$ and $96 \%$ of incoming $\left.\mathrm{PO}_{4}-\mathrm{P}\right)$. However, the increase in nutrient removal efficiency was higher in the step from 2 to $3 \mathrm{~d}$ CRT than in the step from 3 to $4 \mathrm{~d}$ CRT. It should also be noted that, when daily nutrient removal was calculated per liter of reactor, the best performance corresponded to the reactors where CRT was $2 \mathrm{~d}\left(11.7 \mathrm{mg} \mathrm{NH} 4-\mathrm{N} \cdot \mathrm{d}^{-1}\right.$ and $\left.1.9 \mathrm{mg} \mathrm{PO} 4-\mathrm{P} \cdot \mathrm{d}^{-1}\right)$ (figure II.6). It was observed from the obtained data that $24 \mathrm{~h}$ illumination did not present twice as much nutrient removal, but did help achieving very low phosphate levels (figure II.7). These are valuable results to take into account when designing a wastewater treatment system, since a 
compromise has to be found among the quality of the water achieved, the needed reactor volume and the illumination costs. Similarly, a modification in one working parameter can be compensated with a change in another factor.

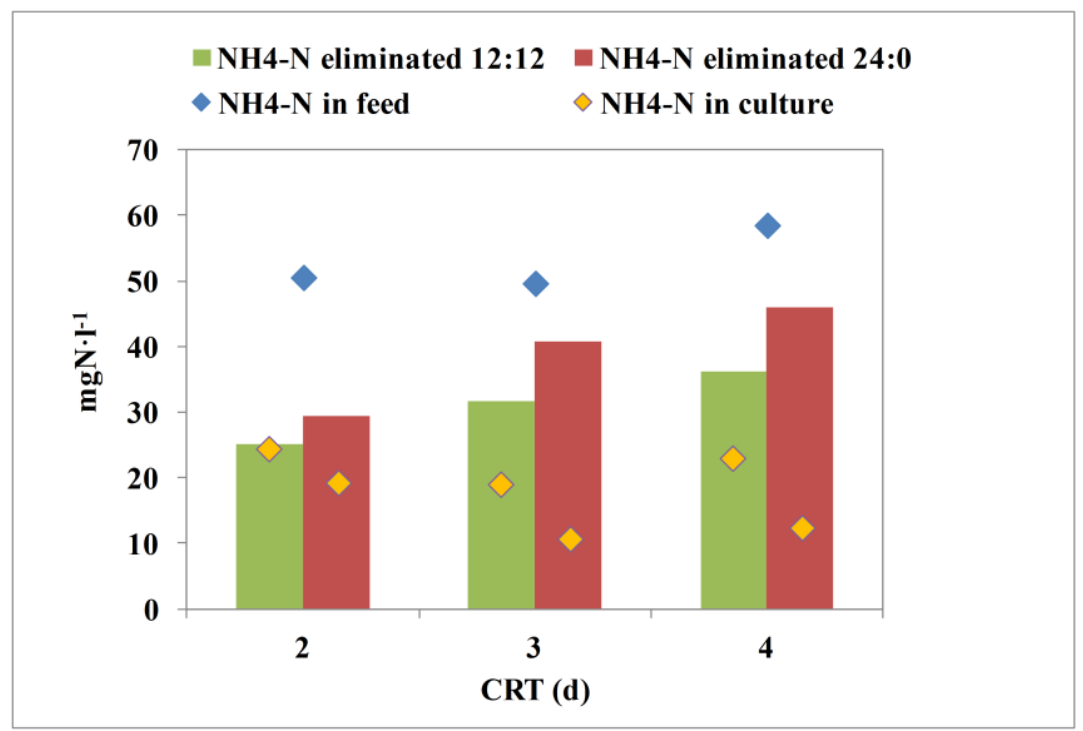

Figure II.4: Ammonium removal per liter of wastewater in the semicontinuous reactors for the tested CRT and concentration of nutrients achieved in the cultures.

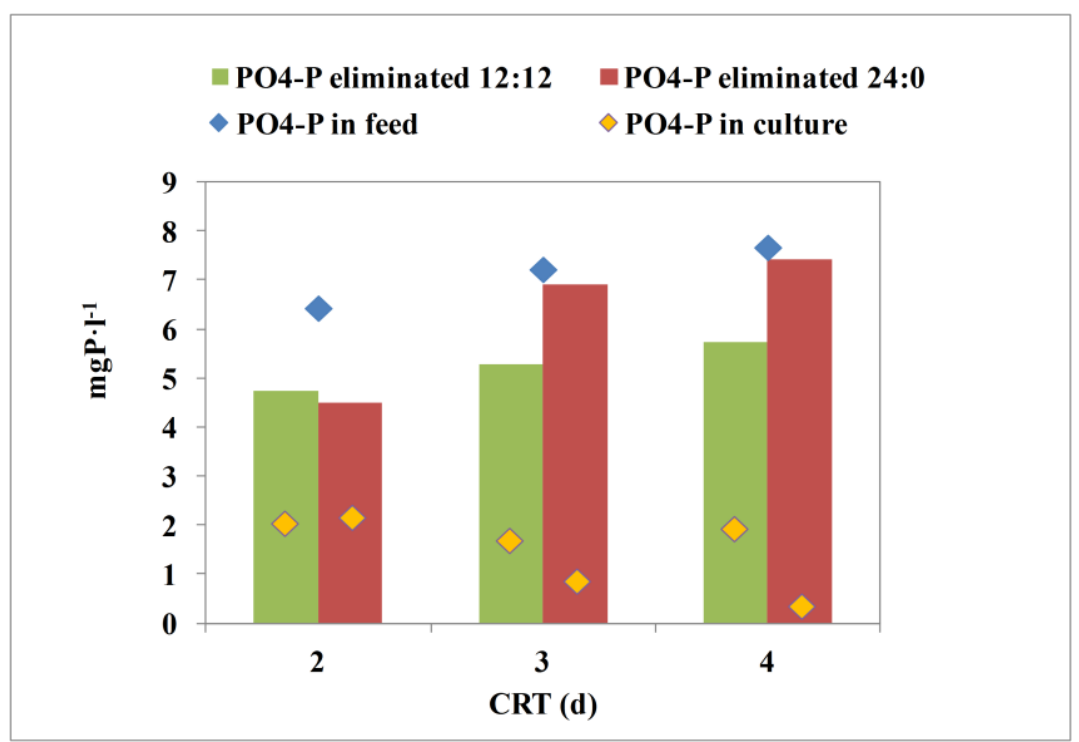

Figure II.5: Phosphate removal per liter of wastewater in the semicontinuous reactors for the tested CRT and concentration of nutrients achieved in the cultures. 


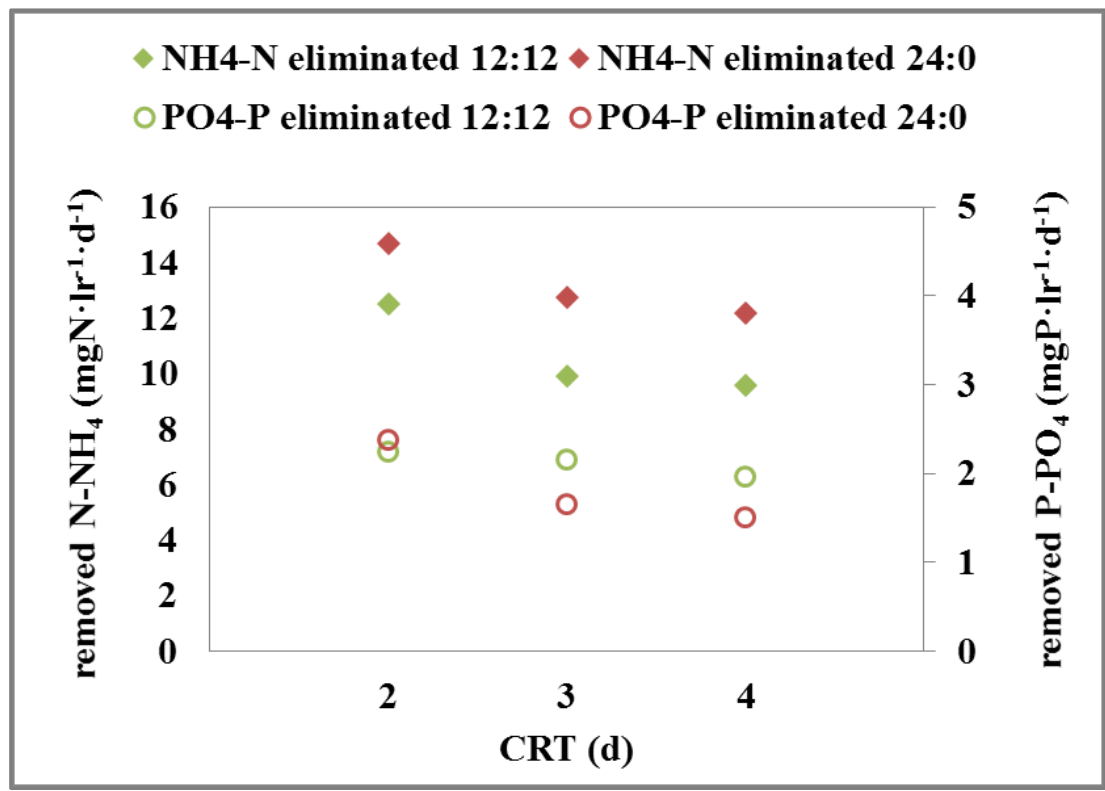

Figure II.6: Ammonium and phosphate removal (per liter of reactor) in the semicontinuous reactors for the tested CRT.

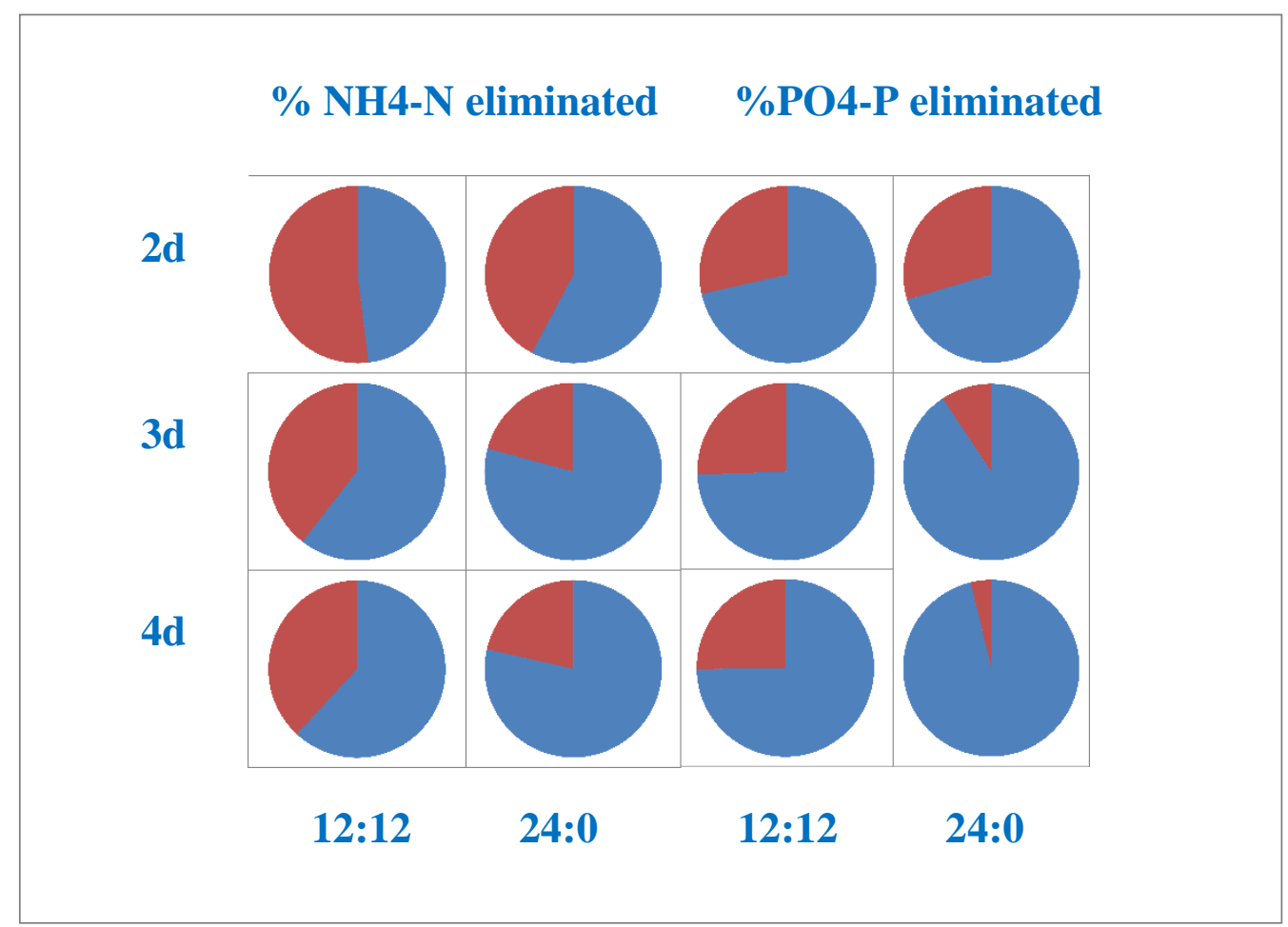

Figure II.7: Summary of the results in terms of percentage nutrient elimination 


\title{
Chapter III
}

\section{Microalgae cultivation in wastewater: nutrient removal from an anaerobic membrane bioreactor effluent}

Ruiz-Martinez, A., Martin Garcia, N., Romero, I., Seco, A., Ferrer, J. (2012) Microalgae cultivation in wastewater: Nutrient removal from anaerobic membrane bioreactor effluent. Bioresource Technology 126, 247-253

\begin{abstract}
This study investigated the removal of nitrogen and phosphorus from the effluent of a submerged anaerobic membrane bioreactor (SAnMBR) by means of a lab-scale photobioreactor in which algae biomass was cultured in a semi-continuous mode for a period of 40 days. Solids retention time was 2 days and a stable $\mathrm{pH}$ value in the system was maintained by adding $\mathrm{CO}_{2}$. Nitrogen and phosphorus concentrations in the SAnMBR effluent fluctuated according to the operating performance of the bioreactor and the properties of its actual wastewater load. Despite these variations, the anaerobic effluent proved to be a suitable growth medium for microalgae (mean biomass productivity was $234 \mathrm{mg} \cdot 1^{-1} \cdot \mathrm{d}^{-1}$ ), achieving a nutrient removal efficiency of $67.2 \%$ for ammonium $\left(\mathrm{NH}_{4}-\mathrm{N}\right)$ and $97.8 \%$ for phosphate $\left(\mathrm{PO}_{4^{-}}\right.$ P). When conditions were optimum, excellent water quality with very low ammonium and phosphate concentrations was obtained.
\end{abstract}





\section{Introduction}

Urban and industrial wastewater must be treated before being discharged into the environment in order to prevent undesirable effects such as pollution and eutrophication. Anaerobic treatments have several advantages over more traditional aerobic systems i.e. they consume less energy and produce less sludge whilst generating biomethane (Ho and Sung, 2010). The combination of anaerobic wastewater treatment with membrane technology gave rise to anaerobic membrane bioreactors, the main advantage of which is the possibility of separating solids retention time (SRT) from hydraulic retention time (HRT), whilst reducing the footprint and achieving high quality effluent in terms of suspended solids.

Pilot-scale submerged anaerobic membrane bioreactors (submerged AnMBR or SAnMBR) have been evaluated with promising COD removal rates (Giménez et al., 2011), but discharge into the aquatic environment or water reuse is not possible without further nitrogen and phosphorus removal (Stuckey, 2012). There is a clear need for research on post-treatments which allow the extended and full-scale use of AnMBR for domestic wastewater treatment (Smith et al., 2012). Possible traditional treatments such as biological nitrificationdenitrification process or enhanced biological phosphorus removal are energy-intense. Partial nitritation/nitrification with Anammox bacteria has lately received increasing attention. However, there is still little literature available for low strength wastewaters, and we have not found any author describing AnMBR effluent treatment with Anammox bacteria. The present study is a novel approach to AnMBR effluent post-treatment using microalgae for nutrient removal and biomass generation. The generated biomass allows nutrient recovery and presents an added value for various industrial applications or energy recovery, as it is presented in this section.

The use of microalgae in wastewater treatment was first proposed by Oswald and Gotaas (1957) and has received much attention in recent decades (Olguín et al., 2003a, Rawat et al., 2010). Microalgae are photosynthetic microorganisms which use energy from the sun to grow, consuming inorganic nutrients and $\mathrm{CO}_{2}$. They accumulate organic matter in the form of proteins, lipids, carbohydrates, hydrocarbons and other small molecules and pigments. Microalgal biomass has been studied and used for human and animal nutrition and for 
producing substances such as fatty acids, $\beta$-carotene, astaxanthin and phycocyanin (Pulz and Gross, 2004).

In recent decades, however, microalgae have been in the spotlight because of their potential use in producing renewable biofuel, mainly biodiesel, via the transesterification of intracellular accumulated oils. Due to their rapid growth and ability to accumulate oil in concentrations of up to $50 \%$ of their dry weight, together with the possibility of year-round production, microalgae can enable higher oil yield than existing oilseed crops (Schenk et al., 2008). As reported elsewhere, the residual biomass can still be used for energy recovery via thermochemical conversion (gasification, liquefaction, pyrolysis, combustion) or biochemical conversion (anaerobic digestion for biomethane production, fermentation for bioethanol production). For a wider review of this topic see Brenan and Owende (2010).

But despite all the technical and biotechnological advances in this field, the start-up and operating costs of algal biofuel production systems are still too high. It was estimated that the costs of algal biodiesel production must be reduced to one tenth if it is to be competitive (Chisti, 2008).

As previously stated, microalgae have been used around the world for wastewater treatment in stabilization ponds or high-rate algal ponds (HRAP). However, these technologies have been used mainly in small communities, partly due to their big spatial footprint. According to Park et al. (2011), the use of HRAPs in wastewater treatment to produce algal biomass has been given little consideration. However, many authors have recently drawn attention again to the potential of combining wastewater nutrient removal and biofuel production, as reviewed by Pittman et al. (2011). With this combination, the nutrients needed for microalgal growth are obtained from wastewater, eliminating the need for clean water and the addition of nutrients, thus reducing production costs. Furthermore, nutrients are not only removed from the wastewater, but can also be captured and returned to the terrestrial environment as agricultural fertilizer. Another advantage of using microalgae to treat wastewater is their photosynthetic $\mathrm{CO}_{2}$ fixation, which contributes to mitigating greenhouse gases. The use of flue gas has also been reported (Van den Ende et al., 2012).

Microalgal cultures have been used successfully to treat artificial and real wastewater (RuizMarín et al., 2010) and to eliminate nutrients from samples taken at different points in a 
wastewater treatment plant, e.g. after primary settling, or after an activated sludge process, or after an A2O system or oxidation ditch (Yang et al., 2011), as well as in tertiary treatment (Wang et al., 2009). Others, e.g. Li et al (2011), also used centrate for microalgal growth. The satisfactory percentages of nutrients removed in some cases confirm the possibility of combining wastewater treatment with microalgal biomass formation. However, to our knowledge, no previous study of microalgae cultivation for nutrient removal in SAnMBR effluent has been reported. Information obtained from a long term assay on nutrient removal using real wastewater is scarce. In our study, nutrients are removed in an 81 reactor and under semi-continuous culture conditions. Additionally, the culture is subject to fluctuations of actual wastewater.

Regarding microalgal species, most studies maintain monocultures in order to compare different microorganisms in their ability to eliminate nutrient or generate specific compounds, but the literature is scant on consortia of microorganisms and their performance. This study aims at providing a proof of concept that a mixed polyculture of autochthonous species is able to grow and can be effective in removing nutrients from the studied wastewater, in an approach which considers that strain selection will happen naturally and the culture will thus evolve with changing conditions. To our opinion, this characteristic in the proposed system confers it great robustness and is realistic for industrial application of wastewater treatment.

\section{Materials and methods}

\subsection{Experimental setup and operation}

\subsubsection{Submerged anaerobic membrane bioreactor plant}

A flow diagram of the SAnMBR pilot plant is shown in Figure III.1. The pilot plant influent was sourced downstream from the pre-treatment units belonging to the "Cuenca del Carraixet" WWTP (an actual, full-scale wastewater treatment plant in Valencia, Spain) which included coarse screening, degritting and grease removal. The pre-treated wastewater then underwent fine screening (RF) before being pumped into an equalization tank (ET) and then fed into the jacketed anaerobic reactor $(\mathrm{AnR}, 1300 \mathrm{l})$ where the temperature was kept above $20^{\circ} \mathrm{C}$. 


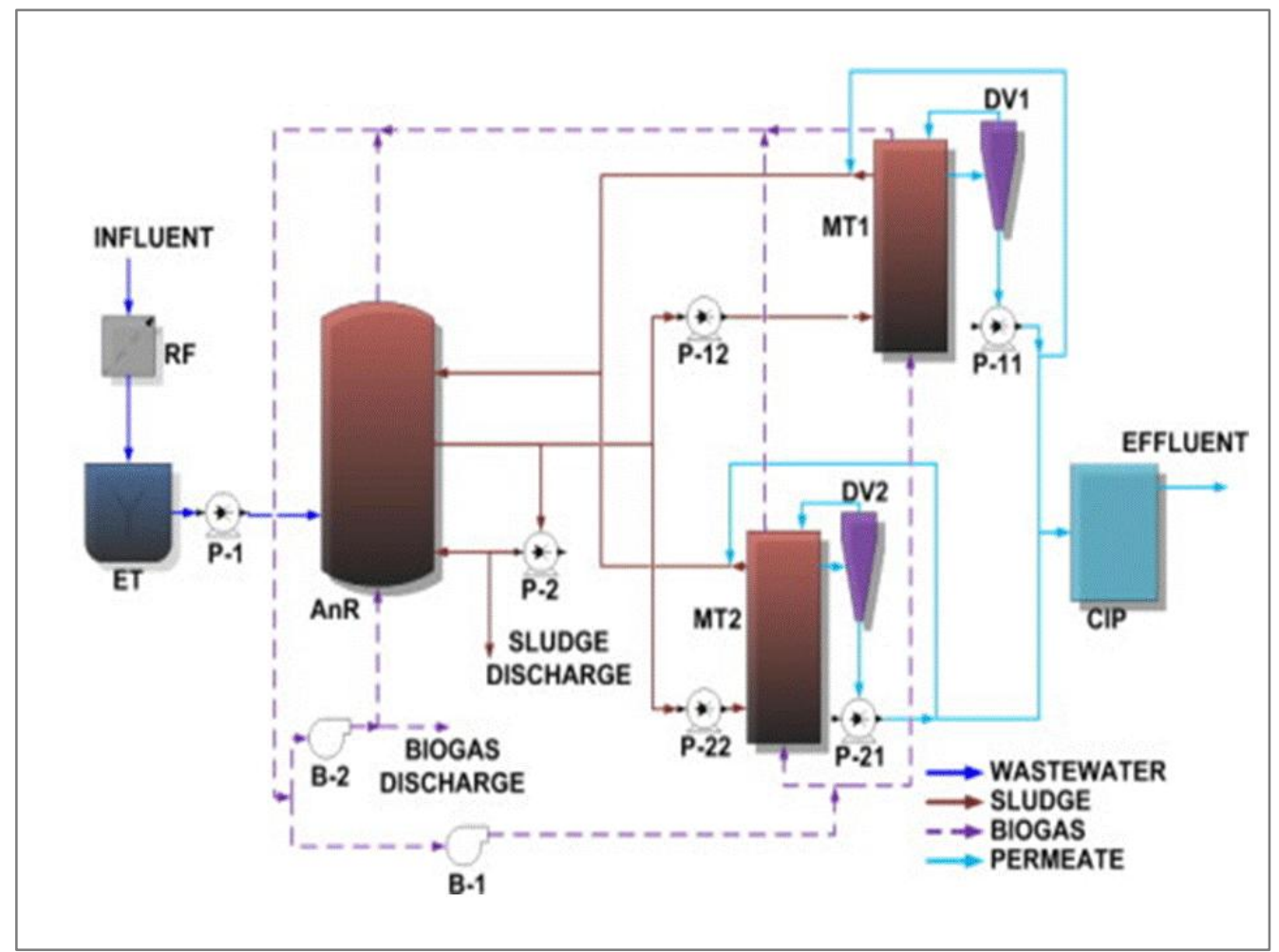

Figure III.1: Flow diagram of the SAnMBR pilot plant. Nomenclature: RF: rotofilter;

ET: equalisation tank; AnR: anaerobic reactor; MT: membrane tanks; DV: degasification vessel; CIP: clean-in-place; P: pump; and B: blower (Robles 2013).

The anaerobic sludge was circulated between the anaerobic reactor and two 8001 membrane tanks (MT1 and MT2, 6001 working volume). Each membrane tank had a $30 \mathrm{~m}^{2}$ ultrafiltration membrane module (PURON® Koch Membrane Systems, $0.05 \mu \mathrm{m}$ pore size). HRT was $13.3 \mathrm{~h}$ and SRT was 30 days for the first 3 weeks of the experiment and then increased to 40 days. Further details of the characteristics and operation of the SAnMBR can be found in a previous study (Giménez et al, 2011). The SAnMBR effluent was collected from the permeate tank (CIP) and taken to the laboratory each day to feed the algae culture in the lab-scale photobioreactor (PBR).

\subsubsection{Lab-scale photobioreactor}

The PBR consisted of a cylindrical, transparent methacrylate tank $(20 \mathrm{~cm}$ internal diameter) with a total and working volume of 10 and 81 respectively (Figure III.2). The PBR was sealed and the algae culture was mixed by recycling the headspace gas at a flow rate of $0.8-1.0$ $1 \cdot \mathrm{min}^{-1}$ through four fine bubble diffusers mounted at the bottom. Pure $\mathrm{CO}_{2}(99.9 \%)$ from a 
pressurized cylinder at 1.5-2 bar pressure was injected into the gas flow in order to maintain a $\mathrm{pH}$ of $7.2 \pm 0.3$ in the PBR. A solenoid valve in synch with the $\mathrm{pH}$ measurements obtained by the data acquisition program opened for 3 seconds every 2 minutes whenever the $\mathrm{pH}$ exceeded the set point value of 7.2. This system enables mixing without using a magnetic stirrer or mechanical agitator, optimizes $\mathrm{CO}_{2}$ consumption and, at the same time, helps control the $\mathrm{pH}$ in the reactor to prevent undesirable phenomena such as phosphate precipitation and ammonia stripping. The seal was however not hermetic. Extreme overpressure is thus avoided and oxygen levels kept close to saturation levels.

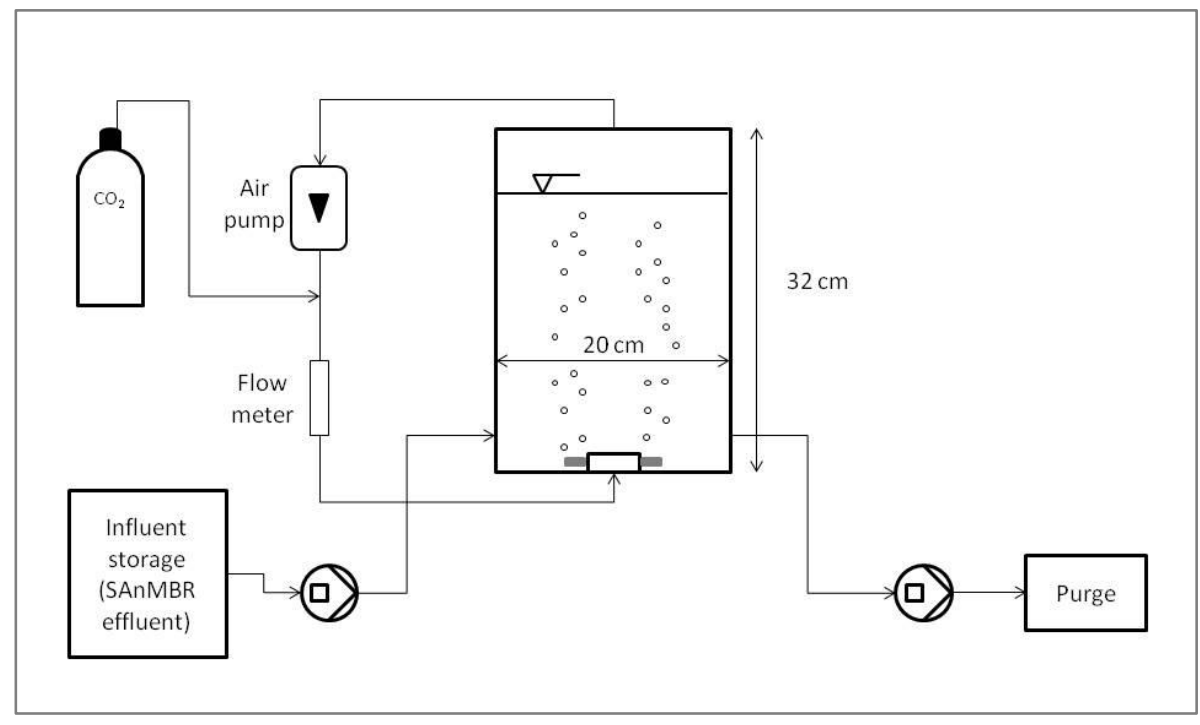

Figure III.2: Lab-scale cylindrical photobioreactor. $\mathrm{CO}_{2}$ is automatically injected into the headspace gas recirculation system for $\mathrm{pH}$ control.

Every six hours, one liter of algae culture was taken from the PBR and replaced with the same volume of SAnMBR effluent using two different peristaltic pumps controlled by a personal computer. This corresponds to solids and hydraulic retention times of $2 \mathrm{~d}$. Two arrays of 5 vertical fluorescent lamps (Sylvania Grolux, $18 \mathrm{~W}$ ) $30 \mathrm{~cm}$ apart continuously illuminated opposite sides of the PBR. Photosynthetically active radiation (PAR) was measured in the bottom, middle and top sections of the illuminated surface of the PBR tank (HOBO ${ }^{\circledR}$ Smart Sensor, s-lia-m003) resulting in values of $159 \pm 39,209 \pm 43$ and $143 \pm 30 \mu \mathrm{E} \mathrm{m} \mathrm{m}^{-2} \mathrm{~s}^{-1}$ respectively. During the experiment no temperature control was employed, resulting in temperatures ranging from 28 to $32^{\circ} \mathrm{C}$. 


\subsection{Microorganisms}

The microalgae used as inoculum were isolated from the walls of the secondary clarifier in the Carraixet WWTP and kept in $250 \mathrm{ml}, 11$ and 21 bottles in the laboratory under semicontinuous feeding conditions with the same effluent used in this study and with continuous illumination varying between 114 and $198 \mu \mathrm{E} \cdot \mathrm{m}^{-2} \cdot \mathrm{s}^{-1}$. Microalgae from the chlorococcales order of the Chlorophyceae class were identified as the main group present, together with cyanobacteria.

\subsection{Sampling, monitoring and analysis}

In our study, nutrient removal by algae culture was evaluated by the daily measurement of inorganic nitrogen and phosphate levels in the influent (SAnMBR effluent) and in the soluble fraction taken from the PBR. The soluble fraction of the culture was obtained by membrane filtration with $0.45 \mathrm{~mm}$ pore size glass fiber filters (Millipore). Ammonium $\left(\mathrm{NH}_{4}-\mathrm{N}\right)$, nitrite $\left(\mathrm{NO}_{2}-\mathrm{N}\right)$, nitrate $\left(\mathrm{NO}_{3}-\mathrm{N}\right)$ and phosphate $\left(\mathrm{PO}_{4}-\mathrm{P}\right)$ levels were determined by applying Standard Methods (APHA, 2005) (4500-NH3-G, 4500-NO2-B, 4500-NO3-H, 4500-P-F respectively) in a Smartchem 200 automatic analyzer (Westco Scientific Instruments, Westco).

Total nitrogen and total phosphorus in the algae culture were measured in duplicate at least three times a week using standard kits (Merck, Darmstadt, Germany, 100613) to measure nitrogen and the acid peroxodisulphate digestion method to measure phosphorus (APHA, 2005). The nitrogen content of the algae biomass was calculated as the difference between total nitrogen and soluble nitrogen. Likewise, the phosphorus content of the particulate fraction was calculated as the difference between total phosphorus and phosphate concentration of the soluble fraction. Total and volatile suspended solids (TSS and VSS) were determined every day as described in Standard Methods (APHA, 2005). Samples were taken in duplicate. Chemical oxygen demand was determined from duplicate samples and according to Standard Methods (APHA, 2005).

To determine the chlorophyll content, $50 \mathrm{ml}$ of culture were filtered using $0.45 \mu \mathrm{m}$ pore size Whatman ${ }^{\circledR}$ cellulose filters which were then frozen at $-20^{\circ} \mathrm{C}$ for 24 hours. Chlorophyll was 
extracted from the algae biomass that accumulated on the filter using $20 \mathrm{ml}$ of a $90 \%$ acetonewater solution whilst kept in the dark at $4{ }^{\circ} \mathrm{C}$ for at least 24 hours. The extracted chlorophyll and the filters were then centrifuged for 5 minutes at $3000 \mathrm{~g}$ (Eppendorf 5804 centrifuge) and absorbance at 630, 646, 664 and $750 \mathrm{~nm}$ was measured by a UV-VIS spectrophotometer (Merck Spectroquant ${ }^{\circledR}$ Pharo 300). The concentrations of chlorophyll a and b were calculated by the trichromatic method using the equations of Jeffrey and Humphrey (APHA, 2005). Samples were taken in duplicate.

The epifluorescence microscopic count method was used to analyze phytoplankton communities. Samples in a $250-\mathrm{ml}$ glass bottle were fixed adding glutaraldehyde until a final concentration of $2 \%$ was attained. They were filtered with $0.2 \mu \mathrm{m}$ membranes (Millipore GTTP) and the filters were washed with distilled water to eliminate the retained salt and then dehydrated with successive 50\%, 80\%, 90\% and 99\% ethanol washes. Each dried filter was placed onto a drop of immersion oil in the center of a slide and two more drops were added on the upper side of the filter. Finally, a cover glass was placed on top of the filter (Fournier, 1978). Phytoplankton counts were performed by epifluorescence microscopy with a Leica DM2500, using the $100 \times$-oil immersion objective. A minimum of 300 cells was counted and at least 100 cells of the most abundant species or genera were counted with an error of less than 20\% (Lund et al., 1958). All reported results were obtained from the previous analyses conducted in duplicate.

The physical and chemical parameters of the algae culture such as conductivity, redox potential, temperature, $\mathrm{pH}$ and dissolved oxygen were monitored online in the PBR and logged in a PC using data acquisition software. For conductivity, redox and $\mathrm{pH}$, the signals from the corresponding electrodes were processed by a multiparametric analyzer (CONSORT C832, Belgium), whilst temperature and dissolved oxygen were measured using a Cellox 325 electrode (WTW, Germany) connected to an oximeter (Oxi 320, SET WTW, Germany). 


\section{Results and discussion}

\subsection{SAnMBR effluent. Nitrogen and phosphorus removal}

The variation in $\mathrm{NH}_{4}-\mathrm{N}$ and $\mathrm{PO}_{4}-\mathrm{P}$ content during the experiment is depicted in figures III.3 and III.4, which also show the levels of these nutrients in the influent to be treated (SAnMBR effluent). Variations in the ammonium and phosphate contents of the PBR influent depend on the operating behavior of the SAnMBR and the properties of its actual wastewater load. Neither nutrient addition nor dilution of the effluent took place. The microalgae in the reactor were thus fed exclusively with the SAnMBR effluent, which supplied them with all the dissolved inorganic nutrients they required for growth. Because microalgae need micronutrients other than ammonium and phosphate, e.g. silica, calcium, magnesium, cobalt, potassium, zinc, iron, manganese, sulfur and copper, it can be assumed that these are contained in the SAnMBR effluent, as is usually the case when wastewater is used for algal growth (Christenson and Sims, 2011).

Microalgae grow by using inorganic carbon obtained via photosynthetic $\mathrm{CO}_{2}$ fixation. The bicarbonate-carbonate buffer system $\left(\mathrm{CO}_{2}-\mathrm{H}_{2} \mathrm{CO}_{3}-\mathrm{HCO}_{3}{ }^{-}-\mathrm{CO}_{3}{ }^{2-}\right)$ in the culture media can provide $\mathrm{CO}_{2}$ for photosynthesis through the following reactions:

$$
\begin{aligned}
& 2 \mathrm{HCO}_{3}{ }^{-} \leftrightarrow \mathrm{CO}_{3}{ }^{2-}+\mathrm{H}_{2} \mathrm{O}+\mathrm{CO}_{2} \\
& \mathrm{HCO}_{3}{ }^{-} \leftrightarrow \mathrm{CO}_{2}+\mathrm{OH}^{-} \\
& \mathrm{CO}_{3}{ }^{2-}+\mathrm{H}_{2} \mathrm{O} \leftrightarrow \mathrm{CO}_{2}+2 \mathrm{OH}^{-}
\end{aligned}
$$

Microalgae, on the other hand, release $\mathrm{CO}_{2}$ through respiration. Dark respiration, however, usually accounts for less than $10 \%$ of total photosynthetic production so its impact is small. Adding carbon dioxide directly to the reactor is, therefore, the best and most convenient way to control $\mathrm{pH}$, while providing a source of inorganic carbon needed for microalgal growth at the same time (Grobbelaar, 2004). Different concentrations of carbon dioxide are often added to the reactor by an aeration system (see Ugwu et al., 2008 for review of this topic). 
The $\mathrm{CO}_{2}$ content of water depends on the thermodynamics and mass transfer phenomena. Inefficient transfer across the gas-liquid interface causes high levels of $\mathrm{CO}_{2}$ in the gas phase, resulting in a loss of $\mathrm{CO}_{2}$ if the gas is released into the atmosphere. The system used in this study was designed to optimize carbon dioxide consumption by recirculating the headspace gas while keeping the $\mathrm{pH}$ of the culture at a set value of 7.2. Hence, the composition of the gas phase used to mix the culture and supply carbon depended on the interaction of a) $\mathrm{CO}_{2}$ consumption; b) microalgal respiration; c) the buffer system in the liquid phase, which depends on alkalinity; d) the mass transfer between the gas and liquid phases; and e) the external $\mathrm{CO}_{2}$ added when the $\mathrm{pH}$ of the culture (liquid phase) deviated from 7.2.

A working $\mathrm{pH}$ of 7.2 was deemed suitable for microalgal growth because the optimal $\mathrm{pH}$ levels reported for algal growth are in the $7-9$ range. On the other hand, one of the main aims of this study was to remove nutrients by assimilation into biomass, avoiding other forms of nutrient removal such as the chemical precipitation of phosphates or ammonia stripping in the gas phase. Both phenomena are enhanced by raising the $\mathrm{pH}$. As reported by Carlsson et al. (1997), the situation for calcium phosphate precipitation is critical when $-\log ([\mathrm{Ca}] \cdot[\mathrm{P}])$ approaches 5.4 if the $\mathrm{pH}$ is 7 . In our case, with mean calcium concentrations of $130 \mathrm{mg} \cdot \mathrm{l}^{-1}$, precipitation was avoided when the phosphorus content remained beneath $37 \mathrm{mg} \cdot \mathrm{l}^{-1}$, which was always achieved. According to De Bashan and De Bashan (2004), struvite (ammoniummagnesium-phosphate) precipitation also takes place when $\mathrm{pH}$ is above 7.5.

As regards ammonia stripping, it is known that the ammonium-ammonia equilibrium is highly influenced by $\mathrm{pH}$, such that a $\mathrm{pH}$ higher than 9 shifts the equilibrium enough to facilitate ammonia stripping, whereas with a $\mathrm{pH}$ of $7, \mathrm{NH}_{4}-\mathrm{N}$ is by far the most dominant form of ammonia nitrogen. The loss of ammonia into the atmosphere became the major mechanism explaining nitrogen removal in cultures where $\mathrm{pH}$ was not controlled and therefore it rose as photosynthetic activity increased (Olguín, 2003b). Therefore, keeping the $\mathrm{pH}$ at 7.2 ensured that the nitrogen and phosphorus elimination in the proposed system was due mainly to biomass growth. The headspace gas recirculating system optimized $\mathrm{CO}_{2}$ consumption in comparison with the same system without recirculation (data not shown). 


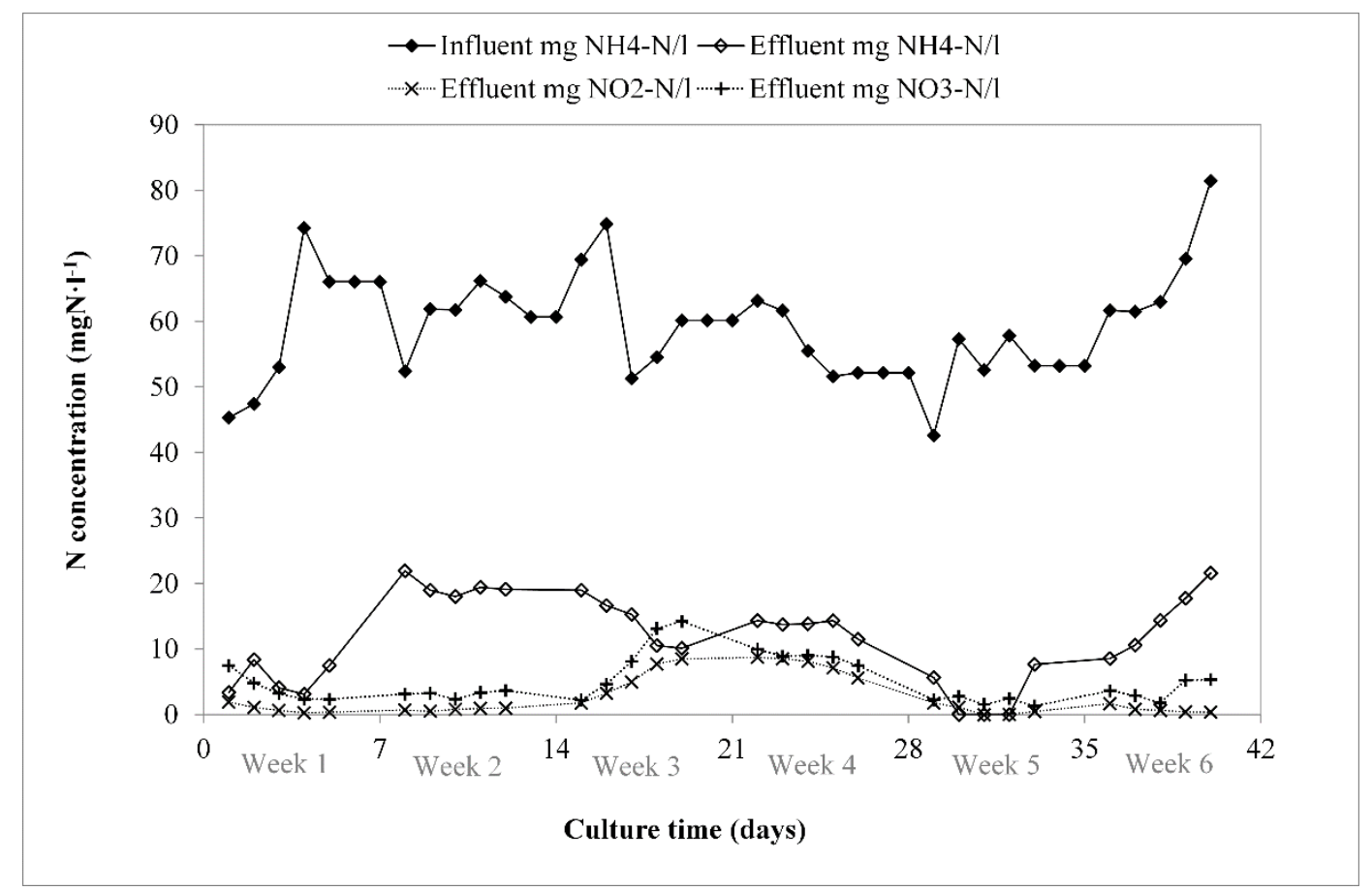

Figure III.3: Soluble nitrogen evolution in the influent (actual SAnMBR effluent) and in the 81 photobioreactor.

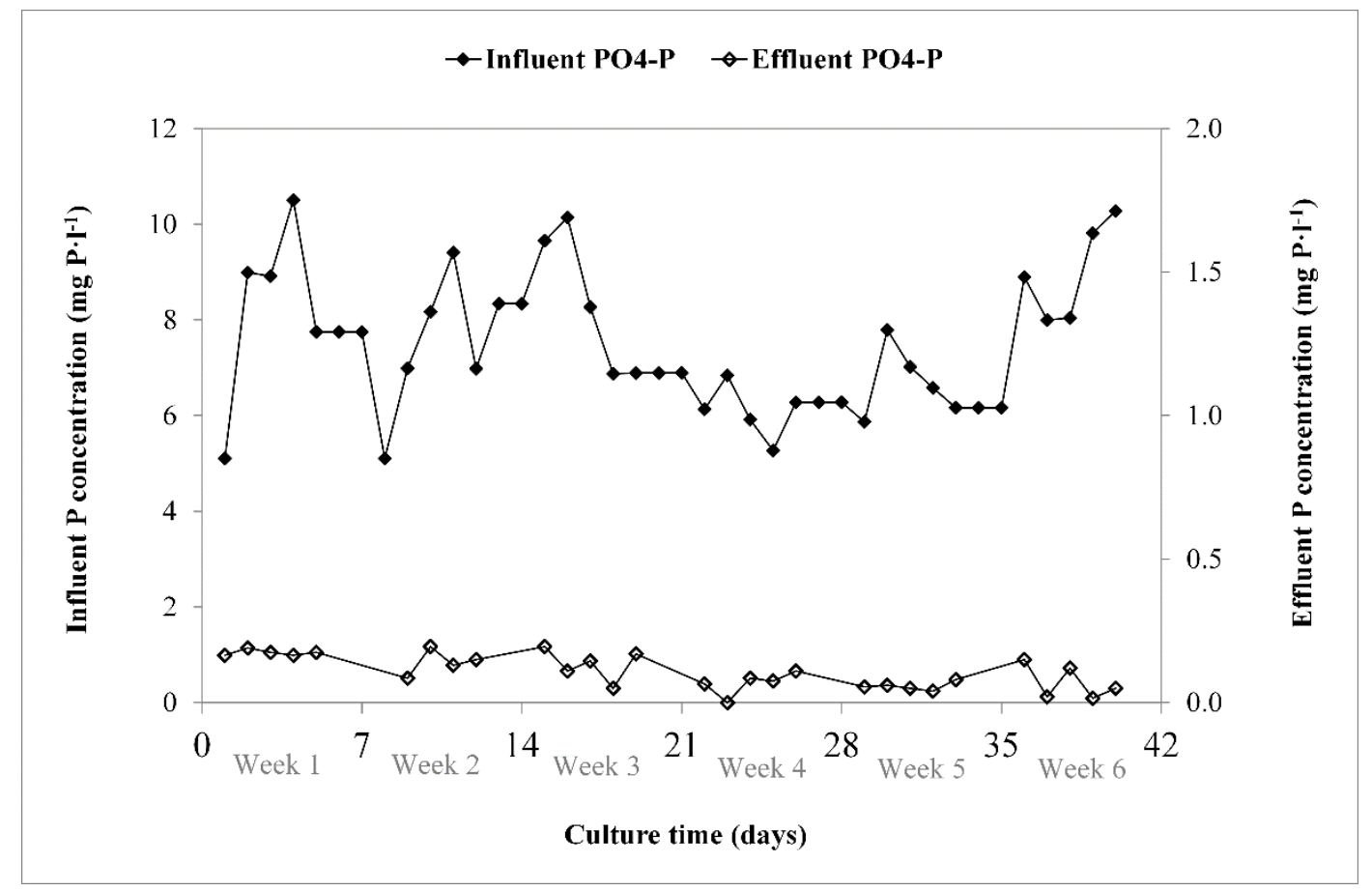

Figure III.4: Soluble phosphorus evolution in the influent (actual SAnMBR effluent) and in the 81 photobioreactor. 
Incoming ammonium during the monitored period oscillated between 42.6 and $81.4 \mathrm{NH}_{4}-\mathrm{N} \cdot \mathrm{l}^{-}$ 1. The average was $59.3 \mathrm{mg} \mathrm{NH} 4-\mathrm{N} \cdot 1^{-1}$. The proposed microalgal system for nutrient removal was influenced by these variations (figure III.3). The levels of ammonium in the reactor are highest when levels are highest in the influent, sometimes with 1 or 2 days' delay. Hence, at the end of week 1 the ammonia level in the reactor rose following the tendency of the influent, and remained at around $20 \mathrm{mg} \mathrm{NH} \mathrm{N}_{4}-\mathrm{N} \cdot \mathrm{l}^{-1}$ during week 2. It is remarkable that, in periods with no peaks in the incoming concentration, such as weeks 4 and 5, when the ammonia content of the influent remained at around $50 \mathrm{mg} \mathrm{NH} 4-\mathrm{N} \cdot 1^{-1}$, the quality of the effluent was excellent: ammonium levels were very low. Towards the end of the study the $\mathrm{NH}_{4}-\mathrm{N}$ concentration rose due to an increase in the SAnMBR effluent. No nitrite or nitrate was detected in the SAnMBR effluent.

Elimination was calculated in terms of total inorganic nitrogen, i.e. not taking into account the amount of $\mathrm{NH}_{4}-\mathrm{N}$ which was transformed into $\mathrm{NO}_{3}-\mathrm{N}$ or $\mathrm{NO}_{2}-\mathrm{N}$ in the reactor. On average, in the given conditions of illumination and temperature, the system studied was able to eliminate daily $38.9 \pm 10 \mathrm{mg}$ of soluble $\mathrm{N}$ in the treated water, which corresponds to a daily removal per reactor volume of $19.5 \pm 5 \mathrm{mg} \cdot \mathrm{l}^{-1} \cdot \mathrm{d}^{-1}$. This is more than or in the same range as other studies (e.g. Kim et al. (2010) reported $20-40 \mathrm{mg} \mathrm{N} \cdot \mathrm{l}^{-1} \cdot \mathrm{d}^{-1}$ eliminated in a flat panel reactor where the microalga Synechocystis was supplied with $90 \mathrm{mg} \mathrm{N} \cdot \mathrm{l}^{-1} \cdot \mathrm{d}^{-1}$, Yuan et al. (2011) reported Spirulina platensis growth in an airlift photobioreactor eliminating $10-22 \mathrm{mg} \mathrm{N} \cdot \mathrm{l}^{-1} \cdot \mathrm{d}^{-1}$ and Park et al. (2010) reported 5-6 $\mathrm{mg} \mathrm{N} \cdot \mathrm{l}^{-1} \cdot \mathrm{d}^{-1}$ removal by Scenedesmus from a filtered and autoclaved anaerobic digestion effluent obtained from a piggery farm).

Levels of nitrification (transformation of ammonium into nitrite and nitrate) were very low (on average 13.4\% of incoming ammonium), except at the end of week 3 and week 4, when nonammonium nitrogen in the soluble part of the reactor effluent peaked at $22.7 \mathrm{mg} \mathrm{N} \cdot \mathrm{l}^{-1}$, i.e. more than $30 \%$ of incoming ammonium. Nitrification is carried out in two steps by nitrifying bacteria, which are also autotrophic microorganisms to be expected in a mixed culture system like the one under study here. Ammonia-oxidizing bacteria (AOB) transform ammonium into nitrite, and nitrite-oxidizing bacteria (NOB) carry out the second step by oxidizing nitrite into nitrate. Although their growth velocities are not always higher than microalgae (Jimenez Douglas (2010) reported a maximum growth velocity of $0.88 \mathrm{~d}^{-1}$ and $0.42 \mathrm{~d}^{-1}$, respectively), 
thin biofilms in the walls of the reactor and other elements could have temporarily been a niche for the development of these microorganisms, preventing them from being washed away and allowing nitrite and nitrate to accumulate in the reactor. The previous accumulation of ammonium in the reactor (during week 2) also provided them, presumably, with the nutrients needed for growth.

In week 5, the levels of ammonium in the reactor fell to undetectable values when taken for microalgal growth. This correlates well with the increase in TSS in week 5, after the previous sharp decrease (figure III.5). In that week the microalgae presumably outcompeted the autotrophic bacteria, which were removed at the same time by the manual cleaning of the reactor walls. $\mathrm{AOB}$ and $\mathrm{NOB}$, together with nitrite and nitrate, were gradually washed out of the reactor by daily purging.

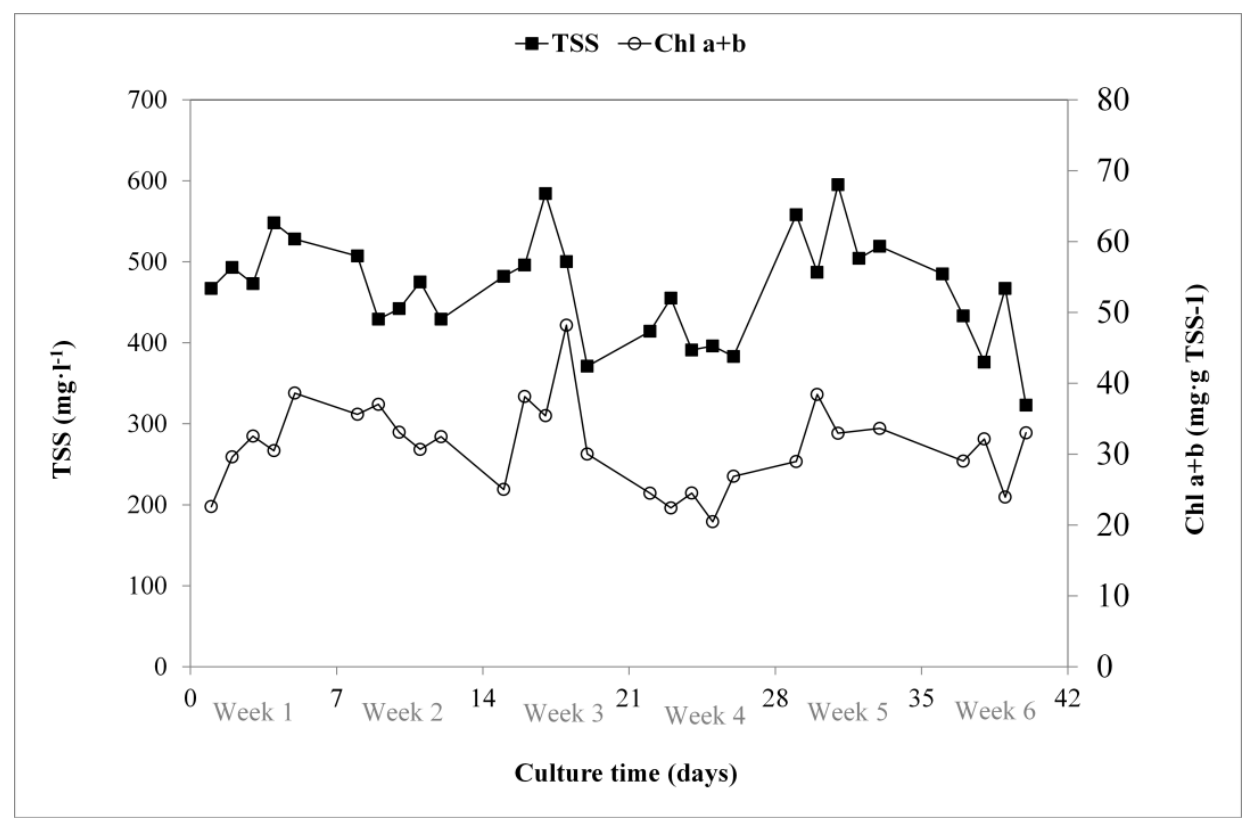

Figure III.5: TSS $\left(\mathrm{mg} \cdot \mathrm{l}^{-1}\right)$ in the 81 photobioreactor and biomass chl a+b content $\left(\mathrm{mg} \cdot \mathrm{g}^{-1}\right)$

It can be concluded from this section that, when the anaerobic membrane bioreactor was operated steadily with effluent concentrations of around $50 \mathrm{mg} \mathrm{NH} 4-\mathrm{N} \cdot 1^{-1}$, the removal rate of inorganic nitrogen was very satisfactory. In the conditions of light and temperature used in the study and when the incoming ammonia level is higher, it remains in the culture and might be used by autotrophic bacteria that coexist in the reactor with the microalgae. 
As regards phosphorus elimination, a satisfactory $97.8 \pm 3.9 \%$ of the incoming phosphate was eliminated, resulting in very high quality treated effluent. This means a daily average elimination of $7.3 \pm 1.6 \mathrm{mg} \mathrm{PO}_{4}-\mathrm{P} \cdot \mathrm{l}^{-1}$ in the treated water and a daily removal per reactor volume of $3.7 \pm 0.8 \mathrm{mg} \cdot 1^{-1} \cdot \mathrm{d}^{-1}$. Figure III.4 shows that, despite the incoming phosphate content varying from 5.1 to $10.5 \mathrm{mg} \mathrm{PO}_{4}-\mathrm{P} \cdot \mathrm{l}^{-1}$, the soluble part of the microalgal system effluent had a mean phosphate concentration of $0.1 \mathrm{mg} \mathrm{PO}_{4}-\mathrm{P} \cdot \mathrm{l}^{-1} \cdot \mathrm{d}^{-1}$ and a maximum of $0.2 \mathrm{mg} \mathrm{PO}_{4}-\mathrm{P} \cdot \mathrm{l}^{-1}$. Hence, the phosphate eliminated is very nearly equal to the amount of phosphate found in the SAnMBR effluent. This suggests that phosphate is, in this case, the limiting nutrient. This is also pointed out by the fact that the mass $\mathrm{N}: \mathrm{P}$ ratio in wastewater $(8 \pm 1.2$ on average $)$ is higher than the N:P ratio the microalgae need for their growth (an average of $5.4 \pm 1.2$ eliminated during this study).

However, the fact that the phosphate content is still detectable suggests that the system has another limitation, probably light intensity. It is hypothesized that a higher light intensity would increase biomass production in as much as phosphorus is still available for growth. Previously cited studies in this section report similar values for phosphate elimination. In Yuan et al. (2011) between 1.4 and $3 \mathrm{mg} \mathrm{PO}-\mathrm{P} \cdot \mathrm{l}^{-1}$ were eliminated and Kim et al. (2010) report between 2.4 and $3.9 \mathrm{mg} \mathrm{PO}_{4}-\mathrm{P} \cdot \mathrm{l}^{-1}$.

Soluble COD content in the photobioreactor was monitored after week 3 and displayed an average value of $51 \mathrm{mg} \mathrm{COD} \cdot \mathrm{l}^{-1}$. Previous experiments (unpublished data) show that this COD corresponds mainly to non-biodegradable soluble organic matter which is present in the SAnMBR effluent.

\subsection{Biomass production and biomass $\mathbf{N}$ and $P$ content}

The evolution of algal biomass, measured using TSS $\left(\mathrm{mg} \cdot \mathrm{l}^{-1}\right)$, and its chlorophyll content (mg.g TSS ${ }^{-1}$ ) is shown in figure III.5. The maximum biomass level was $595 \mathrm{mg} \cdot \mathrm{l}^{-1}$, and the average over the entire period, $467 \pm 65 \mathrm{mg} \cdot \mathrm{l}^{-1}$. Mean chlorophyll content ranged from 20.5 to $48.2 \mathrm{mg} \cdot \mathrm{g}^{-1}$ in the biomass $(2-4.8 \% \mathrm{dw})$, which is in keeping with other studies (Cheirsilp and Torpee, 2012). Self shadowing increases with higher TSS in the culture and the chlorophyll content of the microalgae increases in order to increase light harvesting. 
Because of the high nitrogen content of chlorophyll, there is a relationship between soluble nitrogen elimination (shown in figure III.6, corrected for nitrite and nitrate) and the chlorophyll content of the culture (expressed in $\mathrm{mg}$ chl $\mathrm{a}+\mathrm{b}$ per liter of culture). It is therefore expected that a higher biomass concentration with limited available light would increase the chlorophyll content of the culture and thus improve the nitrogen elimination. The increase in the consumed $\mathrm{N}: \mathrm{P}$ ratio would be of interest in the case of this specific SAnMBR effluent to be treated and future research should aim to increase the biomass concentration.

The biomass production rate (BPR) and the specific growth rate $(\mu)$ were calculated by equations III.4 and III.5 below, respectively:

$B P R=\frac{X \cdot Q}{V}\left(\mathrm{mg} \cdot \mathrm{l}^{-1} \cdot \mathrm{d}^{-1}\right)$

$\mu=\frac{\ln X_{2}-\ln X_{1}}{t_{2}-t_{1}}\left(\mathrm{~d}^{-1}\right)$

where $X\left(\mathrm{mg} \cdot \mathrm{l}^{-1}\right)$ is the biomass concentration, $Q\left(1 \cdot \mathrm{d}^{-1}\right)$ is the flow rate in semi-continuous operation, $V(\mathrm{l})$ is the reactor volume and $t(\mathrm{~d})$ is time. Results showed an average biomass production of $234 \pm 32 \mathrm{mg} \cdot \mathrm{l}^{-1} \cdot \mathrm{d}^{-1}$ and an average daily specific growth rate of $0.66 \pm 0.15 \mathrm{~d}^{-1}$, which is similar to those previously reported (Kim et al., 2010, Ras et al., 2011, Ketheesan and Nirmalakhandan, 2012).

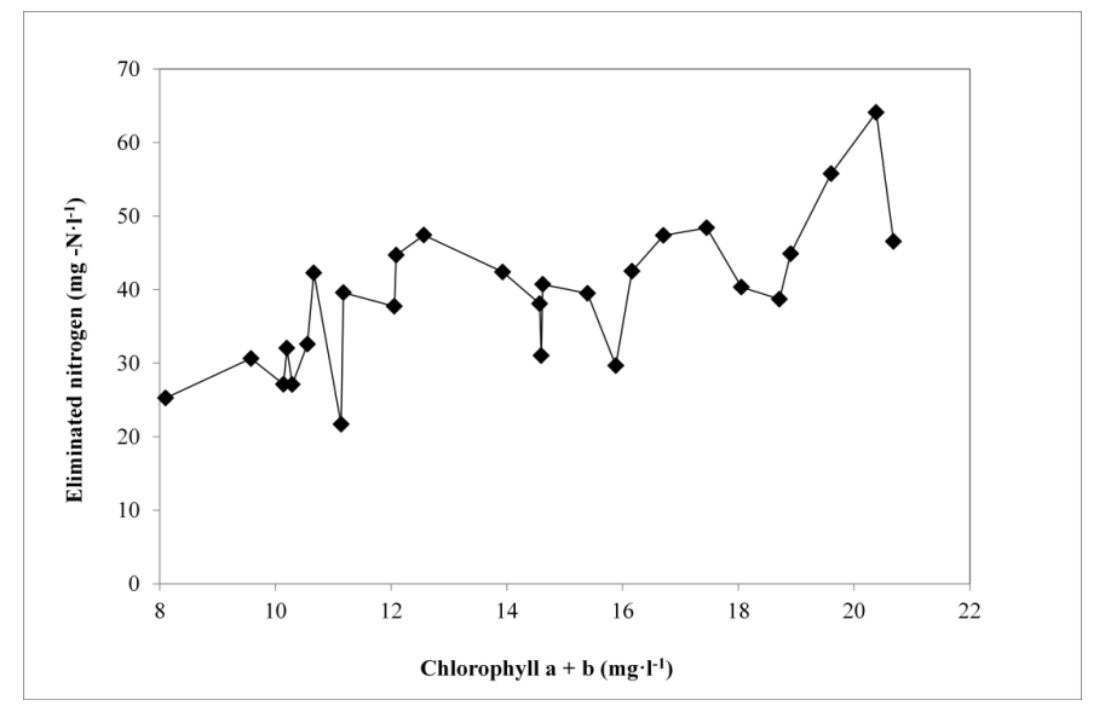

Figure III.6: Relation between eliminated nitrogen and reactor chlorophyll content (mg chl a+b $\cdot 1^{-1}$ ) 
Microalgae cell counts, together with the distribution of Chlorophyceae, diatoms and Cyanobacteria, are shown in table III.1. The mixed culture originally rich in Cyanobacteria developed during cultivation time into a polyculture in which Chlorophyceae were the dominant class. The diatoms content was low throughout the studied period.

Table III.1. Cell counts and microalgae classification during the experiment

\begin{tabular}{cccccccc}
\hline & & Chlorophyceae & \multicolumn{2}{c}{ Diatoms } & \multicolumn{2}{c}{ Cyanobacteria } \\
\hline $\begin{array}{c}\text { Culture } \\
\text { time (d) }\end{array}$ & $\begin{array}{c}\text { Total } \\
\text { cell count }\end{array}$ & $\begin{array}{c}\text { Cell } \\
\text { count }\end{array}$ & $\%$ & $\begin{array}{c}\text { Cell } \\
\text { count }\end{array}$ & $\%$ & $\begin{array}{c}\text { Cell } \\
\text { count }\end{array}$ & $\%$ \\
\hline 3 & $4.40 \cdot 10^{9}$ & $1.48 \cdot 10^{8}$ & $3.35 \%$ & - & - & $4.26 \cdot 10^{9}$ & $96.65 \%$ \\
\hline 10 & $6.72 \cdot 10^{9}$ & $4.33 \cdot 10^{9}$ & $64.36 \%$ & $1.72 \cdot 10^{7}$ & $0.26 \%$ & $2.38 \cdot 10^{9}$ & $35.38 \%$ \\
\hline 24 & $3.98 \cdot 10^{9}$ & $2.62 \cdot 10^{9}$ & $65.71 \%$ & $1.24 \cdot 10^{8}$ & $3.12 \%$ & $1.24 \cdot 10^{9}$ & $31.18 \%$ \\
\hline 40 & $2.56 \cdot 10^{9}$ & $1.85 \cdot 10^{9}$ & $72.13 \%$ & $3.82 \cdot 10^{6}$ & $0.15 \%$ & $7.11 \cdot 10^{8}$ & $27.72 \%$ \\
\hline
\end{tabular}

As reported elsewhere, different species of microalgae have diverse nutrient affinities and are influenced differently by environmental conditions. The advantage of maintaining a system containing different microalgal species is that a polyculture is able to adjust to varying conditions such as nutrient concentration or temperature. Moreover, although $\mathrm{pH}$ and light intensity were kept stable in this experiment, process control is more difficult or more expensive on a larger scale or in outdoor cultures. Variable conditions in such cases would demonstrate the robustness of polycultures. Further research should aim at understanding species distribution and evolution for better operation and control.

The $\mathrm{P}$ and $\mathrm{N}$ contents of the biomass were calculated as a $\%$ of dry weight as follows:

$$
\begin{aligned}
& \% N=\frac{\text { particulate } N\left(\mathrm{mg} \cdot \mathrm{l}^{-1}\right)}{\operatorname{TSS}\left(\mathrm{mg} \cdot \mathrm{l}^{-1}\right)} \\
& \% P=\frac{\text { particulate } P\left(\mathrm{mg} \cdot \mathrm{l}^{-1}\right)}{\operatorname{TSS}\left(\mathrm{mg} \cdot \mathrm{l}^{-1}\right)}
\end{aligned}
$$


The average biomass compositions thus obtained were $7.72 \pm 1.51 \% \mathrm{~N}$ and $1.44 \pm 0.16 \% \mathrm{P}$, which revealed the average mass N:P ratio in the microalgae to be 5.36, which tallies well with the eliminated $\mathrm{N}: \mathrm{P}$ ratio presented in section 3.1, i.e. $5.4 \pm 1.2$. With this biomass average composition, the nitrogen and phosphorus assimilated into the biomass during the studied period account for $92 \%$ and $91 \%$ of the eliminated nitrogen and phosphorus, respectively. Also reported in section 3.1, the mass N:P ratio in the influent ranged from 5.3 to 10.3, being 8 on average . Hence the SAnMBR effluent has a nitrogen surplus: it is phosphorus deficient and therefore eliminates this nutrient to a greater extent.

\subsection{Biomass separation and future perspectives}

The biomass generated enables the nutrients that have been removed from the wastewater to be recycled. Another separation step is needed to extract the microalgae from the culture medium and provide an effluent free of solids. Studies of membrane systems for microalgal biomass separation have been conducted (Rossignol et al., 1999, Zhang et al., 2010), but not very extensively. Further research will focus on microalgal biomass separation with membrane systems, assuming that separating solids retention time from hydraulic retention time will enable the proposed system to be optimized. The algal biomass thus obtained and separated from the culture could then be recycled at the anaerobic stage and used to increase the production of biogas. At the same time, it is of great importance to scale up the system to pilot plant scale and study it under outdoor conditions in order to develop a suitable technology for real scale urban wastewater treatment using the proposed mixed microalgal culture.

\section{Conclusions}

This study determines that it is feasible to use a mixed microalgal culture system for nutrient removal from AnMBR effluents, which could be a first step into spreading their use for domestic wastewater treatment. High nutrient removal rates were maintained whilst operating semi-continuously for 40 days, resulting in a microalgal treatment effluent whose water quality was very good. The combined system proposed, i.e. anaerobic treatment followed by microalgal polyculture, thereby eliminates organic matter from real urban wastewater whilst 
generating biogas, and the remaining ammonium and phosphate are recovered by transformation into microalgal biomass, achieving excellent water quality.

\section{Acknowledgements}

This research project has been supported by the Spanish Research Foundation (CICYT, projects CTM2011-28595-C02-01 and CTM2011-28595-C02-02), and by the Spanish Ministry of Education, Culture and Sport via a pre doctoral FPU fellowship to the first author (AP2009-4903). This support is gratefully acknowledged. The authors would also like to thank the water management entities of the Generalitat Valenciana (EPSAR).

\section{References}

APHA, AWWA and WEF (2005) Standard Methods for the Examination of Waters and Wastewaters, 21 st ed. American Public Health Association, Washington, DC.

Brenan, M., Owende, P. (2010) Biofuels from microalgae - A review of technologies for production, processing, and extraction of biofuels and co-products. Renewable and Sustainable Energy Reviews 14, 557-577.

Carlsson, H., Aspegren, H., Lee, N., Hilmer, A. (1997) Calcium phosphate precipitation in biological phosphorus removal systems. Water Research 31, 1047-1055.

Cheirslip, B., Torpee, S. (2012) Enhanced growth and lipid production of microalgae under mixotrophic culture condition: Effect of light intensity, glucose concentration and fed-batch cultivation. Bioresource Technology 110 , 510-516.

Chisti, Y. (2008) Biodiesel from microalgae beats bioethanol. Trends in Biotechnology 26, 126-131.

Christenson, L., Sims, R. (2011) Production and harvesting of microalgae for wastewater treatment, biofuels, and bioproducts. Biotechnology Advances 29, 686-702.

De Bashan, L., Bashan, Y. (2004) Recent advances in removing phosphorus from wastewater and its future use as fertilizer (1997-2003). Water Research 38, 4222-4246.

Fournier, R. (1978) Membrane filtering. In: Sournia, A., editor. Phytoplankton Manual. Monographs on oceanographic Methodology, Unesco, pp. 197-201.

Giménez, J.B., Robles, A., Carretero, L., Durán, F., Ruano, M.V., Gatti, M.N., Ribes, J., Ferrer, J., Seco, A. (2011) Experimental study of the anaerobic urban wastewater treatment in a submerged hollow-fibre membrane bioreactor at pilot scale. Bioresource Technology 102, 8799-8806.

Grobbelaar, J.U. (2004) Algal nutrition. In: Richmond, A., editor. Handbook of microalgal culture: biotechnology and applied phycology, Blackwell Publishing, Oxford, pp. 97-115. 
Ho, J., Sung, S. (2010) Methanogenic activities in anaerobic membrane bioreactors (AnMBR) treating synthetic municipal wastewater. Bioresource Technology 101, 2191-2196.

Jimenez Douglas, E. (2010) Mathematical modeling of the 2 step nitrification process. Development of calibration methodologies for a SHARON reactor and an Activated Sludge Process. (Modelación matemática del proceso de nitrificación en dos etapas. Desarrollo de metodologías de calibración del modelo para un reactor SHARON y un proceso de fangos activados), PhD thesis, Universitat Politènica de València, Valencia, Spain.

Ketheesan, B., Nirmalakhandan, N. (2012) Feasibility of microalgal cultivation in a pilot-scale airlift-driven raceway reactor. Bioresource Technology 108, 196-202.

Kim, H.W., Vannela, R., Zhou, C., Harto, C., Rittmann, B. E. (2010) Photoautotrophic nutrient utilization and limitation during semi-continuous growth of Synechocystis sp. PCC6803. Biotechnology and Bioengineering 106, 553-563.

Li, Y., Chen, Y., Chen, P., Min, M., Zhou, W., Martinez, B., Zhu, J., Ruan, R. (2011) Characterization of a microalga Chlorella sp. well adapted to highly concentrated municipal wastewater for nutrient removal and biodiesel production. Bioresource Technology 102, 5138-5144.

Lund, J.W.G., Kipling, C. and Le Cren, E.D. (1958) The inverted microscope method of estimating algal numbers and the statistical basis of estimations by counting. Hydrobiologia 11, 143-170.

Oswald, W., Gotaas, H. (1957) Photosynthesis in sewage treatment. American Society of Civil Engineers, Paper No. 2849.

Olguín, E.J. (2003a) Phycoremediation: key issues for cost-effective nutrient removal processes. Biotechnology Advances 22, 81-91.

Olguín, E., Galicia, S., Mercado, G., Pérez, T. (2003b) Annual productivity of Spirulina (Arthrospira) and nutrient removal in a pig wastewater recycling process under tropical conditions. Journal of Applied Phycology 15, 249-25.

Park, J., Jin, H., Lim, B-R., Park, K-Y., Lee, K. (2010) Ammonia removal from anaerobic digestion effluent of livestock waste using green alga Scenedesmus sp. Bioresource Technology 101, 8649-8657.

Park, J., Craggs, R.J., Shilton, A.N. (2011) Wastewater treatment high rate algal ponds for biofuel production. Bioresource Technology 102, 35-42.

Pittman, J.K., Dean, A. P., Osundeko, O. (2011) The potential of sustainable algal biofuel production using wastewater resources. Bioresource Technology 102, 17-25.

Pulz, O., Gross, W. (2004) Valuable products from biotechnology of microalgae. Applied Microbiology and Biotechnology 65, 635-648.

Ras, M., Lardon, L., Sialve, B., Bernet, N., Steyer, J-P. (2011) Experimental study on a coupled process of production and anaerobic digestion of Chlorella vulgaris. Bioresource Technology 102, 200-206.

Rawat, I., Ranjith Kumar, R. (2010) Dual role of microalgae: Phycoremediation of domestic wastewater and biomass production for sustainable biofuels production. Applied Energy 88, 3411-3424. 
Robles, A. (2013) Modelling, simulation and control of the filtration process in a submerged anaerobic membrane bioreactor treating urban wastewater, $\mathrm{PhD}$ thesis, Universitat Politècnica de Valéncia, Valencia, Spain.

Ruiz-Marin, A., Mendoza-Espinosa, L.G., Stephenson, T. (2010) Growth and nutrient removal in free and immobilized green algae in batch and semi-continuous cultures treating real wastewater. Bioresource Technology $101,58-64$.

Rossignol, N., Vandanjon, L., Jaouen, P., Quéméneur, F. (1999) Membrane technology for the continuous separation microalgae /culture medium: compared performances of cross-flow microfiltration and ultrafiltration. Aquacultural Engineering 20, 191-208.

Schenk P, Thomas-Hall S, Stephens E, Marx U, Mussgnug J, Posten C, et al. (2008) Second generation biofuels: high-efficiency microalgae for biodiesel production. BioEnergy Research 1, 20-43.

Smith, A.L., Stadler, L.B., Love, N.G., Skerlos, S.J., Raskin, L. (2012) Perspectives on anaerobic membrane bioreactor treatment of domestic wastewater: A critical review. Bioresource Technology 122, 149-159.

Stuckey, D.C (2012) Recent developments in anaerobic membrane reactors. Bioresource Technology 122, 137 148.

Ugwu, C.U., Aoyagi, H., Uchiyama, H. (2008) Photobioreactors for mass cultivation of algae. Bioresource Technology 99, 4021-4028.

Van den Ende, S., Vervaeren, H., Boon, N. (2012) Flue gas compounds and microalgae: (bio-)chemical interactions leading to biotechnological opportunities. Biotechnology advances 30 (6), 1405-1424.

Wang, L., Min, M., Li, Y., Chen, P., Chen, Y., Liu, Y., Wang, Y., Ruan, R. (2010) Cultivation of green algae Chlorella sp. in different wastewaters from municipal wastewater treatment plant. Applied Biochemical Biotechnology 162, 1174-1186.

Yang, J., Li, X., Hu, H., Zhang, X., Yu, Y., Chen, Y. (2011) Growth and lipid accumulation properties of a freshwater microalga, Chlorella ellipsoidea YJ1, in domestic secondary effluents. Applied Energy 88, 32953299.

Yuan, X., Kumar, A., Sahu, A.K., Ergas, S.J. (2011) Impact of ammonia concentration on Spirulina platensis growth in an airlift photobioreactor. Bioresource Technology 102, 3234-3239.

Zhang, X., Hu, Q., Sommerfeld, M., Puruhito, E., Chen, Y. (2010) Harvesting algal biomass for biofuels using ultrafiltration membranes. Bioresource Technology 101, 5297-5304. 



\title{
Chapter IV
}

\section{Mixed microalgae culture for ammonium removal in the absence of phosphorus: Effect of phosphorus supplementation and process modeling}

\author{
Ruiz-Martinez, A., Serralta, J., Pachés, M., Seco, A., Ferrer, J. (2014) Mixed microalgae \\ culture for ammonium removal in the absence of phosphorus: Effect of phosphorus \\ supplementation and process modeling. Process Biochemistry 49, 2249-2257.
}

\begin{abstract}
Microalgal growth and ammonium removal in a P-free medium have been studied in two batch photobioreactors seeded with a mixed microalgal culture and operated for 46 days. A significant amount of ammonium (106 mg $\left.\mathrm{NH}_{4}-\mathrm{N} \cdot \mathrm{l}^{-1}\right)$ was removed in a P-free medium, showing that microalgal growth and phosphorus uptake are independent processes. The ammonium removal rate decreased during the experiment, partly due to a decrease in the cellular phosphorus content. After a single phosphate addition in the medium of one of the reactors, intracellular phosphorus content of the corresponding microalgal culture rapidly increased, and so did the ammonium removal rate. These results show how the amount of phosphorus internally stored affects the ammonium removal rate. A mathematical model was proposed to reproduce these observations. The kinetic expression for microalgae growth includes a Monod term and a Hill's function to represent the effect of ammonium and stored polyphosphate concentrations, respectively. The proposed model accurately reproduced the experimental data $(r=0.952$, $\mathrm{P}$-value $<0.01)$.
\end{abstract}





\section{Introduction}

Interest on microalgae has increased during the last decades as they constitute a promising alternative for obtaining value-added products and biofuels such as biodiesel, biohydrogen biogas or biocrude. Moreover, microalgal systems for wastewater treatment have long been proposed and studied (Singh et al., 2012). These systems range from open-pond cultures to closed photobioreactors (Christenson and Sims, 2011) and focus primarily on the removal of inorganic nutrients such as ammonium, nitrate and phosphate.

Several studies have proved the suitability of microalgal cultures for nutrient removal in diverse wastewaters. These studies, which showed different degrees of nutrient removal efficiencies, generally agree that the most important advantages of microalgae utilization for this purpose are $\mathrm{CO}_{2}$ abatement and the possibility of reusing biomass as fertilizer or as renewable source of energy (Aravantinou et al., 2013, Arbib et al., 2014) On the other hand, the process spares the otherwise necessary cost of nutrients for algae cultivation. Currently, a rather extended opinion in the scientific community is that the production of algae-based biofuels, at least in the short-term, is neither economically nor energetically feasible without simultaneous wastewater treatment (Pittman et al, 2011)

Phosphorus is an essential component of microalgae. According to the Redfield ratio (Redfield, 1958), it constitutes $0.87 \%$ of its dry weight. Phosphorus is present in basic cell constituents such as phospholipids, nucleic acids or nucleotides. It can also be accumulated to higher levels inside the microalgal cells, where inorganic polyphosphate serves as reservoir. As reviewed by Powell et al. 2009, there are two mechanisms involved in this accumulation: over-compensation, which occurs after re-exposure to phosphorus following a starvation phase, and luxury uptake, where microalgae accumulate much more phosphorus than it is needed for their survival without previous exposure to P-poor medium.

Different studies, which aimed at defining the polyphosphate accumulation and phosphate uptake dynamics, have shown a relationship between phosphorus stress in the medium and low polyphosphate content in the cells, together with recovery of polyphosphate levels after addition of phosphorus (Jansson, 1993, Nishikawa et al., 2006). It is also known that starvation enhances the phosphate uptake rate. The effect of P-starvation on ammonium 
uptake rate is, however, less known. Previous studies did not focus on the influence that polyphosphate content exerts on the nitrogen uptake velocity, as these studies were not undertaken with a wastewater treatment approach.

In the wastewater treatment field mathematical models are useful tools for process design, WWTP scale-up or upgrade, or water quality prediction. Up to now, microalgal growth modelling has been tackled with a diversity of approaches. There are various examples of different complexity-level models which determine phytoplankton evolution in the ecosystems (Geider et al., 1997, Geider et al., 1998, Reichert et al., 2000), content and evolution of intracellular components of interest such as lipids or sugars (Mairet et al., 2011), specific metabolism of single species (Kliphuis et al., 2011), microalgal production inside photobioreactors (Fernández et al., 2012) or others.

The present work was designed to study the ammonium removal process in a phosphate-free medium and the relationship between the microalgal intracellular phosphorus content and the ammonium removal rate, with a view to designing suitable strategies for wastewater treatment. Therefore it is also the aim of this work to define a kinetic expression for microalgae growth considering the effect of ammonium concentration in the medium and the amount of internally stored polyphosphate on the rate of this process. To this aim, a mathematical model considering microalgae growth and death was proposed and model parameters were obtained by minimizing differences between experimental data and model predictions. This model should be useful for prediction of ammonium removal rates in wastewater treatment systems.

A microalgal culture was fed only with ammonium in a lab-scale photobioreactor (PBR) and afterwards separated into two identical PBRs. Phosphate was supplied only to one of them. Nutrient uptake kinetics of the two PBRs were studied, as well as biomass composition (\%N and $\% \mathrm{P})$. Microalgae production-in terms of chemical oxygen demand and suspended solidswas assessed. The experimental data obtained was successfully reproduced by the proposed model. This model can be useful for designing strategies and predicting the behavior of wastewater treatment systems where nutrient removal is achieved by microalgal growth. 


\section{Materials and methods}

\subsection{Experimental setup}

Three identical PBRs were used in this study (initial reactor, Nitrogen Only Reactor and Nitrogen and Phosphorus Reactor, as it will be explained in section 2.2). Each PBR consisted of a cylindrical, transparent methacrylate tank (20 cm internal diameter) with a total volume of 10 liters (see figure IV.1a). The PBRs were closed and the algae culture was mixed by recycling the headspace gas through four fine bubble diffusers mounted at the bottom. Both PBRs were equipped with electronic sensors in order to obtain online measurements of conductivity, oxidation reduction potential, temperature, $\mathrm{pH}$ and dissolved oxygen. The probes were connected to a multiparametric analyzer (CONSORT C832, Belgium) and an oximeter (Oxi 320, SET WTW, Germany), respectively. These devices were in turn connected to a PC for data monitoring and storage. Data sampling was conducted every $60 \mathrm{~s}$.

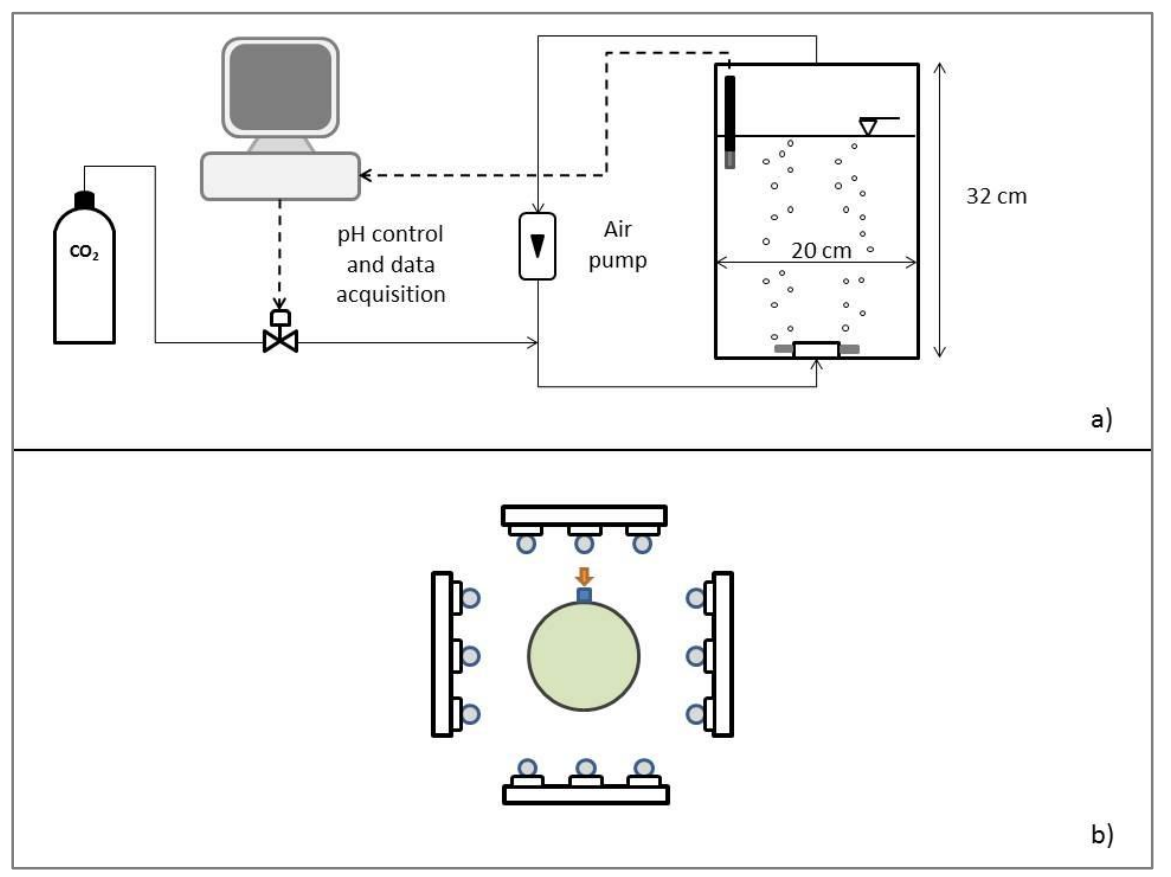

Figure IV.1: a) Experimental setup; b) illumination and measuring point.

$\mathrm{pH}$ in the PBRs was maintained around 7.5 to avoid undesirable processes such as phosphate precipitation and free ammonia stripping. Pure $\mathrm{CO}_{2}(99.9 \%)$ from a pressurized cylinder was injected into the gas flow whenever $\mathrm{pH}$ exceeded the setpoint of 7.5. Recycling gas from the 
headspace contributes to minimize the $\mathrm{CO}_{2}$ requirements for $\mathrm{pH}$ control. Since the reactors were closed $\mathrm{CO}_{2}$ stripping was also minimized but since they were not hermetically sealed extreme overpressure and overaccumulation of oxygen were avoided.

Four arrays of 3 vertical fluorescent lamps (Sylvania Grolux, $18 \mathrm{~W}$ ) $10 \mathrm{~cm}$ apart from each other continuously illuminated each PBR from a minimum distance of $10 \mathrm{~cm}$. Photosynthetically active radiation (PAR) of $153 \pm 16 \mu \mathrm{E} \cdot \mathrm{m}^{-2} \cdot \mathrm{s}^{-1}$ was measured at the surface of the reactors as the arrow in figure IV.1b indicates. The PBRs were placed inside a climatic chamber with air temperature control set to $20{ }^{\circ} \mathrm{C}$. Due to the constant illumination the temperature in the culture resulted in $25.5^{\circ} \mathrm{C}$.

A phosphate-free medium, adapted from Li et al. (2011) was used in this study, one liter of which was composed of $115 \mathrm{~g}\left(\mathrm{NH}_{4}\right)_{2} \mathrm{SO}_{4}, 150 \mathrm{mg} \mathrm{CaCO}$, $400 \mathrm{mg} \mathrm{CaCl}_{2} \cdot \mathrm{H}_{2} \mathrm{O}, 400 \mathrm{mg}$ $\mathrm{Na}_{2} \mathrm{SeO}_{3} \cdot 5 \mathrm{H}_{2} \mathrm{O}, 350 \mathrm{mg} \mathrm{MgSO}_{4} \cdot 7 \mathrm{H}_{2} \mathrm{O}, 54 \mathrm{mg}\left(\mathrm{NH}_{4}\right)_{6} \mathrm{Mo}_{7} \mathrm{O}_{2} \cdot 4 \mathrm{H}_{2} \mathrm{O}, 30 \mathrm{mg} \mathrm{ZnCl}_{2}, 30 \mathrm{mg}$ $\mathrm{HBO}_{3}, 30 \mathrm{mg} \mathrm{NiCl} 2 \cdot 6 \mathrm{H}_{2} \mathrm{O}, 18 \mathrm{mg} \mathrm{CuCl} 2 \cdot 2 \mathrm{H}_{2} \mathrm{O}, 12 \mathrm{mg} \mathrm{K} \mathrm{SO}_{4}, 1.2 \mathrm{mg} \mathrm{FeCl} \cdot 4 \mathrm{H}_{2} \mathrm{O}, 1.2 \mathrm{mg}$ $\mathrm{CoCl}_{2} \cdot 6 \mathrm{H} 2 \mathrm{O}, 0.6 \mathrm{mg}$ EDTA, $0.3 \mathrm{mg} \mathrm{MnCl}_{2} \cdot 4 \mathrm{H}_{2} \mathrm{O}$.

\subsection{Operation}

A microalgal culture (7 1) was maintained for 19 days in ammonium-rich and phosphate-free medium in a lab-scale PBR as described in section 2.1, called initial reactor. Ammonium in the form of $\left(\mathrm{NH}_{4}\right)_{2} \mathrm{SO}_{4}$ was manually added at the beginning of the experiment and when its concentration dropped below $4 \mathrm{mg} \mathrm{NH}_{4}-\mathrm{N} \cdot \mathrm{l}^{-1}$ (day 7). On day 19, when ammonium concentration had reached again $4 \mathrm{mg} \mathrm{NH} 4-\mathrm{N} \cdot \mathrm{l}^{-1}$, the 71 culture was split into two PBRs, with a working volume of 3.51 each. These two PBRs will henceforth be called NOR (Nitrogen Only Reactor) and N\&PR (Nitrogen and Phosphorus Reactor) and were not carried out in duplicate.

Immediately after the splitting, ammonium in the form of $\left(\mathrm{NH}_{4}\right)_{2} \mathrm{SO}_{4}$ was added into $N O R$, reaching a concentration of $28.4 \mathrm{mg} \mathrm{NH}-\mathrm{N} \cdot \mathrm{l}^{-1}$, and phosphate in the form of $\mathrm{KH}_{2} \mathrm{PO}_{4}$ was added into $N \& P R$, reaching a concentration of $11.7 \mathrm{mg} \mathrm{PO}_{4}-\mathrm{P} \cdot \mathrm{l}^{-1}$. From then on, both reactors were operated for 27 days. Ammonium was added again in both reactors when its concentration dropped below $4 \mathrm{mg} \mathrm{NH}-\mathrm{N} \cdot \mathrm{l}^{-1}$ (day 29 in NOR and days 20, 22 and 29 in $N \& P R)$. 


\subsection{Microorganisms}

The initial reactor was seeded with microalgae isolated from the walls of the secondary clarifier in the "Cuenca del Carraixet" WWTP (Valencia, Spain) and maintained in the laboratory under semi-continuous feeding conditions with a cellular retention time of 4 days and continuous illumination varying between 114 and $198 \mu \mathrm{E} \cdot \mathrm{m}^{-2} \cdot \mathrm{s}^{-1}$. The effluent of a submerged anaerobic membrane bioreactor (SAnMBR, described in Giménez et al., 2011) was used as growth medium. This effluent displays a variable N/P ratio and has been proved to sustain algal growth (Ruiz-Martinez et al., 2012 (Chapter III)). Microalgae from the Chlorococcum genus together with Cyanobacteria (Spirulina sp. and Pseudoanabaena sp.) were identified as the main groups present.

\subsection{Analytical Methods}

Nutrient removal was evaluated by regular measurements of inorganic nitrogen and phosphorus levels in the samples taken from the PBRs. Ammonium $\left(\mathrm{NH}_{4}-\mathrm{N}\right)$, nitrite $\left(\mathrm{NO}_{2}-\mathrm{N}\right)$, nitrate $\left(\mathrm{NO}_{3}-\mathrm{N}\right)$ and phosphate $\left(\mathrm{PO}_{4}-\mathrm{P}\right)$ were determined according to Standard Methods (APHA, 2005) (4500-NH3-G, 4500-NO2-B, 4500-NO3-H and 4500-P-F, respectively) in a Smartchem 200 automatic analyzer (Westco Scientific Instruments, Westco).

Total nitrogen in the algae culture was measured using standard kits (Merck, Darmstadt, Germany, 100613). The acid peroxodisulphate digestion method (APHA, 2005) was used for total phosphorus (TP) measurements. The nitrogen content of the algae biomass was calculated as the difference between total nitrogen and soluble nitrogen. Likewise, the phosphorus content of the algae biomass (total suspended phosphorus, TSP) was calculated as the difference between total phosphorus and orthophosphate concentration. Total and volatile suspended solids (TSS and VSS), as well as chemical oxygen demand (COD) were determined according to Standard Methods (APHA, 2005).

All reported results were obtained from the previous analyses conducted in duplicate, except for TSS and VSS where single analysis were made. 


\section{Results and discussion}

\subsection{Nutrient removal}

The composition of the biomass in the initial reactor (7 1 PBR) after inoculation is included in table IV.1. According to Reynolds (2006), a phosphorus concentration in the biomass greater than $3 \%$ suggests that phosphate luxury uptake has taken place. Therefore, the studied microalgal biomass had stored, before the beginning of this experiment (during the cultivation under semi-continuous mode), more phosphate than needed for growth.

Table IV.1: Biomass evolution in the reactors and calculated yields

\begin{tabular}{|c|c|c|c|c|c|c|c|}
\hline Time (d) & $\begin{array}{c}\text { TSS }^{\mathbf{a}} \\
\left(\mathbf{m g} \cdot \mathbf{l}^{-1}\right)\end{array}$ & $\begin{array}{c}\mathrm{VSS}^{\mathrm{a}} \\
\left(\mathrm{mg} \cdot \mathbf{l}^{-1}\right)\end{array}$ & $\begin{array}{c}\text { Susp } \\
\text { COD }^{b} \\
\left(\mathrm{mg} \cdot \mathbf{l}^{-1}\right)\end{array}$ & $\begin{array}{c}\text { Biomass } \\
\text { N content } \\
\left(\mathrm{g} \mathbf{N} \cdot \mathrm{gVSS}^{-1}\right)\end{array}$ & $\begin{array}{l}\text { Biomass } \\
\text { P content } \\
\left(\mathrm{gP}^{\prime} \mathrm{gVSS}^{-1}\right)\end{array}$ & $\begin{array}{c}\text { Yield } \\
\text { coefficient } \\
\text { Y }_{\mathrm{N}-\mathrm{VSS}} \\
\left(\mathrm{gVSS} \mathbf{g N}^{-1}\right)\end{array}$ & 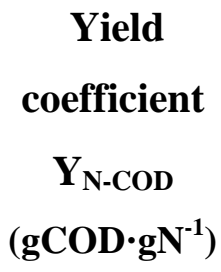 \\
\hline 0 & 380 & 340 & 517 & $11.8 \%$ & $3.7 \%$ & -- & -- \\
\hline 19 (initial) & 882 & 817 & 1176 & $12.0 \%$ & $1.6 \%$ & 8.2 & 11.3 \\
\hline $46(N O R)$ & 1330 & 1224 & 1880 & $10.8 \%$ & $0.8 \%$ & 8.8 & 12.8 \\
\hline $46(N \& P R)$ & 1583 & 1460 & 2320 & $10.6 \%$ & $1.7 \%$ & 8.7 & 13.9 \\
\hline
\end{tabular}

Mean analytical error: ${ }^{\mathrm{a}} 50 \mathrm{mg} \cdot \mathrm{l}^{-1} ;{ }^{\mathrm{b}} 70 \mathrm{mg} \cdot \mathrm{l}^{-1}$;

Figures IV.2a and IV.2b show the ammonium and phosphate evolution in the NOR and $N \& P R$, respectively. The experiment started in the 71 initial reactor with biomass inoculation and ammonium addition. The initial VSS and ammonium concentrations were $340 \mathrm{mg} \mathrm{VSS} \cdot 1^{-1}$ and $32 \mathrm{mg} \mathrm{NH} 4-\mathrm{N} \cdot 1^{-1}$, respectively. Ammonium was added again after 7 days because its concentration was below $4 \mathrm{mg} \mathrm{NH}-\mathrm{N} \cdot 1^{-1}$. During this first period, which is common in both graphs, phosphate concentration in the medium was zero (figure IV.2). However, the microalgal biomass removed a total of $58 \mathrm{mg} \mathrm{NH}_{4}-\mathrm{N} \cdot 1^{-1}$. 


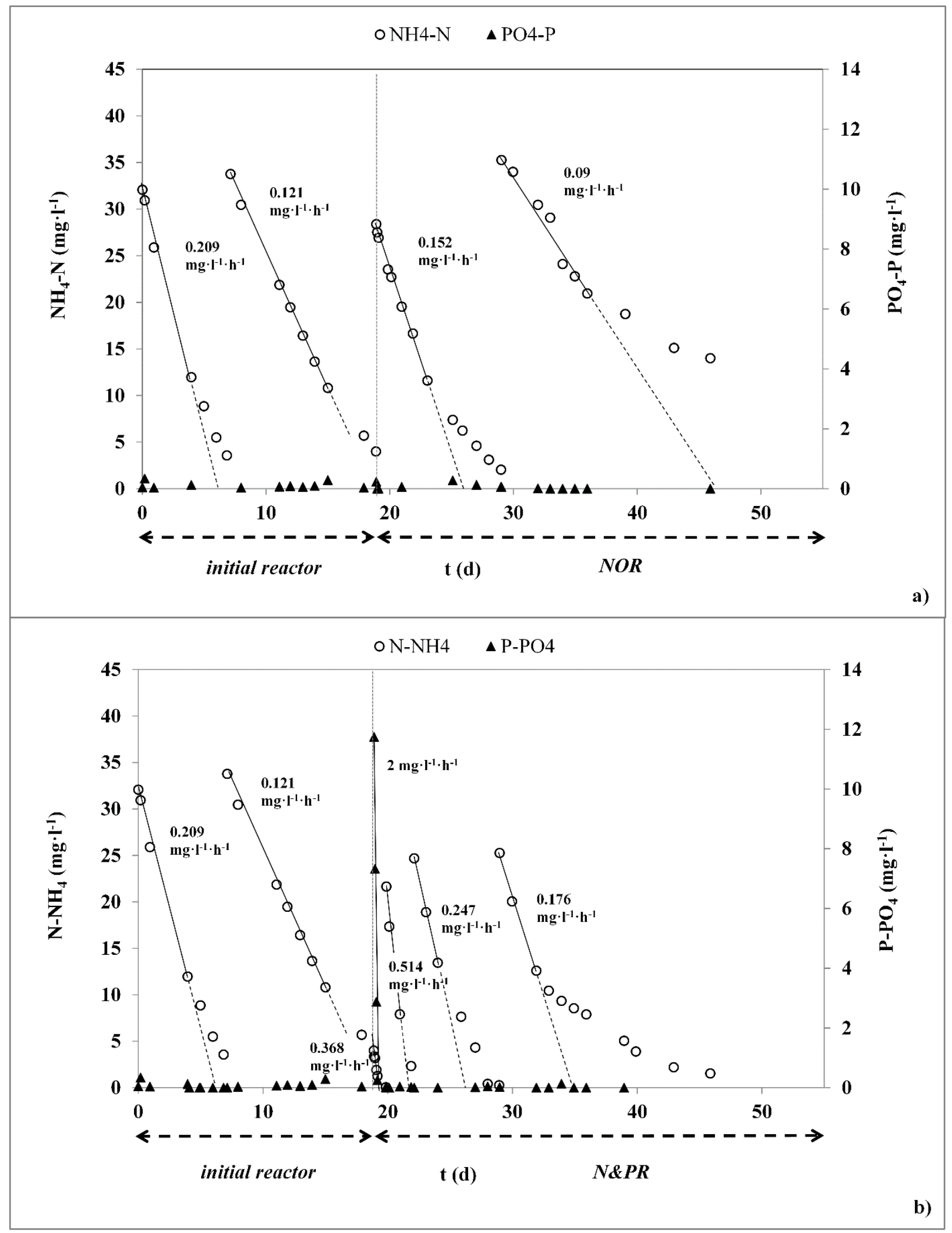

Figure IV.2: Ammonium and phosphate evolution in a) $N O R$ and b) $N \& P R$ during the whole experiment. 
VSS as well as suspended COD concentrations clearly increased in both reactors due to microalgae growth (table IV.1). This increase was greater in $N \& P R$ since the amount of ammonium and phosphate taken up was higher.

The biomass $\mathrm{P}$ content visibly decreased in the initial reactor and in the NOR, since the microalgae growth took place using the internally stored polyphosphate. In the $N \& P R$ the biomass $\mathrm{P}$ content sharply increased on day 19 (to a maximum of 2.8\%) due to phosphorus addition and immediate uptake. It decreased from then on for the rest of the experiment.

Yield coefficients were calculated as the ratio between the amounts of biomass generated, measured as VSS and COD, and the ammonium removed. VSS yield coefficients are similar in the $N O R, N \& P R$ and in the initial reactor, whereas the $N \& P R$ shows a slightly higher COD yield coefficient. It is hypothesized that this difference could be attributed to the amount of phosphate taken up in $N \& P R$ : growth in $N O R$ took place without phosphate addition, like in the initial reactor, while in $N \& P R$ phosphate was available and taken up by microalgae. However, analytical error of the performed measurements (VSS and COD) hinders a clear conclusion on the subject. Biomass $\mathrm{N}$ content obtained in the present work is in accordance with the general Redfield formulation of $9.20 \%\left(0.092 \mathrm{~g} \mathrm{~N} \cdot \mathrm{g}^{-1}\right)$.

\subsubsection{Nitrogen Only Reactor}

As shown in figure IV.2a, microalgal ammonium uptake took place during all the experiment (46 days in total) in the NOR, without any external phosphate addition. This fact demonstrates that ammonium and phosphorus uptake from the medium are two independent processes-in the sense that one can occur without the other-, and clearly demonstrates that this microalgal culture presents a great capacity for removing a high amount of ammonium in the absence of phosphate in the medium. In this reactor a total of $106 \mathrm{mg} \mathrm{NH}-\mathrm{N} \cdot 1^{-1}$ was removed without phosphate in the culture medium.

After each ammonium addition its uptake took place at a constant rate until ammonium concentration decreased to values around $10-13 \mathrm{mg} \mathrm{NH}-\mathrm{N} \cdot \mathrm{l}^{-1}$ (in figure IV.2a. filled lines turn into dashed lines). The ammonium uptake rate significantly decreased when ammonium concentrations were below this threshold. This low ammonium affinity observed in these experiments should be taken into account in the design of PBRs for wastewater treatment 
since large tank volumes or high hydraulic retention times will be required to obtain very low ammonium concentrations. An exception to this was the last slope, when the constant rate was not maintained below $20 \mathrm{mg} \mathrm{NH}-\mathrm{N} \cdot 1^{-1}$. This exception will be discussed later in this section.

In the $N O R$, the ammonium uptake rate decreased with time throughout the experiment, likely due to a decrease in the internally stored polyphosphate. The selfshading effect of the culture also exerted its influence: biomass growth during the experiment led to a decrease in the available light for microalgae even when the incident light remained constant. The calculated ammonium removal rates (slopes shown in figure IV.2a) decreased from $0.209 \mathrm{mg} \mathrm{N} \cdot \mathrm{l}^{-1} \cdot \mathrm{h}^{-1}$ at the beginning of the experiment to $0.09 \mathrm{mg} \mathrm{N} \cdot \mathrm{l}^{-1} \cdot \mathrm{h}^{-1}$ at the end of the experiment. The specific removal rate $\left(\mathrm{mg} \mathrm{N} \cdot \mathrm{mg} \mathrm{VSS}^{-1} \cdot \mathrm{h}^{-1}\right)$ (table IV.2) decreased during all the experiment.

As no phosphate was added at any time in the NOR, the $\mathrm{P}$ required for biomass growth could only be taken from their internal $\mathrm{P}$ pool, which microalgae had accumulated during the previous phase of cultivation under semicontinuous conditions. This internal polyphosphate consumption during the experiment led to a decrease in the biomass $\mathrm{P}$ content, which reached $0.8 \%\left(0.008 \mathrm{~g} \mathrm{P} \mathrm{g} \mathrm{VSS}^{-1}\right.$ ) at the end of the experiment (at day 46, see table IV.1), when ammonium removal was taking place at a very slow rate. These results suggest the existence of a relationship between the $\mathrm{P}$ content of the cells and the ammonium removal rate.

The final biomass $\mathrm{P}$ content is a very small value compared to the initial biomass composition (indicated in table IV.1). It is, according to Reynolds (2006), still higher than the minimum amount of internal phosphorus for cell survival (between $0.2-0.4 \%$ in dry weight). In fact, Markou (2012) has shown a minimum phosphorus content after starvation phase of $0.185 \%$ $\left(0.00185 \mathrm{~g} \mathrm{P} \cdot \mathrm{g}^{-1}\right)$. However, approaching these minimum values of intracellular $\mathrm{P}$ content makes ammonium uptake rate decrease.

Around day 35 of the experiment, biomass in the NOR reached what seems quite a critical $\mathrm{P}$ content. The ammonium uptake rate decreased to very slow values although ammonium concentration was still $20 \mathrm{mg} \mathrm{NH} \mathrm{NH}_{4}-\mathrm{N} \cdot \mathrm{l}^{-1}$. At the same time, as table IV.1 shows, suspended solids significantly increased along the experiment. Mutual shading of the microalgae attenuates light in the PBR and microalgal growth was therefore also slowed down for this reason. 
Table IV.2: Calculated net and specific ammonium removal rate after each ammonium addition in each reactor, together with biomass $\mathrm{P}$ content at those moments (beginning of slope)

\begin{tabular}{|c|c|c|c|c|c|}
\hline Reactor & $\begin{array}{c}\text { Slope } \\
\text { number }\end{array}$ & $\begin{array}{l}\text { Removal rate } \\
\left(\mathrm{mg} \mathrm{N} \cdot \mathbf{l}^{-1} \cdot \mathbf{h}^{-1}\right)\end{array}$ & $\begin{array}{l}\text { Slope } \\
\text { error }\end{array}$ & $\begin{array}{l}\text { Specific removal rate } \\
\left(\mathrm{mg} \mathrm{N} \cdot \mathrm{mg} \mathrm{VSS}^{-1} \cdot \mathbf{h}^{-1}\right)\end{array}$ & $\begin{array}{c}\text { Biomass } P \\
\text { content } \\
\left(\text { g P}^{\prime} \cdot \mathrm{g} \mathrm{VSS}^{-1}\right)\end{array}$ \\
\hline \multirow{2}{*}{ initial } & 1 & 0.209 & 0.018 & $6.15 \cdot 10^{-4}$ & $3.7 \%$ \\
\hline & 2 & 0.121 & 0.002 & $2.11 \cdot 10^{-4}$ & $2.2 \%$ \\
\hline \multirow{2}{*}{$N O R$} & 3 & 0.152 & 0.001 & $1.86 \cdot 10^{-4}$ & $1.6 \%$ \\
\hline & 4 & 0.090 & 0.009 & $8.79 \cdot 10^{-5}$ & $1.0 \%$ \\
\hline \multirow{3}{*}{$N \& P R$} & 3 & 0.514 & 0.051 & $6.07 \cdot 10^{-4}$ & $2.6 \%$ \\
\hline & 4 & 0.247 & 0.004 & $2.41 \cdot 10^{-4}$ & $2.0 \%$ \\
\hline & 5 & 0.176 & 0.014 & $1.41 \cdot 10^{-4}$ & $1.5 \%$ \\
\hline
\end{tabular}

\subsubsection{Nitrogen and Phosphorus Reactor}

Phosphate was added to $N \& P R$ on day 19 and reached a concentration of $11.7 \mathrm{mg} \mathrm{PO}_{4}-\mathrm{P} \cdot \mathrm{l}^{-1}$. Phosphate removal started immediately and its removal rate was $2 \mathrm{mg} \mathrm{PO}_{4}-\mathrm{P} \cdot \mathrm{l}^{-1} \cdot \mathrm{h}^{-1}$ until phosphate concentration was nearly zero. This removal rate was very high, considering that while the added phosphate was consumed, only $2.1 \mathrm{mg} \mathrm{NH}_{4}-\mathrm{N}$ were taken up by the microalgae. The resulting N:P uptake ratio of 0.18 is very low, which is due to the phosphorus starvation condition of the biomass. The majority of literature values on microalgal phosphate uptake rate under balanced conditions are well below the presented value: Aravantinou et al.

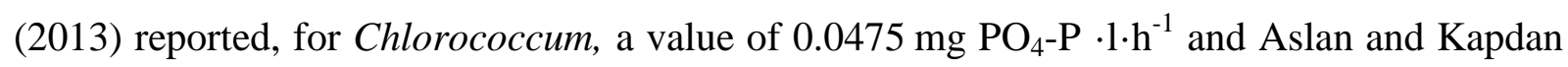
(2006) reported a value of $0.083 \mathrm{mg} \mathrm{PO}_{4}-\mathrm{P} \cdot 1 \cdot \mathrm{h}^{-1}$ for Chlorella sp. Ramos Tercero et al. (2014) 
reported for Chlorella protothecoides a closer value to the one presented in this work of 1.3 $\mathrm{mg} \mathrm{PO}-\mathrm{P} \cdot \mathrm{l}^{-1} \cdot \mathrm{h}^{-1}$.

$N \& P R$ was spiked with ammonium for a third, fourth and fifth time (figure IV.2b). As previously observed in the NOR, the ammonium uptake rates kept constant after the ammonium additions but decreased when ammonium concentration in the medium reached values below 10-13 mg NH $\mathrm{NH}_{4} \mathrm{~N} \cdot \mathrm{l}^{-1}$. The value obtained for the ammonium removal rate after phosphate addition in the $N \& P R$ showed a significant increase, due to a fast increase in intracellular phosphorus concentration. Ammonium removal rate decreased along the rest of the experiment, as in $N O R$, due to an increase of selfshading and a decrease in phosphorus content. At the end of the experiment, ammonium concentrations reached lower values in $N \& P R$ than in $N O R$, and still maintained a faster decreasing trend. At this point, $\mathrm{P}$ content of the biomass had reached $0.017 \mathrm{~g} \mathrm{P} \cdot \mathrm{g} \mathrm{VSS}^{-1}$, which is higher than the biomass $\mathrm{P}$ content reached in NOR $\left(0.008 \mathrm{~g} \mathrm{P} \cdot \mathrm{g} \mathrm{VSS}^{-1}\right)$.

These results suggest that ammonium removal rate depends on the amount of phosphorus stored in microalgae. Other authors modelled phytoplankton colimitation by nitrogen and phosphorus (Bougaran et al., 2010) assuming that the maximum potential for $\mathrm{N}$ uptake takes place at high concentrations of intracellular phosphorus, which is in accordance with the experimental results obtained now in this work.

The specific ammonium uptake rates (with respect to VSS) obtained in the $N \& P R$ and the associated biomass $\mathrm{P}$ content are shown in table IV.2, demonstrating how intracellular polyphosphate content exerted a drastic and positive influence in the specific ammonium removal rate: it decreased for the first 2 injections into initial reactor, continued decreasing after the $\mathrm{N}$ injections into $N O R$ and increased in $N \& P R$ after $\mathrm{P}$ addition, catching up with the initial value of $6 \cdot 10^{-4} \mathrm{mg} \mathrm{N} \cdot \mathrm{mg} \mathrm{VSS}^{-1} \cdot \mathrm{h}^{-1}$. The addition of phosphorus in the medium was the only difference between reactors.

The data shown in table IV.2 demonstrates therefore a high sensitivity of the specific ammonium removal rate to microalgal $\mathrm{P}$ content: the higher the biomass $\mathrm{P}$ content the higher the specific ammonium removal rate. However, the relationship between these variables is far from linear: a sharp increase is observed in the specific ammonium removal rate when biomass $\mathrm{P}$ content lies between 2.2 and 2.6\%. After phosphate addition, the specific 
ammonium removal rate rose from $2.11 \cdot 10^{-4}$ for a $\mathrm{P}$ content of $2.2 \%$ to $6.07 \cdot 10^{-4} \mathrm{mg} \mathrm{N} \cdot \mathrm{mg}$ $\mathrm{VSS}^{-1} \cdot \mathrm{h}^{-1}$ for a $\mathrm{P}$ content of $2.6 \%$. When biomass $\mathrm{P}$ content decreased down to $2.0 \%$ due to microalgae growth without phosphate addition the specific ammonium removal rate decreased to a value close to that previously observed.

On the other hand, the selfshading effect due to biomass growth is evidenced by the fact that almost no difference is observed between the ammonium uptake in the initial reactor $\left(6.15 \cdot 10^{-4} \mathrm{mg} \mathrm{N} \cdot \mathrm{mg} \mathrm{VSS}^{-1} \cdot \mathrm{h}^{-1}\right)$ and the "recovered" uptake rate in $N \& P R\left(6.07 \cdot 10^{-4} \mathrm{mg}\right.$ $\left.\mathrm{N} \cdot \mathrm{mg} \mathrm{VSS} \mathrm{VS}^{-1} \cdot \mathrm{h}^{-1}\right)$ while biomass has quite a different $\mathrm{P}$ content $(3.7 \%$ and $2.6 \% \mathrm{P}$, respectively) and thus a faster ammonium uptake rate would be expected in $N \& P R$ if intracellular content was to be the only influencing factor.

Comparison between the performances of both reactors shows that, for this microalgal culture, below the threshold of around $2.2-2.6 \%$ of internal phosphorus the nitrogen uptake rate decreases considerably and around $1 \%$ the microalgal culture is unsuitable for ammonium removal applications due to the slow rate obtained. It has been demonstrated that under phosphorus limitation the nitrogen uptake process takes place at much slower rates. The obtained data also suggest that selfshading influences growth and nutrient uptake rates. Therefore, these two factors (available light and available intracellular phosphorus content) will be taken into account in the modelling step.

The present work has confirmed, for this microalgal culture, two main consequences of phosphate addition to a P-starving culture:

-Phosphorus supplementation to the medium increases the ammonium removal rate by increasing the amount of polyphosphate the biomass is able to accumulate.

-The added phosphate is removed at a fast rate due to the prior starving conditions. This could be useful in the development of different strategies for wastewater nutrient removal and also shows that biomass growth can still take place with low amounts of phosphorus, as already reported by $\mathrm{Wu}$ et al. (2013a). These authors proposed a P-starvation cultivation mode to minimize phosphorus resource consumption. A low biomass $\mathrm{P}$ content might not be a drawback in some cases, as for instance within a biorefinery concept, where ammonium removal rates are of no concern, or substances of interest are not fertilizers. 


\subsubsection{Biological nutrient removal}

All conclusions drawn from this study are based on the assumption that ammonium and phosphate removal are solely due to microalgal uptake, as the $\mathrm{pH}$ control assures that neither free ammonia stripping nor inorganic salts precipitation takes place. Further indication that no inorganic precipitation occurred is the fact that the VSS percentage was always higher than $92 \%$ of TSS.

The algal culture studied was mainly composed of three species: Chlorococcum sp., Spirulina sp. and Pseudoanabena sp. A pure culture has not been used in this study as the aim of this work is to analyze the behavior of the culture which evolved from feeding a PBR with the effluent of a SAnMBR (Ruiz-Martinez et al., 2012 (Chapter III)). The results obtained might be applied to those cultures with similar species composition, since the results obtained in a microalgal culture composed of close-phylogenetic species with similar nutrient requirements and similar growth conditions might reveal comparable absorption patterns. However, culture from different microalgae clade might show different growth and ammonium removal rates.

On the other hand, the low nitrite and nitrate concentrations measured during all the experiment (highest measured values were $2.2 \mathrm{mg} \mathrm{NO}-\mathrm{N} \cdot 1^{-1}$ and $1.7 \mathrm{mg} \mathrm{NO}_{3}-\mathrm{N} \cdot 1^{-1}$ ) indicate no bacterial nitrification/denitrification activity took place. Constant soluble COD levels (stable around $134 \mathrm{mg} \mathrm{COD} \cdot \mathrm{l}^{-1}$ ) support this hypothesis.

\subsection{Mathematical model}

\subsubsection{Proposed model}

A mathematical model focused on the kinetics of microalgal ammonium uptake was proposed with the aim of representing the ammonium removal process observed in the PBRs. The main characteristics of the proposed model are:

-Microalgal ammonium uptake rate does not depend on phosphate concentration in the medium, since ammonium uptake still takes place in a phosphate depleted medium. The rate of this process depends on the amount of phosphate stored. The Hill function is proposed to simulate the influence of internal phosphorus concentration on ammonium removal rate since a sharp increase was observed when biomass P content exceeded $2.2 \%$. 
-Microalgal ammonium uptake rate depends on ammonium concentration. The Monod kinetics is used to simulate this dependency.

-Biomass is assumed to have a constant composition, excluding the polyphosphate internally stored, which is itself a separate component in the model.

-Phosphate uptake and thus intracellular phosphate accumulation is not considered in the model since this process was not experimentally studied (took place only once when $\mathrm{P}$ was supplemented) and thus experimental data is insufficient for obtaining the corresponding kinetic constants. It is considered that the amount of phosphate removed from the medium becomes intracellular polyphosphate. As previously explained, chemical precipitation is avoided with $\mathrm{pH}$ control.

-Microalgal death is modelled using a first order kinetics: death rate depends on microalgal concentration. Microalgal death produces inert particulate organic material, with the same $\mathrm{N}$ and $\mathrm{P}$ composition as the active biomass. No solubilization processes are considered. The polyphosphate of the dead cells is considered to stay unavailable for further microalgal growth.

-The light influence on the microalgal growth is modelled using the Steele function (IV.1), as suggested by Reichert et al. (2001) or Wu et al. (2013b). A weighted average light intensity, which takes into account the reactor's geometry and the self-shading factor of the microalgae, is used. It is calculated dividing the reactor into discrete concentric sections and applying Lambert-Beer's Law (IV.2) for calculating a uniform light for each section.

$$
\begin{aligned}
& \frac{I}{k_{i}} \exp \left(1-\frac{I}{k_{i}}\right) \\
& I=I_{0} \cdot \exp (-a \cdot T S S \cdot z)
\end{aligned}
$$

Where $I$ is light intensity $\left(\mu \mathrm{E} \cdot \mathrm{m}^{-2} \cdot \mathrm{s}^{-1}\right), k_{i}$ is the optimal light intensity $\left(\mu \mathrm{E} \cdot \mathrm{m}^{-2} \cdot \mathrm{s}^{-1}\right), a$ is the microalgal self-shading factor $\left(\mathrm{m}^{2} \cdot \mathrm{g} \mathrm{TSS}^{-1}\right)$, and $z(\mathrm{~m})$ is the distance from the surface of the reactor.

The components considered in the model are: 
$X_{A \mathrm{lg}}$, microalgal biomass, expressed in $\mathrm{mg} \mathrm{COD} \cdot \mathrm{l}^{-1}$, excluding internally accumulated polyphosphate.

$X_{P P}$, intracellular stored polyphosphate, expressed in $\mathrm{mg} P \cdot \mathrm{l}^{-1}$. It is not included in the mass of $X_{A l g} \cdot$

$X_{D e b}$, inert particulate organic material, expressed in $\mathrm{mg} \mathrm{COD} \cdot \mathrm{l}^{-1}$. Generated in the death process of microalgae, this component accumulated in the reactor during the experiment.

$S_{N H 4}$, ammonium concentration in the medium, expressed in $\mathrm{mg} \mathrm{NH} 4-\mathrm{N} \cdot \mathrm{l}^{-1}$.

The kinetic equations proposed for microalgal growth (IV.3) and death (IV.4) are:

$r=\mu \cdot X_{A \mathrm{lg}} \cdot \frac{S_{N H}}{K_{S}+S_{N H}} \cdot \frac{I}{k_{i}} \cdot \exp \left(1-\frac{I}{k_{i}}\right) \cdot\left(1-\frac{k_{X P P}{ }^{n}}{k_{X P P}{ }^{n}+\left(X_{P P} / X_{A \mathrm{lg}}\right)^{n}}\right)$

$r=b \cdot X_{A l g}$

The time evolution of all the components can be obtained from the following differential equations:

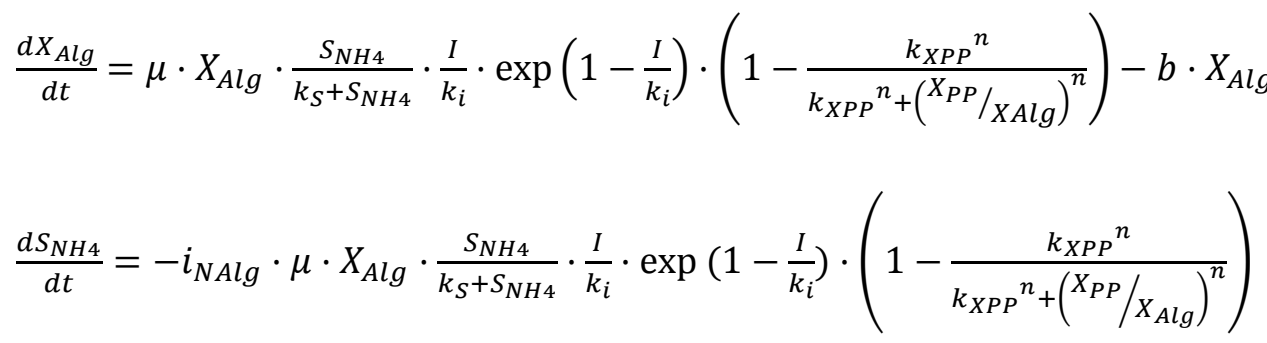

(IV.6)

$\frac{d X_{P P}}{d t}=-i_{P A l g} \cdot \mu \cdot X_{A l g} \cdot \frac{S_{N H 4}}{k_{S}+S_{N H 4}} \cdot \frac{I}{k_{i}} \cdot \exp \left(1-\frac{I}{k_{i}}\right) \cdot\left(1-\frac{k_{X P P}{ }^{n}}{k_{X P P}{ }^{n}+\left(X_{P P} / X_{A l g}\right)^{n}}\right)-b \cdot X_{P P}$

$\frac{d X_{D e b}}{d t}=b \cdot X_{A l g}$ 
Where $i_{\text {PAlg }}\left(\mathrm{g}\right.$ P.g COD $\left.^{-1}\right)$ is the phosphorus content of the microalgal structure (constitutional $\mathrm{P}$ in $\mathrm{X}_{\mathrm{Alg}}$ ), $\mathrm{i}_{\mathrm{NAlg}}\left(\mathrm{g} \mathrm{N} \cdot \mathrm{g} \mathrm{COD}^{-1}\right)$ is the nitrogen content of the microalgal structure, $\mu$ is the maximal growth rate $\left(\mathrm{h}^{-1}\right), K_{S}$ represents the halfsaturation constant for ammonium $\left(\mathrm{mg} \mathrm{N} \cdot 1^{-1}\right), k_{X P P}$ represents the ratio $X_{P P} / X_{A l g}$ that leads to a $50 \%$ reduction of the maximal growth rate $\left(\mathrm{g} \mathrm{P}_{\mathrm{g} \mathrm{COD}} \mathrm{COD}^{-1}\right), n$ is a constant from the Hill function, and $b$ is the microalgae death rate $\left(\mathrm{h}^{-1}\right)$.

\subsubsection{Model calibration}

Model parameters were determined using the Solver program in Microsoft ${ }^{\circledR}$ Excel software 2007 for minimizing the residual sum of squared errors between the two sets of experimental data (ammonium concentrations in $N \& P R$ and $N O R$ ) and the model predictions.

Initial microalgae, debris, and polyphosphate concentrations are required in order to solve the differential equations. These values can be estimated from suspended COD and TSP measurements (IV.9 and IV.10) jointly with the steady-state debris balance (IV.11) applied to the reactor where the microalgae were cultivated in semicontinuous mode.

$$
\begin{aligned}
& \text { susp.COD }=X_{D e b}+X_{A l g} \\
& T S P=X_{P P}+i_{P X A l g} \cdot X_{A l g} \\
& b \cdot X_{A l g} \cdot \theta=X_{D e b}
\end{aligned}
$$

where $\theta$ is the cellular retention time in the semicontinuous reactor where the microalgae used for inoculum were cultivated.

The corresponding boundary conditions were set in the solution procedure every time a reactor was spiked with ammonium. Polyphosphate concentration in $N \& P R$ was increased according to the observed phosphate decrease during the following 7 hours after the phosphate addition. The initial values for the model parameters were selected based on previous experience and on literature. All concentrations were calculated with a time step of 5 minutes. $i_{N A l g}$ was established at the initial nitrogen biomass composition of $9 \% \mathrm{~g} \mathrm{~N} \cdot \mathrm{g} \mathrm{COD}^{-1}$ and for $i_{P A l g}$ a value of $0.1 \% \mathrm{~g} \mathrm{P} \cdot \mathrm{g} \mathrm{COD}^{-1}$ was chosen, which is necessarily below the phosphorus 
total composition of $0.5 \% \mathrm{~g} \mathrm{P} \cdot \mathrm{g} \mathrm{COD}^{-1}$ at the end of the experiment and accounts only for structural phosphorus and not polyphosphate. Figures IV.3a and IV.3b show the model predictions for ammonium concentration and the experimental values along the experiment for $N O R$ and $N \& P R$, respectively. The obtained parameters, shown in table IV.3, accurately reproduce the experimental data in both reactors, as shown in figure IV.4, where predicted values are plotted against their analytical values with a Pearson correlation coefficient of $r=$ 0.952 (P-value < 0.01, statistical analysis carried out using SPSS 16.1).

Table IV.3: Obtained parameters

\begin{tabular}{ccc}
\hline Parameter & Units & $\begin{array}{c}\text { Obtained } \\
\text { value }\end{array}$ \\
\hline$\mu$ & $\mathrm{h}^{-1}$ & 0.042 \\
\hline$k_{S}$ & $-\mathrm{mg} \mathrm{N} \cdot \mathrm{l}^{-1}$ & 12 \\
\hline$n$ & $\mathrm{mg} \mathrm{P} \cdot \mathrm{mg} \mathrm{COD}^{-1}$ & 0.027 \\
\hline$K_{X P P}$ & $\mu E \cdot m^{2} \cdot s^{-1}$ & 200 \\
\hline$k_{I}$ & $\mathrm{~h}^{-1}$ & 0.0005 \\
\hline$a$ & $\mathrm{~m}^{2} \cdot \mathrm{g} \mathrm{TSS}^{-1}$ & 0.03 \\
\hline
\end{tabular}

For further model validation, a set of data from a shorter but analogous experiment was used. The experiment consisted of an identical reactor where the same procedure as in $N \& P R$ was followed, with the difference that phosphate was added to the medium after 7 days and the experiment was stopped after 18 days. Moreover, phosphorus was added at a higher concentration of $37 \mathrm{mg} \mathrm{P} \cdot 1^{-1}$ (figure IV.5). Biomass, ammonium and phosphate were characterized as described in section 2.4 in this work. The parameters shown in table IV.3 were introduced in the model to obtain the corresponding predicted values, which are shown in figure IV.5, and also plotted versus their analytical values in figure VI.4. The obtained 
accuracy $(r=0.97, \mathrm{P}$-value $<0.01)$ confirms the suitability of the model and the determined parameters.

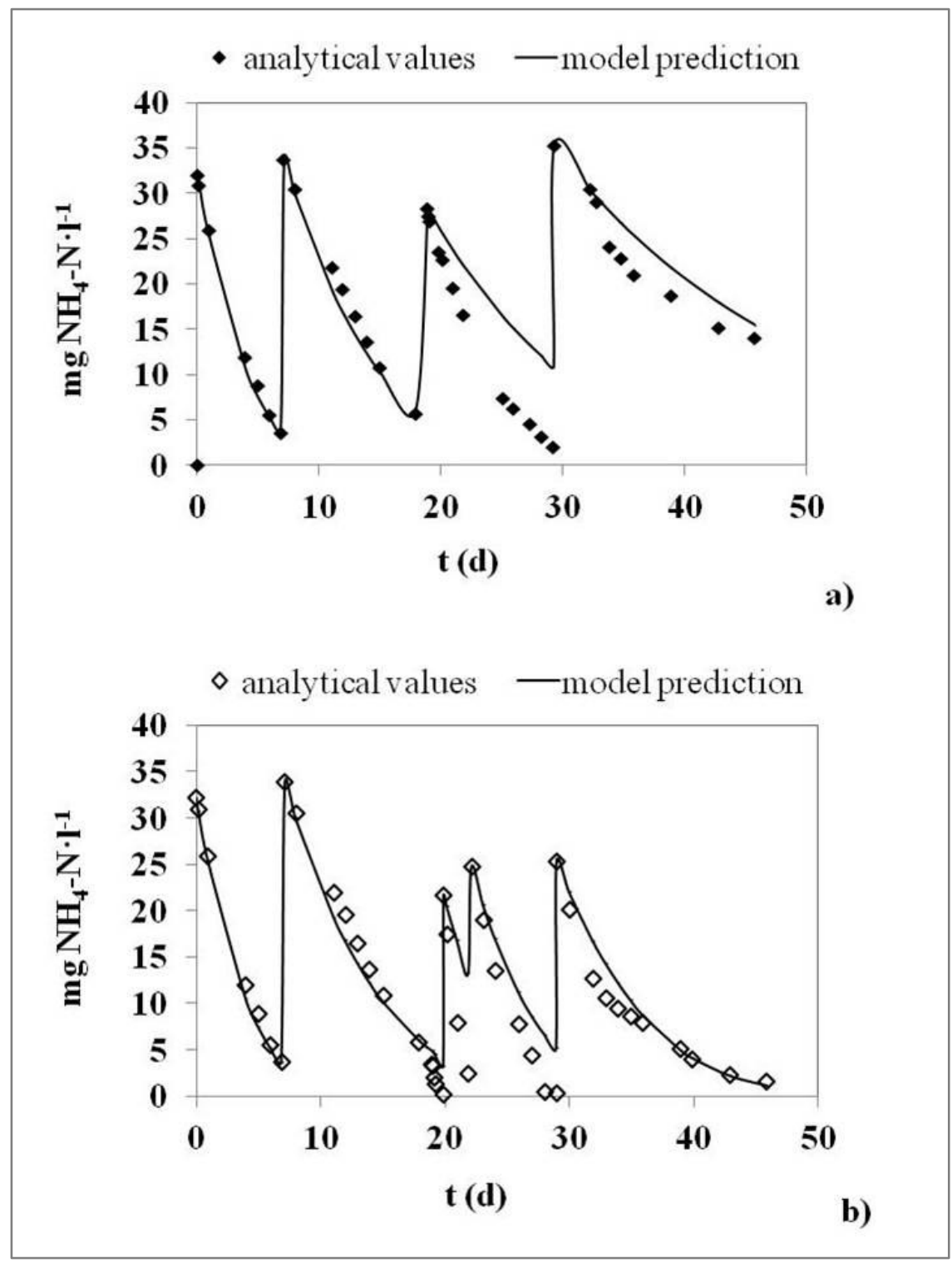

Figure IV.3: Time evolution of ammonium concentration in a) NOR and b) $N \& P R$, along with model predictions.

One of the most important effects of the higher concentration of added phosphate was that $\mathrm{X}_{\mathrm{PP}} / \mathrm{X}_{\mathrm{Alg}}$ ratio reached a maximum of $4 \% \mathrm{mg} \mathrm{P} \cdot \mathrm{mg} \mathrm{TSS}^{-1}$. The simulation shows that from day 12 of the experiment biomass $\mathrm{P}$ content stayed stable around $3 \% \mathrm{mg} \mathrm{P} \cdot \mathrm{mg} \mathrm{TSS}^{-1}$, since ammonium was not available for growth. The high internal phosphorus concentration 
achieved might be the reason why remaining phosphate in the medium was not taken up by the microalgae during this period, as can be seen in figure IV.5.

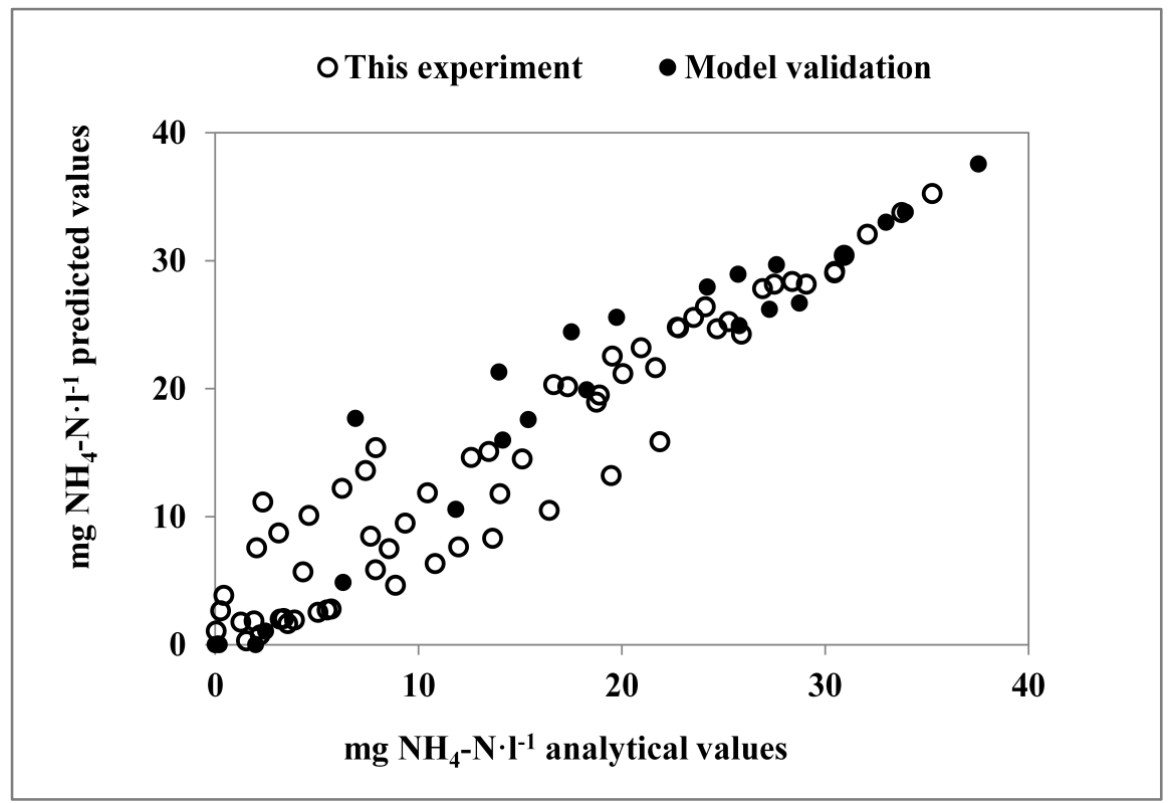

Figure IV.4: Predicted values plotted against their corresponding analytical values. Empty dots correspond to this experiment for model calibration and full dots correspond to data from previous experiment for model validation.

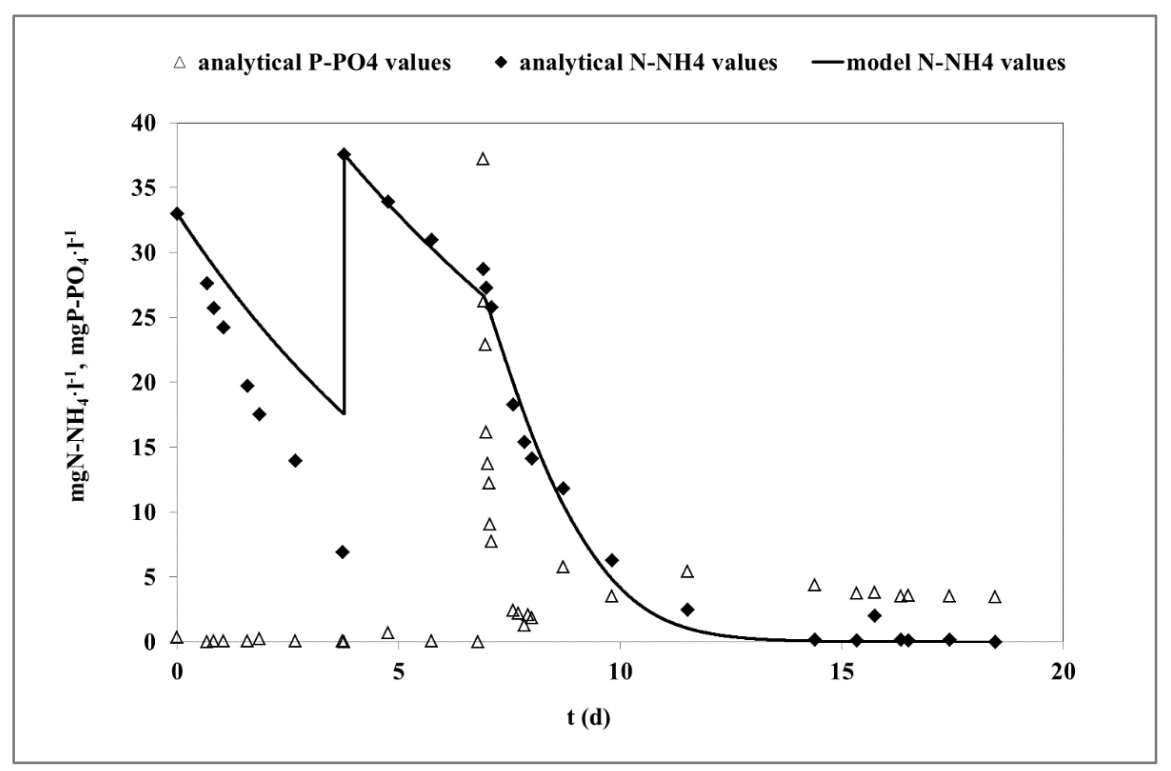

Figure IV.5: Time evolution of ammonium and phosphate concentrations in the model validation dataset, along with model predictions.

The values obtained for $\mu$ and $k_{S}$ are comparable to those obtained by Bougaran et al. (2010). These authors fit ammonium uptake by Scenedesmus sp. LX1 using a Monod equation and 
obtained values between $0.005-0.025 \mathrm{~h}^{-1}$ for $\mu$ and $4.5-13.3 \mathrm{mg} \mathrm{N} \cdot \mathrm{l}^{-1}$ for $k_{S}$. The obtained value for $k_{X P P}$ is in complete accordance with the observations made. Literature $k_{i}$ values vary in a wide range between 20 and $500 \mathrm{~W} \cdot \mathrm{m}^{-2}$ (Broekhuizen et al., 2012 and Reichert et al., 2001, respectively), in which our $200 \mu \mathrm{mol} \cdot \mathrm{m}^{2} \cdot \mathrm{s}^{-1}$ would be included. The selfshading factor, $a$, also varies in a wide range in literature. Similar values to ours are used in Quinn et al. (2011) and Ketheesan and Nirmalakhandan (2013). The value obtained in this study for microalgae death rate $\left(b=0.002 \mathrm{~h}^{-1}\right)$ compares with literature values ranging from $0.0008 \mathrm{~h}^{-1}$ Barbosa et al. (2004) to $0.0058 \mathrm{~h}^{-1}$ Centeno da Rosa et al. (2011).

Table IV.4: Measured COD values. Predicted total COD, $X_{A l g}$ and $X_{D e b}$ values

\begin{tabular}{ccccc}
\hline Time (d) & $\begin{array}{c}\text { Measured } \\
\text { Susp COD } \\
\left(\mathbf{m g} \cdot \mathbf{l}^{-1}\right)\end{array}$ & $\begin{array}{c}\text { Predicted } \\
\text { Susp COD } \\
\left(\mathbf{m g} \cdot \mathbf{I}^{-1}\right)\end{array}$ & $\boldsymbol{X}_{\text {Alg }}$ & $\boldsymbol{X}_{\text {Deb }}$ \\
\hline 0 & 517 & 517 & 434 & 83 \\
\hline 19 & & & & \\
\hline (initial reactor $)$ & 1176 & 1132 & 535 & 596 \\
\hline $46($ NOR $)$ & 1880 & 1554 & 357 & 1196 \\
\hline $46($ N\&PR $)$ & 2320 & 1624 & 412 & 1212 \\
\hline
\end{tabular}

Measured and predicted COD values are shown in table IV.4, together with predicted $X_{A l g}$ and $X_{D e b}$. The predictions of the COD values for initial reactor are in very good accordance with measured values. For NOR and N\&PR the model underestimates COD. Because of the higher mean analytical error in COD measurements, the model has been calibrated to minimize the error in the response for ammonium concentration. The parameters obtained are those which allow the best prediction of ammonium concentration and not of suspended COD values. On the other hand, the assumption of a constant microalgal $\mathrm{N}$ composition (set to its initial measured value of $9 \%$ ) is a simplification of reality. With a different and/or varying microalgal $\mathrm{N}$ content, predicted COD values would have been certainly different. Including a 
variable microalgae $\mathrm{N}$ content according to factors such as $\mathrm{N}$ stress, etc., might be the way for improving a model of this kind. This was, however, out of the scope of this paper.

\section{Conclusions}

Microalgal growth and ammonium removal in the absence of phosphorus were studied in two mixed cultures of autochthonous microalgae. The results showed that microalgal growth and phosphorus uptake are independent processes. It was also proved that ammonium removal rate depends on the amount of phosphorus internally stored. The proposed microalgal growth model, which includes a Monod term for the effect of ammonium concentration, the Hill function for the effect of the stored polyphosphate concentration and the Steele function for light influence, accurately reproduced the experimental data. Further research should make use of these results for the development of nutrient removal strategies using microalgal cultures.

\section{Acknowledgments}

This research work has been supported by the Spanish Ministry of Economy and Competitiveness (MINECO, Projects CTM2011-28595-C02-01 and CTM2011-28595-C0202) jointly with the European Regional Development Fund (ERDF). They are both gratefully acknowledged. This research was also supported by the Spanish Ministry of Education, Culture and Sport via a pre doctoral FPU fellowship to the first author (AP2009-4903). The authors would also like to thank the water management entities of the Generalitat Valenciana (EPSAR).

\section{References}

APHA, AWWA and WEF (2005) Standard Methods for the Examination of Waters and Wastewaters, 21 st ed. American Public Health Association, Washington, DC.

Aravantinou, A.F., Theodorakopoulos, M.A., Manariotis, I.D. (2013) Selection of microalgae for wastewater treatment and potential lipids production. Bioresource Technology 147, 130-134.

Arbib, Z., Ruiz, J., Álvarez-Diaz, P., Garrido-Pérez, C., Perales, J. A. (2014) Capability of different microalgae species for phytoremediation processes: wastewater tertiary treatment, $\mathrm{CO}_{2}$ bio-fixation and low cost biofuels production. Water Research 49, 465-474. 
Aslan, S., Kapdan, I.K. (2006) Batch kinetics of nitrogen and phosphorus removal from synthetic wastewater by algae. Ecological Engineering 28, 64-70.

Barbosa, M.J., Hadiyanto, H., Wijffels, R.H. (2004) Overcoming shear stress of microalgae cultures in sparged photobioreactors. Biotechnology and Bioengineering 85(1), 78-85.

Bougaran, G., Bernard, O., Sciandra, A. (2010) Modeling continuous cultures of microalgae colimited by nitrogen and phosphorus. Journal of Theoretical Biology 265, 443-454.

Broekhuizen, N., Park, J. B. K., McBride, G. B., Craggs, R. J. (2012) Modification, calibration and verification of the IWA River Water Quality Model to simulate a pilot-scale high rate algal pond. Water Research 46 (9) 2911-2926.

Centeno da Rosa, A.P., Fernandes Carvalho, L., Goldbeck, L., Vieira Costa, J.A. (2011) Carbon dioxide fixation by microalgae cultivated in open bioreactors. Energy Convers. Manag. 52, 3071-3073.

Christenson, L., Sims, R. (2011) Production and harvesting of microalgae for wastewater treatment, biofuels, and bioproducts. Biotechnology Advances 29 (6), 686-702.

Fernández, I., García-Acién, F.G., Fernández, J.M., Guzmán, J.L., Magán, J.J., Berenguel, M. (2012) Dynamic model of microalgal production in tubular photobioreactors. Bioresource Technology 126, 172-181.

Geider, R.J., MacIntiyre, H.L., Kana, T.M. (1997) Dynamic model of phytoplankton growth and acclimation: responses of the balanced growth rate and the chlorophyll a:carbon ratio to light, nutrient-limitation and temperature. Marine Ecology Progress Series 148, 187-200.

Geider. R.J., MacIntiyre, H.L., Kana, T.M. (1998) A dynamic regulatory model of phytoplanktonic acclimation to light, nutrients, and temperature. Limnology and Oceanography, 43(4), 679-694.

Giménez, J.B., Robles, A., Carretero, L., Durán, F., Ruano, M.V., Gatti, M.N., Ribes, J., Ferrer, J., Seco, A. (2011) Experimental study of the anaerobic urban wastewater treatment in a submerged hollow-fibre membrane bioreactor at pilot scale. Bioresource Technology 102, 8799-8806.

Jansson, M. (1993) Uptake, exchange, and excretion of orthophosphate in phosphate-starved Scenedesmus quadricauda and Pseudomonas K7. Limnology and Oceanography 38(6), 1162-1178.

Ketheesan, B., Nirmalakhandan, N. (2013) Modeling microalgal growth in an airlift-driven raceway reactor. Bioresource Technology 136, 689-696.

Kliphuis, A.M.J., Klok, A.J., Martens, D.E., Lamers, P.P, Janssen, M., Wijffels, R.H. (2011) Metabolic modeling of Chlamydomonas reinhardtii: energy requirements for photoautotrophic growth and maintenance. Journal of Applied Phycology 24(2), 253-266.

Li, J., Ozgun, H., Ersahin, M. (2011) Procedure of SMA test. Section of Sanitary Engineering, Delft University of Technology.

Mairet, F., Bernard, O., Masci, P., Lacour, T., Sciandra, A. (2011) Modelling neutral lipid production by the microalga Isochrysis aff. galbana under nitrogen limitation. Bioresource Technology 102, 142-149.

Markou, G. (2012) Alteration of the biomass composition of Arthrospira (Spirulina) platensis under various amounts of limited phosphorus. Bioresource Technology 116, 533-535. 
Nishikawa, K., Machida, H., Yamakoshi, Y., Ohtomo, R., Saito, K., Tominaga, N. (2006) Polyphosphate metabolism in an acidophilic alga Chlamydomonas acidophila KT-1 (Chlorophyta) under phosphate stress. Plant Science 170, 307-313.

Pittman, J. K., Dean, A. P., Osundeko, O. (2011) The potential of sustainable algal biofuel production using wastewater resources. Bioresource Technology 102, 17-25.

Powell, N., Shilton, A., Chisti, Y., Pratt, S. (2009) Towards a luxury uptake process via microalgae - Defining the polyphosphate dynamics. Water Research 43, 4207-4213.

Quinn, J., de Winter, L., Bradley, T. (2011) Microalgae bulk growth model with application to industrial scale systems. Bioresource Technology 102, 5083-5092.

Ramos Tercero, E.A., Sforza, E., Morandini, M., Bertucco, A. (2014) Cultivation of Chlorella protothecoides with urban wastewater in continuous photobioreactor: Biomass productivity and nutrient removal. Applied Biochemistry and Biotechnology 172, 1470-1485.

Redfield, A. (1958) The biological control of chemical factors in the environment. American Scientist 46, $205-$ 221.

Reichert, P., Borchardt, D., Henze, M., Rauch, W., Shanahan, P., Somlyódy, L., Vanrolleghem, P. (2001) River Water Quality Model no. 1 (RWQM1):II. Biochemical process equations. Water Science and Technology 43 (5) 11-30.

Reynolds, C. S. (2006) The ecology of phytoplankton, Cambridge University Press, New York.

Ruiz-Martinez, A., Martin Garcia, N., Romero, I., Seco, A., Ferrer, J. (2012) Microalgae cultivation in wastewater: Nutrient removal from anaerobic membrane bioreactor effluent. Bioresource Technology 126, $247-$ 253.

Singh, A., Pant, D., Olsen, S.I., Nigam, P.S. (2012) Key issues to consider in microalgae based biodiesel production. Energy Education Science and Technology Part A: Energy Science and Research 29(1), 563-576

Wu, Y.H., Yu, Y., Hu, H.Y. (2013a) Potential biomass yield per phosphorus and lipid accumulation property of seven microalgal species. Bioresource Technology 130, 599-602.

Wu, Y.H., Li, X., Yu, Y., Hu, H.Y., Zhang, T.Y., Li, F.M. (2013b) An integrated microalgal growth model and its application to optimize the biomass production of Scenedesmus sp. LX1 in open pond under the nutrient level of domestic secondary effluent. Bioresource Technology 144, 445-451. 



\title{
Chapter V
}

\section{Effect of intracellular $P$ content on phosphate removal in Scenedesmus sp. Experimental study and kinetic expression}

Ruiz-Martinez, A., Serralta, J., Romero, I., Seco, A., Ferrer, J. (2015) Effect of intracellular P content on phosphate removal in Scenedesmus sp. Experimental study and kinetic expression. Bioresource Technology 175, 325-332.

\begin{abstract}
The present work determines the effect of phosphorus content on phosphate uptake rate in a mixed culture of Chlorophyceae in which the genus Scenedesmus dominates. Phosphate uptake rate was determined in eighteen laboratory batch experiments, with samples taken from a progressively more P-starved culture in which a minimum $\mathrm{P}$ content of $0.11 \%(\mathrm{w} / \mathrm{w})$ was achieved. The results obtained showed that the higher the internal biomass $\mathrm{P}$ content, the lower the phosphate removal rate. The highest specific phosphate removal rate was $6.5 \mathrm{mg}$ $\mathrm{PO}_{4}-\mathrm{P} \cdot \mathrm{g} \mathrm{TSS}{ }^{-1} \cdot \mathrm{h}^{-1}$. Microalgae with a $\mathrm{P}$ content around $1 \%(\mathrm{w} / \mathrm{w})$ attained $10 \%$ of this highest removal rate, whereas those with a $\mathrm{P}$ content of $0.6 \%(\mathrm{w} / \mathrm{w})$ presented $50 \%$ of the maximum removal rate. Different kinetic expressions were used to reproduce the experimental data. Best simulation results for the phosphate uptake process were obtained combining the Steele equation and the Hill function to represent the effect of light and intracellular phosphorus content, respectively.
\end{abstract}





\section{Introduction}

Large amounts of phosphate are one of the causes of eutrophication in aquatic environments, together with other inorganic nutrients like ammonium, nitrite or nitrate. Several treatments for phosphate removal from wastewater can be applied, such as chemical precipitation or biological phosphorus removal by means of polyphosphate accumulating organisms and other bacteria present in activated sludge systems. However, in the last decades, the use of microalgae for inorganic pollutant removal has raised increasing attention.

Microalgae are photosynthetic microorganisms which use light energy and $\mathrm{CO}_{2}$ for growth, and whose ability to remove inorganic nutrients from different wastewaters has been widely reported (De Alva et al., 2013, Gentili, 2014, Ruiz-Marin et al., 2010, Samorí et al., 2013, Van den Ende et al., 2014). On the other hand, microalgae are a renewable energy source, since they can be transformed into biogas, biodiesel, biocrude, biohydrogen and others (Razzak et al., 2013). Additionally, the recovery of inorganic nutrients from wastewaters in an organic form converts microalgae also into valuable fertilizers. The combination of these advantages makes microalgae an attractive option for wastewater treatment.

Phosphorus is an essential component in microalgae: according to the Redfield ratio it represents the $0.87 \%$ of its dry weight (Redfield, 1958). However, in practice, microalgal $\mathrm{P}$ content varies, due to diverse mechanisms of adaptation to the medium. Reynolds (2006) estimated the minimum phosphorus cell quota to be around $0.2-0.4 \%$ of ash-free biomass, although some species show a minimum value which is an order of magnitude smaller. In fact, Wu et al. (2013) determined a minimal P content or subsistence quota of $0.016 \%$ by fitting real data to a growth model for Scenedesmus sp. LX1.

Minimal intracellular phosphorus concentrations are achieved when microalgae grow under Pstarving conditions, as in the work by Markou (2012), who measured a minimum of $0.185 \%$. On the other hand, when luxury phosphorus uptake takes place, microalgal $\mathrm{P}$ content can raise up to values like $3.85 \%$ as measured by Powell et al. (2009). The main phosphorus storage bodies in microalgae are polyphosphates, which are unbranched chains of $\mathrm{PO}_{4}{ }^{-}$groups linked together by oxygen bridges. The amount of polyphosphate present in the cells depends on 
different factors, such as the available phosphate in the medium, light or temperature (Powell et al., 2008).

In the wastewater treatment field, mathematical models constitute useful tools for process and equipment design, WWTP construction and upgrade or water quality prediction. It is thus essential to have available models that describe in quantitative terms the observed microalgal behavior in the context of nutrient removal.

Most models found in literature for phosphate uptake from the medium use Michaelis-Menten kinetics (equation V.1):

$\frac{d S_{P O 4}}{d t}=\left(\frac{d S_{P O 4}}{d t}\right)_{\max } \cdot \frac{S_{P O 4}}{k_{S}+S_{P O 4}}$

where $S_{P O 4}\left(\mathrm{mg} \mathrm{PO}_{4}-\mathrm{P} \cdot \mathrm{l}^{-1}\right)$ represents phosphate concentration in the medium and $k_{S}\left(\mathrm{mg} \mathrm{PO}_{4^{-}}\right.$ $\left.\mathrm{P} \cdot \mathrm{l}^{-1}\right)$ is the halfsaturation constant for phosphate uptake. However, this model cannot reproduce the observed phenomenon of enhanced phosphate uptake rate due to internal phosphorus deficiency. Michaelis-Menten uptake kinetics is often combined with Droop equation for growth rate (Bougaran et al., 2010, Kwon et al., 2013):

$\mu=\mu_{\max } \cdot\left(1-\frac{q_{\min }}{q}\right)$

Where $\mu_{\max }\left(\mathrm{d}^{-1}\right)$ is the maximum specific growth rate, $q\left(\mathrm{mg} \mathrm{P} \cdot \mathrm{g} \mathrm{TSS}{ }^{-1}\right)$ is the internal microalgae $\mathrm{P}$ content (quota) and $q_{\min }\left(\mathrm{mg} \mathrm{P} \cdot \mathrm{g} \mathrm{TSS}^{-1}\right)$ is the minimum internal nutrient quota for microalgal growth.

However, in these models the internal cell quota does not affect phosphate uptake rate. Some authors have developed model extensions to take into account the influence of internal phosphorus content in the maximum phosphate uptake rate:

Klausmeier and Litchman (2004) defined the maximum phosphate uptake rate as a function of the cells internal P quota with the following term (V.3):

$\left(\frac{d S_{P O 4}}{d t}\right)_{\max }=\frac{\overline{\left(\frac{d S_{P O 4}}{d t}\right)_{\max }} \cdot k_{i n h}-c \cdot\left(q-q_{\min }\right)}{q-q_{\min }+k_{i n h}}$ 
Where $k_{\text {inh }}$ (mg P.mg $\mathrm{TSS}^{-1}$ ) and $c$ (dimensionless) are parameters to model the uptake inhibition.

Bougaran et al. (2010) used equation V.4 for modeling the down-regulation in the uptake rate of an external nutrient by its own internal quota:

$\frac{d S_{P O 4}}{d t}=\left(\frac{d S_{P O 4}}{d t}\right)_{\max } \cdot \frac{q_{\max }-q}{q_{\max }-q_{\min }}$

where $q_{\max }\left(\mathrm{mg} \mathrm{P} \cdot \mathrm{mg} \mathrm{TSS}^{-1}\right)$ represents the hypothetical maximum value for P quota.

Other authors have proposed more complex models for phosphate assimilation: John and Flynn (2000) included 3 phosphorus pools within the cell, and Yao et al. (2011) took into account surface adsorption and desorption, together with the P-pool size and P stress level. The measurements needed for the calibration of these models are also of increased complexity.

It is the aim of this work to study the influence of the intracellular P content on the phosphate uptake rate from the medium and to evaluate different kinetic expressions to find the best one for predicting phosphate removal rates at different biomass compositions.

To this aim, algae adapted to grow in P-sufficient medium were progressively deprived from phosphorus, so that the cells P content gradually decreased. Different samples from the resulting culture were used to seed 18 different batch experiments where phosphate was added and its removal rate was measured. Equations found in literature were used to fit the obtained data with moderately good results. A new expression was developed which improved for the present culture of Scenedesmus sp. the accuracy of model predictions. Light influence was also taken into account in all cases.

\section{Materials and methods}

\subsection{Microorganisms}

Microalgae were isolated from the walls of the secondary clarifier in the "Cuenca del Carraixet" WWTP (Valencia, Spain) and maintained in a 71 laboratory semicontinuous reactor using the effluent of a submerged anaerobic membrane bioreactor (SAnMBR, 
described in Giménez et al., 2011) as growth medium. This effluent displays a variable N:P ratio and has proved to sustain algal growth (Ruiz-Martinez et al., 2012 (Chapter III)). The biomass in the laboratory reactor formed a stable ecosystem where the dominant microalgae belonged to the Chloroccocal order, of which $>99 \%$ to the Scenedesmus genus.

\subsection{Experimental setup and operation}

\subsubsection{Semicontinuous reactor}

The 71 laboratory reactor consisted of a cylindrical methacrylate tank, which was kept at a constant temperature of $28^{\circ} \mathrm{C}$ and under continuous illumination of $156 \pm 17 \mu \mathrm{E} \cdot \mathrm{m}^{-2} \cdot \mathrm{s}^{-1} \cdot \mathrm{pH}$ was regulated at 7.5 with pure $\mathrm{CO}_{2}$ injections (for a more detailed reactor description see Ruiz-Martinez et al., 2014 (Chapter IV)). Cellular retention time was 4 days. During the study, an artificial P-free medium was used for microalgae growth instead of the one described in section 2.1, which had been previously used for culture maintenance. Thus, the internal microalgae $\mathrm{P}$ content started to decrease, since the culture was not supplied with any phosphorus during the whole study, which lasted 45 days. One liter of the artificial medium was composed of $135 \mathrm{mg}\left(\mathrm{NH}_{4}\right)_{2} \mathrm{SO}_{4}, 150 \mathrm{mg} \mathrm{CaCO}, 400 \mathrm{mg} \mathrm{CaCl} \cdot \mathrm{H}_{2} \mathrm{O}, 400 \mathrm{mg}$ $\mathrm{Na}_{2} \mathrm{SeO}_{3} .5 \mathrm{H}_{2} \mathrm{O}, 350 \mathrm{mg} \mathrm{MgSO}_{4} .7 \mathrm{H}_{2} \mathrm{O}, 54 \mathrm{mg}\left(\mathrm{NH}_{4}\right)_{6} \mathrm{Mo}_{7} \mathrm{O}_{2} .4 \mathrm{H}_{2} \mathrm{O}, 30 \mathrm{mg} \mathrm{ZnCl}, 30 \mathrm{mg}$ $\mathrm{HBO}_{3}, 30 \mathrm{mg} \mathrm{NiCl} 2 \cdot 6 \mathrm{H}_{2} \mathrm{O}, 18 \mathrm{mg} \mathrm{CuCl} \cdot 2 \mathrm{H}_{2} \mathrm{O}, 12 \mathrm{mg} \mathrm{K} \mathrm{SO}_{4}, 1.2 \mathrm{mg} \mathrm{FeCl} \cdot 4 \mathrm{H}_{2} \mathrm{O}, 1.2 \mathrm{mg}$ $\mathrm{CoCl}_{2} \cdot 6 \mathrm{H} 2 \mathrm{O}, 0.6 \mathrm{mg}$ EDTA and $0.3 \mathrm{mg} \mathrm{MnCl}_{2} \cdot 4 \mathrm{H}_{2} \mathrm{O}$.

\subsubsection{Batch reactor}

The batch experiments were carried out in a 21 cylindrical glass reactor equipped with electronic sensors in order to obtain on-line temperature and $\mathrm{pH}$ measurements. The reactors were placed inside a climatic chamber with air temperature control set to $20{ }^{\circ} \mathrm{C}$. Due to the constant illumination the temperature reached $28{ }^{\circ} \mathrm{C}$. The probes were connected to a multiparametric analyzer (CONSORT C832, Belgium), which was in turn connected to a PC for data monitoring and storage. Data sampling was conducted every $60 \mathrm{~s}$. A fine bubble diffuser was mounted at the bottom of each reactor in order to mix the algal culture by injecting compressed air. Eight vertical fluorescent lamps (Sylvania Grolux, 18 W) 
continuously illuminated the reactor from a distance of $8 \mathrm{~cm}$ from all sides. Photosynthetically active radiation $(\mathrm{PAR})$ of $180 \pm 21 \mu \mathrm{E} \cdot \mathrm{m}^{-2} \cdot \mathrm{s}^{-1}$ was measured at the reactor surface.

\subsection{Batch experiments}

Different samples taken from the semicontinuous reactor were used to seed 18 batch experiments along the experimental period of 45 days. Each batch experiment started with the transfer of 1.91 of the culture from the semicontinuous reactor into the batch reactor. Phosphate in the form of $\mathrm{KH}_{2} \mathrm{PO}_{4}$ was then supplied, and phosphate concentration in the medium was regularly measured in order to determine its uptake rate. Additionally, nitrite, nitrate and ammonium concentrations were also determined, as well as total suspended solids (TSS), volatile suspended solids (VSS) and total phosphorus concentration. The batch experiments lasted between 4 and 26 hours, according to the observed phosphate uptake rate. To avoid phosphate precipitation and free ammonia stripping, $\mathrm{pH}$ value in all the experiments was maintained around 7.5 by pure $(99.9 \%) \mathrm{CO}_{2}$ injection from a pressurized cylinder.

\subsection{Analytical Methods}

Nutrient removal was evaluated by measuring inorganic nitrogen and phosphate levels in the samples taken from the reactors. Ammonium $\left(\mathrm{NH}_{4}-\mathrm{N}\right)$, nitrite $\left(\mathrm{NO}_{2}-\mathrm{N}\right)$, nitrate $\left(\mathrm{NO}_{3}-\mathrm{N}\right)$ and phosphate $\left(\mathrm{PO}_{4}-\mathrm{P}\right)$ were determined according to Standard Methods (APHA, 2005) (4500NH3-G, 4500-NO2-B, 4500-NO3-H, and 4500-P-F respectively) in a Smartchem 200 automatic analyzer (Westco Scientific Instruments, Westco).

The acid peroxodisulphate digestion method (APHA, 2005) was used for total phosphorus (TP) measurements. The phosphorus in the algae biomass (total suspended phosphorus, TSP) was calculated as the difference between total phosphorus and orthophosphate concentration. TSS and VSS were determined according to Standard Methods (APHA, 2005). All reported results were obtained from the previous analyses conducted in duplicate. 


\section{Results and discussion}

\subsection{Biological phosphate removal}

The $\mathrm{pH}$ control system was activated in all the experiments immediately after seeding, which means that $\mathrm{CO}_{2}$ was automatically injected whenever $\mathrm{pH}$ value exceeded 7.5. This $\mathrm{pH}$ control assured that neither free ammonia stripping nor inorganic salts precipitation took place. Thus, all conclusions drawn from this study are based on the assumption that ammonium and phosphate removal are solely due to biological uptake.

Phosphate was added into each batch culture after seeding, and the first sample was taken after mixing (ca. $20 \mathrm{~s}$ ). Initial phosphate values reached $18 \pm 1.3 \mathrm{mg} \mathrm{PO}_{4}-\mathrm{P} \cdot \mathrm{l}^{-1}$ in all cases. Table V.1 shows the initial biomass P content and TSS concentration for each batch experiment.

The initial biomass $\mathrm{P}$ content in the batch experiments show a general decreasing trend since the microalgae used in each experiment were taken from the culture in the semicontinuous reactor, fed with a P-free medium (table V.1). The study was prolonged until the analytical value for biomass $\mathrm{P}$ content went below $0.2 \%$, as this is, according to Reynolds 2006, a general minimum $\mathrm{P}$ content value for cell survival. The lowest $\mathrm{P}$ content that the microalgae in the culture finally reached was $0.11 \%$. The polyphosphate concentration in the microalgae at this stage was assumed to be almost nonexistent, and $\mathrm{P}$ content was assumed to be almost completely structural phosphorus.

The initial total suspended solids in the last six batch experiments is clearly higher than in the others (table V.1), due to a period of 10 days (between batch experiments number 12 and 13) when no purge was extracted from the reactor. This procedure caused an increase in the TSS of the culture, which allowed the study of the phosphate uptake rate over a wider range of initial biomass concentration. Data from a wider range of TSS was used to take into account the selfshading effect of the microalgae in the kinetic expression proposed. Variable TSS concentration makes the available light for photosynthesis variable even at constant external illumination rates. 
Table V.1: Initial \%P for each batch, together with the measured initial biomass concentration

\begin{tabular}{|c|c|c|c|}
\hline $\begin{array}{c}\text { Batch } \\
\text { experiment } \\
\text { number }\end{array}$ & $\begin{array}{c}\text { Day of } \\
\text { experiment }\end{array}$ & $\begin{array}{l}\text { Initial \%P(mg } \\
\left.\text { P.mg TSS }{ }^{-1}\right)\end{array}$ & $\begin{array}{l}\text { Initial TSS } \\
\left(\mathrm{mg} \mathrm{TSS} \cdot \mathbf{I}^{-1}\right)\end{array}$ \\
\hline 1 & 1 & $1.47 \%$ & 486 \\
\hline 2 & 2 & $1.25 \%$ & 421 \\
\hline 3 & 3 & $1.04 \%$ & 360 \\
\hline 4 & 7 & $0.90 \%$ & 358 \\
\hline 5 & 8 & $0.95 \%$ & 414 \\
\hline 6 & 9 & $1.29 \%$ & 357 \\
\hline 7 & 11 & $0.36 \%$ & 285 \\
\hline 8 & 14 & $0.51 \%$ & 264 \\
\hline 9 & 15 & $0.53 \%$ & 262 \\
\hline 10 & 17 & $0.76 \%$ & 398 \\
\hline 11 & 18 & $0.53 \%$ & 321 \\
\hline 12 & 19 & $0.26 \%$ & 229 \\
\hline 13 & 29 & $0.49 \%$ & 552 \\
\hline 14 & 30 & $0.57 \%$ & 424 \\
\hline 15 & 34 & $0.30 \%$ & 552 \\
\hline 16 & 35 & $0.26 \%$ & 500 \\
\hline 17 & 41 & $0.18 \%$ & 655 \\
\hline 18 & 45 & $0.11 \%$ & 566 \\
\hline
\end{tabular}


Figure V.1 shows the phosphate concentration evolution in the medium for the 18 batch experiments. It can be observed that phosphate concentrations can be fitted to a straight line in all cases, being the slope of this line the phosphate removal rate $\left(\mathrm{mg} \mathrm{PO} 4-\mathrm{P} \cdot \mathrm{l}^{-1} \cdot \mathrm{h}^{-1}\right)$. It can be observed, for all batch experiments, that during the first hours after phosphate addition its uptake rate is constant.

Since the lowest phosphate concentration reached was $8 \mathrm{mg} \mathrm{P} \cdot \mathrm{l}^{-1}$ (at the end of batch experiment 17) it can be stated that phosphate removal rate is constant for phosphate values between 8 and $18 \mathrm{mg} \mathrm{P} \cdot \mathrm{l}^{-1}$. This fact indicates that, should a Michaelis-Menten kinetics be applied to model the influence of phosphate concentration in the medium on phosphate uptake rate, the halfsaturation constant used would be in any case well below $8 \mathrm{mg} \mathrm{P} \cdot 1^{-1}$. On the other hand, high phosphate concentration in the medium at the end of all batch experiments indicates that no phosphorus limitation occurred at any point of the experiment.

The smallest phosphate uptake rates were measured in the first batch experiments, when microalgae P content presented the highest values (figure V.1). The majority of literature values on microalgal phosphate uptake rate under balanced conditions are similar or lower than the values obtained for these first experiments: Dickinson et al. (2013) reported a phosphate uptake rate of $0.104 \mathrm{mg} \mathrm{PO}_{4}-\mathrm{P} \cdot \mathrm{l}^{-1} \cdot \mathrm{h}^{-1}$ for Scenedesmus sp., Aravantinou et al. (2013) reported for Chlorococcum a value of $0.0475 \mathrm{mg} \mathrm{PO} \mathrm{PO}_{4}-\mathrm{P} \cdot \mathrm{l}^{-1} \cdot \mathrm{h}^{-1}$, and Aslan and Kapdan (2006) reported a value of $0.083 \mathrm{mg} \mathrm{PO}_{4}-\mathrm{P} \cdot \mathrm{l}^{-1} \cdot \mathrm{h}^{-1}$ for Chlorella $\mathrm{sp}$.

In contrast, phosphate uptake rates for the last batch experiments (with P-starved cells) reach much higher values than those observed in the first batch experiments, reaching a maximum of $2.9 \mathrm{mg} \cdot \mathrm{l}^{-1} \cdot \mathrm{h}^{-1}$. This value is not far from the one obtained in a previous work (RuizMartinez et al., 2014 (Chapter IV)), where a phosphate uptake rate of $2 \mathrm{mg} \mathrm{PO}_{4}-\mathrm{P} \cdot \mathrm{l} \cdot \mathrm{h}^{-1}$ was achieved.

Figure V.1: a-h) Phosphate concentration in the medium during the batch experiments. Initial values can be fitted to a straight line in all cases, being the slope of this line the phosphate removal rate $\left(\mathrm{mg} \mathrm{PO}_{4}-\mathrm{P} \cdot 1^{-1} \cdot \mathrm{h}^{-1}\right)$. 


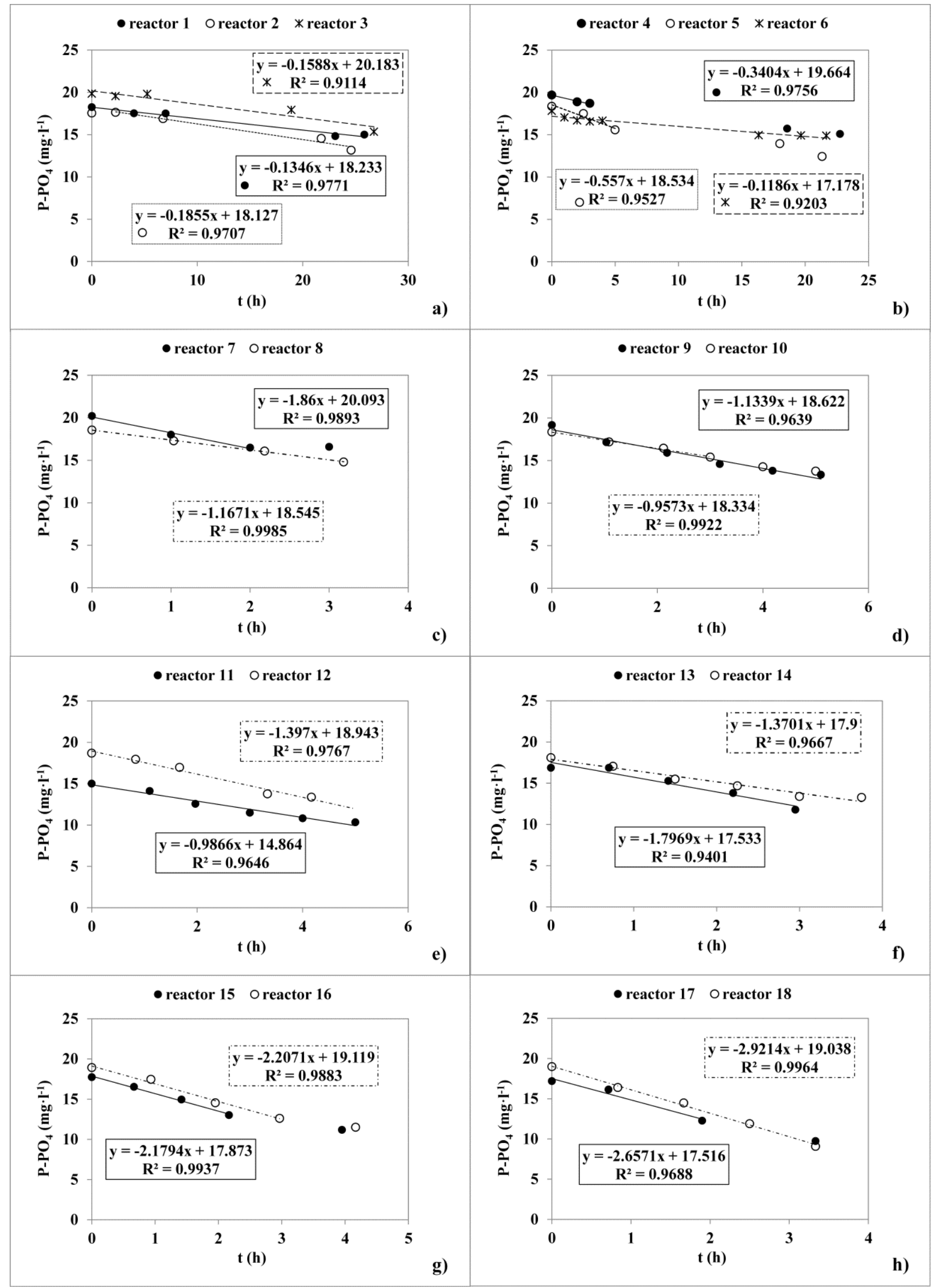


Therefore, the general trend is to find higher phosphate removal rates in those cultures where microalgae have a smaller $\mathrm{P}$ content, although some exceptions can be found to this observation. Since these exceptions are due to the different TSS concentration in the batch cultures and its corresponding selfshading effect, phosphate uptake rates should be compared using specific values $\left(\mathrm{mg} \mathrm{PO}-\mathrm{P} \cdot \mathrm{g} \mathrm{TSS} \mathrm{TS}^{-1} \cdot \mathrm{h}^{-1}\right)$. To this aim, in figure V.2, the phosphate specific uptake rate has been represented versus the biomass $\mathrm{P}$ content at the beginning of each batch experiment.

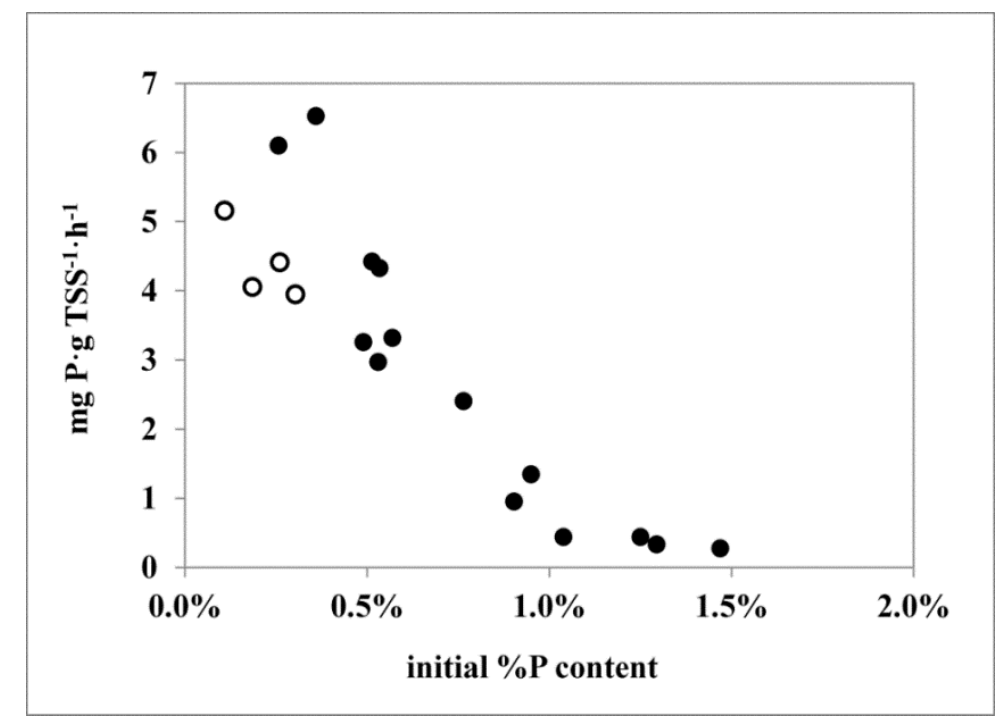

Figure V.2: Specific phosphate uptake rate of the Scenedesmus sp. culture plotted against their intracellular P content. Empty dots correspond to the batch experiments with initial $\mathrm{P}$ content below $0.40 \%$. Suspended solids in the batch reactors were higher at that point (last days of experiment).

The lower specific removal rates were observed in those batch experiments in which biomass presented a higher P content (figure V.2). It can be appreciated that when the culture P content was above $1 \%(\mathrm{w} / \mathrm{w})$, the specific phosphate removal rate was less than $10 \%$ of the maximum removal rate achieved. The region around $0.5 \% \mathrm{P}$ content is the concentration at which phosphorus cellular content reduced phosphate uptake to half of its highest value. The batch experiments with initial P content below $0.40 \%$ (empty dots in the graph) are an exception to the general tendency of faster phosphate uptake rate with smaller biomass $\mathrm{P}$ content. These batch experiments are those carried out at higher initial TSS content. Thus, the light available for the microorganisms in these last experiments was smaller than in the other experiments 
due to the markedly higher suspended solids concentration, which resulted in higher selfshading levels. Therefore, taking the light influence into account in the modeling process proves to be necessary.

This study shows an enhancement of phosphate uptake rate (regulated by light availability) with decreasing biomass $\mathrm{P}$ content through the successive batch experiments. Since the phosphate concentration in the medium was the same at the beginning of all batch experiments, this observation suggests that not only the external phosphate level, but also the internal biomass phosphorus concentration that the microalgae are able to achieve influences the phosphate uptake rate. Therefore, the biomass $\mathrm{P}$ content (relatively easily known by analyzing its composition) proves to be an important indicator of the possible nutrient uptake rate for a given species.

\subsection{Biomass production and composition}

Biomass yield on phosphorus $\left(\mathrm{Y}_{\mathrm{P}}\right.$, mass of generated biomass divided over the mass of phosphorus taken up) varied along the batch experiments. The maximum $Y_{P}$ value $(120 \mathrm{mg}$ TSS $\cdot \mathrm{mg} \mathrm{PO}_{4}-\mathrm{P}^{-1}$ ) was measured for the batch with the higher initial $\mathrm{P}$ content, and very low $\mathrm{Y}_{\mathrm{P}}$ values (2-3 mg TSS $\cdot \mathrm{mg} \mathrm{PO}_{4}-\mathrm{P}^{-1}$ ) correspond to $\mathrm{P}$-starved cells (figure V.3). Actually, these low values account only for the absorbed phosphate mass $\left(\mathrm{mg} \mathrm{PO}_{4}\right)$ and suggest no new biomass formation. Low biomass production in the cases of low initial $\mathrm{P}$ content is explained directly by the lack of this essential nutrient and also by the hindered $\mathrm{N}$ uptake: a smaller initial P content reduces the nitrogen uptake velocity (Ruiz-Martinez et al., 2014 (Chapter IV)), that being one of the causes for eventual lower biomass formation.

The observations of this study suggest that, when the P-stress is relieved, the microalgae first take up high amounts of phosphate from the medium at an increased rate, which is higher the greater the $\mathrm{P}$ deficiency is. On the other hand, the slighter the $\mathrm{P}$ deficiency is, the higher the rate at which biomass is generated. 


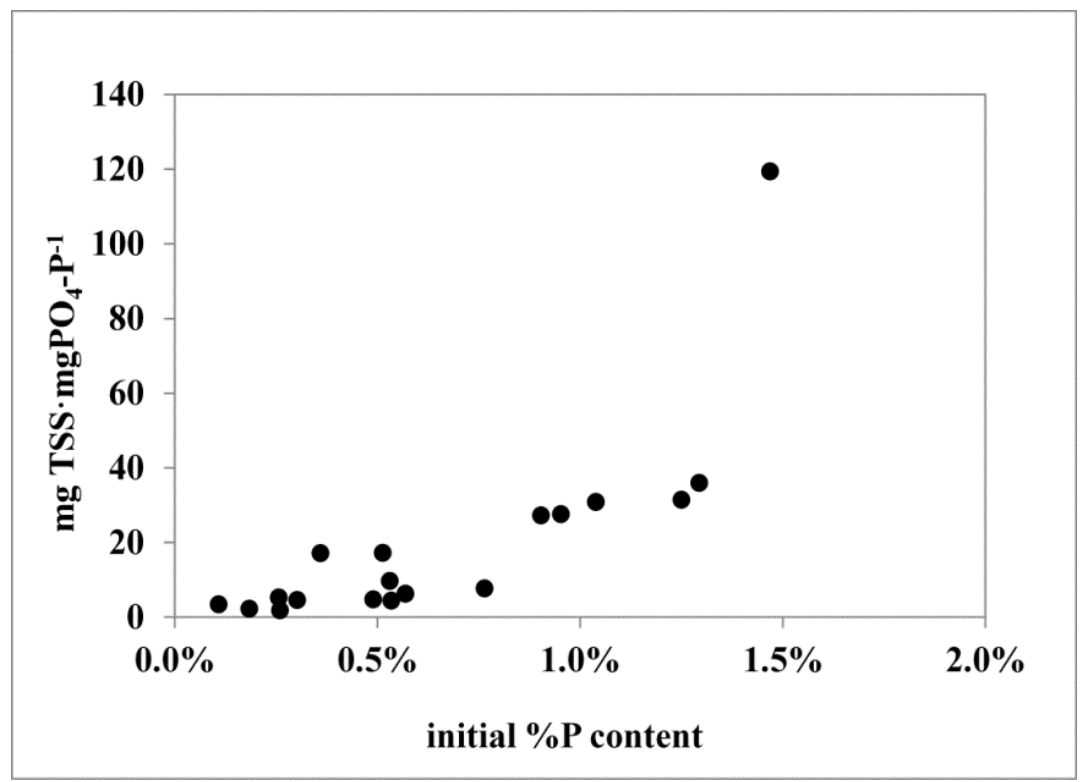

Figure V.3: Dependence between biomass yield on phosphorus and initial polyphosphate content of the cells.

The highest value for final biomass $\mathrm{P}$ content was $2.33 \%$, which indicates that the biomass capacity to take up phosphate from the medium is probably not exhausted at that point. As reviewed in section 1 of this chapter, compositions of up to $3.85 \% \mathrm{P}$ have been reported before. Therefore, it could be assumed that (through a process of luxury uptake) in a longer batch, final P content and final biomass concentrations could reach higher values.

\subsection{Modeling the phosphate uptake process}

The aim of this section is to establish a mathematical expression for modeling the phosphate uptake process by microalgae. The structure of this expression will consist of a maximum phosphate uptake rate multiplied by different terms (equation V.5). Each of these terms includes the effect of a different factor in the phosphate uptake rate: A Monod term models the effect of phosphate concentration, the Steele function (Steele, 1977) was chosen to model the light influence and a term $\tau_{X P P}$ will be established to model the influence of the intracellular $\mathrm{P}$ content of the microalgae:

$\frac{d S_{P O 4}}{d t}=\left(\frac{d S_{P O 4}}{d t}\right)_{\max } \cdot \frac{S_{P O 4}}{k_{S}+S_{P O 4}} \cdot \frac{I}{k_{i}} \cdot \exp \left(1-\frac{I}{k_{i}}\right) \cdot \tau_{X P P}$ 
where $k_{i}\left(\mu E \cdot m^{-2} \cdot s^{-1}\right)$ is the optimal light intensity and $I\left(\mu E \cdot m^{-2} \cdot s^{-1}\right)$ is a weighted average light intensity which takes into account the reactor's geometry and the self-shading factor of the microalgae. $I$ is calculated dividing the reactor into discrete concentric sections and applying Lambert-Beer's Law (equation V.6) for calculating a uniform light for each section.

$I=I_{0} \cdot \exp (-a \cdot T S S \cdot z)$

where $\mathrm{I}_{0}\left(\mu \mathrm{E} \cdot \mathrm{m}^{-2} \cdot \mathrm{s}^{-1}\right)$ is the incident light intensity on the reactor surface, $z(\mathrm{~m})$ is the distance from the reactor surface, TSS are expressed in mg.TSS $l^{-1}$ and $a\left(\mathrm{~m}^{2} \cdot \mathrm{g} \mathrm{TSS}{ }^{-1}\right)$ is the microalgal selfshading factor, for which a value of 0.0758 was used in this study, based on Ketheesan and Nirmalakhandan, 2004.

Other factors which were constant during the experiments, such as ammonium concentration, temperature, salinity or $\mathrm{pH}$ of the medium, have not been taken into account in the kinetic expression.

Since phosphate concentration in the medium was the same at the beginning of each batch experiment, the Monod phosphate term had a constant value. On the other hand, since initial phosphate concentration was high (18 mg PO4-P $\cdot \mathrm{l}^{-1}$ ) compared with usual $\mathrm{k}_{\mathrm{S}}$ values found in literature for Scenedesmus sp. (0.037 - $0.124 \mathrm{mg} \mathrm{P} \cdot 1^{-1}$ in Reynolds, 2006, $0.0353 \mathrm{mg} \mathrm{P} \cdot 1^{-1}$ in Rouzic and Bertru, 1997), the Monod phosphate term did not have any regulating effect over the maximum uptake rate: its value was thus close to one in all cases. This term will be hereafter considered as constant, and included with $\left(\frac{d S_{P O 4}}{d t}\right)_{\max }$ into a single parameter $K_{\text {Max }}$. Expression (V.5) then becomes:

$\frac{d S_{P O 4}}{d t}=K_{M a x} \cdot \frac{I}{k_{i}} \cdot \exp \left(1-\frac{I}{k_{i}}\right) \cdot \tau_{X P P} \quad \quad\left(\mathrm{mg} \mathrm{P} \cdot \mathrm{mg} \mathrm{TSS}^{-1} \cdot \mathrm{h}^{-1}\right)$

\subsubsection{Intracellular $P$ content}

The term $\tau_{X P P}$ is meant to reproduce the effect of the biomass intracellular $\mathrm{P}$ content on the phosphate uptake rate. Initially, two expressions found in literature and presented in section 1 of this chapter were used to reproduce the obtained data: that of Klausmeier and Litchman, 2004 (equation V.3), and that of Bougaran et al., 2010 (equation V.4). The combination of 
them with equation V.6 and V.7 gives the following two expressions for modeling the phosphate uptake rate (equations V.8 and V.9, respectively):

$\frac{d S_{P O 4}}{d t}=\frac{K_{M a x} \cdot k_{i n h}-c \cdot\left(q-q_{\min }\right)}{q-q_{\min }+k_{i n h}} \cdot \frac{I_{0} \cdot \exp (-a \cdot T S S \cdot z)}{k_{i}} \cdot \exp \left(1-\frac{I_{0} \cdot \exp (-a \cdot T S S \cdot z)}{k_{i}}\right)$

and

$\frac{d S_{P O 4}}{d t}=K_{M a x} \cdot \frac{q_{\max }-q}{q_{\max }-q_{\min }} \cdot \frac{I_{0} \cdot \exp (-a \cdot T S S \cdot z)}{k_{i}} \cdot \exp \left(1-\frac{I_{0} \cdot \exp (-a \cdot T S S \cdot z)}{k_{i}}\right)$

Model parameters were determined using the Solver program in Microsoft ® Excel 2007 software for minimizing the residual sum of squared errors between the experimental data and the model predictions. However, some restrictions had to be applied in parameters $\mathrm{q}_{\max }$ and $\mathrm{q}_{\min }$ due to their biological significance. The values obtained for model parameters are shown in table V.2. Figure V.4a shows predicted phosphate uptake rates using both expressions, represented against intracellular $\mathrm{P}$ content, together with the experimental values.

Table V.2: Obtained parameters for equations V.8 and V.9

\begin{tabular}{|c|c|c|c|c|c|c|}
\hline Units & 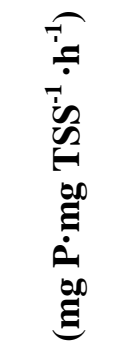 & 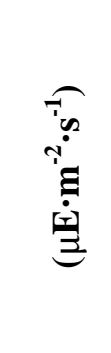 & 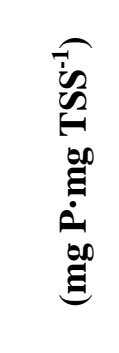 & 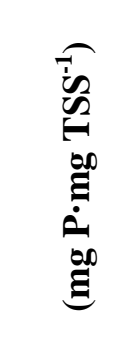 & 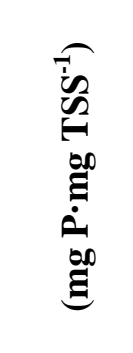 & \\
\hline Parameters & $K_{\max }$ & $k_{i}$ & $q_{\max }$ & $q_{\min }$ & $k_{i n h}$ & $c$ \\
\hline Eq. V.8 & 0.01 & 139.4 & - & $0.10 \%$ & $0.36 \%$ & 0.00264 \\
\hline Eq. V.9 & 0.005 & 29.6 & $1.47 \%$ & $0.10 \%$ & - & - \\
\hline
\end{tabular}

Both model predictions are also represented in figure V.4b against the experimental values. Statistical analysis was carried out using SPSS 16.1, which showed, for equation V.8 a Pearson correlation coefficient of 0.929 (P-value < 0.01) and for equation V.9 a Pearson correlation coefficient of 0.581 (P-value $<0.05$ ). 
The phosphate uptake rate prediction is therefore acceptable using equation V.8 and quite poor using equation V.9. On the other hand, equation V.8 makes it necessary to calibrate 4 parameters, one more than equation V.9.

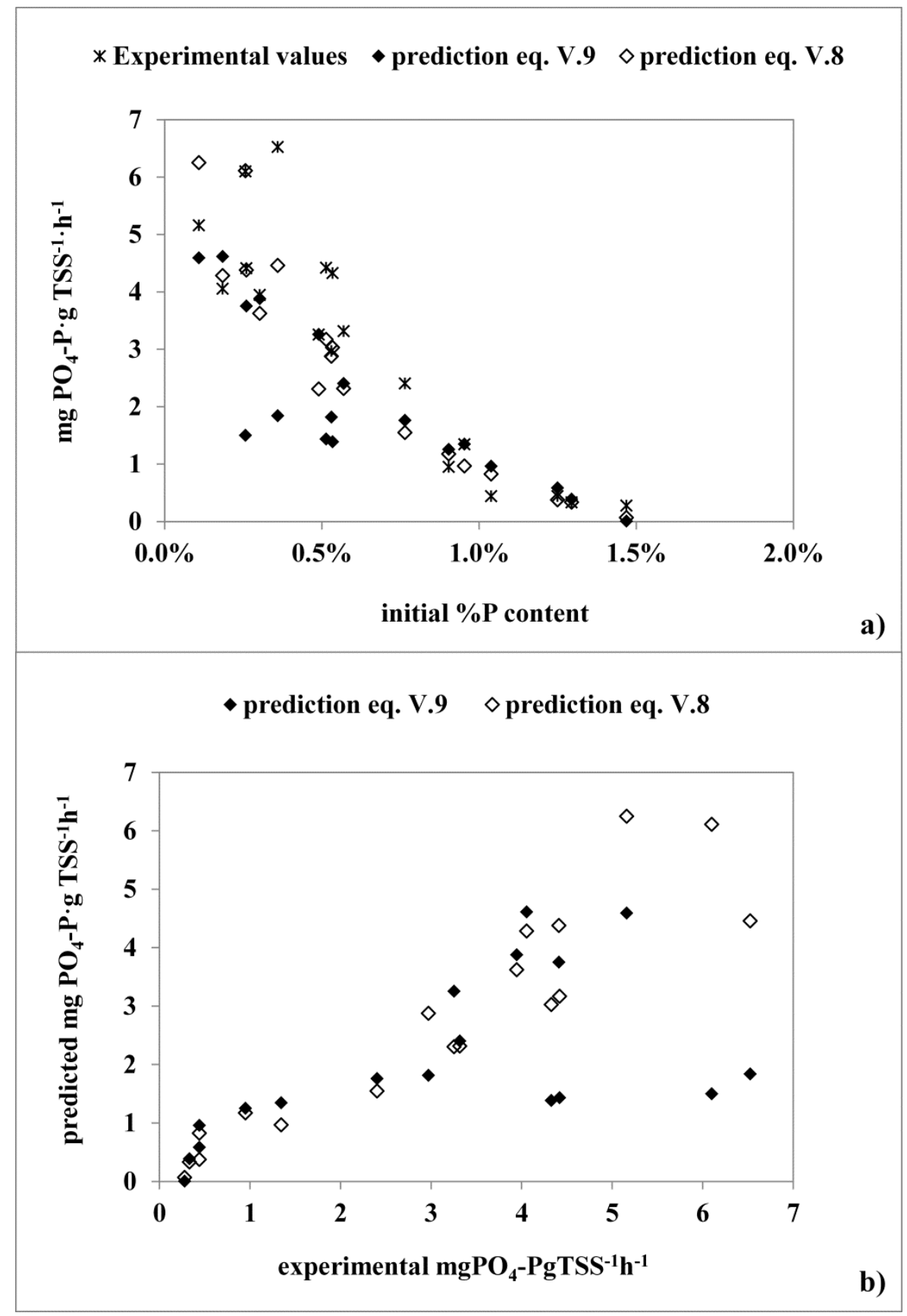

Figure V.4: a) Experimental values of phosphate uptake rate together with model predictions, using eq. V.8 (empty squares) and eq. V.9 (full squares); b) Parity chart for phosphate uptake rate: rates according to eq. V.8 (empty squares) and eq. V.9 (full squares) versus experimental values. 
Based on these results, and on the observation of the data obtained as represented in figure V.2, where a fast change in phosphate uptake rate is observed around a certain biomass $\mathrm{P}$ content $(0.4-0.6 \%)$, the Hill equation was proposed for modeling the influence of intracellular stored phosphorus on the phosphate uptake rate. The resulting full equation that describes phosphate uptake from the medium is therefore:

$\frac{d S_{P O 4}}{d t}=K_{M a x} \cdot \frac{k_{X P P}{ }^{n}}{k_{X P P}{ }^{n}+\left(X_{P P} / X_{A l g}\right)^{n}} \cdot \frac{I_{0} \cdot \exp (-a \cdot T S S \cdot z)}{k_{i}} \cdot \exp \left(1-\frac{I_{0} \cdot \exp (-a \cdot T S S \cdot z)}{k_{i}}\right)$

being $X_{P P} / X_{A l g}$ the intracellular stored polyphosphate, expressed in $\mathrm{g} \mathrm{P} \cdot \mathrm{g} \mathrm{TSS}^{-1}, k_{X P P}(\mathrm{~g} \mathrm{P} \cdot \mathrm{g}$ $\mathrm{TSS}^{-1}$ ) the ratio of $X_{P P} / X_{A l g}$ that leads to a $50 \%$ reduction of the maximal uptake rate (50\% effect concentration) and $n$ the regulation coefficient or Hill number. The Hill equation is of a similar nature to the sigmoidal functions used by John and Flynn (2000) and Flynn (2005) to describe internal P pools dynamics or by Yao et al. (2011) to model phosphate uptake from the medium. Originally used in enzymology, the Hill allosteric regulation model has previously shown to successfully reproduce the influence of intracellular $\mathrm{P}$ content on the ammonium uptake rate (Ruiz-Martinez et al., 2014 (Chapter IV)). De la Hoz Siegler et al. (2011) studied its use for $\mathrm{N}$ uptake, in order to reproduce his observations of growth uncoupled from nitrogen uptake and the consequent accumulation of intracellular nitrogen compounds. The Hill equation showed the best fit among the studied models. However, they concluded that a simpler model like Michaelis-Menten should be chosen in exchange of a slightly worse fit.

In this study, the intracellular stored polyphosphate was calculated as the difference between the total suspended phosphorus (measured) and the $\mathrm{P}$ content of the microalgal structure (constitutional or structural phosphorus, not polyphosphate), which was considered a constant of the model, $\mathrm{i}_{\mathrm{PAlg}}\left(\mathrm{g} \mathrm{P} \cdot \mathrm{g} \mathrm{TSS}{ }^{-1}\right)$. For $i_{P A l g}$ a value of $0.1 \%\left(0.001 \mathrm{~g} \mathrm{P} \cdot \mathrm{g} \mathrm{TSS}^{-1}\right)$ was set, which is below the phosphorus total composition at the end of the experiment $\left(0.0011 \mathrm{~g} \mathrm{P} \cdot \mathrm{g} \mathrm{TSS}^{-1}\right)$. It is assumed that at the final point there is nearly no polyphosphate in the cells.

A local sensitivity analysis of equation V.10 was performed, setting the initial parameters values based on previous experience and literature. Sensitivity was calculated as described in Marsili-Libelli et al., 2001: 
$S_{P j}=\frac{\Delta x}{\Delta P j} \cdot \frac{P j_{\text {nom }}}{x_{\text {nom }}}$

Where $S_{P j}$ is the sensitivity of parameter $P j$ with respect to the state variable $x$, which was, in this case, the average calculated specific phosphate uptake rate. $\mathrm{Pj}_{\mathrm{nom}}$ is the parameter nominal value and $\mathrm{x}_{\mathrm{nom}}$ is the model response when the nominal parameters are used. The applied parameter variation $(\Delta P j)$ to obtain the test values with which to calculate $\Delta x$ was $\pm 20 \%$ of $\mathrm{Pj}_{\text {nom }}$.

The sensitivity analysis gives information about the impact of the parameters into the response of the model. The results indicate that the biggest influence is exerted by parameter $K_{\text {Max }}$, followed by $k_{X P P}$ and $k_{i}$. Hill number, $n$, bears the least significance. This result is however dependent on the initial value of $k_{X P P}$, due to the shape of the Hill function when represented against $X_{P P} / X_{A l g}$ for different $k_{X P P}$ values. This function takes values close to zero or close to one for most of the spectrum, and values between zero and one for a narrow range of $X_{P P} / X_{A l g}$. How abrupt that change is depends on Hill number, $n$, so it is logical that the influence of this parameter is only detected in a local sensitivity analysis when the initial values are close to the point where the change takes place. Therefore, if a sensitivity analysis was performed in specific points of the $\mathrm{P}$ content spectrum (for example, only the first batch experiments, or only the last batch experiments), the results might be different, since the sensitivity analysis was performed on the average phosphate uptake calculated for all batch experiments.

The proposed model accurately reproduces the experimental data (figures V.5a and V.5b). Pearson correlation coefficient $(\mathrm{P}$-value $<0.01)$ was 0.971 . These results clearly improve those obtained with equation V.9. The advantages with respect to equation V.8 are two: a better fit and one parameter less which needs to be calibrated.

Model parameters were determined using the Solver program in Microsoft @ Excel 2007 software for minimizing the residual sum of squared errors between the experimental data and the model predictions. The best fit obtained for the parameters is shown in table V.3.

Literature $\mathrm{k}_{\mathrm{i}}$ values vary in a wide range between 20 and $500 \mathrm{~W} \cdot \mathrm{m}^{-2}$ (Broekhuizen et al., 2012 and Reichert et al., 2001, respectively), in which the value obtained in this study of 180 $\mu \mathrm{mol} \cdot \mathrm{m}^{2} \cdot \mathrm{s}^{-1}$ would be included. Regarding $k_{X P P}, 0.5 \%$ is the value for $\mathrm{P}$ content around which phosphate uptake rate is $50 \%$ of its maximum. The value obtained for maximum phosphate 
uptake is $8 \mathrm{mg} \mathrm{P} \cdot \mathrm{g} \mathrm{TSS}^{-1} \cdot \mathrm{h}^{-1}$, which is also in agreement with the fact that the highest obtained value in the experiment was $6.90 \mathrm{mg} \mathrm{P} \cdot \mathrm{g} \mathrm{TSS}^{-1} \cdot \mathrm{h}^{-1}$, being the Monod and Hill terms for that batch experiment almost one and the light influence term 0.85 .

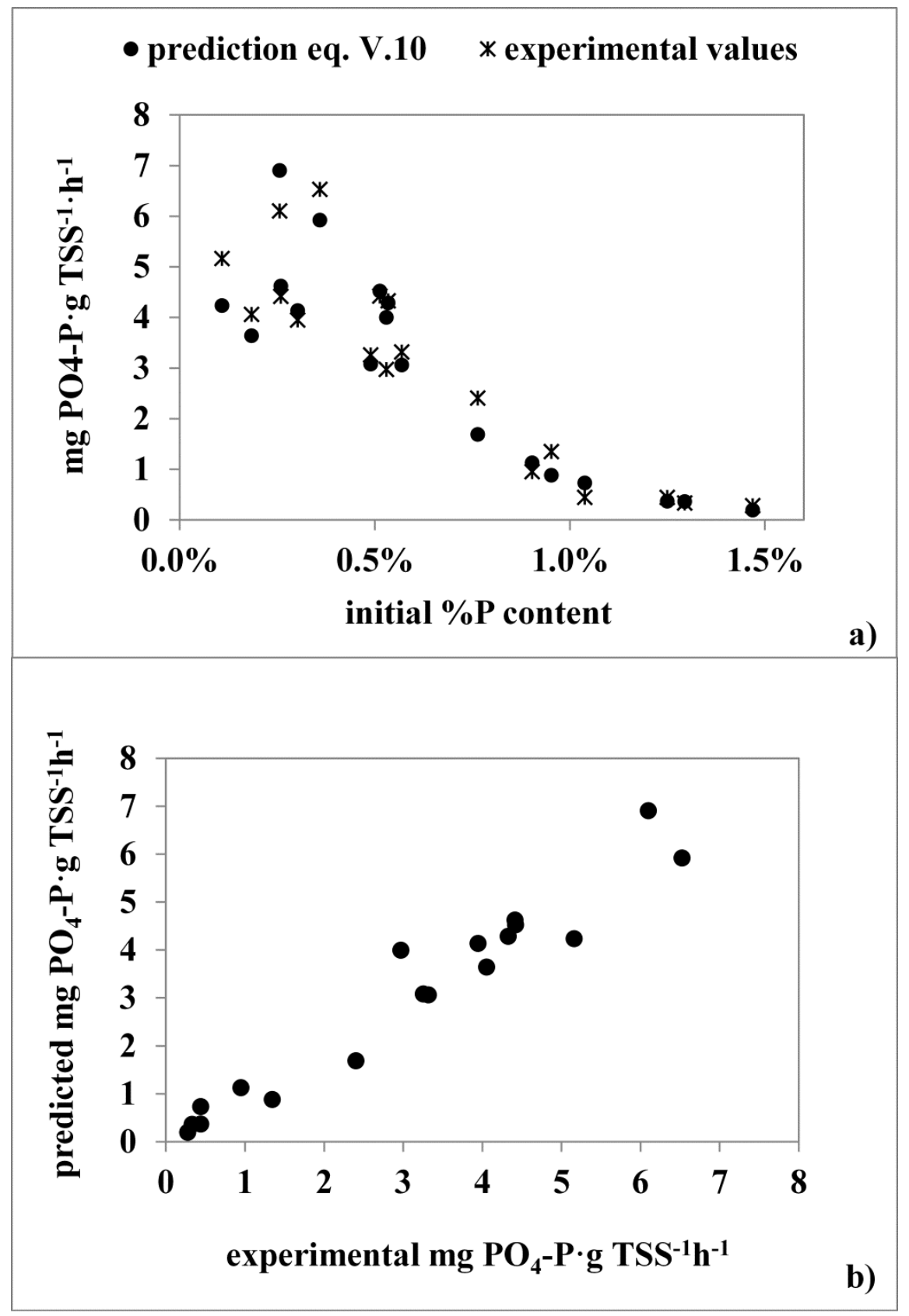

Figure V.5: a) calculated (equation V.10) and observed phosphate uptake rates plotted together vs initial \% content; b) calculated phosphate uptake rates (equation V.10) plotted vs observed phosphate uptake rates. 
Table V.3: Parameter sensitivity for equation V.10 and best fit obtained.

\begin{tabular}{ccc}
\hline Parameter & Sensitivity & Best fit value \\
\hline$K_{\text {Max }}\left(\mathrm{mg} \mathrm{P} \cdot \mathrm{h}^{-1} \cdot \mathrm{mg} \mathrm{TSS}^{-1}\right)$ & 1 & 0.008 \\
\hline$k_{X P P}\left(\mathrm{~g} \mathrm{P} \cdot \mathrm{g} \mathrm{TSS}^{-1}\right)$ & 0.733 & $0.51 \%$ \\
\hline$k_{i}\left(\mu \mathrm{E} \cdot \mathrm{m}^{-2} \cdot \mathrm{s}^{-1}\right)$ & 0.626 & 180 \\
\hline$n$ & 0.006 & 3.2 \\
\hline
\end{tabular}

\section{Conclusions}

A Scenedesmus sp. culture was progressively deprived from phosphorus and, as a consequence, phosphate uptake rate rose. Equations found in literature reproduce the obtained data moderately good. A new expression was proposed, which includes a Steele term for modeling the light influence and the Hill equation for modeling the influence of the biomass phosphorus content. The presented model improved the accuracy obtained and decreased the number of parameters needed. It can be used for phosphate removal rate prediction based on the microalgal composition, and thus it represents a useful tool for designing and simulating wastewater treatment systems using microalgal cultures.

\section{Acknowledgments}

This research work has been supported by the Spanish Ministry of Economy and Competitiveness (MINECO, CTM2011-28595-C02-01/02) jointly with the European Regional Development Fund (ERDF) which are gratefully acknowledged. This research was also supported by the Spanish Ministry of Education, Culture and Sport via a pre doctoral FPU fellowship to the first author (AP2009-4903). The authors would also like to thank the water management entities of the Generalitat Valenciana (EPSAR). 


\section{References}

APHA, AWWA and WEF (2005) Standard Methods for the Examination of Waters and Wastewaters, 21st ed. American Public Health Association, Washington, DC.

Aravantinou, A.F., Theodorakopoulos, M.A., Manariotis, I.D. (2013) Selection of microalgae for wastewater treatment and potential lipids production. Bioresource Technology 147, 130-134.

Aslan, S., Kapdan, I.K. (2006) Batch kinetics of nitrogen and phosphorus removal from synthetic wastewater by algae. Ecological Engineering 28, 64-70.

Bougaran, G., Bernard, O., Sciandra, A. (2010) Modeling continuous cultures of microalgae colimited by nitrogen and phosphorus. Journal of Theoretical Biology 265, 443-454.

Broekhuizen, N., Park, J. B. K., McBride, G. B., Craggs, R. J. (2012) Modification, calibration and verification of the IWA River Water Quality Model to simulate a pilot-scale high rate algal pond. Water Research 46 (9) 2911-26.

De Alva, M.S., Luna-Pabello, V.M., Cadena, E., Ortíz, E. (2013) Green microalga Scenedesmus acutus grown on municipal wastewater to couple nutrient removal with lipid accumulation for biodiesel production. Bioresource Technology 146, 744-748.

De la Hoz Siegler, H., Ben-Zvi, A., Burrell, R.E., McCaffrey, W.C. (2011) The dynamics of heterotrophic algal cultures. Bioresource Technology 102, 5764-5774.

Dickinson, K.E., Whitney, C.G., McGinn, P.J. (2013) Nutrient remediation rates in municipal wastewater and their effect on biochemical composition of the microalga Scenedesmus sp. AMDD. Algal Research 2 (2) 127134.

Flynn, K.J. (2005) Modelling marine phytoplankton growth under eutrophic conditions. Journal of Sea Research 54, 92-103.

Gentili, F.G. (2014) Microalgal biomass and lipid production in mixed municipal, dairy, pulp and paper wastewater together with added flue gases. Bioresource Technology 169, 27-32.

Giménez, J.B., Robles, A., Carretero, L., Duran, F., Ruano, M.V., Gatti, M.N., Ribes, J., Ferrer, J., Seco, A. (2011) Experimental study of the anaerobic urban wastewater treatment in a submerged hollow-fibre membrane bioreactor at pilot scale. Bioresource Technology 102, 8799-8806.

Gotham, I.J., Rhee, G.Y. (1981) Comparative kinetic studies of phosphate-limited growth and phosphate uptake in phytoplankton in continuous culture. Journal of Phycology 17, 257-265.

John, E.H., Flynn, K.J. (2000) Modelling phosphate transport and assimilation in microalgae; how much complexity is warranted? Ecological Modelling 125, 145-157.

Ketheesan, B., Nirmalakhandan, N. (2013) Modeling microalgal growth in an airlift-driven raceway reactor. Bioresource Technology 136, 689-696.

Klausmeier, C.A., Litchman, E. (2004) Phytoplankton growth and stoichiometry under multiple nutrient limitation. Limnology and Oceanography 49, 1463-1470. 
Kwon, H.K., Oh, S.K., Yang, H-S (2013) Growth and uptake kinetics of nitrate and phosphate by benthic microalgae for phytoremediation of eutrophic coastal sediments. Bioresource Technology 129, 387-395.

Lehman, J., Botkin, D., Likens, G. (1975) The assumptions and rationales of a computer model of phytoplankton population dynamics. Limnology and Oceanography 20 (3), 343-364.

Markou, G. (2012) Alteration of the biomass composition of Arthrospira (Spirulina) platensis under various amounts of limited phosphorus. Bioresource Technology 116, 533-535.

Marsili-Libelli, S., Ratini, P., Spagni, A. \& Bortone, G. (2001) Implementation, study and calibration of a modified ASM2d for the simulation of SBR processes. Water Science and Technology 43 (3), 69-76.

Powell, N., Shilton, A., Pratt, S., Chisti, Y. (2008) Factors influencing luxury uptake of phosphorus by microalgae in waste stabilization ponds. Environmental Science and Technology 42 (16), 5958-5962.

Powell, N., Shilton, A., Chisti, Y., Pratt, S. (2009) Towards a luxury uptake process via microalgae - defining the polyphosphate dynamics. Water Research 43 (17), 4207-4213.

Razzak, S.A., Hossain, M.M., Lucky, R.A., Bassi, A.S., De Lasa, H. (2013) Integrated $\mathrm{CO}_{2}$ capture, wastewater treatment and biofuel production by microalgae culturing - A review. Renewable and sustainable Energy Reviews 27, 622-653.

Redfield, A. (1958) The biological control of chemical factors in the environment. American Scientist 46, $205-$ 221.

Reichert, P., Borchardt, D., Henze, M., Rauch, W., Shanahan, P., Somlyódy, L., Vanrolleghem, P. (2001) River Water Quality Model no. 1 (RWQM1):II. Biochemical process equations. Water Science and Technology 43 (5) 11-30.

Reynolds, C. S. (2006). The ecology of phytoplankton, Cambridge University Press, New York.

Rouzic, B., Bertru, G. (1997) Phytoplankton community growth in enrichment bioassays: possible role of the nutrient intracellular pools. Acta ecologica 18 (2), 121-133.

Ruiz-Marin, A., Mendoza-Espinosa, L.G., Stephenson, T. (2010) Growth and nutrient removal in free and immobilized green algae in batch and semi-continuous cultures treating real wastewater. Bioresource Technology $101,58-64$.

Ruiz-Martinez, A., Martin Garcia, N., Romero, I., Seco, A., Ferrer, J. (2012) Microalgae cultivation in wastewater: Nutrient removal from anaerobic membrane bioreactor effluent. Bioresource Technology 126, $247-$ 253.

Ruiz-Martinez, A., Serralta, J., Pachés, M., Seco, A., Ferrer, J. (2014) Mixed microalgae culture for ammonium removal in the absence of phosphorus: Effect of phosphorus supplementation and process modeling. Process Biochemistry 49, 2249-2257.

Samorí, G., Samorí, C., Guerrini, F., Pistocchi, R. (2013) Growth and nitrogen removal capacity of Desmodesmus communis and of a natural microalgae consortium in a batch culture system in view of urban wastewater treatment: Part I. Water Research 47, 791-801.

Steele, J.H. (1977) In: Lapidus, L., Amundson, N.R., editors. Microbial Kinetics and Dynamics in Chemical Reactor Theory. Prentice-Hall, Englewood Cliffs, NJ, pp. 405-483. 
Nutrient removal from an anaerobic membrane bioreactor effluent using microalgae. Study and modeling of the process

Van den Ende, S., Carré, E., Cocaud, E., Beelen, V., Boon, N., Vervaeren, H. (2014) Treatment of industrial wastewaters by microalgal bacterial flocs in sequencing batch reactors. Bioresource Technology 161, 245-254.

Wu, Y.H., Yu, Y., Hu, H.Y. (2013) Potential biomass yield per phosphorus and lipid accumulation property of seven microalgal species. Bioresource Technology 130, 599-602.

Yao, B., Xi, B., Hu, C., Huo, S., Su, J., Liu, H. (2011) A model and experimental study of phosphate uptake kinetics in algae: considering Surface adsorption and P-Stress. Journal of Environmental Sciences 23 (2), 189198. 


\title{
Chapter VI
}

\section{Effect of temperature on ammonium removal in Scenedesmus sp.}

\author{
Ruiz-Martinez, A., Serralta, J., Seco, A., Ferrer, J. (2015) Effect of temperature on ammonium
} removal in Scenedesmus sp. Bioresource Technology 191, 346-349.

\begin{abstract}
The effect of temperature on microalgal ammonium uptake was investigated by carrying out four batch experiments in which a mixed culture of microalgae, composed mainly of Scenedesmus sp., was cultivated under different temperatures within the usual temperature working range in Mediterranean climate $\left(15-34{ }^{\circ} \mathrm{C}\right)$. Ammonium removal rates increased with temperature up to $26^{\circ} \mathrm{C}$ and stabilized thereafter. Ratkowsky and Cardinal Temperatures models successfully reproduced the experimental data. Optimum $\left(31.3^{\circ} \mathrm{C}\right)$, minimum $\left(8.8^{\circ} \mathrm{C}\right)$ and maximum $\left(46.1{ }^{\circ} \mathrm{C}\right)$ temperatures for ammonium removal by Scenedesmus sp. under the studied conditions were obtained as model parameters. These temperature-related parameters constitute very useful information for designing and operating wastewater treatment systems using these microalgae.
\end{abstract}





\section{Introduction}

Interest in microalgae has risen in the last decades due to the combination of several factors, three of which are highlighted here for their somewhat bigger impact on research: a) microalgae can be used to obtain renewable fuels such as biodiesel, biohydrogen or biogas, therefore contributing to reduce fossil fuel consumption b) microalgae use $\mathrm{CO}_{2}$ for their growth, and therefore contribute to reduce greenhouse gas emissions and c) pollutants such as phosphate, nitrate and ammonium can be successfully removed from wastewaters by microalgae, since they grow on inorganic nutrients which they take from the medium.

Several authors have indeed proved that the use of microalgae is a valid option for wastewater treatment, as reviewed by $\mathrm{Wu}$ et al. (2014). Many efforts have also been made to study their growth kinetics (Aslan and Kapdan, 2006, Ruiz et al., 2013, Wu et al., 2013), or to predict their production of biomass or substances of interest, such as lipids or sugars (Adesanya et al., 2014, Tevatia et al., 2012). Temperature influence on microalgal growth has also been modeled in various ways. Béchet et al. (2013) and Ras et al. (2013) present reviews of this matter. The former recommends uncoupled models (those which do not account for interdependence of light and temperature) and the latter insists on the important effect that high temperatures and microalgal adaptation to environmental conditions have on the functioning of outdoor production systems.

Essentially, the Arrhenius Law (equation VI.1) has been widely used for describing temperature influence on microalgal growth (for instance by Geider et al.,1998 or Ketheesan and Nirmalakhandan, 2013), although it was originally proposed for chemical reaction rates and it does not describe properly the negative effect of high temperature on microbial growth.

$\mu(T)=\mu\left(T_{r}\right) \cdot \theta^{\left(T-T_{r}\right)}$

where $T_{r}\left({ }^{\circ} \mathrm{C}\right)$ is the reference temperature and $\theta$ is the Arrhenius constant.

Ratkowsky et al. (1983) were the first to model the microbial growth rate reduction observed at temperatures above an optimum value (equation VI.2).

$\sqrt{\mu(T)}=b \cdot\left(T-T_{\min }\right) \cdot\left\{1-\exp \left[c \cdot\left(T-T_{\max }\right)\right]\right\}$ 
where $b$ and $c$ are parameters with no biological meaning obtained by data fitting and $T_{\min }$ and $T_{\max }$ are the minimum and maximum temperatures, respectively, at which growth rate is zero.

Otherwise, Bernard and Rémond (2012) used the so-called cardinal temperature model with inflexion (CTMI) (equation VI.3) to predict the effect of temperature on microalgal growth using parameters which all have a biological meaning:

$\mu=\mu_{\max } \cdot \frac{\left(T-T_{\max }\right) \cdot\left(T-T_{\min }\right)^{2}}{\left(T_{o p t}-T_{\min }\right) \cdot\left[\left(T_{o p t}-T_{\min }\right) \cdot\left(T-T_{o p t}\right)-\left(T_{o p t}-T_{\max }\right) \cdot\left(T_{o p t}+T_{\min }-2 T\right)\right]}$

Where $T_{\min }\left({ }^{\circ} \mathrm{C}\right)$ is the temperature below which the growth is assumed to be zero, $T_{\max }\left({ }^{\circ} \mathrm{C}\right)$ is the temperature above which there is no growth and at temperature $T_{\text {opt }}\left({ }^{\circ} \mathrm{C}\right)$ maximal growth rate $\mu_{\max }\left(\mathrm{d}^{-1}\right)$ occurs. To our knowledge, this expression has been previously used for microalgal growth only by this author.

The purpose of this study is to assess the direct influence of temperature on the ammonium uptake rate, due to the aforementioned interest on the microalgal ability to remove pollutants from wastewater, and to select a mathematical equation to model the observations. To this aim, four reactors seeded with a mixed culture of indigenous microalgae with clear predominance of Scenedesmus sp. were kept at different temperatures and the microalgal ammonium uptake rate was measured. The models previously detailed in this section were used to reproduce the observed data. Temperature-related parameters for ammonium removal could thus be obtained.

\section{Materials and methods}

\subsection{Microorganisms}

Microalgae were isolated from the walls of the secondary clarifier in the WWTP "Cuenca del Carraixet" (Valencia, Spain) and maintained in the laboratory in a 71 semicontinuous reactor, using as growth medium the effluent of a pilot-scale submerged anaerobic membrane bioreactor (SAnMBR) which operates in the WWTP (Giménez et al., 2011). The SAnMBR treats a small fraction of the WWTP incoming wastewater, and therefore its effluent displays

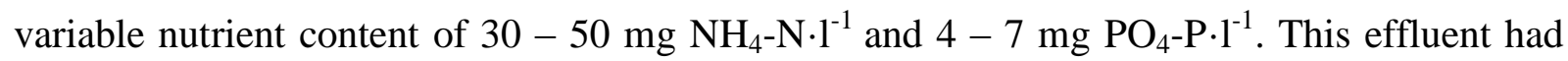


previously proved to contain all necessary micronutrients to sustain algal growth (RuizMartinez et al., 2012 (Chapter III)). The biomass formed a stable ecosystem where the dominant microalgae belonged to the Chloroccocal order, of which $>99 \%$ to the Scenedesmus genus.

\subsection{Experimental setup and operation}

Four experiments were carried out in four cylindrical glass reactors with a total and working volume of 2 and 1.81 , respectively. Around each reactor a coil of transparent silicon tube was installed for temperature control. Cooling/heating water temperatures were controlled by thermostatic baths (Lauda Alpha RA8). Reactors 1 to 4 were thus kept at $15^{\circ} \mathrm{C}, 18{ }^{\circ} \mathrm{C}, 26{ }^{\circ} \mathrm{C}$ and $34{ }^{\circ} \mathrm{C}$, respectively. Each reactor was equipped with electronic sensors in order to obtain on-line temperature and $\mathrm{pH}$ measurements. The probes were connected to a multiparametric analyzer (CONSORT C832, Belgium), which was in turn connected to a PC for data monitoring and storage. Data sampling was conducted every $60 \mathrm{~s}$. A fine bubble diffuser was mounted at the bottom of each reactor in order to mix the algal culture by injecting compressed air. Pure (99.9\%) $\mathrm{CO}_{2}$ from a pressurized cylinder was injected into the compressed air flow whenever $\mathrm{pH}$ rose above 7.5. This $\mathrm{pH}$ control avoided phosphate precipitation and free ammonia stripping. The reactors stood in two confronted lines of two reactors each. From the front of the first line and from the back of the last line, a total of eight vertical fluorescent lamps (Sylvania Grolux, $18 \mathrm{~W}$ ) constantly illuminated the reactors (four lamps in the front and four lamps in the back). Photosynthetically active radiation (PAR) of $180 \pm 21 \mu \mathrm{E} \mathrm{m}^{-2} \mathrm{~s}^{-1}$ was measured at the center of the empty setup.

At the beginning of the experiments, which were carried out in batch mode, $1300 \mathrm{ml}$ of the SAnMBR effluent (containing $34 \mathrm{mg} \mathrm{NH}-\mathrm{N} \cdot \mathrm{l}^{-1}$ and $5.6 \mathrm{mg} \mathrm{PO}_{4}-\mathrm{P} \cdot \mathrm{1}^{-1}$ ) were transferred into each reactor. Phosphate (in the form of $\mathrm{KH}_{2} \mathrm{PO}_{4}$ ) and ammonium (in the form of $\left(\mathrm{NH}_{4}\right)_{2} \mathrm{SO}_{4}$ )

were added to each reactor in order to reach the concentrations of $14 \mathrm{mg} \mathrm{PO}-\mathrm{P} \cdot \mathrm{l}^{-1}$ and $42 \mathrm{mg}$ $\mathrm{NH}_{4}-\mathrm{N} \cdot 1^{-1}$, respectively. These values were considered high enough for avoiding $\mathrm{N}$ or $\mathrm{P}$ deficiency during the whole experiment. When the temperature setpoint was reached, $500 \mathrm{ml}$ of biomass culture (taken from the semicontinuous reactor as explained in section 2.1) were added to each reactor. Total Suspended Solids (TSS) measured in this culture allowed us to calculate the initial biomass concentration resulting in each reactor, which was $115 \mathrm{mg}$ TSS $\cdot 1^{-}$ 
1. The experiments lasted between 25 and 53 hours, during which ammonium and biomass concentrations were measured periodically.

\subsection{Analytical Methods}

Ammonium and phosphate were determined according to Standard Methods (APHA, 2005) (4500-NH3-G and 4500-P-F, respectively) in a Smartchem 200 automatic analyzer (Westco Scientific Instruments, Westco). TSS were determined at the beginning and the end of the experiment according to Standard Methods (APHA, 2005), and calculated during the batch experiments using the equation which describes their linear relationship with absorbance. Absorbance was measured at $750 \mathrm{~nm}$ by a UV-VIS spectrophotometer (Merck Spectroquant ${ }^{\circledR}$ Pharo 300). All reported results were obtained from the previous analyses conducted in duplicate.

\section{Results and Discussion}

\subsection{Temperature influence on ammonium uptake}

Initial ammonium concentration was measured in each reactor immediately after microalgae addition, and periodically during the rest of the experiment. Time evolution of ammonium concentrations in the four reactors is shown in figure VI.1. It is hypothesized that initial ammonium concentrations are not identical in all experiments due to the time lapse (for temperature stabilization) between nutrient addition in the reactors and microalgae addition (when the $\mathrm{pH}$ control system was switched on). Ammonium concentrations always decreased at a constant rate in all the reactors: four straight lines can be observed in figure VI.1, one for each temperature tested. The slope of each line represents the ammonium removal rate of the corresponding reactor. The least-squares fitting method from Excel ${ }^{\circledR}$ was applied to fit the obtained data and to calculate the slope of each trendline.

$$
\begin{array}{ll}
\mathrm{r}_{\mathrm{NH} 4-15^{\circ} \mathrm{C}}=4.3 \mathrm{mg} \mathrm{N} \cdot \mathrm{l}^{-1} \cdot \mathrm{d}^{-1} & \mathrm{r}_{\mathrm{NH} 4-18^{\circ} \mathrm{C}}=6.7 \mathrm{mg} \mathrm{N} \cdot \mathrm{l}^{-1} \cdot \mathrm{d}^{-1} \\
\mathrm{r}_{\mathrm{NH} 4-26^{\circ} \mathrm{C}}=15.7 \mathrm{mg} \mathrm{N} \cdot \mathrm{l}^{-1} \cdot \mathrm{d}^{-1} & \mathrm{r}_{\mathrm{NH} 4-34^{\circ} \mathrm{C}}=17 \mathrm{mg} \mathrm{N} \cdot \mathrm{l}^{-1} \cdot \mathrm{d}^{-1}
\end{array}
$$


These values are in the same range or higher than those obtained by other authors. Park and Jin. (2010) reported an ammonium removal rate of $5-6 \mathrm{mg} \mathrm{N} \cdot \mathrm{l}^{-1} \cdot \mathrm{d}^{-1}$ by Scenedesmus $\mathrm{sp}$. from a piggery farm wastewater with no mention to temperature. Voltolina et al. (2005) reported an ammonium removal rate of $8-9 \mathrm{mg} \mathrm{N} \cdot \mathrm{l}^{-1} \cdot \mathrm{d}^{-1}$ by Scenedesmus obliquus in artificial wastewater at $25.5^{\circ} \mathrm{C}$, which is a smaller value than the one obtained in this study for a similar temperature. Also at $25^{\circ} \mathrm{C}$, Kim et al. (2013) optimized nitrogen removal by Scenedesmus sp. by changing the wavelength of the used light, and reported a maximum removal rate of $15 \mathrm{mg} \mathrm{N} \cdot \mathrm{l}^{-1} \cdot \mathrm{d}^{-1}$, which is similar to the value obtained in this study.

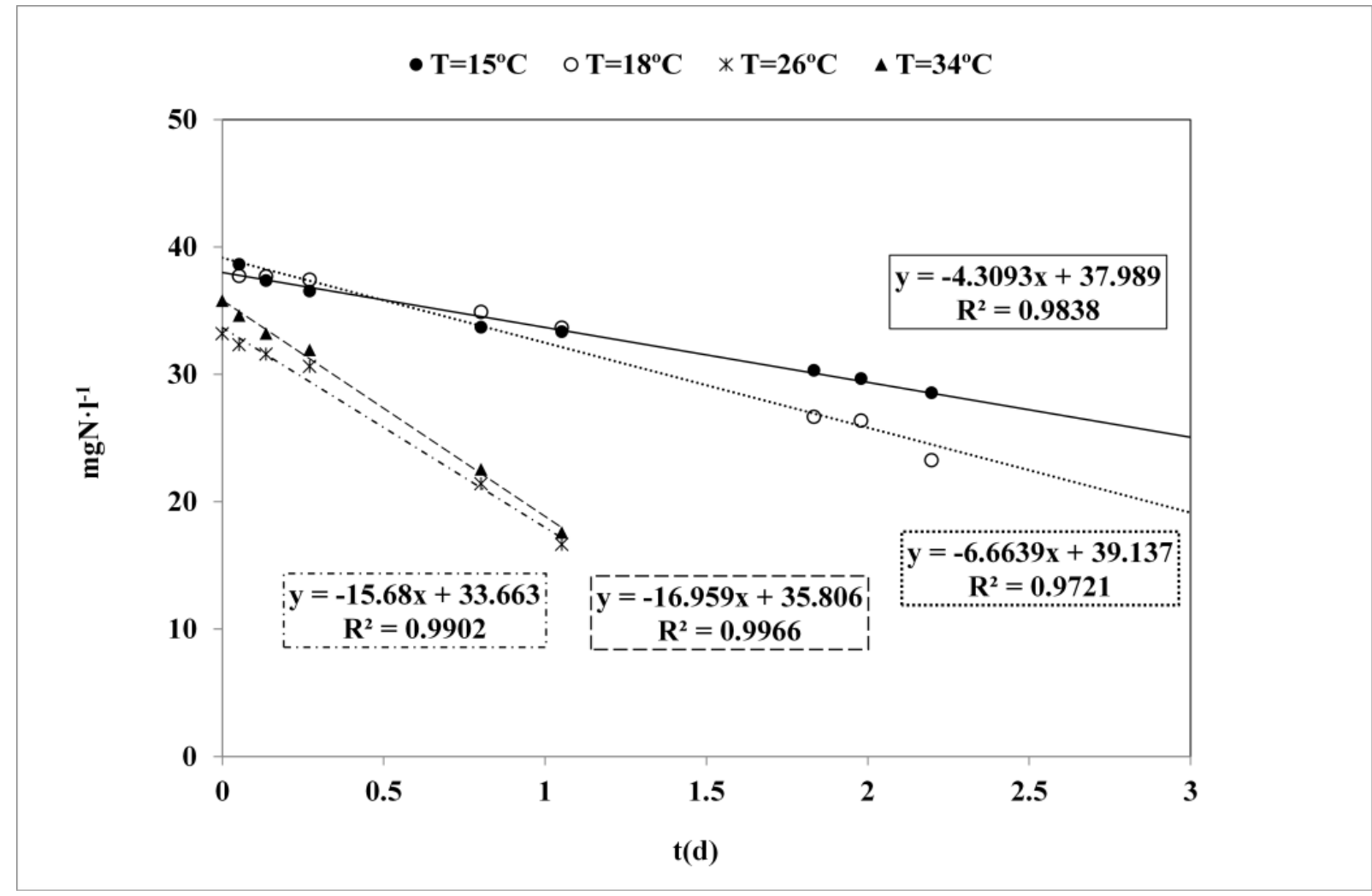

Figure VI.1: Experimental data: Ammonium concentrations measured in each reactor during the experiment.

Phosphate concentrations in the reactors were measured at the end of each experiment to rule out any possible effect of phosphorus limitation. Phosphorus limitation was discarded since phosphate levels in the reactors remained in all cases above $5 \mathrm{mg} \mathrm{PO}_{4}-\mathrm{P} \cdot \mathrm{l}^{-1}$.

Regarding the variation of ammonium removal rates with temperature, a bell-shaped curved is expected for describing the relationship between microalgal activity and temperature, although 
individual shapes are species dependent, and also influenced by environmental conditions (Ras et al., 2013). In this study, a fast (lineal) increase was observed for the first three temperatures evaluated: ammonium removal rate at $26^{\circ} \mathrm{C}$ was twice the value obtained at 18 ${ }^{\circ} \mathrm{C}$. In contrast, no substantial difference was observed between the values obtained at $26{ }^{\circ} \mathrm{C}$ and at $34^{\circ} \mathrm{C}$.

It is undeniable that temperature is an operation parameter which, being on the one hand relatively easy to control, defines on the other hand the refrigerating or heating costs of the process, which might amount to a high fraction of the total costs and affect process sustainability. Taking the influence of temperature on ammonium removal rate into account can help optimizing the compromise between operation costs and removal efficiency.

\subsection{Mathematical models evaluation and calibration}

Using the Solver program in Microsoft ${ }^{\circledR}$ Excel 2007 software for minimizing the residual sum of squared errors between the experimental data and the model predictions, experimental data were accurately reproduced with Ratkowsky's expression (figure VI.2a), obtaining the following parameter values:

$$
b=0.36 \quad c=0.04 \quad T_{\min }=7.1^{\circ} \mathrm{C} \quad T_{\max }=47.4^{\circ} \mathrm{C}
$$

Statistical analysis was carried out using SPSS 16.1. Pearson correlation coefficient (P-value < 0.01) was 0.998 .

The cardinal temperature model with inflexion (CTMI) adopted by Bernard and Rémond (2012) for microalgal growth could also accurately reproduce the experimental data of ammonium removal rates (figure VI.2b). Pearson coefficient (P-value < 0.01) was 0.997 and the following parameter values were obtained:

$$
r_{N H 4 \max }=17.5 \mathrm{mg} \mathrm{N} \cdot 1^{-1} \cdot \mathrm{d}^{-1} \quad T_{\min }=8.8^{\circ} \mathrm{C} \quad T_{\max }=46.1^{\circ} \mathrm{C} \quad T_{\text {opt }}=31.3^{\circ} \mathrm{C}
$$

Maximum ammonium removal rate obtained is in agreement with our observations. Minimum and maximum temperatures are in accordance with the values obtained with Ratkowsky's model, as well as optimum temperature. Although Ratkowsky's model does not include a 
model parameter representing the optimum temperature as such, it does predict an optimum temperature around $30^{\circ} \mathrm{C}$ (see figure VI.2a).

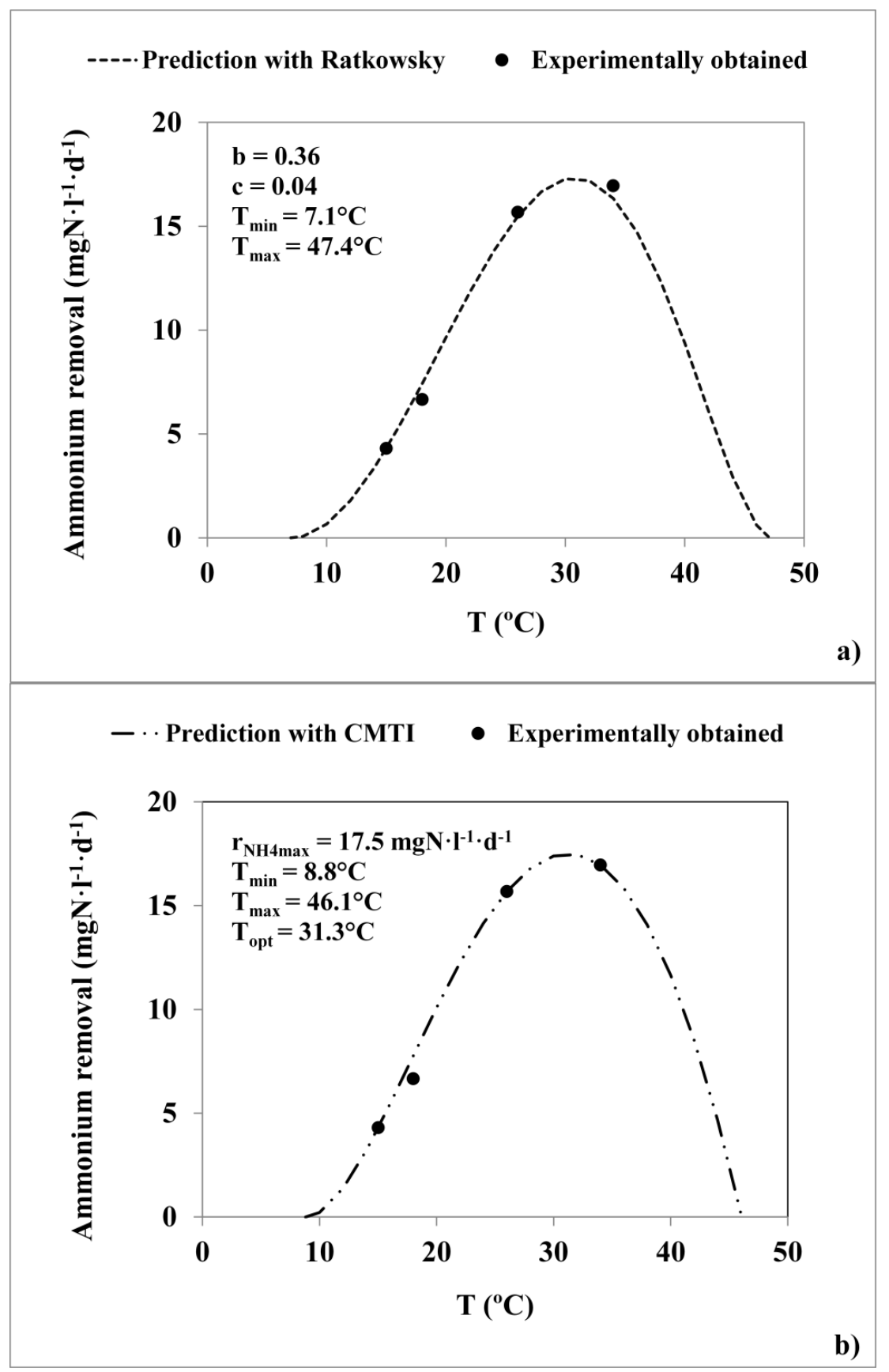

Figure VI.2: Data fitted using a) Ratkowsky's equation and b) the cardinal temperature model with inflexion.

The shape of the removal rate curve versus temperature is in the case of the CTMI more asymmetrical, showing a faster decrease after the optimum temperature. The area under the curve is also smaller, since the minimum temperature is slightly higher than in the case of the 
Ratkowsky's equation, and the maximum temperature is slightly smaller. Nonetheless, the predictions obtained with both models are very similar, and both models accurately reproduced the experimental data. Under these circumstances, the CTMI expression was preferred for modeling the effect of the temperature on the ammonium removal rate of Scenedesmus sp. under the studied conditions, since the parameters have a biological significance whose meaning is straightforward to understand, thus making calibration easier (for instance the decision for the initial values of parameters). In contrast, parameters $\mathrm{b}$ and $\mathrm{c}$ in Ratkowsky's model have no direct biological interpretation, being mathematical parameters defined in order to reproduce the experimental data.

Hodaifa et al. (2010) reported an optimum temperature for Scenedesmus obliquus growth rate of $29.6^{\circ} \mathrm{C}$, and Sánchez et al. (2008) reported, for Scenedesmus almeriensis, optimum growth temperatures of $30-35^{\circ} \mathrm{C}$ depending on light intensity and a maximum temperature of $48^{\circ} \mathrm{C}$. These parameters are in agreement with the ones obtained in this study.

\section{Conclusions}

This work describes the effect of temperature on ammonium removal rate of the microalgae Scenedesmus sp. The cardinal temperature model used by Bernard and Rédmond (2012) for microalgal growth was successfully used to fit the data and to obtain theoretical minimum, maximum and optimum temperatures for ammonium removal by Scenedesmus sp. This information is very useful for the operation of microalgae based wastewater treatment systems, since removal rates are affected by temperature, which is an easy to control parameter while at the same time responsible for a percentage of the operation costs.

\section{Acknowledgements}

This work has been supported by the Spanish Ministry of Economy and Competitiveness (MINECO, CTM2011-28595-C02-01/02), the European Regional Development Fund (ERDF) and the Spanish Ministry of Education, Culture and Sport (pre doctoral FPU fellowship to the first author (AP2009-4903)). The support is gratefully acknowledged. The authors would also like to thank the water management entities of the Generalitat Valenciana (EPSAR). 


\section{References}

Adesanya, V.O., Davey, M.P., Scott, S.S., Smith, A.G. (2014) Kinetic modelling of growth and storage molecule production in microalgae under mixotrophic and autotrophic conditions. Bioresource Technology 157, $293-304$.

APHA, AWWA and WEF (2005) Standard Methods for the Examination of Waters and Wastewaters, 21st ed. American Public Health Association, Washington, DC.

Aslan, S., Kapdan, I.K. (2006) Batch kinetics of nitrogen and phosphorus removal from synthetic wastewater by algae. Ecological Engineering 28, 64-70.

Béchet, Q., Shilton, A., Guieysse, B. (2013) Modeling the effects of light and temperature on algae growth: State of the arte and critical assessment for productivity prediction during outdoor cultivation. Biotechnology Advances 31, 1648-1663.

Bernard, O., Rémond, B. (2012) Validation of a simple model accounting for light and temperature effect on microalgal growth. Bioresource Technology 123, 520-527.

Geider, R.J., MacIntyre, H.L., Kana, T.M. (1998) A dynamic regulatory model of phytoplanktonic acclimation to light, nutrients, and temperature. Limnology and Oceanography 43, 679-694.

Giménez, J.B., Robles, A., Carretero, L., Duran, F., Ruano, M.V., Gatti, M.N., Ribes, J., Ferrer, J., Seco, A. (2011) Experimental study of the anaerobic urban wastewater treatment in a submerged hollow-fibre membrane bioreactor at pilot scale. Bioresource Technology 102, 8799-8806.

Hodaifa, G., Martínez, M.E., Sánchez. S. (2010) Influence of temperature on growth of Scenedesmus obliquus in diluted olive mill wastewater as culture medium. Engineering in Life Sciences 10 (3), 257-264.

Ketheesan, B., Nirmalakhandan, N. (2013) Modeling microalgal growth in an airlift-driven raceway reactor. Bioresource Technology 136, 689-696.

Kim, T-H, Lee, Y., Han, S-H, Hwang, S-J (2013) The effects of wavelength and wavelength mixing ratios on microalgae growth and nitrogen, phosphorus removal using Scenedesmus sp. for wastewater treatment. Bioresource Technology 130, 75-80.

Park, J., Jin, H. (2010) Ammonia removal from anaerobic digestion effluent of livestock waste using green alga Scenedesmus sp. Bioresource Technology 101, 8649-8657.

Ras, M., Steyer, J-P., Bernard, O. (2013) Temperature effect of microalgae: a crucial factor for outdoor production. Reviews in Environmental Science and Bio/Technology 12 (2), 153-164.

Ratkowsky, D.A., Lowry, R.K., McMeekin, T.A., Stokes, A.N., Chandler, R.E. (1983) Model for bacterial culture growth rate throughout the entire biokinetic temperature range. Journal of Bacteriology 154, 1222-1226.

Ruiz, J., Arbib, Z., Álvarez-Diaz, P.D., Garrido-Pérez, C., Barragán, J., Perales, J.A. (2013) Photobiotreatment model (PhBT): a kinetic model for microalgae biomass growth and nutrient removal in wastewater. Environmental Technology 34 (8), 979-991.

Ruiz-Martinez, A., Martin Garcia, N., Romero, I., Seco, A., Ferrer, J. (2012) Microalgae cultivation in wastewater: Nutrient removal from anaerobic membrane bioreactor effluent. Bioresource Technology 126, 247253. 
Sánchez, J.F., Fernández-Sevilla, J.M., Acién, F.G., Cerón, M.C., Pérez-Parra, J., Molina-Grima, E. (2008) Biomass and lutein productivity of Scenedesmus almeriensis: influence of irradiance, dilution rate and temperature. Applied Microbiology and Biotechnology 79, 719-729.

Tevatia, R., Demirel, Y., Blum, P. (2012) Kinetic Modeling of Photoautotropic Growth and Neutral Lipid Accumulation in terms of Ammonium Concentration in Chlamydomonas reinhardtii. Bioresource Technology $119,419-424$.

Voltolina, D., Gómez-Villa, H., Correa, G. (2005) Nitrogen removal and recycling by Scenedesmus obliquus in semicontinuous cultures using artificial wastewater and a simulated light and temperature cycle. Bioresource Technology 96, 359-362.

Wu, Y.H., Li, X., Yu, Y., Hu, H.Y., Zhang, T.Y., Li, F.M. (2013) An integrated microalgal growth model and its application to optimize the biomass production of Scenedesmus sp. LX1 in open pond under the nutrient level of domestic secondary effluent. Bioresource Technology 144, 445-451.

Wu, Y-H., Hu, H-Y., Yu, Y., Zhang, T-Y, Zhu, S-F, Zhuang, L-L, Zhang, X., Lu, Y. (2014) Microalgal species for sustainable biomass/lipid production using wastewater as resource: A review. Renewable \& Sustainable Energy Reviews 33, 675-688. 


\title{
Chapter VII
}

\section{Modeling light and temperature influence on ammonium removal by Scenedesmus sp. under outdoor conditions}

Ruiz-Martinez, A., Serralta, J., Seco, A., Ferrer, J. Modeling light and temperature influence on ammonium removal by Scenedesmus sp. under outdoor conditions. Submitted to Journal of Biotechnology, September 2015.

\begin{abstract}
The ammonium removal rate of the microalga Scenedesmus sp. was studied under outdoor conditions. Microalgae were grown in a 5001 flat-plate photobioreactor and fed with the effluent of a Submerged Anaerobic Membrane Bioreactor (SAnNMR). Temperature ranged between $9.5^{\circ} \mathrm{C}$ and $32.5^{\circ} \mathrm{C}$ and maximum light intensity was $1860 \mu \mathrm{mol} \cdot \mathrm{m}^{-2} \cdot \mathrm{s}^{-1}$. A maximum specific ammonium removal rate of $3.71 \mathrm{mg} \mathrm{NH}-\mathrm{N} \cdot \mathrm{g} \mathrm{TSS}^{-1} \cdot \mathrm{h}^{-1}$ was measured (at $22.6^{\circ} \mathrm{C}$ and with a light intensity of $\left.1734 \mu \mathrm{mol} \cdot \mathrm{m}^{-2} \cdot \mathrm{s}^{-1}\right)$. A mathematical model considering the influence of ammonium concentration, light and temperature was validated. The model successfully reproduced the observed values of ammonium removal rate obtained and it is thus presented as a useful tool for plant operation.
\end{abstract}





\section{Introduction}

Microalgae are photosynthetic microorganisms whose ability to eliminate inorganic nutrients from different kind of wastewaters is well known (Wu et al., 2014). Their application for such purposes has also the advantages of atmospheric $\mathrm{CO}_{2}$ fixation, less energy consumption than conventional wastewater treatment methods, and biomass generation, among others. Generated microalgal biomass can be used for biofuels obtention and as fertilizer (Brenan and Owende, 2010).

Predicting the behavior of microalgal cultures is a very complex task, especially when the cultivation takes place outdoors, under changing environmental conditions of light and temperature. Nutrient levels are also variable in applications which use real wastewaters as growth medium. Changing conditions, together with the microalgal responses to these external conditions (such as selfshading, photoacclimation or changes in pigments, metabolites and reserve compounds) and with the physical characteristics of the photobioreactor system (such as geometry and agitation, which influence mass and heat transfer) should all be taken into account in order to obtain the best reproduction of the processes taking place in the microalgal culture.

However, the higher the number of known phenomena taken into account, the higher the complexity of the models obtained. Thus, when a model is proposed in order to predict the microalgal behavior in a real wastewater treatment system, a compromise needs to be found between accuracy and ease of application and computation.

The aim of this work was to propose and validate a mathematical model which accounts for the effect of ammonium concentration, light and temperature on the microalgal ammonium removal rate under full scale changing outdoor conditions. For this, the authors proposed a multiplicative combination of mathematical expressions which are able to accurately reproduce experimental data under stable laboratory conditions (Ruiz-Martinez et al., 2014; Ruiz-Martinez et al., 2015a; Ruiz-Martinez et al., 2015b). The suitability of these expressions to also reproduce the observed ammonium removal rates taking place in a bigger scale under outdoor conditions was therefore tested and validated, and the corresponding parameters were obtained. 


\section{Material and methods}

\subsection{Microorganisms}

Microalgae were isolated from the walls of the secondary clarifier in the "Cuenca del Carraixet" WWTP (Valencia, Spain) and maintained in the laboratory in a 71 semicontinuous reactor (for details see Ruiz-Martinez et al., 2014 (Chapter IV)), using as growth medium the effluent of a submerged anaerobic membrane bioreactor (SAnMBR) described in Giménez et al., 2011. The biomass formed a stable ecosystem where the dominant microalgae belonged to the Chloroccocal order, of which $>99 \%$ to the Scenedesmus genus. The photobioreactor (PBR) was seeded with this culture (10\% of the PBR volume) and the effluent from the SAnMBR system (90\% of the PBR volume). Microalgae were then allowed to grow in batch mode until a concentration of $600 \mathrm{mg} \mathrm{TSS} \cdot \mathrm{1}^{-1}$ was reached.

\subsection{Experimental setup and operation}

Microalgae cultivation was performed during 30 days in a 5001 flat-plate PBR made of transparent methacrylate and placed outdoors, in the "Cuenca del Carraixet" WWTP. Its dimensions were $125 \times 200 \times 25 \mathrm{~cm}$ (height $\times$ length $\times$ width). The 125 × $200 \mathrm{~cm}$ surface (perpendicular to the ground) was facing south in order to improve solar irradiance. The PBR was continuously stirred by air sparging, which allowed homogenization of the culture and prevented wall fouling. $\mathrm{pH}$ was controlled at 7.5 by adding pure (99.9\%) $\mathrm{CO}_{2}$ through an automatic valve whenever the $\mathrm{pH}$ reached the maximum value established.

The PBR was fed with the effluent from the existing SAnMBR system described in Gimémez et al. (2011). This SAnMBR system is fed with the pre-treated urban wastewater (screening, degritter, and grease removal) of the "Cuenca del Carraixet" WWTP. Influent nutrient load was therefore variable $\left(46.9 \pm 4.3 \mathrm{mg} \mathrm{NH}-\mathrm{N} \cdot \mathrm{l}^{-1}\right.$ and $\left.5.9 \pm 1.3 \mathrm{mg} \mathrm{PO}_{4}-\mathrm{P} \cdot \mathrm{l}^{-1}\right)$, depending on the influent to the WWTP and on the performance of the SAnMBR plant. Nitrite and nitrate concentration were negligible $\left(\sim 0 \mathrm{mg} \cdot \mathrm{l}^{-1}\right)$, as expected from an anaerobic effluent.

The SAnMBR effluent was fed daily to the PBR in a total of 5 to 10 deliveries (depending on the cellular retention time (CRT)), which were evenly distributed during the light hours. The 
CRT at which the PBR was operated was varied during the operational period. It was established at 3 days during the first 5 days and at 5.5 days from day 6 until the end of the operational period. Temperature and solar irradiation varied freely at all times as a result of the changing environmental conditions.

A group of on-line sensors submerged in the reactor constantly monitored the culture. They consisted of the following: one pH-temperature transmitter (HachLange pHD-S sc), one turbidity sensor to measure total suspended solids (TSS) (HachLange SOLITAX sc), one dissolved oxygen (DO) sensor (HachLange LDO) and one ammonium-nitrate $\left(\mathrm{NH}_{4}-\mathrm{N}\right.$ and $\mathrm{NO}_{3}-\mathrm{N}$ ) concentration sensor (HachLange AN-ISE sc). An irradiation sensor (HOBO® Smart Sensor, s-lia-m003), which measured only the photosynthetically active radiation (PAR), was located on the vertical surface of the PBR facing south. Data was continuously acquired and saved on a PC during the 30 days of operation, during which the PBR was fed around 200 times.

\subsection{Analytical Methods}

Phosphate level in the PBR was determined weekly according to Standard Methods (APHA 2005, 4500-P-F) in a Smartchem 200 automatic analyzer (Westco Scientific Instruments, Westco). Samples were analyzed in duplicate.

\section{Results and discussion}

\subsection{Ammonium removal rates}

Figure VII.1 shows the evolution of light, temperature and ammonium concentration in the PBR on a sunny day when light intensity increased in the morning and decreased in the afternoon without important oscillations (dotted line). It was observed that temperature increase generally suffered a lag with respect to light intensity, so that maximum temperatures occurred during the last minutes of daylight (dashed line). Ammonium (filled line) started decreasing when light intensity increased (at sunrise), and continued to do so during the light hours, with the exceptions of the times when the SAnMBR effluent was added. At those points, ammonium concentration rapidly increased. Seven of these rapid increases can be seen 
in figure VII.1. For each day of the experiment, a temperature-light-ammonium profile was obtained. Since the PBR was placed outside, these profiles were different for each day.

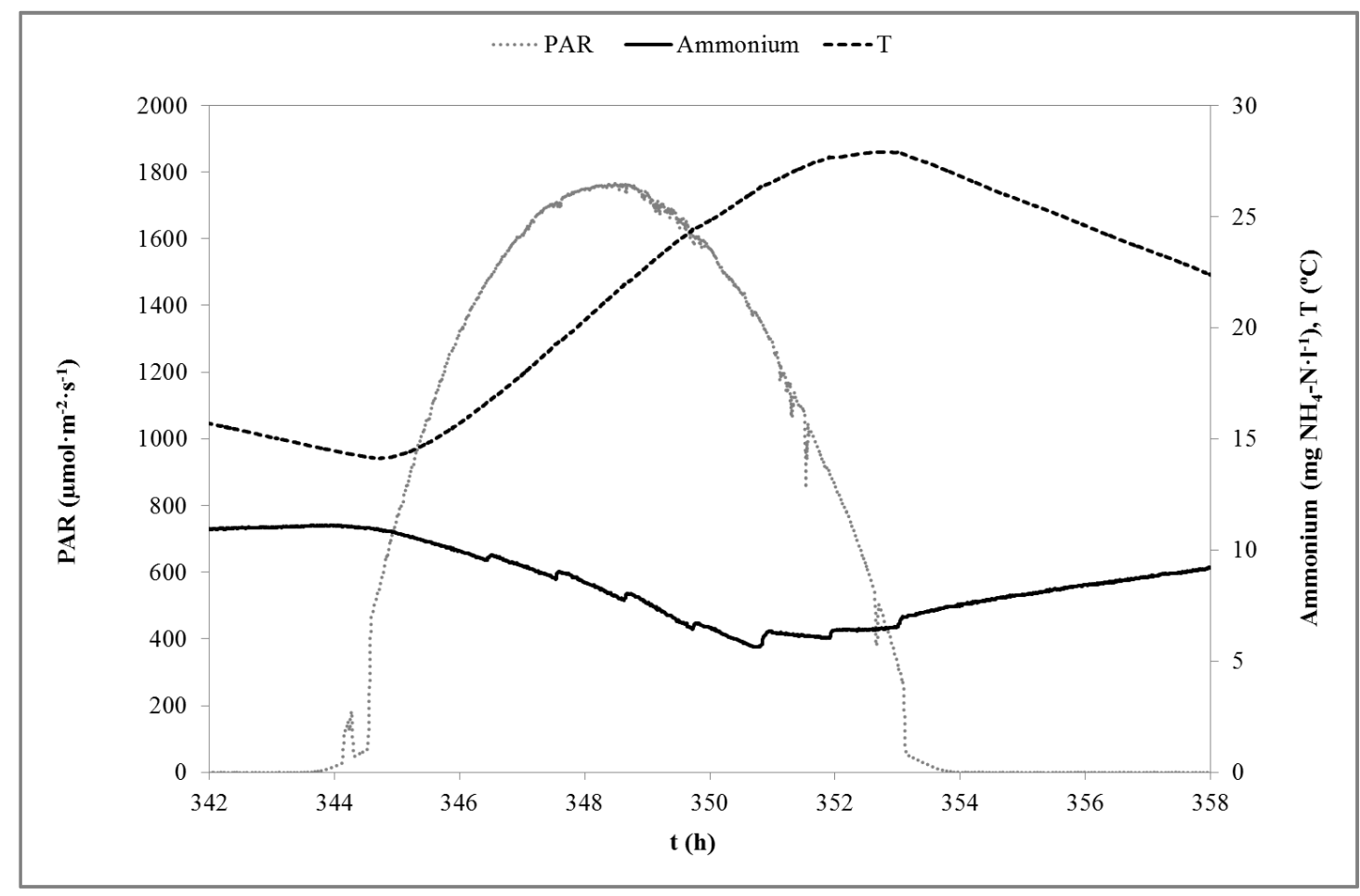

Figure VII.1: Ammonium, temperature and light intensity during day 14 of the experiment.

The data taken by the ammonium sensor revealed the decrease of ammonium to be linear between two consecutive feed deliveries. Ammonium decrease was due to microalgae activity, who took it up from the medium, provided the light intensity was high enough. Microalgal ammonium uptake rate after every SAnMBR effluent injection was thus calculated -using Microsoft (® Excel 2007- as a linear regression of the ammonium concentration values represented versus time. Data provided by the suspended solids sensor allowed calculating the specific ammonium uptake rate. PAR intensity and temperature were averaged (for each period of linear ammonium decrease between SAnMBR effluent additions) from the information recorded by the respective sensors. When the light oscillation was too abrupt data were discarded since an average value would not be representative. Thus, 183 sets of data were obtained, each of them consisting of four values: the measured specific ammonium removal rate immediately after the feed injection and the corresponding averaged ammonium concentration, temperature and light intensity to which the culture was subject during the period of linear ammonium decrease. 
Maximum light intensity was $1860 \mu \mathrm{mol} \cdot \mathrm{m}^{-2} \cdot \mathrm{s}^{-1}$ and temperature ranged between $9.5{ }^{\circ} \mathrm{C}$ and $32.6^{\circ} \mathrm{C}$. Suspended solids in the reactor were stable around $640 \mathrm{mg}$ TSS $\cdot 1^{-1}$ for the first 8 days and decreased afterwards to oscillate in the range of $320-480 \mathrm{mg} \mathrm{TSS} \cdot 1^{-1}$. Ammonium concentration ranged between 1.1 and $22.4 \mathrm{mg} \mathrm{NH} 4-\mathrm{N} \cdot 1^{-1}$. The changes in ammonium and biomass concentration were not only influenced by microalgal metabolism and environmental conditions, but also by pilot plant operation (mainly the modification in CRT). Phosphate

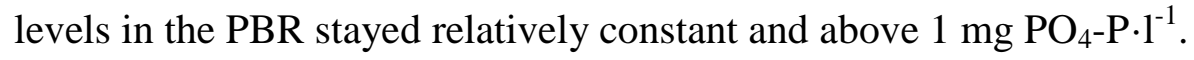

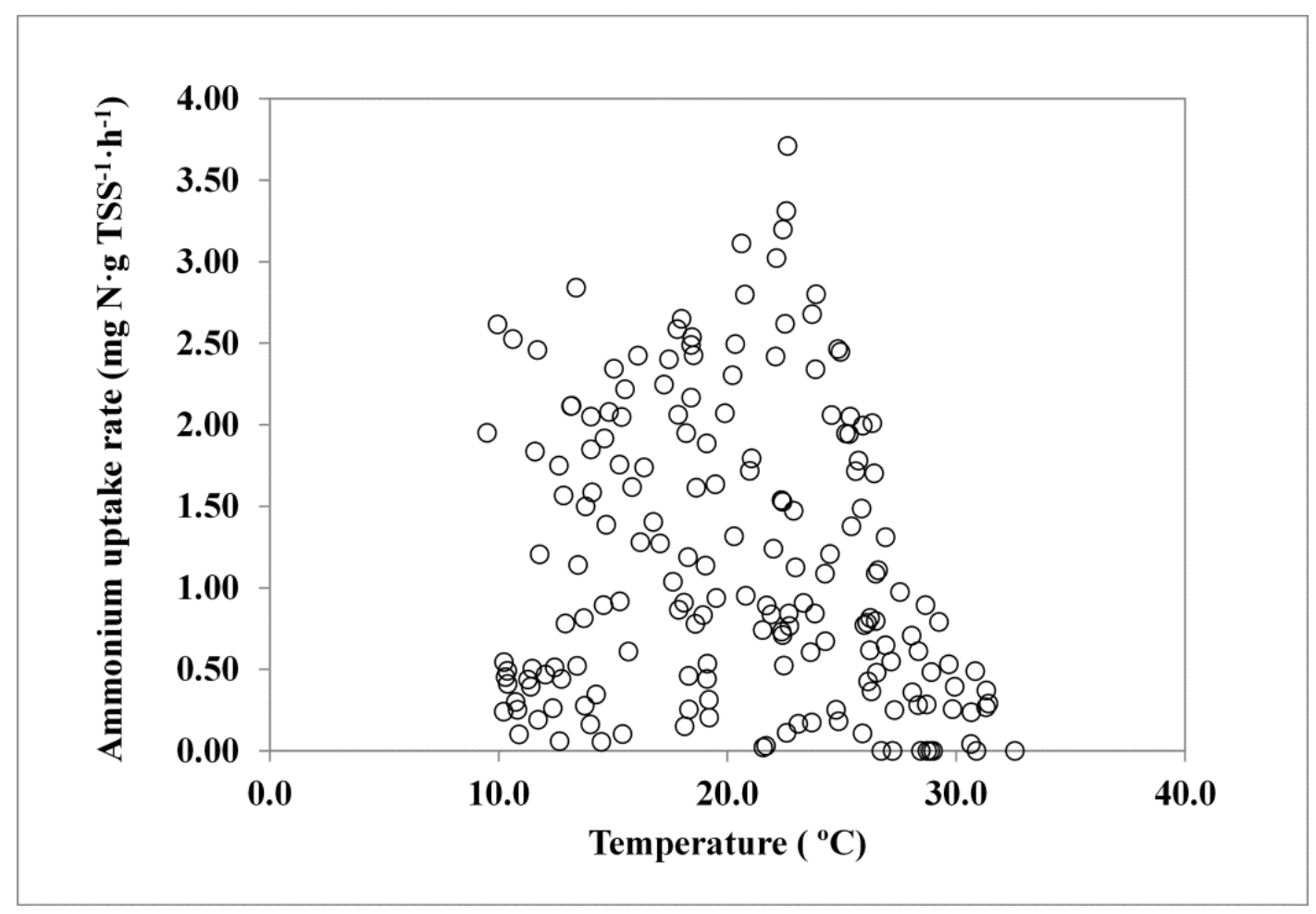

Figure VII.2: Calculated ammonium removal rates distributed along a temperature axis.

When the calculated ammonium removal rates are represented along a temperature axis, a bell-shaped distribution can be observed (figure VII.2). Since different removal rates were measured for the same temperature (data points situated vertically above each other along the whole temperature range), it is clear that other factors, such as light intensity and ammonium concentration, also affected the microalgal ammonium uptake rate. Maximum uptake rates increased with increasing temperature until reaching $22.6^{\circ} \mathrm{C}$, where the highest removal rate of the whole experimental period was obtained. Maximum ammonium uptake rates for each temperature decreased thereafter. The high ammonium removal rates (between 2 and $3 \mathrm{mg}$ $\mathrm{NH}_{4}-\mathrm{N} \cdot \mathrm{g} \mathrm{TSS}{ }^{-1} \cdot \mathrm{h}^{-1}$ ) obtained at times when average temperature was around $10^{\circ} \mathrm{C}$ correspond 
to high light average (> $\left.1100 \mu \mathrm{mol} \cdot \mathrm{m}^{-2} \cdot \mathrm{s}^{-1}\right)$. These are times around noon, when light intensity has increased rapidly and temperature is still low.

The maximum ammonium uptake rate measured was $1.54 \mathrm{mg} \mathrm{NH}-\mathrm{N} \cdot \mathrm{l}^{-1} \cdot \mathrm{h}^{-1}$, which is similar to the values reported by Wang and Lan (2011) (1.8 $\mathrm{mg} \mathrm{NH} \mathrm{NH}_{4} \mathrm{~N} \cdot \mathrm{l}^{-1} \cdot \mathrm{h}^{-1}$ for Neochloris oleoabundans) or Ackerstrom et al. (2014) (1.37-1.7 $\mathrm{mg} \mathrm{NH}_{4}-\mathrm{N} \cdot \mathrm{l}^{-1} \cdot \mathrm{h}^{-1}$ for Chlorella sp.) and higher than the value reported by McGinn et al. (2012) $\left(1 \mathrm{mg} \mathrm{NH}-\mathrm{N} \cdot \mathrm{l}^{-1} \cdot \mathrm{h}^{-1}\right.$ for Scenedesmus sp.). The corresponding maximum specific ammonium uptake rate was $3.71 \mathrm{mg} \mathrm{NH}_{4}-\mathrm{N} \cdot \mathrm{gTSS}^{-}$

${ }^{1} \cdot \mathrm{h}^{-1}$. This ammonium uptake rate corresponded to averaged ammonium concentration and light intensities of $7.7 \mathrm{mg} \mathrm{NH} 4-\mathrm{N} \cdot \mathrm{l}^{-1}$ and $1734 \mu \mathrm{mol} \cdot \mathrm{m}^{-2} \cdot \mathrm{s}^{-1}$, respectively.

\subsection{Model development}

A mathematical model was proposed to describe the influence of ammonium concentration, light and temperature on the ammonium removal rate observed in the PBR. Influence of intracellular phosphorus content was not taken into account, since the level of phosphate in the medium stayed above $1 \mathrm{mg} \mathrm{PO}_{4}-\mathrm{P} \cdot \mathrm{l}^{-1}$ during the whole duration of the study, and it was thus possible to assume that microalgae intracellular phosphorus concentration was relatively constant. This simplifies the effort and the time required to obtain the model input.

As previously proposed and validated for a laboratory scale microalgae culture (RuizMartínez et al., 2014 (Chapter IV)), the influence of ammonium concentration in the medium was represented using Monod kinetics (eq. VII.1), light influence was modeled by Steele equation (eq. VII.2) and temperature was modeled using the Cardinal Temperatures Model with inflexion (eq. VII.3) proposed by Bernard and Rémond (2012) for microalgae and previously used by the authors for modeling a laboratory scale microalgal system (RuizMartinez et al., 2015b (Chapter VI)):

$$
\begin{aligned}
& \frac{S_{N H 4}}{k_{S}+S_{N H 4}} \\
& \frac{I}{k_{i}} \cdot \exp \left(1-\frac{I}{k_{i}}\right) \\
& \frac{\left(T-T_{\max }\right) \cdot\left(T-T_{\min }\right)^{2}}{\left(T_{o p t}-T_{\min }\right) \cdot\left[\left(T_{o p t}-T_{\min }\right) \cdot\left(T-T_{o p t}\right)-\left(T_{o p t}-T_{\max }\right) \cdot\left(T_{o p t}+T_{\min }-2 T\right)\right]}
\end{aligned}
$$


where $S_{N H 4}\left(\mathrm{mg} \mathrm{N} \cdot 1^{-1}\right)$ represents ammonium concentration in the medium and $k_{S}\left(\mathrm{mg} \mathrm{N} \cdot 1^{-1}\right)$ is the semisaturation constant for ammonium. $I\left(\mu \mathrm{E} \cdot \mathrm{m}^{-2} \cdot \mathrm{s}^{-1}\right)$ is light intensity and $k_{i}\left(\mu \mathrm{E} \cdot \mathrm{m}^{-2} \cdot \mathrm{s}^{-1}\right)$ is the optimal light intensity. $T_{\min }\left({ }^{\circ} \mathrm{C}\right)$ is the temperature below which the growth is assumed to be zero, $T_{\max }\left({ }^{\circ} \mathrm{C}\right)$ is the temperature above which there is no growth and at temperature $T_{\text {opt }}$ $\left({ }^{\circ} \mathrm{C}\right)$ maximal growth rate occurs.

Thus, the expression used to predict microalgal specific ammonium removal rate was a combination of the above explained equations (eq. VII.4):

$r_{\text {spN }}=r_{\text {spNmax }} \frac{S_{N H 4}}{k_{S}+S_{N H 4}} \frac{I}{k_{i}} \exp \left(1-\frac{I}{k_{i}}\right) \frac{\left(T-T_{\max }\right) \cdot\left(T-T_{\min }\right)^{2}}{\left(T_{\text {opt }}-T_{\min }\right) \cdot\left[\left(T_{\text {opt }}-T_{\min }\right) \cdot\left(T-T_{\text {opt }}\right)-\left(T_{\text {opt }}-T_{\max }\right) \cdot\left(T_{\text {opt }}+T_{\min }-2 T\right)\right]}$

where $r_{\text {spNmax }}$ represents the maximum specific nitrogen uptake rate $\left(\mathrm{mg} \mathrm{N} \cdot \mathrm{h}^{-1} \cdot \mathrm{mg} \mathrm{TSS}^{-1}\right) . I$ was calculated as an average light intensity, taking into account the reactor's geometry and Lambert-Beer's Law (eq. VII.5) for representing the selfshading effect of the biomass:

$I=I_{0} \cdot \exp (-a \cdot T S S \cdot z)$

where $I_{0}\left(\mu \mathrm{E} \cdot \mathrm{m}^{-2} \cdot \mathrm{s}^{-1}\right)$ is incident light intensity, $a\left(\mathrm{~m}^{2} \cdot \mathrm{gTSS}^{-1}\right)$ is the microalgal self-shading factor, and $z(\mathrm{~m})$ is the distance from the surface of the reactor. As in previous studies (RuizMartinez et al., 2015a (Chapter V)) a microalgal self-shading factor of $0.0758 \mathrm{~m}^{2} \cdot \mathrm{g} \mathrm{TSS}^{-1}$ was used.

\subsection{Model calibration}

The 183 sets of data obtained allowed calibration of the proposed model, using the Solver program in Microsoft ${ }^{\circledR}$ Excel 2007 software for minimizing the residual sum of squared errors between the experimental data and the model predictions. The initial values for the model parameters were selected based on previous results (Ruiz-Martinez et al., 2014) and on the obtained experimental data (figure VII.2). The values obtained for the model parameters (Table VII.1) accurately reproduced the experimental data (figure VII.3). Statistical analysis was carried out using SPSS 16.1, which showed a Pearson correlation coefficient of 0.876 (Pvalue $<0.01)$. 
Table VII.1: parameters obtained during model calibration

\begin{tabular}{ccc}
\hline Parameter & Units & Obtained value \\
\hline $\mathrm{r}_{\mathrm{spNmax}}$ & $\left(\mathrm{mg} \mathrm{N} \cdot \mathrm{g} \mathrm{TSS}^{-1} \cdot \mathrm{h}^{-1}\right)$ & 4.7 \\
\hline$k_{S}$ & $\mathrm{mg} \mathrm{N} \cdot \mathrm{l}^{-1}$ & 2.5 \\
\hline$k_{I}$ & $\mu E \cdot \mathrm{m}^{2} \cdot \mathrm{s}^{-1}$ & 477 \\
\hline$T_{\min }$ & ${ }^{\circ} \mathrm{C}$ & 2 \\
\hline$T_{\max }$ & ${ }^{\circ} \mathrm{C}$ & 32 \\
\hline$T_{\text {opt }}$ & ${ }^{\circ} \mathrm{C}$ & 20.5 \\
\hline
\end{tabular}

The obtained maximum specific ammonium removal rate, $r_{s p N m a x}=4.7 \mathrm{mg} \mathrm{N} \cdot \mathrm{g} \mathrm{TSS}^{-1} \cdot \mathrm{h}^{-1}$, is in accordance with the maximum ammonium uptake rate measured in the experiment $(25 \%$ higher). A value of $2.5 \mathrm{mg} \mathrm{N} \cdot \mathrm{l}^{-1}$ for parameter $k_{S}$ implies a high affinity of the microalgae for ammonium, which is reasonable for the given growth conditions. $k_{i}$ presents a higher value than the parameters obtained in our previous laboratory scale studies $\left(180\right.$ and $200 \mu \mathrm{E} \cdot \mathrm{m}^{2} \cdot \mathrm{s}^{-1}$ according to Ruiz-Martinez et al., 2014 and Ruiz-Martinez et al., 2015b, respectively), possibly since in the outdoor pilot plant the microalgal culture is adapted to higher light intensities, and thus the optimal intensity for the present culture is higher than for the microalgae which have grown under lower light intensities in the laboratory experiments of the cited works. According to Richmond (1986), species cultivated under outdoor conditions should be able to tolerate light variations and should have a high light saturation constant.

While the minimum temperature obtained in the present study is comparable to that one previously found in the laboratory $\left(8.8^{\circ} \mathrm{C}\right.$ in Ruiz-Martinez et al., 2015b (Chapter VI)), the optimum and maximum temperatures obtained in the present experiment are sensibly smaller. This discrepancy is possible due to the very different conditions in which microalgae are growing in the PBR outdoors and in the laboratory. Xin et al. (2011) actually reported an 
optimal temperature of $20^{\circ} \mathrm{C}$ for Scenedesmus sp. biomass production, which is in agreement with the result obtained in this study.

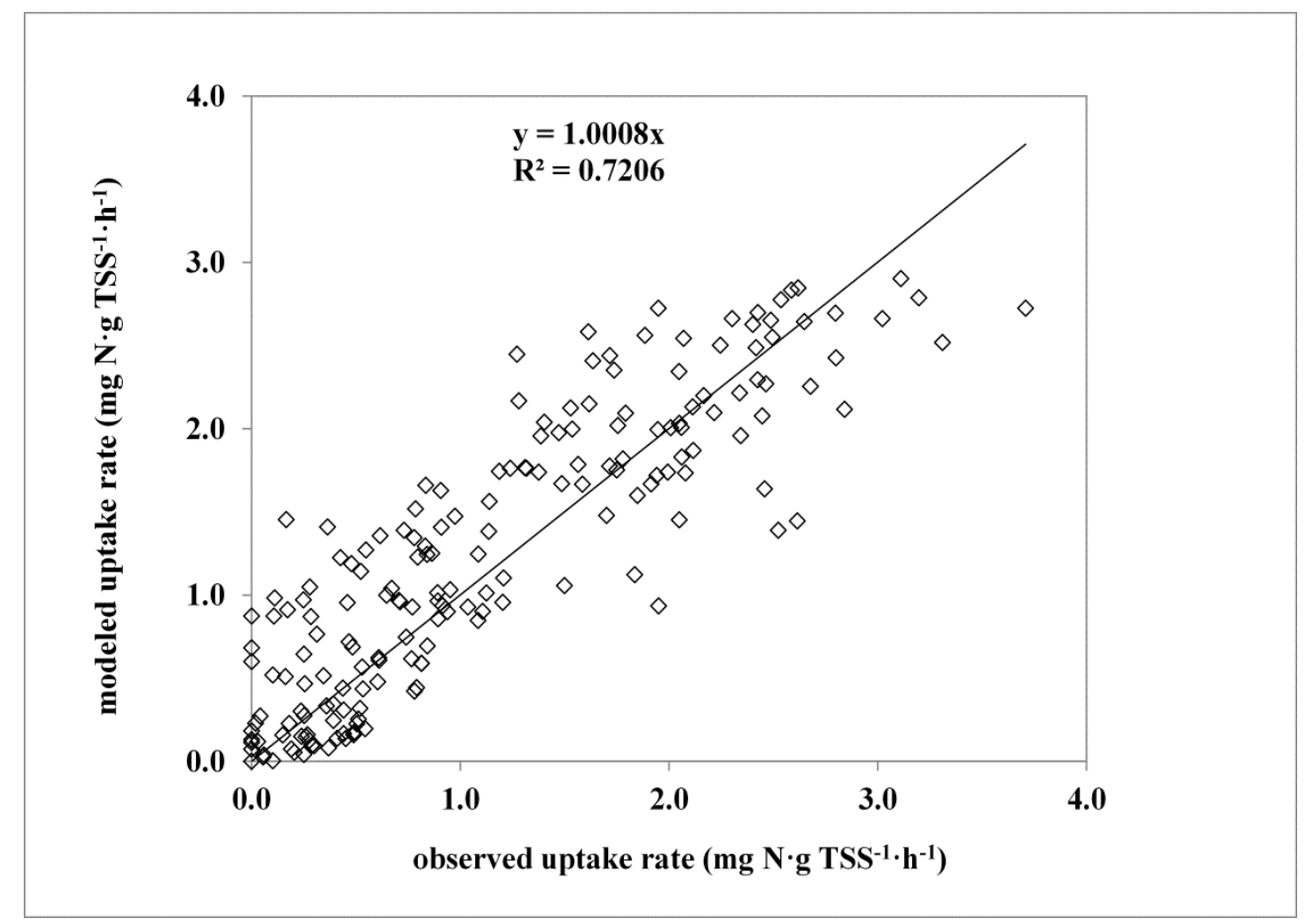

Figure VII.3: Parity plot comparing model predictions with observed ammonium uptake rates, using model parameters as indicated in table VII.1.

It can therefore be assumed that the mathematical expressions which reproduce data obtained in the laboratory can also be combined and used to predict the behavior of microalgae cultivated under outdoor conditions, which constitutes a useful tool for plant design and operation. It has been proved that the model proposed is easy to implement, since calculations are not complex and model input can be continuously obtained with the sensors that monitor the basic culture parameters

\section{Conclusions}

The present work proposed a mathematical model which represents microalgal ammonium removal rate taking into account the ammonium concentration in the medium, light and temperature. Influences of these parameters were represented with functions which had previously been validated for laboratory scale cultures: a Monod kinetics term, the Steele function and the cardinal temperatures model, respectively. The combination of these terms 
successfully reproduced the experimental data, therefore validating its suitability for use at full scale and under changing outdoor conditions as well. However, since the microalgal culture was adapted to different conditions, different model parameters were obtained.

\section{Acknowledgements}

This research work has been supported by the Spanish Ministry of Education, Culture and Sports (CTM2011-28595-C02-01/02) jointly with the European Regional Development Fund (ERDF) and Generalitat Valenciana (ACOMP2013/203) which are gratefully acknowledged. This research was also supported by the Spanish Ministry of Education, Culture and Sport via a pre doctoral FPU fellowship to the first author (AP2009-4903). The authors also gratefully acknowledge the support from the water management entities of the Generalitat Valenciana (EPSAR).

\section{References}

Ackerström, A.M., Mortensen, L.M., Rusten, B., Gislerod, H.R. (2014) Biomass production and nutrient removal by Chlorella sp. as affected by sludge liquor concentration. Journal of Environmental Management 144, 118-124.

APHA, AWWA and WEF (2005) Standard Methods for the Examination of Waters and Wastewaters, 21st ed. American Public Health Association, Washington, DC.

Bernard, O., Rémond, B. (2012) Validation of a simple model accounting for light and temperature effect on microalgal growth. Bioresource Technology 123, 520-527.

Brenan, M., Owende, P. (2010) Biofuels from microalgae - A review of technologies for production, processing, and extraction of biofuels and co-products. Renewable and Sustainable Energy Reviews 14, 557-577.

Giménez, J.B., Robles, A., Carretero, L., Duran, F., Ruano, M.V., Gatti, M.N., Ribes, J., Ferrer, J., Seco, A. (2011) Experimental study of the anaerobic urban wastewater treatment in a submerged hollow-fibre membrane bioreactor at pilot scale. Bioresource Technology 102, 8799-8806.

McGinn, P.J., Dickinson, K.E., Park, K.C., Whitney, C.G., MacQuarrie, S.P., Black, F.J., Frigon, J-C, Guiot, S.R., O'Leary, S.J.B. (2012) Assessment of the bioenergy and bioremediation potentials of the microalga Scenedesmus sp. AMDD cultivated in municipal wastewater effluent in batch and continuous mode. Algal Research 1, 155-165.

Richmond, A. (1986) Outdoor mass cultures of microalgae. In: Handbook of microalgal mass cultures, edited by Richmond A., pp. 285-329 CRC Press, Boca Raton, Florida.

Ruiz-Martinez, A., Martin Garcia, N., Romero, I., Seco, A., Ferrer, J. (2012) Microalgae cultivation in wastewater: Nutrient removal from anaerobic membrane bioreactor effluent. Bioresource Technology 126, 247253. 
Ruiz-Martinez, A., Serralta, J., Pachés, M., Seco, A., Ferrer, J. (2014) Mixed microalgae culture for ammonium removal in the absence of phosphorus: Effect of phosphorus supplementation and process modeling. Process Biochemistry 49, 2249-2257.

Ruiz-Martinez, A., Serralta, J., Romero, I., Seco, A., Ferrer, J. (2015a) Effect of intracellular P content on phosphate removal in Scenedesmus sp. Experimental study and kinetic expression. Bioresource Technology 175, 325-332.

Ruiz-Martinez, A., Serralta, J., Seco, A., Ferrer, J. (2015b) Effect of temperature on ammonium removal in Scenedesmus sp. Bioresource Technology 191, 346-349.

Wang, B., Lan, C. (2011) Biomass production and nitrogen and phosphorous removal by the green alga Neochloris oleoabundans in simulated wastewater and secondary municipal wastewater effluent. Bioresource Technology 102 (10), 5639-44.

Wu, Y-H., Hu, H-Y., Yu, Y., Zhang, T-Y, Zhu, S-F, Zhuang, L-L, Zhang, X., Lu, Y. (2014) Microalgal species for sustainable biomass/lipid production using wastewater as resource: A review. Renewable and Sustainable Energy Reviews 33, 675-688.

Xin, L., Hong-Ying, H., Zhang, Y-P (2011) Growth and lipid accumulation properties of a freshwater microalga Scenedesmus sp. under different cultivation temperature. Bioresource Technology 102, 3098-3102. 



\title{
Chapter VIII
}

\section{Behavior of mixed Chlorophyceae cultures under prolonged dark exposure. Respiration rate modeling}

Ruiz-Martinez, A., Serralta, J., Seco, A., Ferrer, J. Behavior of mixed Chlorophyceae cultures under prolonged dark exposure. Respiration rate modeling. Accepted for revision in Ecological Engineering, July 2015.

\begin{abstract}
The behavior of three different microalgal cultures, when exposed for a long period ( $>48 \mathrm{~h})$ to dark conditions, was studied with a methodology based on respirometry. The cultures were transferred to darkness and the oxygen evolution in the reactors was monitored after successive air injections. Several sequential oxygen uptake rates were thus calculated and a respiration constant, assuming a first order decay of a fraction of the biomass, was obtained by calibration. Initial specific oxygen uptake rates were in the range of 0.9-5.1 $\mathrm{mg} \mathrm{O}_{2} \cdot \mathrm{g} \mathrm{TSS}^{-1} \cdot \mathrm{h}^{-1}$ and dark respiration constants in the range of $0.005-0.018 \mathrm{~h}^{-1}$.
\end{abstract}





\section{Introduction}

Interest in microalgae has risen in the last decade due to the potential these microorganisms have on fighting climate change (Kumar et al., 2011), producing renewable biofuels (Parmar et al., 2011) and removing pollutants from wastewater (Rawat and Kumar, 2010).

Predicting the behavior of microalgal cultures is a very complex task, especially when outdoor conditions (variable light and temperature) and operational conditions (light attenuation, photobioreactor dimensions, hydrodynamics, etc.) should be taken into account. However, the wider the knowledge about microalgal behavior and the ability to predict it, the easier it will be to optimize their cultivation and to fully develop their potential.

Different approaches have been taken to model algal growth. Many models were developed in order to represent the behavior of microalgae in rivers and lakes (Buzzelli et al., 2014; Reichert et al., 2001; Muylaert et al., 2005). Other models have been developed in order to predict metabolites production (lipids, carbohydrates, substances of interest, etc.) (Adesanya et al., 2014; Mairet et al., 2011; Packer et al., 2011). Some authors have also taken into account physical phenomena such as variable light and temperature, mixing, or gas transfer. (GarcíaCamacho et al., 2012; Pegallapati and Nirmalakhandan, 2012; Vunjak-Novakovic et al., 2005).

When microalgae are cultivated in closed photobioreactors, microalgal biomass density increases and, due to selfshading, a fraction of the culture cannot receive the amount of light required for photosynthesis. This fact makes it necessary to take respiration losses into account, since they will be the dominant metabolic activity in the dark regions. This will also be the case for the whole culture during dark periods (nights) and inside dark plant elements. In these cases, microalgal growth in the reactor will cease and therefore biomass loss will take place. Under optimal conditions, respiration rates are about $20-30 \%$ of growth rates, but the ratio of respiration to growth increases under suboptimal conditions (Geider and Osborne, 1989). Several authors report respiration losses of $2-10 \%$ of biomass in outdoor cultivation systems (Kethesaan and Nirmalakhandan, 2013), although losses of up to $35 \%$ of the biomass have been reported during nighttime (Vonshak, 1987, for Spirulina). 
When modeling microalgal growth there is usually a hidden term in the "net" growth rate which accounts for some dark respiration losses. Indeed, a fraction of respiration losses is proportional to microalgal growth. This fraction corresponds to the cost of biosynthesis: ion uptake, transformation of ions into intermediates, synthesis of cell structural and functional metabolites, etc. The other term which contributes to respiration losses is the maintenance metabolic costs (also called basal respiration: motility, volume regulation, turnover of macromolecules). These costs are, by definition, independent of growth and proportional to biomass (Geider et al., 1998).

Knowing the rate of microalgal respiration in the dark is important for microalgal growth modeling under outdoor conditions, since biomass production and net carbon balance are affected by day/night cycles and by the volume fraction of the photoreactors which is in the dark (Bernard, 2011). This affects the economic and environmental balance of the system. Moreover, gaining knowledge on the behavior of microalgae under prolonged exposure to dark will help designing other wastewater treatment systems with opaque modules such as those for microalgae storage, filtration, etc.

The aim of this work was to study the behavior of different microalgal cultures during prolonged exposure to darkness ( $>48 \mathrm{~h}$ ). To our knowledge, no such long exposures have been previously studied. Based on dissolved oxygen measurements (respirometry), a methodology was developed to obtain the associated respiration rate. A comparison of the behavior of the cultures and a possible explanation for the differences among them is also given

\section{Materials and methods}

\subsection{Microorganisms}

Three different types of microalgae cultures were studied. Microalgae had previously been isolated from the walls of the secondary clarifier in the "Cuenca del Carraixet" WWTP (Valencia, Spain) and maintained as a mixed autochthonous culture in the laboratory in 71 semicontinuous reactors (for a more detailed explanation of the reactors setup see RuizMartinez et al., 2014 (Chapter IV)). The effluent of a submerged anaerobic membrane bioreactor (SAnMBR, described in Giménez et al., 2011) was used as growth medium. 
The cultures used in the experiments were the following:

- Dark kept culture (DC): this culture was stored in a dark fridge $\left(8^{\circ} \mathrm{C}\right)$ for 15 days previous to the respirometric study. The culture was allowed to increase temperature until reaching $20^{\circ} \mathrm{C}$ during 12 hours prior to the respirometry. It consisted of a mixed culture of microalgae dominated by the class Chlorophyceae.

- Nutrient limited culture (LC): this culture was the accumulated purge of a semicontinuous reactor kept under laboratory conditions as explained above. The purge was accumulated in a translucent container with no agitation nor $\mathrm{CO}_{2}$ addition. $\mathrm{pH}$ did not increase higher than 8 . The respirometric study started $48 \mathrm{~h}$ after nutrient depletion, a total of $96 \mathrm{~h}$ after being purged from the reactor. The microalgae present were Chlorophyceae, of which $>99 \%$ from the Chlorococcales order.

- Replete culture (RC): this culture was directly taken from a running semicontinuous reactor and placed under dark conditions immediately. The microalgae present were Chlorophyceae, of which $>90 \%$ from the Chlorococcales order.

\subsection{Experimental setup and operation}

The experiments were carried out in three photobioreactors (PBRs). Each PBR consisted of a cylindrical, transparent methacrylate tank (20 cm internal diameter) with total and working volumes of 10 and 7 1, respectively. The PBRs were (not hermetically) sealed and they were kept in the dark in a climatic chamber with a temperature set point of $20{ }^{\circ} \mathrm{C}$. A pH probe connected to a multiparametric analyzer (CONSORT C832, Belgium) recorded the $\mathrm{pH}$ in the reactors, which ranged in all cases between 7 and 8.4.

Under the above mentioned conditions photosynthesis could not take place and only respiration (oxygen consumption for maintenance) occurred. Dissolved oxygen concentration (DO) was measured using a Cellox 325 electrode (WTW, Germany) connected to an oximeter (Oxi 320, SET WTW, Germany). The measured dissolved oxygen values were logged in a PC using data acquisition software. Ambient air was injected at a flow rate of $0.8-1.01 \cdot \mathrm{min}^{-1}$ through four fine bubble diffusers mounted at the bottom whenever DO concentration was below $1 \mathrm{mg} \mathrm{O} \mathrm{O}_{2} \cdot \mathrm{l}^{-1}$ until it reached again a concentration of $6 \mathrm{mg} \mathrm{O} \cdot \mathrm{I}^{-1}$. The experiments were 
programmed to last $50 \mathrm{~h}$. However, in view of the results (see section 3) in the case of LC it was prolonged until $200 \mathrm{~h}$ and in the case of RC until $600 \mathrm{~h}$.

\subsection{Analytical methods}

Ammonium and phosphate were determined according to Standard Methods (APHA, 2005) (4500-NH3-G and 4500-P-F, respectively) in a Smartchem 200 automatic analyzer (Westco Scientific Instruments, Westco). Total suspended solids (TSS) were determined according to Standard Methods (APHA, 2005). All analyses were conducted in duplicate.

\section{Results and discussion}

\subsection{Dissolved Oxygen Measurements and Respiration Rates}

The time evolution of dissolved oxygen concentrations was obtained for the three experiments (figures VIII.1a, b and c). Due to microalgal consumption in the dark, oxygen concentration decreased linearly after each air addition until it reached $1 \mathrm{mg} \mathrm{O} \cdot \mathrm{I}^{-1}$ and the aeration was switched on again. Successive Oxygen Uptake Rates (OUR, $\mathrm{mg} \mathrm{O}_{2} \cdot \mathrm{l}^{-1} \cdot \mathrm{h}^{-1}$ ) were calculated as linear regressions $\left(\mathrm{R}^{2}>0.95\right.$ for all) of these decreasing stretches (figure VIII.1a). Due to the aeration, the DO concentration increased up to $6 \mathrm{mg} \mathrm{O}_{2} \cdot \mathrm{l}^{-1}$, and then the blower was switched off. A significant decrease was observed in most cases immediately afterwards (first 10 minutes). This corresponded to the re-establishing of the equilibrium and had been previously observed in blank reactors with only tap water (data not shown).

Successive OURs became smaller with time, which means that endogenous respiration declined in all cases. This showed that, due to the adverse environmental conditions (darkness, absence of nutrients) and the consumption of microalgal reserves, the metabolic activity decreased. The calculated OURs $\left(\mathrm{mg} \mathrm{O}_{2} \cdot \mathrm{l}^{-1} \cdot \mathrm{h}^{-1}\right)$ during each experiment are represented in figure VIII.2 versus time. It can be appreciated that the OUR values did not decrease linearly with time. Instead, they decreased exponentially, approaching a stable value in the long term (hence the prolonged experiment time for LC and RC).

Figure VIII.1: Dissolved Oxygen concentration during the experiments. DC (a), LC (b) and RC (c). 

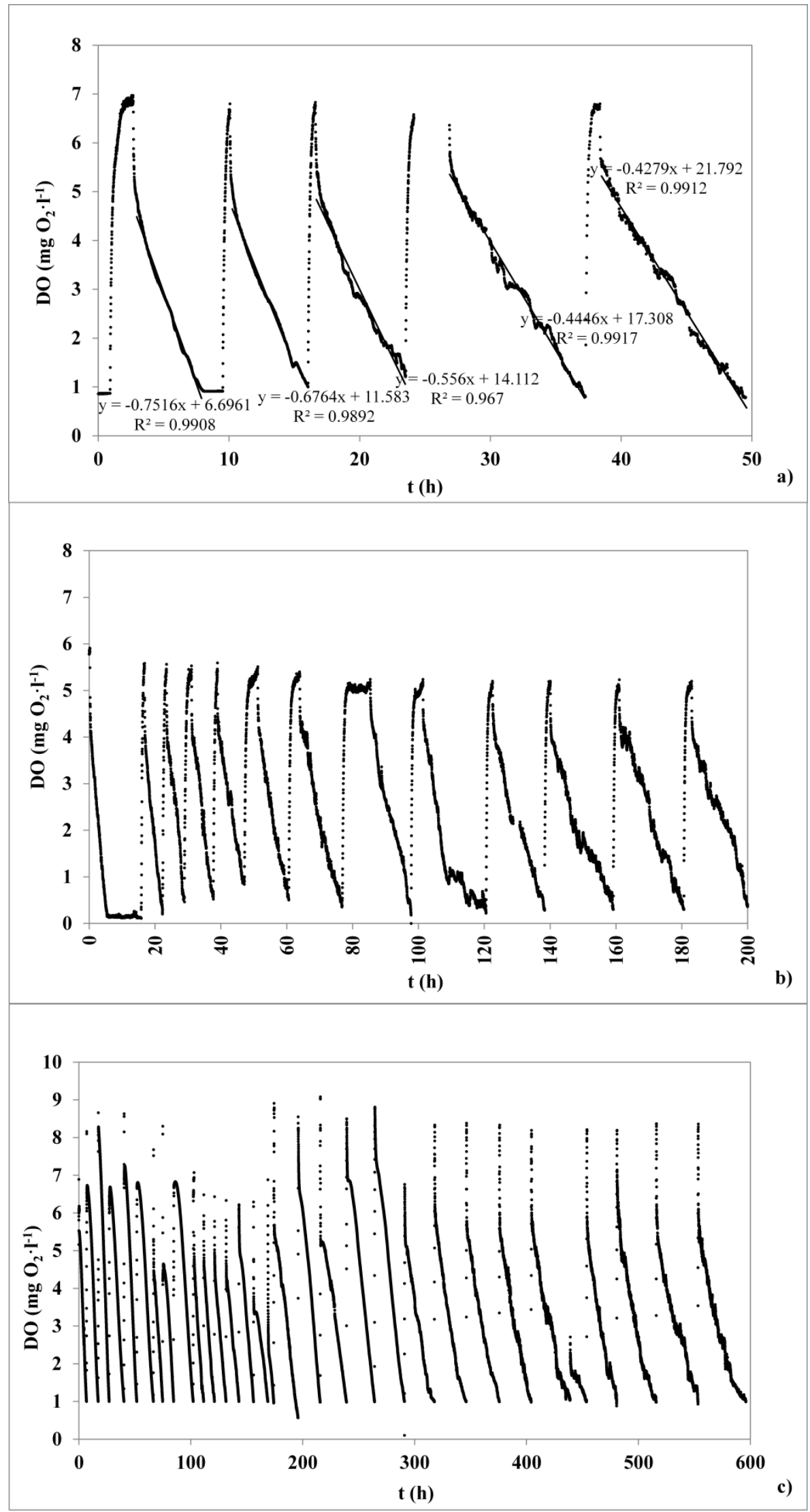


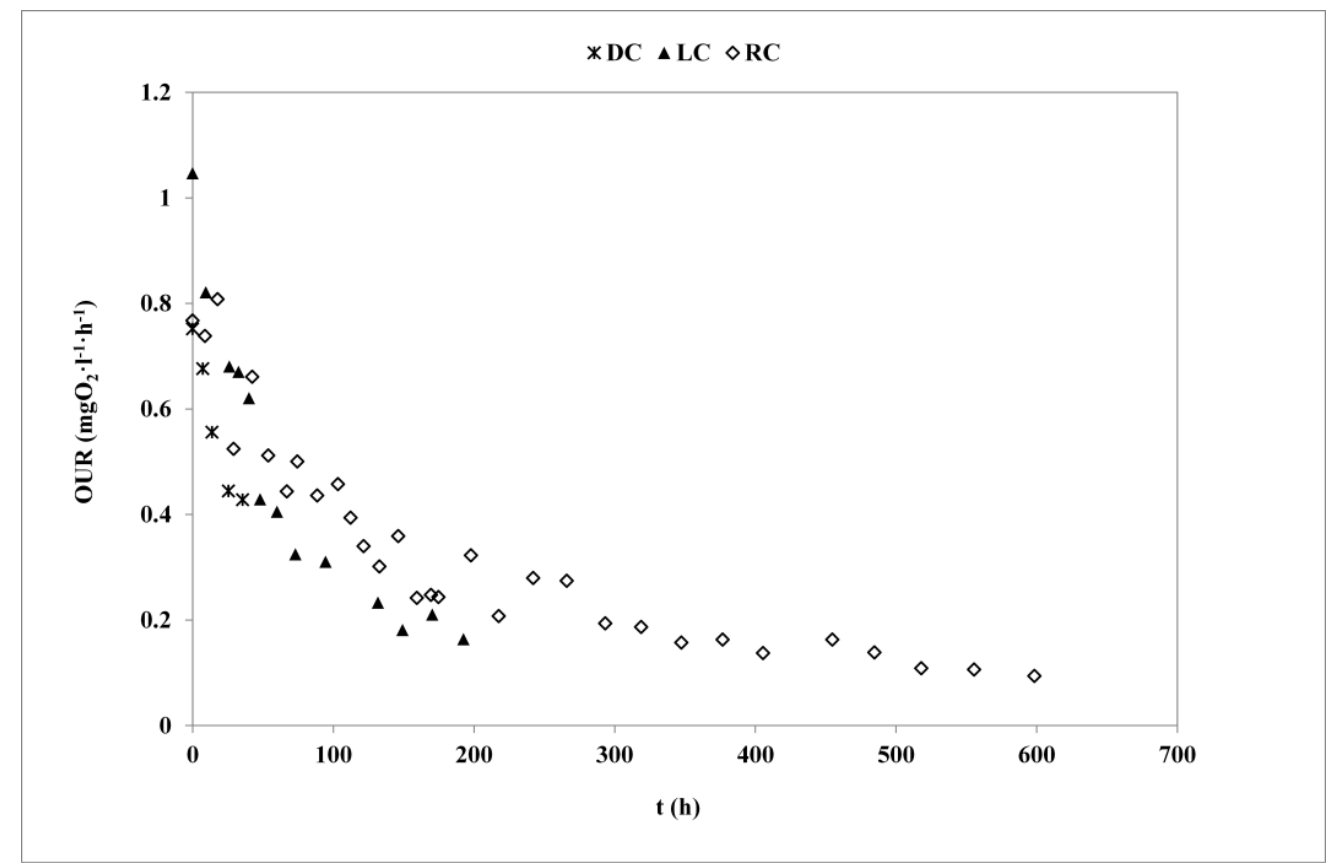

Figure VIII.2: OURs $\left(\mathrm{mg} \mathrm{O}_{2} \cdot \mathrm{l}^{-1} \cdot \mathrm{h}^{-1}\right)$ measured over time in DC, LC and RC systems

At the beginning of the experiments, the OURs were $0.75 \mathrm{mg} \mathrm{O}{ }^{-1} \cdot \mathrm{h}^{-1}$ for DC and RC, and 1 $\mathrm{mg} \mathrm{O} \mathrm{O}_{2} \mathrm{l}^{-1} \cdot \mathrm{h}^{-1}$ for LC. These values are however not directly comparable, due to the different TSS in the cultures. For comparison, TSS were measured in each reactor at $t=0$ of each experiment, allowing the calculation of the specific respiration rate. Results are shown in table VIII.1: specific respiration rate was highest for LC and similar values were obtained for DC and RC.

Table VIII.1: Initial specific respiration rates and obtained respiration constants for the three cultures

\begin{tabular}{cccc}
\hline & $\begin{array}{c}\text { Dark } \\
\text { Culture }\end{array}$ & $\begin{array}{c}\text { Limited } \\
\text { Culture }\end{array}$ & $\begin{array}{c}\text { Replete } \\
\text { culture }\end{array}$ \\
\hline Initial TSS $\left(\mathbf{m g ~ T S S} \cdot \mathbf{I}^{\mathbf{1}}\right)$ & 588 & 206 & 833 \\
\hline Initial dark respiration rate & 1.3 & 5.1 & 0.9 \\
$\left(\mathbf{m g ~ O}_{\mathbf{2}} \cdot \mathbf{g ~ T S S}^{-\mathbf{1}} \cdot \mathbf{h}^{-\mathbf{1}}\right)$ & & & \\
\hline $\boldsymbol{k}_{\boldsymbol{r}}\left(\mathbf{h}^{-\mathbf{1}}\right)$ & 0.018 & 0.014 & 0.005 \\
\hline
\end{tabular}


Respiration rates depend on the physiological state of the culture (growth state, age of the culture) and environmental conditions (nutrients, cell content, light intensity, temperature) (Geider, 1989). For instance, Grobbelaar and Soeder (1985) reported lower respiration rates after growth at optimal temperature than at other temperatures, and after growth under weaker illumination than under stronger irradiations. Ogbonna and Tanaka (1996) also found that microalgae with higher cell carbohydrate content showed higher biomass loss during the night.

The values obtained in this study are in accordance with the range obtained by Grobbelar and Soeder (1985). The lowest value corresponded to RC, the replete or "healthiest" culture, whereas the highest value corresponded to LC, the culture which was subject to nutrient stress and higher light (lower biomass concentration and therefore less selfshading results in higher light). A similar value was obtained for DC, the culture which, although it had been exposed to very dim light, was in the worst state regarding nutrient levels at the beginning of the respirometry.

Oxygen consumption of the microalgal cultures during the first hours after dark exposure (for instance, 12 hours of darkness in outdoor nights) can be estimated from the results of this study. Assuming that there is no microalgal growth during a long dark period, the COD balance indicates that the oxygen consumption rate is equal to the biomass COD loss. Therefore, the culture RC would present the smaller night COD loss: $11 \mathrm{mg}$ COD. $\mathrm{g} \mathrm{TSS}^{-1}$, the culture DC would present a loss of $16 \mathrm{mg} \mathrm{COD} \cdot \mathrm{g} \mathrm{TSS}^{-1}$, and cultures under nutrient limiting conditions would loose around $61 \mathrm{mg} \mathrm{COD} \cdot \mathrm{g} \mathrm{TSS}^{-1}$, which could represent between 3 and $4 \%$ of the biomass.

The resistance stage in which the culture entered allowed the microalgae to keep their photosynthetic capacity until the end of the respirometric experiment: a rapid increase in dissolved oxygen was observed when the light was switched on at the end of the three experiments (data not shown). This described survival strategy is in accordance with previous observations (Myers and Cramer, 1947; Geider et al., 1998) although not such long exposures to dark had been reported up to date. 


\subsection{Data fit and calibration}

During endogenous respiration, microalgae catabolize accumulated metabolites, usually carbohydrates (Geider and Osborne, 1989, Ogbonna and Tanaka, 1996). Due to the observed OURs (figure VIII.2), and in agreement with literature (Buehner et al., 2009), in this study an exponential decay of biomass was assumed:

$\frac{d x}{d t}=-k_{r} \cdot x$

where $x$ represents the biomass, expressed in $\operatorname{mg} \operatorname{COD} \cdot 1^{-1}$ and $k_{r}\left(\mathrm{~h}^{-1}\right)$ is the respiration constant.

And since biomass decay equals the oxygen consumption rate:

$\frac{d x}{d t}=-k_{r} \cdot x=\frac{d O_{2}}{d t}$

The combination and integration of equations VIII.1 and VIII.2 renders:

$\exp \left(-k_{r} \cdot t\right)=\frac{\left[\frac{d O_{2}}{d t}\right]_{t}}{\left[\frac{d O_{2}}{d t}\right]_{0}}$

which enabled the reproduction of the obtained data (figures VIII.3a, b and c) and determine with a good fit $\left(\mathrm{R}^{2}>0.9\right.$ in all cases) the respiration constant $k_{r}$ for each culture (table VIII.1). An ANOVA analysis (carried out using SPSS 16.1) of the three sets of data represented in figures VIII.3a, b and c confirmed the difference $(\mathrm{P}$-value < 0.05$)$ among the cultures.

The obtained $k_{r}$ values were, as expected, different for each culture. Other authors have determined smaller $\left(0.006 \mathrm{~h}^{-1}\right.$ for Nannochloropsis by Hueseman et al., 2013, $0.0004 \mathrm{~h}^{-1}$ for Chlorella by Decostere et al., 2013), similar $\left(0.015 \mathrm{~h}^{-1}\right.$ for Nannochloropsis and Scenedesmus by Pegallapati and Nirmalakhandan, 2012) and higher (Sciandra, 1985 obtained a range of $0.006-0.03 \mathrm{~h}^{-1}$ for Phaeodactylum) respiration constants. 


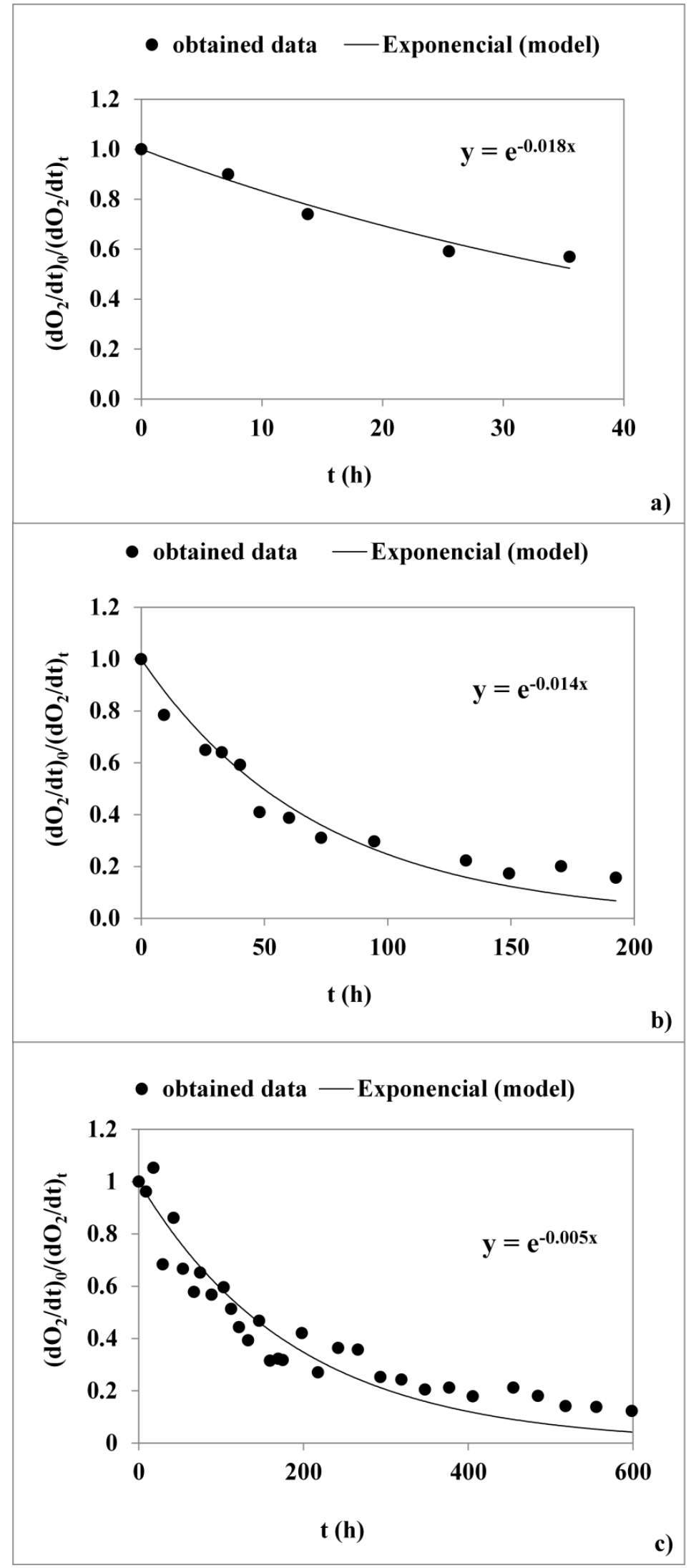

Fig VIII.3: Data fit to equation VIII.3 for DC (a), LC (b) and RC (c). 
A higher respiration rate (DC) means a faster decrease in the OUR values consecutively measured, and a lower respiration rate achieved after a set amount of time. A smaller respiration rate $(\mathrm{RC})$ means a more stable value of the consecutive OURs measured, which become smaller with time but at a much slower speed.

\section{Conclusions}

In this study specific dark respiration rates were obtained for three different microalgal cultures by measuring dissolved oxygen evolution after being transferred to darkness. The smallest specific respiration rate $\left(0.9 \mathrm{mg} \mathrm{O} \mathrm{O}_{2} \cdot \mathrm{g} \mathrm{TSS}^{-1} \cdot \mathrm{h}^{-1}\right)$ was obtained for a fresh and nutrient replete Chlorophyceae culture, whereas the highest specific respiration rate $\left(5.1 \mathrm{mg} \mathrm{O}_{2} \cdot \mathrm{g} \mathrm{TSS}^{-}\right.$ ${ }^{1} \cdot \mathrm{h}^{-1}$ ) corresponded to a nutrient limited culture previously grown under continuous illumination. The methodology used proved useful for the calibration of an exponential decay equation and obtention of the respiration constants for each case, which ranged from $0.005 \mathrm{~h}^{-1}$ to $0.018 \mathrm{~h}^{-1}$. The accuracy of current basic models which otherwise do not take respiration into account could be improved by including this decay equation and determining the corresponding respiration constant.

\section{Acknowledgements}

This research work has been supported by the Spanish Ministry of Economy and Competitiveness (MINECO, CTM2011-28595-C02-01/02) jointly with the European Regional Development Fund (ERDF) which are gratefully acknowledged. This research was also supported by the Spanish Ministry of Education, Culture and Sport via a pre doctoral FPU fellowship to the first author (AP2009-4903). The authors would also like to thank the water management entities of the Generalitat Valenciana (EPSAR).

\section{References}

Adesanya, V.O., Davey, M.P., Scott, S.S., Smith, A.G. (2014) Kinetic modelling of growth and storage molecule production in microalgae under mixotrophic and autotrophic conditions. Bioresource Technology 157, 293 -304.

APHA, AWWA and WEF (2005) Standard Methods for the Examination of Waters and Wastewaters, 21 st ed. American Public Health Association, Washington, DC. 
Bernard, O. (2011) Hurdles and challenges for modelling and control of microalgae for $\mathrm{CO}_{2}$ mitigation and biofuel production. Journal of Process Control 21 (10), 1378-1389.

Buehner, M.R., Young, P.M., Willson, B., Rausen, D., Schoonover, R., Babbitt, G., and Bunch, S. (2009) Microalgae Growth Modeling and Control for a Vertical Flat Panel Photobioreactor. American Control Conference, Hyatt Regency Riverfront, St. Louis, MO, USA, June 10-12, 2009.

Buzzeli, C., Doering, P.H., Wan, Y., Sun, D., Fugate, D. (2014) Modeling ecosystem processes with variable freshwater inflow to the Caloosahatchee River Estuary, southwest Florida. I. Model development. Estuarine, Coastal and Shelf Science 151, 256-271.

Decostere, B., Janssens, N., Alvarado, A., Maere, T., Goethals, P., Van Hulle, S.W.H., Nopens, I. (2013) A combined respirometer-titrimeter for the determination of microalgae kinetics: Experimental data collection and modelling. Chemical Engineering Journal 222, 85-93.

Garcia-Camacho, F., Sánchez-Mirón, A., Molina-Grima, E., Camacho-Rubio, F., Merchuck, J.C. (2012) A mechanistic model of photosynthesis in microalgae including photoacclimation dynamics. Journal of Theoretical biology 304, 1-15.

Geider, R., Osborne, B.A. (1989) Respiration and microalgal growth: a review of the quantitative relationship between dark respiration and growth. New Phytology 112, 327-341.

Geider, R.J., MacIntyre, H.L., Kana, T.M. (1998) A dynamic regulatory model of phytoplanktonic acclimation to light, nutrients, and temperature. Limnology and Oceanography 43, 679-694.

Giménez, J.B., Robles, A., Carretero, L., Duran, F., Ruano, M.V., Gatti, M.N., Ribes, J., Ferrer, J., Seco, A. (2011) Experimental study of the anaerobic urban wastewater treatment in a submerged hollow-fibre membrane bioreactor at pilot scale. Bioresource Technology 102, 8799-8806.

Grobbelaar JU., Soeder, C.J. (1985) Respiration losses in planktonic green algae cultivated in raceway ponds. Journal of Plankton Research 7, 497-506.

Hueseman, M.H., Van Wagenen, J., Miller, T., Chavis, A., Hobbs, S., Crowe, B. (2013) A Screening Model to Predict Microalgae Biomass Growth in Photobioreactors and Raceway Ponds. Biotechnology and Bioengineering 110 (6), 1583-1594.

Ketheesan, B., Nirmalakhandan, N. (2013) Modeling microalgal growth in an airlift-driven raceway reactor Bioresource Technology 136, 689-696.

Kumar K, Dasgupta CN, Nayak B, Lindblad P, Das D. (2011) Development of suitable photobioreactors for $\mathrm{CO}_{2}$ sequestration addressing global warming using green algae and cyanobacteria. Bioresource Technology 102(8):4945-4953.

Mairet, F., Bernard, O., Masci, P., Lacour T., Sciandra, A. (2011) Modelling neutral lipid production by the microalga Isochrysis aff. galbana under nitrogen limitation. Bioresource Technology 102, 142-149.

Muylaert, K., Tackx, M., Vyverman, W. (2005) Phytoplankton growth rates in the freshwater tidal reaches of the Schelde Estuary (Belgium) estimated using a simple light-limited primary production model. Hydrobiologia 540, $127-140$.

Myers, J., Cramer, M. (1948) Metabolic conditions in Chlorella. The Journal of general physiology 32 (1), 103 110. 
Ogbonna, J.C., Tanaka, H. (1996) Night biomass loss and changes in biochemical composition of cells during light/dark cyclic culture of Chlorella pyrenoidosa. Journal of Fermentation and Bioengineering 82 (6), 558-564.

Packer, A., Li, Y., Andersen, T., Hu, Q., Kuang, Y., Sommerfeld, M. (2011) Growth and neutral lipid synthesis in green microalgae: A mathematical model. Bioresource Technology 102, 111-117.

Parmar A, Singh NK, Pandey A, Gnansounou E, Madamwar D. (2011) Cyanobacteria and microalgae: a positive prospect for biofuels. Bioresource Technology 102(22):10163-10172.

Pegallapati, A.K., Nirmalakhandan, N. (2012) Modeling Algal Growth in Bubble Columns under Sparging with $\mathrm{CO}_{2}$-enriched Air. Bioresource Technology 124, 137-145.

Rawat, I., Ranjith Kumar, R. (2010) Dual role of microalgae: Phycoremediation of domestic wastewater and biomass production for sustainable biofuels production. Applied Energy 88, 3411-3424.

Reichert, P., Borchardt, D., Henze, M., Rauch, W., Shanahan, P., Somlyódy, L., Vanrolleghem, P. (2001) River Water Quality Model no. 1 (RWQM1): II. Biochemical process equations. Water Science and Technoloy 43 (5), 11-30.

Ruiz-Martinez, A., Martin Garcia, N., Romero, I., Seco, A., Ferrer, J. (2012) Microalgae cultivation in wastewater: Nutrient removal from anaerobic membrane bioreactor effluent. Bioresource Technology 126, $247-$ 253.

Sciandra, A. (1986) Study and modelling of a simple planktonic system reconstituted in an experimental microcosm. Ecological Modelling 34, 61-82.

Vonshak A. (1987) Mass production of Spirulina: an overview. In Biotecnologie per la produzione di Spirulina, ed. L.Tomaselli. CNR IPRA, Rome, pp. 9-14.

Vunjak-Novakovic, G., Kim, Y., Wu, X., Berzin, I., Merchuk, J.C. (2005) Air-Lift Bioreactors for Algal Growth on Flue Gas: Mathematical Modeling and Pilot-Plant Studies. Industrial and Engineering Chemistry Research 44, 6154-6163. 
Chapter IX

Summary and general discussion 



\section{Summary and general discussion}

Anaerobic membrane bioreactors present a number of advantages when compared with aerobic treatments, such as less sludge production, lower energy demand and biogas generation. A pilot-scale AnMBR treating municipal wastewater has been evaluated with promising COD removal rates, but ammonium and phosphate are still present in the effluent at concentrations unsuitable for discharge. In this thesis the removal of these inorganic nutrients by means of microalgae cultivation was studied.

First of all, microalgae were isolated from a local wastewater treatment plant and a polyculture was established under laboratory conditions. The ability of an autochthonous microalgae consortium to grow on the AnMBR effluent was thus demonstrated. The effluent was not diluted, supplemented nor sterilized. The nutrient levels of the growth medium were therefore oscillating daily, depending on the pilot plant performance. The most abundant groups present in the autochthonous polyculture were Chlorophyceae and Cyanobacteria.

Chapters II and III represent the proof of concept that this mixed culture is capable of satisfactory nutrient removal from the SAnMBR effluent:

In Chapter II, a semi-batch cultivation mode was maintained, testing cellular retention times from 2 to 4 days. Maximum ammonium and phosphate removal rates in the wastewater were

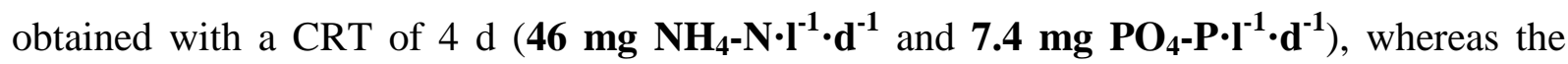
highest eliminations per reactor volume were achieved under a CRT of $2 \mathrm{~d}$. Continuous light and light-dark cycles were applied, showing that the continuously illuminated cultures were able to achieve very low nutrient levels, and that deprivation of light had stronger influence on biomass growth than on nutrient removal. The results obtained in this first study suggest that further analysis is necessary to determine the optimal combination of CRT and light cycles in each case, since several factors such as wastewater flow, water quality, biomass generation and reactor or illumination costs must be taken into consideration.

In Chapter III, the stability of the proposed system for nutrient removal of the SAnMBR effluent was further tested: a semicontinuous reactor for microalgal culture was set up and 
operated for 42 days. A CRT of $2 \mathrm{~d}$ and continuous illumination were chosen in order to optimize reactor volume and biomass production, respectively. Ammonium and phosphate levels in the culture fluctuated, as expected, according to the wastewater load entering the reactor, while on average $39 \mathrm{mg} \mathrm{NH}-\mathrm{NH}_{4} \cdot \mathbf{I}^{-1} \cdot \mathbf{d}^{-1}$ and $7.3 \mathrm{mg} \mathrm{PO} \mathbf{P O}_{4}-\mathbf{P} \cdot \mathbf{l}^{-1} \cdot \mathbf{d}^{-1}$ were removed. These removal rates were higher than those previously obtained in Chapter II under the same CRT and light conditions, probably due to improvements in reactor operation and control and because of the adjustment of the biomass population to the medium. It was demonstrated that excellent water quality can be obtained with a stable system load. Results also showed that phosphorus is the limiting nutrient in the anaerobic effluent to be treated, since it was almost completely removed.

Along the first experiments conducted, a clear decrease in Cyanobacteria was observed while the Chlorophyceae cell count increased by an order of magnitude. This consistently repeated thereafter, and thus the naturally obtained polyculture evolved into cultures where the species Scenedesmus sp. or Chlorococcum sp. clearly dominated, possibly depending on the specific culture conditions, which were, in the laboratory, different from their natural habitat. These prevalent strains were able to proliferate more efficiently in the culture, the composition of which therefore naturally changed towards a monoculture (see Appendix). In other words: the wastewater effluent to be treated was used to feed a mixed microalgal culture and by doing so the strain composition of the culture adjusted to the new conditions. This adjustment gave the security that the species finally present were the best performers, in the given conditions, amongst the different species originally present. This mechanism confers great robustness to the system proposed and makes its industrial application for wastewater treatment a realistic option. It is indeed known that native strains from local environments perform better outdoors than selected strains from culture collections (Challagulla et al., 2015), and a naturally occurring strain selection points at the best candidates on each occasion.

Since phosphorus had demonstrated to be the limiting nutrient in the anaerobic effluent, two experiments were designed to study the influence of prolonged phosphorus limitation in the culture. These studies confirmed the influence of intracellular phosphorus content both in ammonium and phosphate removal. They are presented in Chapters IV and V. 
Chapter IV demonstrated that ammonium and phosphate uptake are two independent processes, since ammonium removal still took place in a P-free medium. However, Pstarving progressively decelerated ammonium uptake (from 0.6 to $0.09 \mathrm{mg} \mathrm{N} \cdot \mathrm{mg} \mathrm{VSS}^{-1} \cdot \mathrm{h}^{-}$ ${ }^{1}$ ). Analogously, an increase in the intracellular $\mathrm{P}$ content of the biomass, through $\mathrm{P}$ supplementation in the medium, enhanced the ammonium removal rate and brought it to initial values. The nitrogen uptake rate in the studied Chlorococcum sp. culture decreased considerably below the threshold of around $2.2-2.6 \%(\mathrm{w} / \mathrm{w})$ of internal phosphorus, whereas around a content of $1 \%(\mathrm{w} / \mathrm{w})$ the microalgal culture was unsuitable for ammonium removal applications due to the slow rate obtained. The internal state of the microalgae with regard to phosphorus content was therefore established as an important parameter to determine ammonium removal. A mathematical model based on the Hill function was proposed to reproduce this influence. The model, which also contemplated the effect of light and of ammonium concentration, was calibrated and validated.

The influence of light was demonstrated to be an important addition to the proposed model, even under the studied conditions of constant artificial illumination. The reason for this lies in the selfshading effect of the biomass. In every culture, the effective light intensity inside the reactor (and away from its surface) decreases exponentially due to light attenuation and according to the Lambert-Beer law. If biomass concentration increases, the light attenuation effect becomes stronger, and this in turn makes microalgal growth decrease. Constant illumination does not mean, therefore, constant effective light at the disposal of the microorganisms, nor constant growth, even if every other environmental condition remains unchanged. For that reason, light influence on microalgal growth needs to be taken into account (for which the Steele function was proposed in chapters IV, V and VII of this thesis), whereas available light intensity needs to be calculated considering the microalgal biomass concentration (making use of the Lambert-Beer law).

Chapter V determined the effect of phosphorus cellular content on the phosphate uptake rate, confirming that a P-starved culture takes up phosphate faster than a P-replete one. A minimum P content of $0.11 \%$ (w/w) was achieved, and the highest specific phosphate removal rate measured was $6.5 \mathrm{mg} \mathrm{PO}_{4}-\mathrm{P} \cdot \mathrm{g} \mathrm{TSS}^{-1} \cdot \mathrm{h}^{-1}$. Microalgae with a cellular $\mathrm{P}$ content of $0.6 \%$ $(\mathrm{w} / \mathrm{w})$ presented $50 \%$ of the maximum removal rate. The lowest phosphate uptake rate measured was $0.28 \mathrm{mg} \mathrm{PO}_{4}-\mathrm{P} \cdot \mathrm{g} \mathrm{TSS} \mathrm{TS}^{-1} \cdot \mathrm{h}^{-1}$, although it was noteworthy that values of 
microalgal phosphate removal rates found in literature were in the same range (Dickinson et al., 2013, Aravantinou et al., 2013). This might be because studies of phosphate elimination with microalgae are normally done under nutrient sufficient conditions and not under Plimited conditions. Obtained experimental data were best reproduced by a combination of the Steele equation (to represent the effect of light) and the Hill function (to represent the influence of intracellular phosphorus). The model was again calibrated and the corresponding parameters for Scenedesmus sp. obtained.

Further research related to cellular $\mathrm{P}$ content should aim at understanding how $\mathrm{P}$ starving affects cell composition, since measured $\mathrm{P}$ content has proved to -under certain circumstances- become very low, while still a minimum amount of phosphorus is known to be vital for some components of the microalgal cells (such as ATP, DNA or NADPH). Theoretical calculations of minimum cellular $\mathrm{P}$ requirements for such components could be then connected and compared to measured values in practice, which would help understanding the microalgal metabolism under P starving conditions.

After light, temperature is the most important factor for microalgae culturing. Since the Steele equation had already been successfully used to reproduce light influence on the microalgal ammonium and phosphate removal rates (Chapters IV and V), an experiment was designed in order to determine the temperature influence and to select an equation which accurately describes it. This experiment is presented in Chapter VI. The Ratkowsky equation and the Cardinal Temperatures Model were able to successfully reproduce the experimental data, including the ammonium uptake rate decrease at temperatures higher than the optimum temperature. Since exceeding maximum temperatures could result in the total loss of the culture, this information is of vital importance for outdoor cultivation of microalgae -where there is often no strict temperature control. Both models rendered similar maximum, optimum and minimum temperatures for a Scenedesmus sp. culture $\left(46{ }^{\circ} \mathrm{C}, 31{ }^{\circ} \mathrm{C}\right.$ and $9{ }^{\circ} \mathrm{C}$, respectively). The Cardinal Temperatures Model was preferred since its use is more intuitive, given the biological significance of all its parameters. This model was applied in the work presented in Chapter VII.

Given that the final purpose of this thesis is the treatment of an existing wastewater from an existing anaerobic MBR, scaling up the proposed cultivation system implies not only 
increasing the reactor volume but also working under varying outdoor conditions. The evolution of a microalgal culture under changing light intensities and temperatures increases in complexity, and therefore the control of a photobioreactor under such circumstances. Still, in Chapter VII the equations previously selected for reproducing light and temperature influence on ammonium removal under constant light and temperature were tested. A Scenedesmus sp. culture was grown in a 5001 flat-plate photobioreactor placed outdoors, situated downstream of the SAnMBR pilot plant and fed with its effluent in a semicontinuous mode. Ammonium removal rate was monitored for 30 days, and measured ammonium removal rates were sensibly higher than those observed under laboratory conditions. The suggested model (a multiplicative model composed of Steele, CTM and Monod equations) was able to reproduce the experimental data, although the accuracy decreased when compared to the results obtained previously in the laboratory. Taking into account the simplifications assumed and the ease of its application (only ammonium concentration, light intensity and temperature need to be measured), a slight accuracy loss can be considered an acceptable compromise. It can therefore be concluded that the proposed model is suitable for predicting ammonium removal rates under outdoor conditions.

The experiment presented in Chapter VII also demonstrated that re-calibration of the model is necessary before it can be used under different environmental conditions, and/or for different microalgae species or consortia, since some parameters obtained in Chapter VII differed from those previously obtained in Chapters IV, V and VI. Those parameters were the optimal light intensity and minimum, optimum and maximum temperatures. Optimal light intensity was -not surprisingly- higher for the microalgae cultivated outdoors, since the culture was in that case subject to higher light intensities. Minimum, maximum and optimum temperatures were higher for the culture grown under laboratory conditions (Chapter VI), possibly since the Scenedesmus sp. strains for which higher temperatures are more favorable to growth survived and dominated the culture in that case. Since the usual temperatures outdoors were lower (Chapter VII), it is assumed that the Scenedesmus sp. strains for which lower temperatures are more favorable to growth dominated, in that case, after some cultivating time. This connects with the previously discussed theory that strain composition adjustment renders a culture of best performers. The ammonium semisaturation constant was 
smaller in the culture grown under outdoor conditions, showing that the affinity of those microalgae for ammonium was higher.

Light intensity in outdoor experiments was higher than the intensity provided by artificial illumination in the laboratory. Therefore, higher ammonium removal rates were observed and higher biomass concentrations, at least during daytime, could be attained. In this case, a larger fraction of the photobioreactor could become a dark area, where respiration losses are more significant than photosynthesis. Regardless of this, a culture grown under outdoor conditions is subjected to day/night cycles, and therefore a non-trivial biomass loss takes place during nighttime. For these reasons, a study was conducted to calculate the microalgal (dark) respiration constant by means of a methodology based on respirometry. A first order decay of a fraction of the biomass was assumed, and different respiration constants were obtained for different cultures. The results of this study -which allow calculations of biomass loss in dark areas of the reactor, in dark equipment units and during nighttime-, are shown in Chapter VIII. The study of a basic selection of processes taking place in microalgal cultivation for nutrient removal was thus completed.

The research conducted in this thesis validates the theory that a wild microalgal culture is able to grow in an anaerobic effluent containing mainly ammonium and phosphate. The growth is maintained based solely on this effluent, while removal of an important fraction of the nutrients takes place. Natural adjustment of the strains that compose the total population takes place, and the mixed culture becomes practically a monoculture of the best suited species for enduring the prevailing conditions. The system is a promising and robust option for wastewater treatment, since excellent water quality has been obtained under laboratory conditions. However, future research should still aim at achieving lower nitrogen and phosphorus concentrations, so that legal discharge limits are fully met. A successful scale-up is predicted, since no dilution nor sterilization seem to be needed for the endurance of the culture. Problems with invading species are not expected, given that the culture is the result of the combination of autochthonous microalgae present in the environment with the waste effluent used as growth medium. On the other hand, PBRs like the one presented in Chapter VII can be installed in parallel configuration, although important factors have to be taken into consideration, such as available light regime, seasonal variations and space use. 
On the other hand, this thesis presents valid equations for reproduction of the observed phenomena. The influence of internal parameters (intracellular $\mathrm{P}$ content) and external conditions (light and temperature) on phosphate and ammonium removal can be predicted using the developed models. This facilitates the mathematical simulation of the system, so that future research can be conducted in the direction of developing new strategies for optimizing nutrient removal and biomass production.

Some possible strategies include, for instance, phosphate addition for improving ammonium removal rates when intracellular phosphate content is too low. Phosphate can be obtained from other points of the WWTP, such as the centrate from sludge digestion (after nitrogen recovery, which could take place via ammonia stripping), thus avoiding the need of artificial fertilizers. Whether this is a viable option or not, can be elucidated with help of the work here presented. Artificial illumination could also be considered under certain circumstances and in spite of the related cost. For this, a cost-productivity balance can be made with help from the models developed and experience acquired. In the same sense, artificial shading of the culture to prevent cell damage during specific parts of the day when light intensity is too high would be a strategy evaluated by modeling results.

In order to test any possible strategy, the combination of all equations developed in this thesis in a general model, and the implementation of this model in a simulation program would be a major progress. Future research should include a photobioreactor unit -where the processes here described are represented- in the simulation program DESASS (Design and Simulation of Activated Sludge Systems). Recalibration of the general model, if necessary, and its validation with real data from outdoor operation would confer significant value to the simulation tool.

On the other hand, separation of the cellular and hydraulic retention times is also considered essential for increasing the biomass concentration in the photobioreactor and the treatment capacity of the system. For this, a microfiltration membrane unit has been installed in the microalgal cultivation pilot plant described in Chapter VII, which in turn provides a high quality effluent (free of particles). Future research in this area will determine the best practice regarding retention times and filtration operation, in order to obtain, with an optimal energetic consumption, a treated effluent which can be discharged in the environment. 
Future works could also be developed in the field of model-based bioprocess control, which is currently a research field with great potential. Indeed, a proper instrumentation and control system is required for pilot plant operation. In some cases it is possible to apply modeling techniques to the information provided by the installed sensors in order to develop a control system.

Lastly, it is of outmost importance to find the best application for the generated microalgal biomass in order to recover nutrients and energy. The necessary experiments need to be carried out in order to evaluate the potential of the microalgal biomass as fertilizer and for biogas generation. The proposed energy recovery system is anaerobic digestion, which would take place after microalgal concentration and render a nutrient-rich digestate which can be used as fertilizer. Future efforts will be directed to the successful and complete integration of the SAnMBR, the microalgal PBR and the microalgal anaerobic digester for an effective COD and nutrients removal of urban wastewater and maximum biogas generation. Further use of the proposed system for other wastewater streams in different WWTP will also be possible, the final goal being the technology transfer so that it can be applied in a full scale WWTP. 


\section{References}

Aravantinou, A.F., Theodorakopoulos, M.A., Manariotis, I.D. (2013) Selection of microalgae for wastewater treatment and potential lipids production. Bioresource Technology 147, 130-134.

Challagulla, V., Fabbro, L., Nayar, S. (2015) Biomass, lipid productivity and fatty acid composition of fresh water microalga Rhopalosolen saccatus cultivated under phosphorous limited conditions. Algal Research 8, 6975.

Dickinson, K.E., Whitney, C.G., McGinn, P.J. (2013) Nutrient remediation rates in municipal wastewater and their effect on biochemical composition of the microalga Scenedesmus sp. AMDD. Algal Research 2 (2) $127-$ 134. 

Chapter X

General conclusions 

The aim of this thesis was to study the nutrient recovery process from an anaerobic membrane bioreactor effluent by using a microalgal culture and to obtain the main kinetic expressions governing the process. From the work presented, the following conclusions can be drawn:

\section{Microalgae cultivation in the effluent of an anaerobic membrane bioreactor}

1. A mixed culture of autochthonous microalgae were isolated from the environment and successfully cultivated using as growth medium the effluent of an anaerobic membrane bioreactor, without dilution nor sterilization.

2. The microalgal culture performed satisfactory nutrient removal in both batch and semicontinuous systems, demonstrating that, under the appropriate circumstances, an excellent water quality can be obtained.

3. It was demonstrated that the combination of a SAnMBR for organic matter removal with a microalgal culture for nutrient removal is an effective option for urban wastewater treatment.

4. The originally mixed culture, composed mainly of Cyanobacteria and Chlorophyceae, naturally evolved into a monoculture of Scenedesmus sp. when cultivated in the anaerobic effluent. In a P deficient medium, the culture was dominated by microalgae from the Chlorococcum genus.

5. The wastewater $\mathrm{N}: \mathrm{P}$ ratio was higher than the ratio consumed by microalgae. Therefore, phosphorus showed to be the limiting nutrient in the cultures.

\section{Ammonium removal in the absence of phosphorus. Effect of phosphorus supplementation and process modeling}

6. Ammonium removal took place in a P-free medium, thus demonstrating that ammonium removal is a process independent from phosphate uptake.

7. Ammonium removal rate became slower with smaller microalgal cellular phosphorus, and recovered to initial values after phosphate addition to the medium and its rapid uptake.

8. The influence of internal phosphorus content in the microalgal ammonium uptake rate can be successfully modeled with the Hill function. The Hill function was combined with a Monod function to reproduce the effect of ammonium concentration in the 
medium and the Steele function to represent the influence of light. The corresponding parameters were obtained by model calibration.

\section{Effect of intracellular $P$ content on phosphate removal and process modeling.}

9. Phosphate uptake rates increase with decreasing intracellular phosphorus content of the biomass.

10. The effect of internal phosphorus content on the phosphate uptake rate can be successfully modeled with the Hill function. The Hill function was combined with a Steele function to represent the influence of light. The corresponding parameters were obtained by model calibration.

\section{Effect of temperature on ammonium removal.}

11. The effect of temperature on the ammonium removal rate by Scenedesmus sp. can be successfully reproduced both by the Cardinal Temperature Model and Ratkowsky equation.

12. The optimum temperature under laboratory conditions, obtained by calibration, was 31 ${ }^{\circ} \mathrm{C}$. Minimum and maximum temperatures were 9 and $46{ }^{\circ} \mathrm{C}$, respectively.

\section{Modeling light and temperature influence on ammonium removal under outdoor conditions}

13. The equations used to reproduce the light and temperature influence on ammonium removal under constant laboratory conditions (Steele and Cardinal Temperature models) are also suitable for modeling an outdoor culture grown under changing conditions, albeit in a less accurate manner.

14. Since a microalgal culture grown under outdoor conditions is adapted to different conditions than in the laboratory, different model parameters are obtained during model calibration. This is especially true for the optimum, minimum and maximum temperatures (lower) and the optimal light intensity (higher). 


\section{Prolonged dark exposure. Respiration rate modeling}

15. A respiration constant from an exponential decay equation, which is useful for biomass loss prediction, can be calculated with the methodology proposed. This methodology is based on successive oxygen uptake rate measurements. 



\section{Appendix}

Diagram of culture chronology 
The following simplified flow diagram (figure A.1) reflects the overall history of the autochthonous microalgal cultures used in this thesis: from isolation from the environment into laboratory first experiments (Chapters II and III) and subsequent cultivation in auxiliary 8L cylindrical PBRs. The needed volumes of microalgal culture were taken from these auxiliary PBRs and studied in the different setups corresponding to Chapters IV to VIII.

Conditions in the auxiliary PBRs were:

$$
\mathrm{pH}=7.5 \quad \mathrm{~T}=25-28^{\circ} \mathrm{C} \quad \mathrm{I}=150-200 \mu \mathrm{E} \cdot \mathrm{m}^{-2} \cdot \mathrm{s}^{-1} \quad \mathrm{TRC}=2-4 \mathrm{~d}
$$

Identification of microalgae communities was carried out based on their morphology (cell shapes, flagella or other cell extensions, size and shape of the chloroplasts and their red or orange autofluorescence) (Tomas, 1997), which was analyzed using optical microscopy (Leica DM2500) in all cases and cryo-scanning electron microscopy (SEM) in Chapter IV.

\section{References}

Tomas, C.R. (1997) Identifying marine phytoplankton. Academic Press, San Diego.

Fig A.1: Diagram of culture chronology 


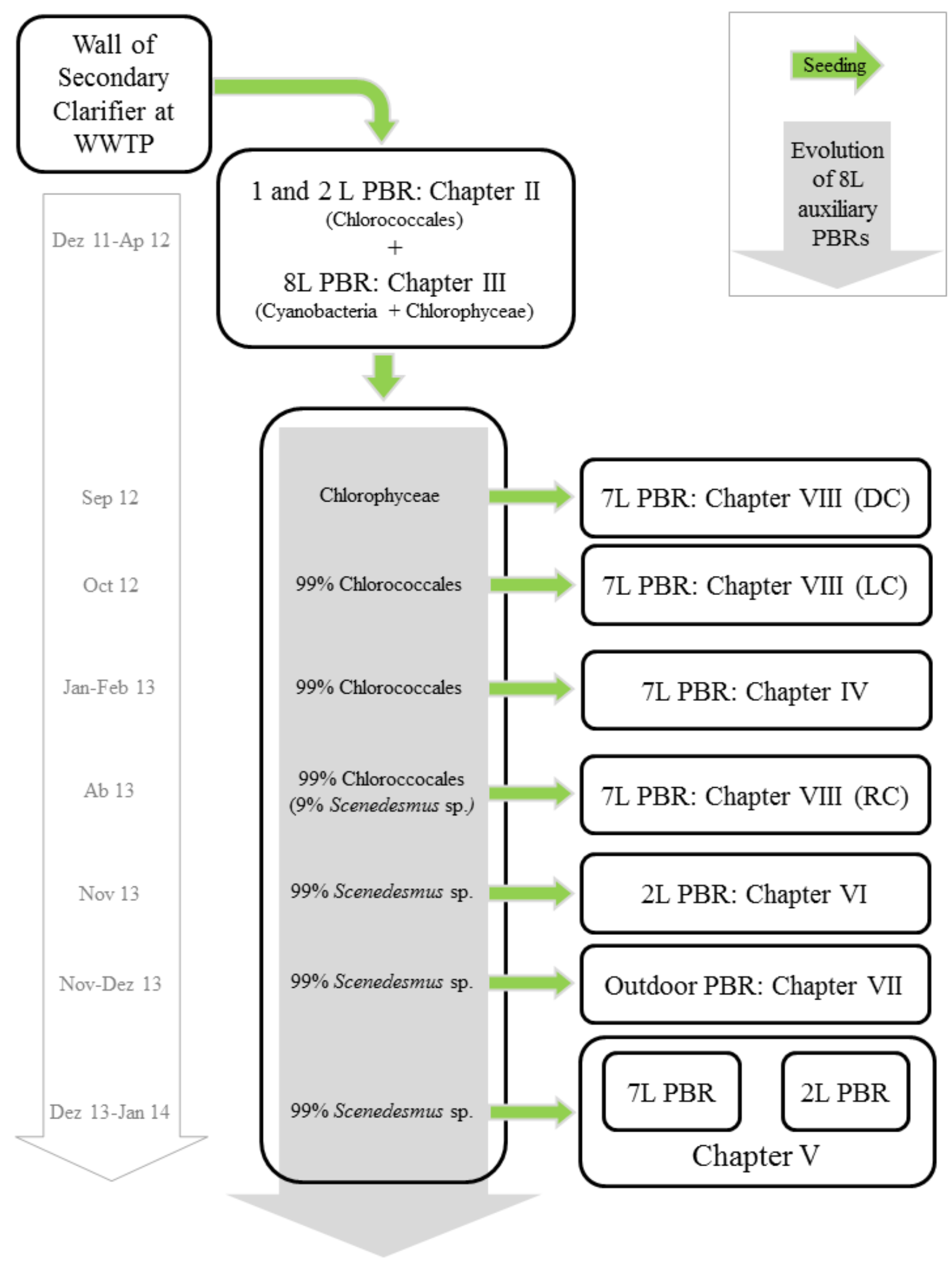


